



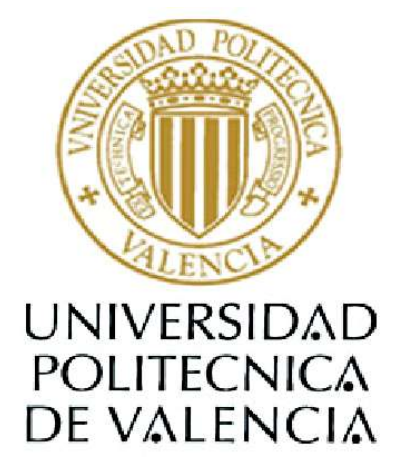

Departamento de Economía y Ciencias Sociales

\title{
GESTIÓN COMPETITIVA \\ EN LOS DESTINOS TURÍSTICOS DE INTERIOR
}

\author{
TESIS DOCTORAL \\ Presentada por: \\ Dạ Estefanía Osorio Acosta \\ Dirigida por: \\ Dr.D. Baldomero Segura García del Río
}



El amor más fuerte y más puro no es el que sube desde la impresión, sino el que desciende desde la admiración.

Sta. Catalina de Siena (S.XIV) 



\section{AGRADECIMIENTOS}

Quiero expresar, en primer lugar, mi gratitud a mi director de tesis, Baldomero Segura, por sus orientaciones y consejos y por el apoyo que siempre me ha proporcionado.

Agradezco también el interés y la valiosa colaboración de Joaquín Puig, alcalde de Morella y de su equipo, especialmente de Rebeca Pérez, concejal de Cultura y Turismo y de Jose Miguel Adell. También a todos los miembros del joven Comité de Innovación Turística y a los del Patronato de Turismo. Mis felicitaciones y agradecimiento a los ciudadanos de Morella.

Quisiera también agradecer a todos los expertos en gestión de desarrollo turístico local que han participado desinteresadamente en la fase experimental por sus amables aportaciones y opiniones.

A mis compañeros del departamento de Economía y Ciencias Sociales, del INECO y del Master Internacional en Turismo por sus consejos y los ánimos proporcionados en los momentos más necesarios. A Roberto y a $M^{a} J o s e ́$.

Mi especial agradecimiento a mis hermanos, los ya doctores, Javier, Ezequiel y Ángel por su apoyo incondicional y solidario, por las risas y por toda la vida en común que nos une, también a Mónica y Rosa Mari. A mis padres. A mis hijos y a quien no quiere que le nombre.

Mi agradecimiento a Javier Gallego. 



\section{RESUMEN}

El objetivo principal de la presente Tesis Doctoral es llegar a determinar empíricamente, cuáles son las dimensiones básicas y los factores claves del éxito que deben ser adecuadamente gestionados por los órganos con competencias en la definición y ejecución de las políticas y estrategias de los destinos turísticos de tipo rural que se encuentran en su fase inicial de desarrollo, para lograr alcanzar y mantener una posición competitiva sostenible, estableciendo, asimismo, la vital importancia que tiene para el logro de este objetivo, que dicho modelo sea definido y gestionado en estrecha vinculación con la comunidad local del destino turístico.

A tal efecto, se ha realizado una investigación para establecer el grado de percepción que de los impactos económicos, sociales y medioambientales del turismo tienen los residentes de un destino turístico del interior de la Comunidad Valenciana, y cómo esta percepción determina su actitud hacia el desarrollo de la actividad siendo posible, igualmente, identificar diferentes grados en la misma según sea el nivel de vinculación profesional que se detenta en el proceso productivo de la actividad turística en el municipio en cuestión.

Metodológicamente se realiza, en primer lugar, un análisis de los determinantes que mayor atención han recibido en los diferentes campos de conocimiento relacionados con la competitividad y el desarrollo turístico, para llegar a establecer cuáles son las dimensiones y factores clave que determinan la posición competitiva sostenible en la gestión de los destinos turísticos.

Posteriormente, y con el objetivo de, por un lado, contrastar la elección de las dimensiones y factores clave propuestos y, por otro lado, valorar la importancia relativa de cada una de estas dimensiones y factores clave, se 
define un cuestionario dirigido a gestores expertos en desarrollo turístico local para probar la validez de los planteamientos expuestos.

Como consecuencia de los trabajos anteriores, se ha puesto de manifiesto que el enfoque más adecuado para abordar la gestión competitiva en los destinos turísticos en fase inicial de desarrollo, es aquél que exige el análisis y consideración de factores claves del éxito que tienen su origen en tres dimensiones fundamentales, y que son la eficiencia, la calidad y el posicionamiento estratégico. Estas dimensiones requieren, igualmente, un enfoque integrado y holístico para poder lograr su máxima operatividad.

Asimismo, estimamos que el logro de una posición competitiva sostenible sólo podrá conseguirse cuando la gestión de los destinos turísticos adopte el marco estratégico como el instrumento imprescindible para definir la gestión de las organizaciones públicas con competencias en el diseño e ejecución de las políticas y estrategias de los destinos turísticos estableciendo, asimismo, la necesaria línea de separación entre la política general que ha de regir el municipio o localidad en su conjunto, de la estrategia que debe marcar la pauta de la gestión del destino turístico como producto en el mercado y, por tanto, del ente gestor, que ha de estar necesariamente integrado por representantes de la gestión pública, de la iniciativa privada y de la comunidad local . 


\section{SUMMARY}

The main aim of this doctoral thesis is to empirically determine both the basic scope and the essential factors required of governing bodies that are responsible for defining and executing policy and strategy of rural tourism destinations in their initial phase of development, so that they can not only attain, but also maintain, a sustainable competitive position. It is also of vital importance that such models are defined and managed with the close collaboration of the local community of the tourist destination.

Research has been carried out to establish the degree of perception residents of a particular tourist destination in the interior of the Valencian Community have regarding the economic, social and environmental impacts of tourism. This perception determines their attitude towards tourism development, which at the same time varies depending on the how close their profession is to the productive process of the tourist activity in that area.

Methodologically, the most important criteria in the various fields of knowledge relating to competitiveness and tourist development are analysed. This helps us to establish the dimensions and factors that determine sustainable and competitive positions in the management of tourist destinations.

Next, a questionnaire is put together and directed at managers who are experts in local tourist development, in order to check the validity of all analyses presented.

According to the results of these analyses, the best way to tackle the competitive management of rural tourism destinations in their initial phase of development is to focus on, analyse and consider the key success factors, i.e. efficiency, quality and strategic positioning. These factors require an 
integrated and holistic focus in order to achieve their maximum operating effectiveness.

Similarly, a sustainable competitive position will only be achieved when governing bodies responsible for defining and executing policy of rural tourism destinations select the correct strategy tool. Also, the necessary distinction should be made between the general policy governing the municipality as a whole and the strategy followed to manage the tourism destination as a market product. In this way, the managing entity - which should be integrated by representatives of public management - should be separated from private initiative and the local community. 


\section{RESUM}

La finalitat d'aquesta tesi és la demostració empírica de quines són les dimensions bàsiques i els factors clau de l'èxit que cal gestionar adequadament pels òrgans amb competències en la definició i execució de les polítiques i estratègies de les destinacions turístiques de tipus rural, que es troben en la seua fase inicial de desenvolupament, per tal d'arribar i mantenir una posició competitiva sostenible, establint, tanmateix, la vital importància que té per a aconseguir aquesta finalitat, que aquest model siga definit i gestionat amb estreta vinculació amb la comunitat local de la destinació turística.

Tenint en compte aquesta idea, s'ha dut a terme una investigació per tal d'establir el grau de perfecció que dels impactes econòmics, socials i mediambientals del turisme tenen els residents d'una destinació turística de l'interior de la Comunitat Valenciana, i com aquesta percepció determina la seua actitud davant el desenvolupament de l'activitat, fent possible, igualment, identificar diferents graus en aquesta, segons siga el nivell de vinculació professional que es retinga en el procés productiu de l'activitat turística al municipi de referència.

La metodologia utilitzada suposa la realització en primer lloc, de l'anàlisi dels determinants que major atenció han rebut en els diferents camps del coneixement relacionats amb la competitivitat i el desenvolupament turístic per tal d'establir quines són les dimensions i els factors determinants de la posició competitiva sostenible en la gestió de les destinacions turístiques.

Amb posterioritat, i amb l'objectiu de, per una banda, contraposar l'elecció de les dimensions i factors claus proposats i, per altra banda, valorar la importància relativa de cadascuna d'aquestes dimensions i factors claus, es defineix un qüestionari dirigit a gestors experimentats en gestió 
de destinacions turístiques locals, per tal de validar els plantejaments exposats.

Com a conseqüència dels treballs anteriors, ha quedat manifest que l'enfocament més adient per tal de dur endavant la gestió competitiva a les destinacions turístiques en fase inicial de desenvolupament, és aquell que requereix l'anàlisi i consideració de factors claus de l'èxit que tenen el seu origen en tres dimensions fonamentals, i que són l'eficiència, la qualitat i el posicionament estratègic. Aquestes dimensions requereixen, igualment, un enfocament integrat i holístic per tal d'aconseguir la seua màxima operativitat.

Tanmateix concloem que per obtenir una posició competitiva sostenible, cal que la gestió de les destinacions turístiques adopte el marc estratègic com l'eina imprescindible per tal de definir la gestió a les organitzacions publiques amb competències en el disseny i execució de les polítiques i estratègies de les destinacions turístiques establint, tanmateix la necessària separació entre la política general que regirà el municipi o localitat en el seu conjunt, de l'estratègia que marcarà la pauta de la gestió de la destinació turística com a producte al mercat i, per tant, de l'organisme gestor, que cal que estiga necessàriament integrat per representants de la gestió pública, de la iniciativa privada i de la comunitat local. 
INDICE 



\section{ÍNDICE GENERAL}

\section{Capítulo 1. PLANTEAMIENTO Y OBJETIVOS DE LA INVESTIGACIÓN}

1.1 Introducción................................................................ 01

1.1.1 El liderazgo en el logro de la competitividad de los destinos turísticos..............03

1.1.2 Cómo se articula la competitividad en un destino turístico.......................09

1.1.2.1 La eficiencia .............................................11

1.1.2.2 Coordinación público-privada.................................14

1.2 Los destinos turísticos rurales o de interior................................... 17

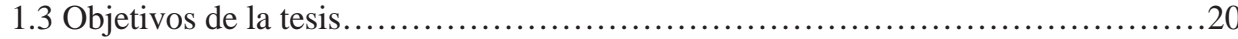

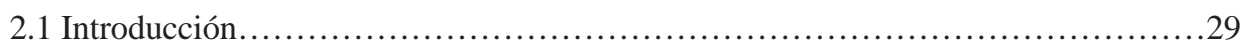

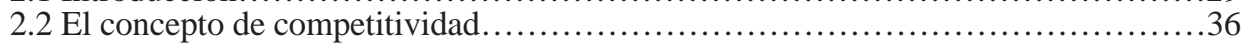

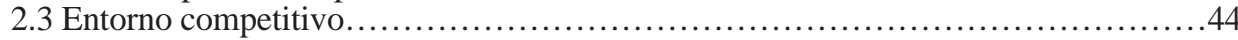

2.4 Empresa, sector y territorio................................................... 49

2.5 Enfoques para el estudio de la actividad turística................................ 53

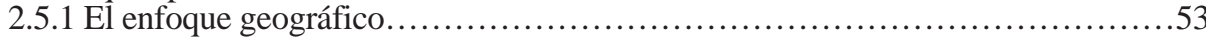

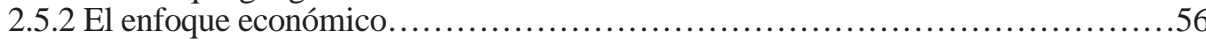

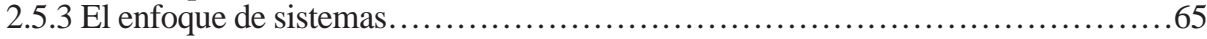

3.1 La idea de destino turístico................................................... 73

3.1.1 Producto turístico de base territorial........................................ 77

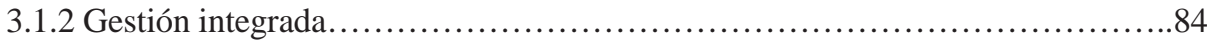

3.2 Estructura competitiva de los destinos turísticos.................................. 89

3.2.1 Modelos de competitividad............................................ 89

3.2.1.1 El modelo de Ritchie y Crouch.....................................91

3.2.1.2 Teoría de los recursos y capacidades aplicada a los destinos turísticos............................................................97

3.2.1.3 Modelos cuantitativos...........................................100

3.3 Gestores del Destino Turístico................................................... 105

3.3.1 Gestores con capacidad normativa....................................... 107

3.3.2 Gestores con capacidad ejecutiva....................................... 108

3.3.3 Gestores con capacidad política.......................................... 110

3.3.4 La comunidad Local......................................................... 110

3.4 Morella como destino turístico.La percepción de la comunidad local..................115

3.4.1 Caracterización del destino turístico Morella...............................115

3.4.2 Actitud de la población residente ......................................... 122

3.4.2.1 Método de obtención de la información............................124

3.4.2.2 Elaboración del cuestionario...................................126

3.4.2.3.Análisis de los resultados....................................128

3.4.2.3.1 Impactos económicos...................................128

3.4.2.3.2 Impactos sociales.....................................134

3.4.2.3.3 Impactos medioambientales................................137

3.4.2.4 Percepción de Morella como destino turístico por sus residentes...............................................141 


\section{ÍNDICE DE TABLAS}

Tabla 1 Análisis Estratégico de la Posición competitiva de la

Comunidad Valenciana a principios de la década

de los noventa.

Tabla 2 Paralelismo entre patrones grupales y porcentajes de individuos de cada grupo manifestados en distintas nvestigaciones.

Tabla 3 Variables explicativas de la actitud de los residentes hacia el turismo....345

Tabla 4 Municipios integrantes de la marca turística "el Maestrazgo" de la provincia de Castellón.

Tabla 5 Municipios integrantes de la marca turística "el Maestrazgo" pertenecientes a la provincia de Teruel.

Tabla 6 Variables climatológicas y altitud media de la Comarca de Els Ports de Morella en relación al resto de España....

Tabla 7 Municipios beneficiarios de iniciativas Leader I y II que han desarrollado proyectos turísticos en la provincia de Castellón....

Tabla 8 Municipios beneficiarios de iniciativas Leader I y II que han desarrollado proyectos turísticos en la provincia de Teruel

Tabla 9 Inversiones comprometidas proyecto Leader I- Els Ports, período (1991-1995)

Tabla 10 Inversiones comprometidas proyecto Leader II- Els Ports-Maestrat, período (1996-1999).

Tabla 11 Proyectos turísticos financiados con fondos del programa Leader I (Medida $3^{\mathrm{a}}$ )...

Tabla 12 Crecimiento de la oferta de casas rurales en la comarca de Els Ports, período (1996-2002).

Tabla 13 Número de establecimientos hoteleros de la comarca de Els Ports....

Tabla 14 Número de plazas en restaurantes de la zona Leader de desarrollo rural...357

Tabla 15 Distribución de la población de Morella por género y edad (año 2004)..126

Tabla 16 Presupuestos del Plan Marco de Competitividad del Turismo Español (mill.ptas.)

Tabla 17 Ejemplo de ofertas-demandas antes de la estancia.

Tabla 18 Ejemplo de ofertas-demanda durante la estancia 
Tabla 19 Ejemplo de ofertas-demandas después de la estancia.....................360

Tabla 20 Modelo de Auditoría de Gestión Turística Competitiva (AGTC)........273

Tabla 21 Valoración otorgada por los expertos a las subvariables..................275

Tabla 22 Criterios de puntuación del modelo.................................278

Tabla 23 Subvariables estratégicas.......................................283

Tabla 24 Divergencias sector público/sector privado...........................286

Tabla 25 Puntuación obtenida por el GDT de Morella............................292 


\section{ÍNDICE DE FIGURAS}

Figura 1 Competitividad y Sostenibilidad en Destinos.......................93

Figura 2 El proceso de Auditoría de Destinos............................... 96

Figura 3 Crecimiento anual del número de unidades y de plazas de alojamiento rural en la comarca de Els Ports $(1996-2002) \ldots \ldots \ldots \ldots \ldots \ldots 118$

Figura 4 Evolución de la población empadronada en la ciudad de Morella,

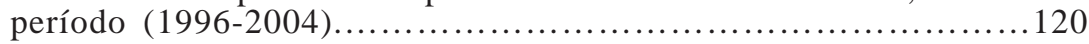

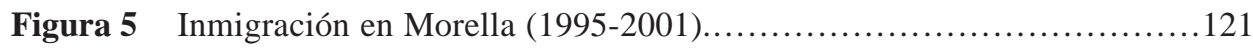

Figura 6 Evolución de la población de Morella por tramos de edad.................122

Figura 7 Cadena de valor de un destino turístico........................... 177

Figura 8 Evolución de la Política Turística Española............................185

Figura 9 Sistema de calidad del ICTE............................... 195

Figura 10 Tipología de destinos SICTE..............................203

Figura 11 Las percepciones básicas determinan cómo contemplan las personas a la innovación.....................................212

Figura 12 Modelos de innovación......................................215

Figura 13 Factores de sensibilidad en la innovación tecnológica en el sector turístico...........................................226

Figura 14 Organismos de gestión turística................................291

Figura 15 Equilibrio de las Dimensiones Competitivas.........................295

Figura 16 Situación de Equilibrio Competitivo del Destino Turístico Morella..............................................296 

CAPÍTULO 1

PLANTEAMIENTO Y OBJ ETIVOS DE LA INVESTIGACIÓN 



\subsection{Introducción}

Tras una época de crecimiento continuado, a partir de la década de los 90, el sector turístico, tanto nacional como internacional, se ha visto afectado por una serie de profundos cambios estructurales que han variado sustancialmente el entorno competitivo en el que, tradicionalmente, se desarrollaba la actividad turística.

Así, y como consecuencia de la globalización y liberalización de la economía, la fuerte entrada de nuevos capitales inversores ha producido un aumento constante de la oferta turística que, unida a una acusada segmentación de la demanda turística, obliga a que las empresas y organizaciones involucradas en la industria turísticas deban competir de forma distinta a como se venía haciendo anteriormente si desean mantener su competitividad, entendida como "la capacidad de obtener beneficios y de mantenerlos en circunstancias cambiantes" (S.G.T., 1992)

La constatación fehaciente por parte de las organizaciones públicas y privadas de este cambio en el entorno del sector turístico, motiva un creciente interés en la investigación de aspectos relacionados con el posicionamiento estratégico de destinos turísticos, si bien no siempre la incorporación de los conceptos vinculados a este campo del conocimiento han ido acompañados de la suficiente claridad conceptual ni del desarrollo de modelos teóricos.

Así, se han incorporado ya al acervo de la industria turística conceptos como posición competitiva, mejora o pérdida de competitividad, entre otros, sin que ello implique que el despliegue semántico empleado esté acorde con conceptos unívocos y sin determinar, por tanto, qué se quiere significar exactamente cuando, por ejemplo, se dice: "un destino turístico ha perdido competitividad". ¿Supone esto que ha tenido un número inferior de visitantes 
en un período concreto en comparación con otro período anterior?, ¿que la ratio de pernoctaciones por cliente ha disminuido?, ¿que el gasto promedio del visitante ha sido inferior?, ¿que las empresas de alojamiento han tenido que mantener o bajar sus precios respecto a años anteriores?, ¿que los comerciantes locales han reducido sus ventas?, ¿que se han recaudado menos ingresos por impuestos indirectos ?, ¿o todo ello a la vez?.

Es evidente que el concepto macroeconómico de competitividad es difícilmente aplicable a destinos turísticos emergentes o en el inicio de su fase de madurez ya que es muy compleja su medición allí donde no existe una suficiente información de partida como pueden ser los indicadores del número de visitantes y turistas recibidos, de los índices de repetición o recompra, de las fortalezas y debilidades del destino o del gasto promedio realizado por el turista o visitante. En la inmensa mayoría de los casos y, parafraseando a D. Quijote, cuando hablando con Sancho le dice: "ladran, luego cabalgamos", se ha venido utilizando, prácticamente en exclusividad, el dato del número de turistas que pernoctan como indicador de competitividad de tal manera que, "si vienen más turistas que el año pasado, somos más competitivos".

Por lo que se refiere a la otra parte de la ecuación, al concepto destino turístico, tampoco es sencillo encontrar una definición, unánimemente aceptada, tanto por la doctrina como por los gestores públicos y privados de la industria turística. De hecho, no fue hasta diciembre de 2002, cuando en el seno del Consejo de Educación de la Organización Mundial del Turismo (OMT), se logró congregar a un grupo de expertos internacionales, representantes de las más prestigiosas universidades del mundo especializadas en turismo, de gobiernos y de entidades privadas, para elaborar una definición de lo que debiera ser considerado como destino turístico. Definición que, 
a fecha de hoy, sigue sin ser unánimemente aceptada ni por los especialistas e investigadores ni por los gobiernos, ni por las empresas privadas.

Por tanto, preguntas básicas para analizar la competitividad que en otros sectores productivos pueden obtener fácil respuesta (cuál es el producto ofrecido, qué cuota de mercado detenta, cuáles son los competidores, cuáles son las fuentes de ventajas competitivas) nos crean problemas añadidos al propio análisis estratégico cuando nos referimos al sector turístico.

Ahora bien, de la dificultad y complejidad que tiene la aplicación del concepto de la competitividad a los destinos turísticos nace la propia justificación y necesidad de avanzar en su conocimiento y estudio puesto que, igualmente, tampoco ofrece ninguna duda que el sector turístico, dada su trascendencia en muchas economías, necesita avanzar en este campo del conocimiento aplicado.

De entre todas las cuestiones que pueden ser objeto de estudio a la hora de abordar el análisis de la competitividad en el sector turístico nos parecen especialmente relevantes dos que, a nuestro modo de ver, son los ejes centrales del mismo: ; quién debe llevar a cabo el liderazgo en el logro de la competitividad? y ¿cómo se articula este proceso de búsqueda de la competitividad; , es decir, qué protocolo de actuación debería seguirse para alcanzar la competitividad de un destino turístico.

\subsubsection{El Liderazgo en el logro de la competitividad de los destinos turísticos}

Existe una línea de pensamiento (Monfort, 1999; Camisón y Monfort, 1993) 
que otorga el liderazgo en el logro de la competitividad de los destinos turísticos al sector empresarial privado, puesto que sostiene que el éxito competitivo en los mercados internacionales de un destino turístico será producto de la iniciativa empresarial desarrollada individualmente por las organizaciones más decididas en la búsqueda de la posición competitiva para ese destino.

Si se efectúa un estudio detallado de cómo se ha desarrollado el turismo en España desde sus inicios, los datos apoyan claramente esta tesis (Secall, 2000). En efecto, hasta la década de los 90 no existía una conciencia colectiva en el sector turístico español, ni internacional, de que la industria turística tuviera necesidad de una intervención del sector público que fuera más allá de fijar un marco normativo regulador de la actividad turística y de llevar a cabo acciones de promoción turística.

Asentados en las confortables ventajas comparativas de las que gozaba el producto turístico español de sol y playa (bondad climatológica, extensos kilómetros de costa y playas, precios asequibles, cercanía a los núcleos emisores de origen, seguridad ciudadana, estabilidad política), las empresas turísticas sólo tenían que saber gestionar los costes operativos. Incluso muchas de esas empresas han estado controladas por tour operadores internacionales que gestionan la demanda en origen, los procesos de distribución y los transportes hasta los destinos turísticos españoles, por lo que el riesgo en el proceso de comercialización ha sido, en muchos casos, mínimo. Por supuesto, no existe ninguna referencia en estos años (décadas de los 60, 70 y 80) a la sostenibilidad de los recursos invertidos en el proceso de desarrollo turístico. 
La crisis que el turismo en España sufre entre los años 91 al 93 supone un aviso para la industria turística española de que la situación, es decir, el panorama turístico internacional estaba variando profundamente y que "las reglas del juego" aplicadas hasta ese momento ya no serían válidas por más tiempo, tal y como estableció el Plan Futures de España. A partir de este momento es cuando la preocupación por la competitividad alcanza también a la Comunidad Valenciana (Tabla 1, anexo).

Ante las dificultades existentes para poder aplicar el concepto de competitividad a los destinos turísticos, por un lado, y visto el devenir del desarrollo turístico español, por otro, está perfectamente justificado que los investigadores centraran su análisis en la parte más tangible y medible de un destino turístico: las empresas, por lo que, en la medida que las empresas radicadas en un destino turístico alcanzan el éxito, también lo hace ese destino midiendo así el nivel de competitividad.

Sin que ello implique negar completamente la validez de los argumentos expuestos por los investigadores que representan la línea de pensamiento anterior, consideramos que el éxito empresarial no determina, directamente, el éxito competitivo de un destino turístico. Ello supondría, a nuestro juicio, reducir el concepto de destino turístico a un conjunto de empresas privadas. Sin necesidad de hacer uso de otros instrumentos, tan sólo con el análisis deductivo, se puede comprobar fácilmente que un destino turístico, especialmente en el caso de una localidad o municipio concreto, tiene una complejidad de recursos, bienes, servicios y relaciones, que excede, con mucho, a las empresas turísticas que lo forman.

Desde el punto de vista económico, la intervención del sector público en 
turismo se justifica por la existencia de fallos del mercado que le afectan de forma directa (OMT, 1998: 161-163) y que son los siguientes:

- La existencia de estructuras de mercado imperfectamente competitivas, lo que requiere de la presencia del sector público para garantizar las condiciones de competencias del mismo, llevando a cabo una asignación de los recursos de forma óptima y eficiente.

- $\quad$ La necesidad de bienes públicos que actúan como parte indisoluble del destino turístico, lo que determina la presencia del sector público llevando a cabo la provisión adecuada de aquellos, contribuyendo así a aumentar el valor turístico del espacio o territorio en cuestión.

- La presencia de externalidades asociadas al desarrollo turístico impactos positivos (economías externas) e impactos negativos (deseconomías externas) - que afectan directamente a los ámbitos económico, socio-cultural y medioambiental y, por ende, a la competitividad de las empresas y al bienestar de turistas y residentes locales, que hace imprescindible la presencia del sector público para evitar lo que algunos autores (Cals, Matas, y Riera, 1993) denominan la paradoja de la degradación (grupos económicos que buscan beneficios a corto plazo y que no desarrollan una estrategia de beneficio sostenido a largo plazo).

Para esta línea de pensamiento resulta evidente que el desarrollo competitivo de un destino turístico requiere de la acción del sector público en una doble dimensión: 
- $\quad$ Estableciendo el marco adecuado y creando las condiciones idóneas para que se produzca un desarrollo competitivo de las empresas del sector lo que, a su vez, redundará en una mejora del bienestar y de la calidad de vida de la comunidad local,

- Gestionando los recursos invertidos en el proceso turístico de modo tal que "se satisfagan las necesidades del presente sin comprometer la posibilidad de satisfacciones propias de las generaciones futuras (Informe Brutland, ONU, 1987).

El éxito de un destino turístico, es decir, la competitividad del mismo, debe estar íntimamente ligado a la sostenibilidad de tres dimensiones: económica, sociocultural y medioambiental, de tal modo que la estrategia de los destinos turísticos debe tener como obligatoria referencia la búsqueda de una armonía entre las variables citadas.

En este sentido, conviene recordar que en el uso y disfrute del destino turístico - bienes y servicios que en él se engloban- se produce, a diferencia de otros sectores productivos un hecho de enorme trascendencia para la determinación del éxito: productores y consumidores coinciden en el tiempo y en el espacio. Por otro lado, muchos de los bienes y servicios que componen el producto "destino turístico" que un turista adquiere - playas, infraestructuras, servicios públicos- son también de uso ciudadano no estrictamente turístico. Es más, tal y como manifiestan todos lo estudios realizados sobre los impactos turísticos en un destino (Mathieson y Wall, 1982; Krippendorf,1987; Pearce y Wardford, 1993) la actitud que manifiesten los residentes hacia el turista es uno de los principales factores que determinan el éxito o no de los destinos turísticos. 
Por tanto, uno de los ejes centrales de la actuación a desarrollar por los gestores de un destino turístico tiene que ser el de lograr la armonización de los intereses de dos tipos de clientes: el cliente externo, es decir, el consumidor final, visitante o turista; y el cliente interno que, a su vez, podríamos dividir en dos grupos: los miembros de la industria turística local, con mayor o menor nivel de implicación directa en ella, y los residentes locales no implicados directamente en la industria turística. Y esto sólo lo puede llevar a cabo el sector público, puesto que es el que tiene la capacidad y competencias adecuadas para articular los mecanismos de cohesión entre ambos grupos.

Partimos de la premisa que la competitividad de un determinado destino turístico será la suma de la competitividad que tengan todos y cada uno de los productos turísticos que conformen la oferta de este destino turístico, lo cual hace imprescindible que deba articularse una gestión del destino turístico "como si de una organización única se tratara" desde una visión holística e integradora de la misma.

En este cometido nos parece incuestionable que el sector público tiene un papel clave a desempeñar, si bien, este papel, como luego veremos, no debe ser de liderazgo impositivo sino cooperativo.

Por tanto, como conclusión inicial de esta cuestión, consideramos que la existencia de un sector privado altamente competitivo no será el único factor que justifique el éxito de un destino turístico. Será, desde luego, condición necesaria pero no suficiente. 


\subsubsection{Cómo se articula la competitividad en un destino turístico}

Por lo que se refiere al cómo, y atendiendo ahora a la segunda de las cuestiones planteadas, es decir, la forma en que se articula el proceso de búsqueda de la competitividad, la línea de pensamiento planteada por Camisón, Pedreño, y Monfort , (1996) sostiene que será la capacidad que tengan las empresas turísticas para diseñar una estrategia adecuada lo que le permitirá obtener ventajas competitivas en el mercado que, en definitiva, viene a aplicar al sector turístico la tesis mantenida por autores que consideran que, a igualdad de condiciones de entorno, la competitividad de una empresa “[...] depende de ella misma" (Fernández, 1992) o bien, "son las empresas, no las naciones, quienes compiten en los mercados internacionales" (Porter,1991).

Por las mismas razones que hemos argumentando para considerar que el liderazgo para el logro de la competitividad en un destino turístico no podía ser competencia exclusiva del sector privado, tampoco ahora podemos sumarnos completamente a la tesis planteada por algunos de los autores citados.

La existencia o no de unos recursos y condiciones de partida condicionan, y mucho, el éxito que pueda tener un destino turístico. Sin duda alguna, la habilidad que tengan las empresas para adoptar sus estrategias más adecuadas será un factor clave para que se obtenga el mencionado éxito. Ahora bien, nos podríamos preguntar si, por ejemplo, las empresas turísticas sólo nacen en un territorio que, por la tenencia de unas determinadas condiciones de partida, ha generado de modo natural una demanda turística hacia ese lugar y las empresas, simplemente, han sabido aprovechar adecuadamente ese 
escenario favorable, o si realmente han sido éstas las impulsoras de la creación de un flujo de demanda hacia un destino. De hecho, hay notables ejemplos de importantes destinos turísticos en los que se podría decir, incluso, que las condiciones del medio físico eran completamente desfavorables inicialmente (Las Vegas, Orlando) y ha sido la acción empresarial la que los ha convertido en lo que son hoy.

Ahora bien, nos parece igualmente incuestionable que, en la mayor parte de los casos, sin la existencia de unos recursos y condiciones de partida (clima, playas, proximidad a núcleos emisores, recursos patrimoniales o naturales) esos destinos turísticos no hubieran alcanzado su éxito. Así, tomando el caso de España a modo de ejemplo, la proximidad a los núcleos emisores justifica buena parte del éxito que tuvo la Costa Brava en los inicios del desarrollo turístico español. Igualmente, por su mayor bondad climática, Benidorm posee una temporada turística más larga que la Costa Brava. Lo mismo se podría decir de las Islas Canarias con respecto a los destinos de costa de la España peninsular. Análogamente, la cercanía de la costa mediterránea al mayor núcleo emisor español (Madrid) justifica el éxito de localidades como Benidorm, Gandía o Peñíscola.

Del mismo modo, tampoco parece ofrecer dudas de que no sólo estas condiciones iniciales de partida están en la base del diferente nivel de éxito que determinados destinos turísticos con condiciones de producto similares hayan tenido. A poco que se estudien los casos de destinos turísticos españoles con éxito (Benidorm, Tenerife, Barcelona, Mallorca) se puede comprobar que la existencia de aeropuertos cercanos, la creación y puesta en marcha de planes urbanísticos certeramente diseñados, la dotación de infraestructuras básicas, la inversión en programas de marketing y la organización de eventos 
internacionales han sido factores clave que han marcado positivamente el desarrollo de estos destinos turísticos.

Así, y en línea con lo expuesto por la OMT, en el entorno turístico actual, caracterizado por ser altamente cambiante y dinámico, es imprescindible que las organizaciones tanto públicas como privadas desarrollen nuevos modelos de gestión para poder mantener su nivel de competitividad en línea con sus respectivos entornos, siendo, por tanto, la mejora continua de la posición competitiva la clave para garantizar el éxito sostenible de un destino u organización.

Ya no serán las ventajas comparativas, esto es, los factores y recursos propios del destino turístico, en los que se ha basado su producto turístico (clima, recursos geoturísticos, mano de obra disponible), sino las ventajas competitivas nacidas de la gestión profesional de esos recursos, de la innovación constante, del conocimiento aplicado y del liderazgo las que determinarán el éxito o no de un destino turístico en sus respectivos mercados de referencia.

Otra cuestión importante sería dilucidar cómo se debe producir esa intervención del sector público para lograr alcanzar las mayores cuotas de competitividad de sus respectivos destinos turísticos. A nuestro modo de ver, dicha intervención debe realizarse a través de dos claros vectores que orienten dicha actuación: la eficiencia y la cooperación.

\subsubsection{La eficiencia}

Si llevamos a cabo un análisis somero sobre el desarrollo turístico tomando como ejemplo el modelo español, podremos observar cómo las actuaciones 
del sector público dirigidas a la promoción y desarrollo del sector turístico se pueden agrupar en dos campos:

a) Acciones sectoriales, dirigidas directamente al sector turístico, y realizadas por el Departamento con competencias en la materia del órgano de la Administración Pública correspondiente (Ministerio, Consejería, Diputación, Ayuntamiento) que, a su vez, se han venido centrando en dos ámbitos fundamentales:

- Ordenación, haciendo referencia a la potestad normativa y sancionadora de que dispone la Administración (elaboración de normativa, otorgamiento de licencias, inspecciones, sanciones...)

- Promoción, impulsando acciones de fomento y desarrollo de la imagen turística de los destinos correspondientes (asistencia a ferias, realización de soportes de comunicación, organización de eventos...)

b) Acciones genéricas, no específicamente del sector turístico, sino dirigidas al conjunto de la ciudadanía pero con una indudable repercusión en el sector turístico (dotación de infraestructuras, regulaciones fiscales, políticas monetarias, educación, etc).

Desde la entrada en vigor de la Constitución Española en el año 1978, y el posterior desarrollo de los correspondientes Estatutos de Autonomía, el reparto de competencias entre la Administración Central y las respectivas Autonomías ha generado un panorama más complejo del existente en los inicios del desarrollo turístico. Cuestión que siendo sin duda de gran interés, no es objeto de este trabajo de investigación, por lo que no profundizaremos en ella. No obstante, sí podemos hacer una caracterización de muchas de 
estas actuaciones al afirmar que la falta de coordinación y, en muchos casos, de coherencia ha sido la tónica dominante a la hora de fijar objetivos, articular programas, y elegir instrumentos de actuación.

Efectivamente, todavía es muy frecuente observar cómo la descoordinación preside las acciones que llevan a cabo distintas entidades públicas dentro del mismo sector turístico pero en ámbitos territoriales distintos: nacional, autonómico, provincial y local.

Del mismo modo, también es fácilmente observable cómo dentro del mismo escalón territorial de un gobierno se producen incoherencias entre diferentes departamentos. La brecha de la descoordinación se acentúa en el caso de la existencia de antagonismos políticos en la dirección de los distintos organismos públicos.

Asimismo, como denominador común de casi todas estas actuaciones, se observa cómo la Administración Turística, responsable del desarrollo turístico, no goza de las competencias jurídicas que le permitan actuar sobre los factores clave que le ayuden a mejorar la competitividad de los destinos turísticos. Por mencionar sólo las más visibles, infraestructuras, cultura, medioambiente, sanidad o educación no suelen formar parte del ámbito competencial del gestor del destino turístico y, sin embargo, son fuente clara y evidente de creación de valor en ese destino turístico.

Por tanto, si la mejor fuente de ventajas competitivas de que dispone una organización nace de su propia capacidad para gestionar los recursos y competencias de que dispone, y en los destinos turísticos los gestores públicos no pueden actuar sobre la mayor parte de los recursos que podrían ser fuente 
de ventaja competitiva, ¿implica esto que no pueden obtenerse ventajas competitivas nacidas desde la gestión pública de los destinos turísticos?

Entendemos que la respuesta a esta cuestión debe ser negativa. Creemos que sí se pueden obtener, pero para ello es imprescindible asumir un nuevo enfoque respecto a cuál debe ser el papel de los gestores públicos teniendo como objetivo fundamental la búsqueda de la eficiencia como fuente de ventaja competitiva. Y ello, implicaría, una doble dirección:

- Buscando la mejora de la eficiencia vertical, esto es, en las actuaciones sobre el destino turístico que deban ser desarrolladas por diferentes niveles de la Administración Pública (internacional, nacional, autonómica, provincial y local);

- $\quad$ Fomentando la mejora de la eficiencia horizontal a través una mejor coordinación entre los diferentes departamentos de un mismo ente territorial.

\subsubsection{Coordinación público- privada}

El segundo vector de actuación del papel público en su proceso de liderazgo para el desarrollo de los destinos turísticos es el de la coordinación con el sector privado.

En esta línea, conviene recordar el papel fundamental que el Plan Futures otorga al sector público como eje central impulsor de la mejora de la industria turística española, partiendo del reconocimiento de que ya no es posible competir en el mercado turístico actual y futuro sobre la base de las ventajas 
comparativas de los destinos turísticos y con el factor precio como única ventaja competitiva poniendo de relieve la necesidad de establecer órganos de colaboración conjunta interministeriales (Comisión Interministerial), con las comunidades autónomas (Conferencia Sectorial) pero también con los representantes del sector privado (Mesa de Turismo) como instrumento imprescindible para articular un diálogo constante y sistematizado con los representantes de la industria.

Igualmente, la OMT (2003) establece que la cooperación y el asociacionismo están siendo crecientemente utilizado en el sector turístico para el logro de objetivos, tanto del sector privado como de las propias comunidades locales. Las actuaciones internacionales realizadas bajo este concepto se centran en los campos de la creación de nuevos productos turísticos, en la mejora de la eficiencia y calidad, la mejora de las economías de escala, la apertura de nuevos mercados o, incluso, en la obtención de sinergias derivadas de la utilización conjunta de recursos.

Cuando el sector público colabora activamente con el sector privado en turismo pueden obtenerse significativas ventajas competitivas derivadas de:

- $\quad$ Acceso a nuevas fuentes de capital.

- Mejoras importantes en el desarrollo de infraestructuras.

- Compartimiento de riesgos en la búsqueda de nuevas oportunidades de negocio.

- Mantenimiento y mejora de los estándares de calidad ofrecidos en los servicios y productos turísticos del destino.

- $\quad$ Acceso a conocimiento especializado que redunde en mejoras de los procesos de planificación, gestión y prestación del servicio. 
- Optimización de los recursos invertidos en la creación de la cadena de valor del destino.

- Optimización de los beneficios económicos derivados del desarrollo turístico.

Por su parte, los beneficios que el sector privado puede obtener de esta colaboración son:

- Acceso a nuevos mercados a los que no podría acceder cada una de las empresas si actuara unilateralmente.

- Aumento de la capacidad para mejorar sus habilidades y competencias en el proceso de gestión y desarrollo de su producto.

- Expansión de sus productos y servicios más allá de sus recursos propios, por la unión de los recursos combinados.

- Reforzamiento de la credibilidad del producto ofrecido, al formar parte de una cadena de valor mayor.

- Obtención de retornos de los recursos invertidos acordes con los riesgos y méritos asumidos por los diferentes actores en el proceso.

Una de las características que define al panorama turístico, quizás motivado por el importante número de sectores económicos que interactúan en el proceso productivo, es su gran fragmentación, lo que se traduce en un gran número de empresas y organizaciones de pequeño y mediano tamaño que forman parte de la cadena de valor de un destino.

Desde un punto de vista global, el sector público con competencias en la planificación y desarrollo de los destinos turísticos debe buscar nuevas formas de colaboración con el sector privado para desarrollar de forma 
conjunta y estratégica nuevos productos, nuevos mercados y alcanzar nuevas metas más ambiciosas. Debe iniciar este proceso reconociendo que un destino turístico representa un ramillete de experiencias que todas, de forma conjunta, van a configurar un cluster competitivo. Y si bien son las empresas privadas las que "hacen el destino", no son sólo ellas las que determinan y proveen las atracciones, actividades, las cosas que ver y las cosas que hacer. La cadena de valor en turismo empieza antes de que el visitante llegue al destino turístico, desde el momento en que "el turista tiene la idea de viajar y ésta se convierte en una decisión de viajar" (OMT, op cit.).

Por tanto resulta concluyente extraer que la gestión de un destino turístico debe abordarse desde una perspectiva integradora de todas las organizaciones y entidades que configuran el conjunto de experiencias turísticas de un destino y que dan como resultado el cluster turístico.

Por todo lo expuesto, parece claro que en el sector turístico existe el total convencimiento de que la competitividad sostenible debe ser el fin último que oriente las políticas turísticas de los destinos, pero no existe unanimidad respecto a quién debe liderar ese proceso, y tampoco existe dicha conformidad respecto a cuál debe ser el modelo teórico-conceptual que fije las líneas de actuación de estos actores en la búsqueda de ese objetivo, si bien, parece que la eficiencia y la coordinación son factores clave para ello.

\subsection{Los destinos turísticos rurales o de interior}

En la actualidad, en el ámbito europeo en general y en España en particular, y debido tanto al creciente desarrollo del sector turístico como a la variedad y calidad de productos que componen la oferta turística, así como a la 
segmentación de la demanda turística, el denominado turismo rural o de interior, en sus distintas variantes (aventura, cultural, deportivo) es uno de los mercados en mayor crecimiento, si bien, y conviene matizarlo, a una distancia muy considerable del grueso del mercado turístico que sigue -y seguirá- estando configurado, en nuestro país, por los productos de sol y playa.

Estimulados por la aparente facilidad con la que el turismo se ha desarrollado en España, muchos municipios de zonas de interior han visto en el turismo una opción de desarrollo que permitiera corregir y compensar buena parte de los problemas de subsistencia y permanencia que les estaban acuciando.

En la práctica totalidad de estos incipientes desarrollos turísticos ha sido el sector público en sus diferentes ámbitos de competencia, nacional, autonómico y local, los que, en algunos casos de forma coordinada y en otros de forma un tanto improvisada, han puesto en marcha los proyectos y programas específicos.

Es indudable que no todos los destinos turísticos de interior, al igual que ocurre con los destinos de sol y playa, están teniendo el mismo nivel de éxito. Pero, del mismo modo que se pone de manifiesto al hacer referencia a la competitividad de los destinos turísticos tradicionales de sol y playa, la experiencia demuestra que aquellos destinos que, además de tener una serie de ventajas comparativas de salida (recursos monumentales, bellezas paisajísticas, recursos naturales) han aplicado enfoques y políticas de gestión adecuada, con instrumentos mínimamente articulados, han logrado un mejor posicionamiento en los mercados que aquellos que no lo han hecho. 
añaden mayor complejidad a su desarrollo competitivo:

- Las zonas de interior suelen tener, generalmente, graves deficiencias iniciales en equipamientos e infraestructuras.

- No tienen una demanda turística consolidada y estable durante todo el año o buena parte de él que permita generar un efecto multiplicador constante y estimule a la inversión privada.

- No suele haber capital inversor "ocioso" dispuesto a invertir en proyectos con una tasa de retorno más larga de lo habitual que en otros sectores.

- No hay tejido empresarial estable y con experiencia profesional en turismo.

- $\quad$ No hay muchos operadores de mercado interesados todavía en este tipo de productos al ser, de momento, productos minoritarios que no generan suficiente masa crítica de consumidores como para justificar la apertura de líneas de negocio específico.

- La demanda de estos núcleos suele estar formado, en su mayoría, por turismo doméstico, situación que resta competitividad en los mercados internacionales.

Por tanto, la necesidad de que estos incipientes destinos turísticos dispongan de un instrumento que oriente la gestión para el logro de ventajas competitivas vuelve a ser, al igual que ocurría en los destinos de sol y playa, un factor clave para desarrollo turístico sostenible. 


\subsection{Objetivos de la tesis}

El sector turístico es en la actualidad uno de los motores fundamentales del desarrollo social y económico de numerosas zonas del mundo. En la Europa mediterránea la consolidación del turismo como fuente económica ha estado basada tradicionalmente en la combinación de productos basados en los recursos ligados al sol y a la playa junto a una estrategia de comercialización orientada a lograr el máximo volumen de demanda.

Ahora bien, esta situación, que hasta mediados de los años ochenta ha sido predominante en la casi totalidad de los destinos turísticos nacionales ha empezado a cambiar de forma lenta pero sostenida con la aparición de nuevos productos turísticos basados en un esquema, aparentemente, opuesto al anterior que ha favorecido una nueva modalidad de turismo considerada por algunos como "turismo alternativo". Se trata del denominado "turismo rural" también denominado "agroturismo" y que nosotros denominaremos de manera genérica, turismo de interior.

El cambio de escenario anteriormente descrito se encuentra íntimamente relacionado con un giro muy importante que experimenta, en la misma época, la Política Agraria en la Unión Europea.

Por primera vez, el objetivo principal de la Polítia Agraria Común (PAC) deja de ser exclusivamente la modernización y eficiencia de las estructuras productivas agrarias para contemplar el medio rural en su conjunto dentro del ámbito territorial y social de referencia, proclamándose la multifuncionalidad como alternativa a las rentas agrarias a través de la diversificación. 
Siendo conscientes de que este desarrollo y diversificación no se producirá de modo espontáneo, la Comunidad Europea arbitra una política de desarrollo rural basada en potentes mecanismos técnicos y financieros para inducir dichos proceso. Así, desde principio de los años noventa, se fomentan unos planes en los que participaban de modo coordinado los tres fondos estructurales (FEDER, FSE, FEOGA) y se materializa en la iniciativa LEADER que se extienden desde 1992 a 2004. En aquellas zonas donde se han podido cumplir, con más eficiencia la mayoría de los objetivos planteados por la PAC mantenimiento de la población rural, conservación del entorno natural y del patrimonio cultural- el vehículo fundamental parecer ser que ha sido el turismo (Blanco y Benayas del Álamo, 1994).

Podemos preguntarnos por los factores que han hecho posible que una zona rural pueda llegar a considerarse como destino turístico de interior; por los elementos que han sido necesarios para alcanzarlo, cómo mantenerse en el futuro y si es posible el mantenimiento en el tiempo de una rentabilidad sostenida que tenga como base el turismo.

Si los objetivos de mejora estructural y mejora de la competitividad, - propios de una política agraria "tradicional" -, y los objetivos de ordenación del espacio rural, mejora social y defensa de la naturaleza y del medio ambiente, - propios de una política agraria "moderna" -, son perfectamente compatibles entre sí (Sumpsi, 1994) y, aparentemente, perfectamente compatibles con un desarrollo turístico sostenible en el tiempo, podría ser que la posición competitiva de un destino turístico no sólo viniera determinada por la actuación conjunta público-privada, sino que también, y quizás con mayor impacto, la capacidad de coordinar actuaciones en el ámbito público pudiera tener mayor trascendencia. 
La gestión integral de un destino turístico es una actividad altamente compleja debido a la cantidad de variables endógenas y exógenas que intervienen simultáneamente. Las variables endógenas son específicas de cada destino y están relacionadas con los recursos que poseen y la capacidad de desarrollarlos con vistas a alcanzar una favorable posición competitiva. Las variables exógenas dependen de la estructura y la organización del sector turístico, caracterizado éste por ser muy dinámico y con una alta competitividad internacional.

En esta línea, son muchos los autores que insisten en la necesidad de abordar los estudios sobre competitividad con enfoques internos y externos. Entre los autores contemporáneos, se podría afirmar que ha sido Porter (1980, 1985, 1990, 1998) el que más atención ha prestado a la influencia que los aspectos externos a las empresas y a los sectores tienen sobre la competitividad empresarial.

Por otra parte, tal y como recogen Priem y Butler (2001), son numerosos los autores que basan el modelo de competitividad empresarial en la teoría de los recursos. Así, es común el considerar que "los recursos que posee una empresa se consideran fuente de ventajas competitivas si son escasos, especializados, inaccesibles, valiosos, raros, difíciles de imitar o de sustituir" (Amit y Schoemaker, 1993; Barney, 1991).

Sin embargo, esta explicación es cuestionable cuando se desea aplicar a un destino turístico, puesto que una buena parte de la explicación del éxito global de un destino se sustenta en la propia capacidad competitiva de las empresas que se asientan en él y si algo tienen en común éstas es, precisamente, que comparten los recursos. El factor de atracción de un destino se justifica 
por los recursos que posee (recursos físicos - naturales y artificiales humanos, tecnológicos, financieros y la reputación), y éstos recursos son compartidos, en mayor o menor medida, por las empresas turísticas que componen el destino. De hecho, altos niveles de competencia entre las empresas que comparten recursos de un destino suele ser consecuencia de la saturación de éstos debido a que mientras el destino se encuentra en proceso de desarrollo -o se actúa políticamente sobre él - es habitual que las empresas se complementen entre sí con respecto al mercado de referencia, elevando conjuntamente el nivel global de competitividad. Así pues, el problema estratégico estriba en cómo crear nuevos recursos o cómo conseguir que los recursos que se tienen continúen siendo valiosos en el futuro.

Esta peculiaridad de los destinos turísticos ha conducido a la formulación de diversos modelos explicativos de la competitividad cuya validez se circunscribe, en la mayoría de los casos, a la realidad concreta para la que fueron formulados. La aplicación de estos modelos de competitividad a cualquier destino turístico y en particular a los destinos de interior, requiere un estudio previo de la validez de las hipótesis sobre las que se sustentan. Por ello, nos planteamos como objetivo genérico de nuestra investigación confirmar las hipótesis sobre los modelos de gestión competitiva a través del estudio de la aplicación de las variables que determinan la posición competitiva de un destino turístico de interior.

Para alcanzar este objetivo genérico nos planteamos unas metas específicas que nos permitan avanzar en nuestro conocimiento del aspecto principale objeto de investigación.

Estos objetivos operativos son los siguientes: 
1. Delimitación del marco conceptual de destino turístico, para poder disponer de los elementos determinantes que mayor atención ha recibido en la literatura turística contemporánea: concepto, límites, elementos estructurales y parámetros de competitividad.

2. Descripción de las variables determinantes de la posición competitiva de un modelo de destino turístico de interior.

3. Investigación empírica del papel que desempeña la comunidad local en relación al desarrollo turístico competitivo.

4. Diseño de un instrumento de gestión que sirva de orientación a los gestores locales de municipios de interior que deseen llevar a cabo un proceso de desarrollo turístico, estableciendo las bases de actuación mínimas imprescindibles para que el destino sea competitivo.

Estos objetivos responden a las siguientes reflexiones: ¿es posible determinar qué se entiende por competitividad en los destinos turísticos?. Si ello es así, ¿cuáles son las variables que afectan o influyen para que un destinos turístico que no haya alcanzado su estado de madurez sea competitivo?, ¿qué papel desempeña la comunidad local en el logro de la competitividad?. La respuesta a estas preguntas determina los distintos objetivos específicos que se han ido planteando a lo largo de la exposición teórica y de la investigación.

En primer lugar hemos de situar el marco teórico general que sustentará la investigación, haciendo un recorrido por las principales teorías que han abordado el tópico de la competitividad y se presentan los distintos enfoques que la literatura científica ha ido adoptando en torno al turismo para, 
finalmente, fundamentar el porqué del enfoque adoptado en la Tesis.

A continuación nos centraremos en los planteamientos teóricos específicos de la competitividad en los destinos turísticos a partir del estudio de los antecedentes teóricos disponibles.

Con este bagaje estaremos en disposición de abordar el objetivo final de la tesis y se plantean las hipótesis que se desean exponer y probar para la creación de un modelo de gestión competitiva de los destinos turísticos en fase de desarrollo, exponiendo las dimensiones y factores que se consideran clave para el desarrollo del modelo que se propone. En este mismo capítulo se presenta la investigación experimental realizada, se expone la información obtenida, se analiza el resultado y se propone el modelo de gestión competitiva.

Por último, se exponen las conclusiones de la investigación, sintetizando las principales aportaciones realizadas y proponiendo futuras líneas de investigación partiendo de este estudio.

Finalmente, en la última parte se recoge toda la bibliografía y se complementa con los anexos de soporte a la investigación. 

CAPÍTULO 2

COMPETITIVIDAD Y ACTIVIDAD

TURÍSTICA 



\subsection{Introducción}

En la actualidad, la búsqueda de la competitividad constituye la referencia obligada de las actuaciones de las organizaciones a la hora de fijar los objetivos, asignar recursos, organizar procesos y, en definitiva, en la toma de decisiones aplicadas en el ámbito de la gestión propia de cada una de ellas.

Si bien este enfoque, como tal, no es novedoso por cuanto venía utilizándose en el ámbito de la gestión empresarial, aunque de manera mucho más restrictiva que lo reducía, de facto, a la noción de productividad, entendiendo ésta, a su vez, como una mejora de costes operativos en los distintos procesos productivos que integraban la creación de sus bienes y servicios. Del mismo modo, la mayor parte de las experiencias y estudios sobre la competitividad se han venido centrando, casi de forma exclusiva, en el ámbito de los sistemas industriales y sólo a partir de la década de los 90 del pasado siglo se inicia su aplicación a otros ámbitos de las diferentes economías de los países y regiones.

Así, las fuerzas económicas y políticas y las tendencias que de forma especial han influido en tal cambio se podrían agrupar en torno a las siguientes ideas centrales (Carpi, 1998):

1) La creciente apertura de las economías nacionales y la disminución de la capacidad de regulación pública han generado una significativa reducción de las barreras defensivas y la necesidad por parte de las empresas de gran número de sectores de salir a los mercados internacionales para garantizar su supervivencia. 
2) La crisis fiscal, la competencia de los actores públicos por la atracción de inversiones y su renovado compromiso con la liberalización y la competencia, así como los aludidos problemas de regulación, han obligado a los gobiernos a adoptar políticas que fomentan la competitividad, al ser éstas las únicas que en este tipo de contextos pueden aportar soluciones adecuadas a los problemas derivados de la transformación tecnológica, económica y social que aquellos comportan. En este sentido, las políticas de regulación de la demanda y de redistribución de la riqueza ha dejado paso a políticas más orientadas al fomento de la innovación como factor clave para el logro de la competitividad.

3) La aceleración del cambio tecnológico y el impulso que la revolución de la información ha impuesto a la dinámica innovadora han generado nuevos retos y oportunidades. Así, se ha estimulado la transformación del proceso productivo y la racionalización de la organización y la gestión, a la búsqueda de mayores logros en la eficiencia y la eficacia productiva (productividad, flexibilidad, calidad del proceso y calidad del producto). Igualmente, se han ampliado enormemente las posibilidades de innovación de los productos.

Ahora bien, la transformación que la tecnología está produciendo es de tal magnitud que la exigencia de adaptación tecnológica y de creación de nuevas ventajas competitivas se ha hecho imprescindible para todos los sectores productivos y todos los espacios y territorios, con independencia del nivel de desarrollo que pudieran detentar, de tal modo que aquellas empresas que no se adapten corren el riesgo de quedar fuera de sus mercados correspondientes, y los territorios con menor dinamismo sufrirán significativas 
perdidas en sus niveles de renta y de empleo.

4) El acortamiento del ciclo de vida de los productos, la mayor microsegmentación, el creciente dinamismo de los mercados y la obligatoriedad de una mayor diferenciación de los productos ofrecidos, con la consiguiente adopción de modelos de organización y gestión mucho más flexibles y en permanente adaptación a los cambios del entorno, han afectado de forma muy profunda el alcance y condiciones de la competitividad. El factor precio como referencia fundamental de la competitividad en mercados de bienes muy estandarizados y de cambios lentos y muy previsibles ya no puede continuar siéndolo en un contexto productivo en el que la innovación del producto, la calidad y la diferenciación del mismo, la adaptación a las necesidades y expectativas del cliente - cada vez mayores y más variadas- deben ser los ejes fundamentales de la actividad de las organizaciones productivas. Por ello, y junto a los factores propios que determinan la eficiencia productiva los factores relacionados con el marketing - investigación de mercados, definición de producto y comercialización - serán los determinantes de la competitividad.

5) Las retos impuestos por el nuevo paradigma tecnológico, económico y social obligan a las organizaciones a llevar a cabo un profundo replanteamiento de sus modelos organizativos y productivos, así como a la definición de sus objetivos y estrategias, determinando que sea la capacidad de generar recursos y conocimiento de toda la organización, y su habilidad para poder mantener una total sintonía con el mercado, condiciones indispensables para el logro de la competitividad. 
Por tanto, y a la vista de que el entorno, el sistema educativo, los procesos de I+D+i, las infraestructuras, las relaciones socio-políticas y económicas, y la gestión pública sobre todos estos elementos resultan fundamentales para la obtención de ventajas competitivas sostenibles, es perfectamente justificable el que el concepto de la competitividad haya pasado a ser un elemento central de las políticas de actuación de los diferentes gobierno.

En este nuevo contexto es lógico que tanto las empresas como los gobiernos pasen de adoptar posturas defensivas y de reserva de mercado a planteamientos preactivos.

El sector turístico no es ajeno a esta competencia global y los cambios que se han producido en los últimos diez años pueden sintetizarse de la siguiente manera:

\section{1) Consumidores}

Hasta principios de los años 90 del siglo pasado el turista buscaba, casi de forma exclusiva, destinos de sol y playa, lo que comportaba una tendencia Norte-Sur en el flujo turístico, siendo la cuenca mediterránea y, especialmente, España, los grandes destinatarios de esas corrientes turísticas. A su vez, y dentro de los destinos de sol y playa, la oferta complementaria requerida se centraba en productos y servicios con motivaciones muy limitadas, fundamentalmente restauración y ocio.

En la actualidad, aunque el producto líder sigue siendo el sol y playa, el abanico de opciones y necesidades del turista se ha ampliado notablemente. Éste, mucho más experto y conocedor de las opciones y posibilidades que 
ofrece la oferta turística internacional y con una información inmediata y accesible desde su propio domicilio, ya no desea productos turísticos convencionales. La búsqueda de nuevas experiencias turísticas, el deseo de ser diferente y la exigencia de calidad en la prestación del producto son líneas claras en la determinación de las tendencias actuales de la demanda turística internacional.

\section{2) Cadena de Valor}

La cadena de valor del proceso de prestación del servicio turístico se amplía, ya no se consideran exclusivamente las actuaciones que se llevan a cabo cuando el turista llega al destino turístico, sino que, gracias a la tecnología, se intenta ofrecer una experiencia integral que se inicia desde el momento en que el posible y futuro consumidor empieza la búsqueda de información sobre el producto en cuestión, continúa con el proceso de compra, el posterior consumo en destino y la post venta del mismo una vez ha regresado a su lugar de origen.

\section{3) Producción}

La situación anterior a la década que contemplamos se caracterizaba por productos maduros en los que la competencia se basaba en la variable precio, siendo incluso frecuente la utilización de políticas agresivas de devaluación de la moneda en determinados países receptores de turismo como medio para aumentar la competitividad de sus destinos turísticos (Poon, 1993). La venta de paquetes rígidos, fuertemente estandarizados y la presión de los operadores turísticos generalizaba un oferta muy homogénea, poco diferenciada y, por tanto, con pocas opciones para la creación de 
estrategias de posicionamiento individual de productos turísticos.

La búsqueda del aumento continuo en el tamaño de la empresa se justificaba por la obtención de economías de escala, lo que comportaba frecuentes procesos de integración vertical y horizontal entre las empresas del sector.

Hoy en día la competencia ya no se basa exclusivamente en los precios, sino que se busca a través de la diferenciación entre productos ofrecidos. Se sigue persiguiendo la realización de economías de escala, pero a través de la especialización en productos y mercados, lo que genera ventajas competitivas para las organizaciones derivadas de un mejor saber hacer profesional en la gestión de productos. Igualmente, esta especialización está determinando la creciente aparición de integraciones diagonales protagonizadas por empresas que buscan mejores posicionamientos estratégicos en determinadas fases de la cadena de valor del producto turístico.

\section{4) Gestión}

Los productos turísticos actuales compiten en un escenario caracterizado por importante número de oferentes de productos similares o sustitutivos, situación que obliga a los gestores de la oferta turística a tener que salir a los mercados para lograr el adecuado posicionamiento de sus productos, lo que implica un exhaustivo conocimiento de los mercados para anticiparse a sus necesidades, expectativas y evolución.

Asimismo, las empresas deben establecer los mecanismos imprescindibles para lograr una óptima gestión de la de la calidad con el objetivo de lograr una relación con sus clientes que sea estable, duradera y altamente rentable 
para ambas partes.

Igualmente, el hecho de que los tour operadores ya no controlen en su totalidad el mercado -derivado tanto de la ampliación de canales de comercialización y distribución de tipo directo, como de la continua aparición en el mercado de operadores de menor tamaño pero altamente especializadosobliga a las organizaciones oferentes de los productos turísticos, tanto públicas como privadas, a gestionar directamente sus procesos de comercialización turística.

\section{5) Condiciones del entorno}

Según la OMT, (1999) las principales tendencias que afectarán al entorno turístico durante los próximos años serán las siguientes:

- Aumento de la conciencia social y medioambiental. Se demandará de forma creciente una mayor protección de los espacios naturales, una mejor utilización de las energías y recursos y una mayor consideración y respeto a la identidad cultural de las comunidades receptoras de turismo. Por tanto, la sostenibilidad de los recursos de los destinos turísticos será un factor clave para el logro y mantenimiento de la competitividad de los mismos.

- Los destinos turísticos serán un elemento de moda y de valoración social, factor éste que supondrá que los gestores de los destinos turísticos deberán llevar a cabo la definición e implantación de procesos sistematizados de mejora de la calidad y de innovación para lograr una mejor valoración por parte de los consumidores. 
- Globalización y localización, lo que se conoce con el nombre de "glocalización turística", es decir, que si bien está siendo claramente perceptible el aumento del poder económico que muchas multinacionales poseen en la industria turística internacional, la actuación en espacios físicos concretos -localidades y municipios turísticos- obligará a que éstas lleven a cabo mayores esfuerzos de adaptación y compromiso con las sociedades locales. Los grupos sociales y culturales de estas localidades exigirán derechos y reconocimientos que deberán ser considerados en las estrategias de las empresas, es decir, la sostenibilidad socio-cultural de los destinos turísticos será clave.

- Los destinos turísticos ya no compiten entre sí exclusivamente sobre la base de factores de proximidad geográfica. El turista actual puede acceder a casi cualquier parte del mundo y, por tanto, la capacidad de desplazamiento no será un límite de imposible solución. En este sentido, la mejora de los transportes traerá una mayor oferta y, en consecuencia, una mejora de los precios, lo que redundará, a su vez, en una mayor facilidad para el viaje para muchas personas de niveles de renta medios y medios bajos.

\subsection{El concepto de competitividad}

El estudio de la competitividad ha sido abordado desde diversas concepciones a lo largo de la historia del pensamiento económico, especialmente en el ámbito de la organización de empresas y de la economía industrial, siendo, a partir de la década de los 80 del pasado siglo, cuando se ha producido un mayor debate entre las distintas escuelas de pensamiento estratégico, debate que, hasta la fecha, sigue sin estar cerrado. 
En todo caso, el concepto de competitividad tiene su origen en el ámbito de la microeconomía y se ha ido trasladando al plano macroeconómico, sobre todo, a partir de las significativa aportación de la obra de Michael Porter (1980, 1985, 1990, 1991, 1996, 2003) a esta cuestión, por cuanto logra unir los aspectos más significativos de las formulaciones teóricas de la economía industrial y las de la organización de empresas.

La cuestión sobre qué es la competitividad, a pesar de ser uno de los pilares fundamentales de buena parte de la literatura empresarial y económica de las últimas décadas, responde a una noción, aceptada por todos, pero que muy pocos han llegado a definir categóricamente. Algunas definiciones que se han formulado se recogen a continuación:

- Competitividad es el grado en que una nación puede, bajo condiciones de libertad e igualdad de mercado, producir bienes y servicios que satisfagan las exigencias de los mercados internacionales al tiempo que mantiene o incrementa los ingresos reales de sus ciudadanos. (Informe del presidente de la Comisión sobre competitividad del Reino Unido, 1985; Informe de la OCDE sobre Competitividad Mundial, París 1997).

- La capacidad de obtener beneficios y de mantenerlos en circunstancias cambiantes. (Plan Marco de Competitividad del Turismo Español, 1992, Secretaría General de Turismo).

- $\quad$ Por competitividad de una empresa se entiende la capacidad de la organización para mantener o incrementar su cuota de mercado (Alonso, 1992). 
- La competitividad es igual a la capacidad para competir (Montfort, 1999).

- La competitividad surge de la productividad con la que las empresas emplean en una ubicación esos factores (...mano de obra, capital y recursos naturales) para producir bienes y servicios valiosos. (Porter, 2003:13).

A los efectos de nuestra investigación, asumiremos el enfoque que considera que la competitividad de una organización empresarial o, extendiendo la perspectiva, de una agrupación de empresas localizadas en un territorio dado, consiste en su capacidad para mantener o incrementar su participación en la oferta de sus mercados de referencia y/o abrir nuevos mercados, sirviéndose del incremento en la eficiencia (productividad) y eficacia (calidad y dinámica de producto, capacidad de acceso a los mercados y adaptabilidad y creatividad de la organización) y haciéndolo compatible con la elevación de la renta real y las condiciones de vida y trabajo de los actores del proceso productivo (Carpi, 1998).

Partiendo de la consideración de que una ventaja competitiva es la característica o atributo de que dispone una organización para poder competir de forma rentable y sostenida en sus mercados de referencia, la línea de pensamiento que nace desde la organización de empresas considera que la capacidad competitiva de una organización estaría estrechamente ligada a la capacidad que tenga esa organización de generar y mantener ventajas competitivas en relación con su entorno y sus mercados de referencia.

Por tanto, será la capacidad que tenga la organización para dotarse de una 
estructura que optimice sus recursos, le mantenga en plena sintonía con su entorno y le permita generar un proceso de innovación permanente, la que determine su ventaja competitiva y la sostenibilidad en el tiempo de la misma: "la competitividad de una empresa no está determinada de forma inequívoca por las características del territorio en el que actúa o por las del sector a los que formalmente pertenezca; la capacidad de una empresa para tener éxito en mercados cada vez más grandes, abiertos y competitivos depende, sobre todo, de ella misma" (Fernández, 1992).

Son los atributos de la empresa, difíciles de imitar, los que determinan sus actuaciones y sus resultados (Wernenfelt 1984; Grant,1991) considerando a la empresa como un conjunto de recursos y capacidades, de tal modo que es en este conjunto donde residen las verdaderas raíces de las ventajas competitivas (Bueno, 1995).

Inicialmente, la teoría de los recursos y capacidades afirmaba que las empresas debían tener como principal objetivo la identificación, desarrollo, protección y despliegue de los recursos y capacidades que aseguren el logro de una ventaja competitiva sostenible y obtener así rentas superiores en el largo plazo. Según esta teoría, el crecimiento de la empresa depende de los recursos de que dispone y no de la demanda de sus actuales productos. Sin embargo, la investigación actual sobre la empresa y los recursos apunta básicamente hacía distintas áreas, de tal modo que se pueden diferenciar dos líneas de interpretación directamente derivadas de esta teoría: el enfoque basado en los recursos y el que centra su consideración en las capacidades dinámicas o competencias esenciales.

Así, Barney (1991, 2001) define recursos como los activos tangibles o 
mismo autor, los recursos considerados estratégicos deben reunir unas condiciones determinadas: el recurso debe ser valioso, en el sentido de ser capaz de crear valor, debe ser escaso, debe tener una movilidad imperfecta y ha de ser difícil de imitar.

Grant (1991) por su parte, clasificó los recursos de la empresa en cinco categorías: recursos financieros, físicos, humanos, tecnológicos y de reputación. Un aspecto destacable de la aportación de este autor es que hizo hincapié en las ventajas que pueden proporcionar los recursos intangibles basados, sobre todo, en la información, lo que les hace tener unas características propias, en el sentido de que son difíciles de acumular y susceptibles de uso simultáneo. Asimismo, no suelen depreciarse, sino que mejoran cuando se aplican y comparten (Fernández, 1993).

Este planteamiento de los recursos como fuente de la ventaja competitiva fue trasladado al campo de la investigación en turismo (Bull 1991; Gray 1982; Pigram 1980; Mathieson y Wall 1982) si bien su aportación quedaba muy reducida ámbito de los recursos naturales. Sobre este aspecto volveremos posteriormente al hablar de los destinos turísticos.

En definitiva, para los defensores de esta teoría, los recursos son fuente de las capacidades y ambos deben constituir la base en las que apoyar y definir las estrategias de la empresa. Las capacidades, en esencia, son conocimiento y, al igual que las personas, las organizaciones están limitadas y condicionadas a actuar en aquello que saben hacer bien.

Por otra parte, el enfoque que está acaparando mayor atención en los últimos años es el referido a la otra línea de pensamiento, a la denominada " teoría de las capacidades dinámicas o competencias esenciales", que pone su acento 
en los aspectos dinámicos de la organización, tales como la innovación, el aprendizaje organizativo, la acumulación de recursos, la creación de capacidades, el desarrollo de sus modelos de gestión o la gestión del conocimiento (Teece, Pisano y Shuen, 1997; Fernández, Montes y Vázquez, 1997; Eisenhardt y Martín, 2000).

Una de las críticas más frecuentes a la teoría de los recursos y capacidades (en adelante TRC) reside precisamente en el que al centrarse la competitividad distintiva en la posesión y utilización de recursos únicos, inimitables, intransferibles e inherentes a la empresa, no se tiene en cuenta las fuerzas cambiantes del mercado. En este sentido, Foss (1997) aunque defiende esta teoría a la que considera relativamente nueva, admite que no está completa y que presenta fallos en su conexión con el entorno.

Igualmente, Fernández, Montes y Vázquez (1997) opinan que la TRC es válida para explicar la obtención de ventajas competitivas siempre que se sitúe en un contexto dinámico que haga mayor énfasis en los procesos de cambio que en las condiciones estáticas de equilibrio.

Porter (1996) señala que "lo peor de la TRC es que es circular -una empresa alcanza el éxito porque tiene recursos únicos, pero ¿cómo ha conseguido estos recursos valiosos?, ¿qué es lo que hace suponer que seguirán siendo valiosos en el futuro?". En esta misma línea, Priem y Butler (2001) afirman que, efectivamente, en la TRC subsisten afirmaciones tautológicas en el sentido de que son los beneficios extraordinarios de las empresas las que les permiten adquirir recursos únicos y valiosos y que es obvio responder afirmativamente a la pregunta: ¿generan mayores rentas los recursos críticos?. Estos autores recomiendan tratar en futuras investigaciones cuestiones más 
profundas relativas a cómo, cuándo y por qué se crean los recursos. Asimismo, recomiendan la incorporación del factor tiempo a los estudios ya que este componente puede ayudar a conseguir una mayor comprensión sobre la compleja interacción que se da a lo largo del tiempo entre los recursos de una empresa y su entorno competitivo, ya que ésta teoría debería integrarse en un modelo de análisis del entorno.

Finalmente, varios autores (Priem y Butler, 2001; Foss, 1997; Bueno, 1995), entre otros, coinciden en afirmar que la TRC y los modelos de estudio del entorno, como el Diamante de Porter (1991) o el modelo DAFO (Ansoff, 1965) deben ser estudiados como enfoques complementarios para comprender, crear y mantener ventajas competitivas que permitan a las empresas obtener beneficios extraordinarios.

Es en esta línea de pensamiento en la que nos gustaría enmarcar nuestra investigación, ya que si bien son las empresas las que generan y mantienen las ventajas competitivas en las que basar su estrategia competitiva y, consiguientemente, su éxito empresarial, no todos los factores son propios e internos de la organización, sino que la existencia de las condiciones marco de la actividad industrial (Gönenç 1994), es decir, factores externos a la empresa tales como el tejido empresarial, marco jurídico, entorno sociocultural, políticas de I+D, políticas públicas) condicionan muy poderosamente la existencia y evolución de esas ventajas competitivas.

En este sentido nos parece igualmente apropiada la aportación de Pelikan (cit. por Carpi,1998) cuando considera que las organizaciones empresariales tienen cuatro tipos de competencias: 
a) Asignativas, esto es, referidas a la habilidad de la organizción para decidir sobre cantidades y precios de inputs y outputs o para elegir técnicas de producción, es decir, la que expresa la versatilidad y capacidad de adaptación productiva a la dinámica del entorno mercadológico (mercado de outputs, factores e inputs).

b) Asociativas, que hace referencia a la capacidad para diseñar, conectar, modificar o abandonar organizaciones, es decir, versatilidad organizativa.

c) De aprendizaje, que implica la existencia del talento económico o empresarial y, por tanto, capacidad de aprender las anteriores competencias.

d) Técnicas, que se refiere a la capacidad de diseñar productos y procesos en términos científicos.

Existe una estrecha relación entre la empresa, el sector al que pertenece y el territorio en el que actúa, ya que la estrategia y el desarrollo de las competencias de una empresa definen su posición competitiva en referencia a las existentes en su entorno, pero será la estructura del sector y su dinámica interna la que definen las relaciones entre las empresas, de éstas con sus respectivos mercados de referencia, la dinámica de la innovación y las relaciones de poder (Carpi, 1998).

La aplicación de la competitividad a los destinos turísticos nos obliga a llevar a cabo su consideración con un enfoque más próximo al de la economía industrial, sin que ello implique perder de referencia muchos de los aspectos mencionados por los autores de organización de empresas, puesto que, 
reiteramos, nos parece que el enfoque no debe ser alternativo -uno u otrosino combinado, puesto que esta realidad es más claramente visible, si cabe, cuando del desarrollo de destinos turísticos se trata. Esto es debido a que el propio producto ofrecido por las empresas turísticas se enmarca, de forma ineludible, en un contexto territorial determinado que condiciona y determina, en mayor o menor medida en función del tipo de producto de que se trate, la experiencia del consumidor turístico, por un lado, y la capacidad de "fabricar" su producto, por otro.

\subsection{Entorno competitivo}

A la hora de abordar el estudio del entorno que rodea a las organizaciones es necesario llevar a cabo una distinción entre el macroentorno, que hace referencia al conjunto de variables y aspectos que conforman el marco de actuación más externo al ámbito de la empresa u organización, y el microentorno o sector específico que es el más próximo a la empresa u organización y es donde ésta, en realidad, compite.

Siguiendo a Garrido (2003), se puede definir el entorno como "todo el medio externo relevante en relación con la actividad a desarrollar", siendo por tanto, la propia actividad a la que se dedique la organización la que delimitará el ámbito de la observación y consideración de cuál es el entorno y que, de forma sintética, viene caracterizado por cinco dimensiones: cultural, económica, tecnológica, política y legal. Ahora bien, dada la amplitud que cada una de ellas tiene per se obliga a que el análisis siempre deba limitarse a un número más reducido de ellas, o a una parte de cada una de ellas, de acuerdo con la propia experiencia, las características de la actividad de que se trate y la posibilidad de obtener datos fiables y seguros en los que 
fundamentar las posteriores decisiones estratégicas.

Para el análisis del entorno se suelen considerar las siguientes variables:

- Estabilidad, que hace referencia a la cantidad, rapidez, profundidad y predictibilidad o no de los cambios que le afectan.

- Complejidad, que determina si la comprensión y adaptación a los cambios se puede llevar a cabo de manera sencilla o no.

- Diversidad, que hace referencia a la necesidad de disponer de un buen número de variables y factores para poder reconocer y entender los cambios que operan en el entorno.

- Hostilidad, que hace referencia a la intensidad de los cambios, la velocidad con la que se presentan, y si suelen ser habituales las reacciones agresivas - defensivas u ofensivas de los competidores.

De la combinación de estos cuatro variables surgen distintos tipos de entorno. Así, Ansoff (1979) considera que se pueden establecer los escenarios en cinco tipos: estable, reactivo, anticipativo, explorador, creativo.

En lo que respecta al entorno más próximo a la organización -el microentorno o sector competitivo- han sido diversos los autores que han investigado en este campo, si bien y de modo general, quienes estudian las características de los sectores se centran en el tamaño de los mismos, en la concentración, en el grado de madurez y en sus dimensiones o fuerzas competitivas, como son el número de competidores, la diferenciación de los productos, las 
barreras de entrada y el poder de negociación que se posea (Garrido, 2003)

Así, para Schreder (1996) la estructura de un sector viene determinada por:

1- Número de vendedores y compradores.

2- Diferenciación de productos.

3- Barreras de entrada.

4- Estructura de costes.

5- Integración vertical.

6- Estructura conglomeral.

No obstante, será Porter (1980) quien establezca que la esencia de la formulación de una estrategia competitiva consiste en relacionar una empresa con su sector de referencia y con su posicionamiento competitivo dentro del sector. La estructura sectorial es relativamente estable pero puede cambiar con el transcurso del tiempo, a medida que el sector evoluciona. Esta estructura está caracterizada por unos factores o elementos clave que determinan el conocido modelo de las cinco fuerzas competitivas de este autor:

1- El poder negociador de los proveedores.

2- El poder negociador de los clientes.

3- La amenaza de entrada de nuevos competidores

4- La amenaza derivada de la aparición de productos substitutivos

5- La propia rivalidad existente entre las empresas que compiten en ese mercado

La intensidad de las cinco fuerzas varía de un sector a otro y la combinación 
de ellas es la que determina la rentabilidad a largo plazo de ese sector, conformando la estructura de precios, los costes y las inversiones necesarias para competir. De tal modo que "es en el sector en particular, donde las empresas pierden o ganan las ventajas competitivas. La nación donde radican influye en la capacidad de sus empresas para triunfar en determinados sectores" (Porter,1991). Un sector, estratégicamente diferenciado, comprende productos cuyas fuentes de ventajas competitivas pueden ser similares. Las empresas, por medio de la estrategia competitiva, intentan definir un modelo o protocolo de actuación rentable y sostenible para competir en su propio sector.

Por tanto, la elección de la estrategia competitiva correspondiente vendrá determinada, por un lado, por la propia estructura del sector por cuanto no todos los sectores productivos son iguales y por tanto no ofrecen las mismas oportunidades para lograr una rentabilidad sostenida y, por otro lado, por el posicionamiento detentado. El enfoque que la empresa adopte a la hora de competir deberá estar basado, básicamente, en la ventaja competitiva de que se disponga y que puede ser de coste o de diferenciación.

La ventaja en coste se genera cuando por los recursos y competencias de que dispone una empresa a la hora de diseñar, fabricar, comercializar o prestar un producto o servicio, es capaz de hacerlo de forma más eficiente que sus competidores, lo que implica que, a igual estructura de precios que sus competidores, obtiene márgenes superiores.

La estrategia de diferenciación, por el contrario, parte de la premisa de que la empresa es capaz de ofrecer al consumidor un producto o servicio que dispone de atributos y características diferentes a los ofrecidos por los 
competidores, aportando, en consecuencia, un valor añadido superior para los compradores, lo cual le otorga una mayor fuerza a la hora de competir y podría obtener un precio superior al de sus competidores, por lo que obtendría, a igualdad de costes, unos márgenes superiores.

Nada impide, desde un plano teórico, argumentar que una empresa puede competir utilizando ambas estrategias simultáneamente pero es altamente improbable que una empresa pueda obtener unos costes operativos inferiores y, al mismo tiempo, ofrecer un producto claramente diferenciado.

La idea del posicionamiento como eje central de la estrategia ha sido rechazado por algunos autores (Grant, 1991) que consideran que los competidores pueden copiarlo fácilmente dando lugar, en muchos casos, a una ventaja competitiva temporal.

El propio Porter (1996) sale al paso de estas críticas considerando que este problema surge al no distinguir adecuadamente entre "eficiencia operacional" y estrategia, de tal modo que la búsqueda constante de la productividad, calidad y flexibilidad ha originado que las técnicas de gestión hayan ocupado el lugar de la estrategia.

Sostiene Porter que la eficacia operativa supone realizar actividades similares de forma mejor que lo hacen los competidores por lo que incluye la eficiencia pero no está limitada, exclusivamente, a ella, mientras que el posicionamiento estratégico implica o bien desarrollar actividades diferentes a las que realizan los competidores o bien hacer las mismas actividades pero de forma diferente a como ellos lo hacen. Sin una constante mejora de la eficiencia operacional es imposible que una empresa obtenga un beneficio superior, pero sólo con ella, nos está garantizado el éxito a largo plazo. 
La estrategia es la creación de una posición única y valiosa, incluyendo un diferente conjunto de actividades, con el fin de producir un valor reconocido en el mercado. Si hubiera una única posición idónea, no existiría la estrategia.

El posicionamiento, por tanto, no sólo determina qué actividades desarrollará la empresa, sino que implica definir cómo se articularán esas actividades entre sí. La eficiencia operacional busca optimizar cada una de las actividades individuales, en términos de coste y en términos de valor añadido, mientras que la estrategia persigue obtener un buen resultado por la combinación de todas ellas.

\subsection{Empresa, sector y territorio.}

Los autores que, originariamente, más relevancia han otorgado al territorio han sido Porter (1990) y Krugman (1991), siendo los primeros en señalar el papel relevante de la localización geográfica como eje central para la concentración de empresas y el dinamismo competitivo. Porter, para representar significativamente la concentración de empresas y organizaciones en un ámbito determinado utiliza el término cluster definiéndolo como un entramado de empresas, organizaciones e instituciones que comparten conocimiento, tecnología, factores de producción y/o canales de distribución y entre las que se crea relaciones tanto de colaboración como de competencia. En recientes ediciones, Porter (2003) plantea el problema de la deslocalización espacial de empresas, pero observa que es para aprovechar ventajas competitivas temporales que, a su vez, propician la introducción en el nuevo espacio de nuevos miembros atraídos por la posibilidad de hacer negocios, creándose nuevos clusters y reactivando, en definitiva, la competitividad internacional. 
La importancia de la concentración geográfica y, sobre todo, la evidencia de la existencia de clusters industriales se ha estudiado ampliamente desde su formulación Sin embargo, tal y como han puesto de relieve distintos investigadores (Lagendijk, 1999a; Bergman y Feser, 1999; Enright, 2000; Raines 2001) el concepto porteriano de clusters ha sido tan ampliamente interpretado, que existen múltiples aplicaciones, más acordes con las necesidades de quien las formula, que con el rigor del concepto. Esta situación conduce a que no exista un marco teórico unificado que permita utilizar una metodología determinada para analizar los clusters, sino una serie de teorías e ideas que constituyen lo que Brown (2001) denomina "una cierta lógica de cluster".

Los gobiernos regionales de algunos países europeos, especialmente de aquellos con estructuras políticas muy descentralizadas (Alemania, España), han adoptado este enfoque como una forma efectiva de promover la competitividad a través de un proceso de especialización regional, o bien han utilizado el concepto para estimular el crecimiento regional o local promoviendo las oportunidades de negocio. En España han sido las Autonomías de Cataluña y el País Vasco las que han alcanzado un mayor grado de desarrollo en el despliegue de este enfoque político.

Estudios promovidos por el Centro de Investigaciones Europeas ponen de manifiesto que en la Unión Europea se pueden apreciar dos tipos de enfoques en la adopción de la metodología de cluster en las estrategias políticas nacionales, aunque no siempre con límites muy claro entre ellos. Estos enfoques estratégicos son: 
- Estrategias holísticas o específicas de cluster (Noruega, Finlandia, Suecia, Países Bajos) en las que el objetivo es reforzar el desarrollo o incentivar la aparición de tipologías de negocio concretos dentro de un cluster

- Estrategias inspiradas en los cluster (Francia, Alemania, Reino Unido) que, utilizando técnicas basadas en este marco teórico, como es el entramado de empresas y organizaciones para la cooperación y el desarrollo, adoptan objetivos de interés político preferente concentrando los esfuerzos económicos en las medidas concretas tendentes al logro de los objetivos de referencia.

Según se ha puesto de manifiesto (Carpi, 1998) la capacidad de un territorio para gestionar adecuadamente su economía excede a la capacidad individualmente considerada de los actores participantes en el proceso de creación y desarrollo de una determinada dinámica territorial puesto que ésta se verá fuertemente influenciada por:

a) La propia estructura sectorial y organización productiva.

b) La capacitación general de los recursos humanos, los valores, actitudes y creencias de la población, así como las relaciones sociales imperantes.

c) El nivel de desarrollo del sistema de I+D y el marco institucional y sus cualidades para estimular la movilización y desarrollo de los recursos y capacidades económicas. 
d) El grado de cohesión y de movilidad social existente.

e) Las cualidades de representantes, líderes y organizaciones para movilizar actores y capacidades internas e influir en instancias político-económicas externas.

La proximidad física con proveedores, colaboradores y competidores y el nivel de eficiencia en la organización interna, conjuntamente con la estrategia desplegada, determinará el posicionamiento competitivo de la empresa, pero son las capacidades disponibles en el territorio lo que confiere más relevancia al marco territorial a la hora de determinar, no ya la competitividad particular de las empresas, sino el desarrollo competitivo de una región o país.

En consecuencia, el liderazgo del sector público en este proceso deviene capital, ya que éste es el responsable principal, pero no único, en el objetivo de lograr que un territorio concreto sea competitivo, como expresión del comportamiento relativo de un espacio respecto a otros y en relación al nivel de vida sus habitantes (Fagerberg, 1996), si bien ello no puede ser explicable, a su vez, sin la referencia a la competitividad de las propias empresas radicadas en dicho territorio (Canals, 1993).

Así pues, consideramos que el liderazgo del sector público en diferentes niveles territoriales, la coordinación entre las diferentes instancias públicas, el nivel de desarrollo de los servicios públicos, instituciones de apoyo, definición e implantación de programas de estímulo a la innovación, así como el desarrollo de actuaciones estratégicas dentro del cluster y la existencia de una relación fluida con el sector privado son condiciones esenciales para lograr la optimización de las políticas sectoriales turísticas. 


\subsection{Enfoques para el estudio de la actividad turística}

\subsubsection{EI Enfoque geográfico}

La esencia del turismo viene caracterizada por el movimiento de personas que se desplazan de sus lugares habituales de residencia a otros distintos por motivos distintos a los de trabajo o residencia, y cuya estancia en este lugar es superior a veinticuatro horas (OMT, 1998), por lo que las implicaciones que este tipo de movimiento tiene, sobre los espacios físicos de origen, tránsito y, especialmente, acogida o destino son indudables. Sus implicaciones en los cambios de morfología del territorio, el aprovechamiento de los recursos naturales y el impacto medioambiental ha despertado el interés de numerosos investigadores (Vera, 1996; Yepes, 1999; Viñals y Bernabé, 1999; Ivars, 2003) muchos de los cuales provienen del campo de la geografía y, especialmente en los últimos años, en el ámbito de la planificación territorial.

A la hora de efectuar un análisis de las diferentes líneas de pensamiento que se han venido manifestando en el estudio de la geografía del turismo, se evidencia la existencia de dos líneas de investigación (Hall y Page 1999). La primera basada en la perspectiva de análisis espacial en su dimensión aplicada , mucho más evolucionada respecto a los enfoques más tradicionales y estáticos, y que aporta, además de información territorial básica, técnicas y protocolos para la planificación y gestión del territorio turístico. La segunda perspectiva, más reflexiva, ofrece una visión y un conocimiento teórico imprescindible en todo proceso de planificación al orientar dichos procesos para que puedan cumplir su necesaria función social. 
Ivars (2003) sostiene que los trabajos de investigación y análisis se pueden agrupar en las siguientes materias:

- Estudio de los recursos territoriales como elementos esenciales del potencial turístico de cada espacio. Los recursos territoriales constituyen importantes factores de atracción de las actividades turísticas, por lo que es imprescindible, en una primera fase, llevar a cabo el adecuado estudio de su potencialidad para determinar su valoración como "atractor" de la actividad turística. Finalmente, se determinan los modelos de gestión más adecuados que permitan su mantenimiento y mejora, aspecto este último que en la actualidad se está considerando desde el enfoque de la gestión para el desarrollo turístico sostenible (Lew y Hall, 1998).

- Los impactos del turismo en el medio en el que se ha desarrollado y las consecuencias que ello ha generado (Mathieson y Wall (1982). Esta línea de investigación, fundamentalmente descriptiva a partir del estudio de casos y situaciones concretas, ha ido permitiendo la elaboración de lo que podríamos denominar "código de buenas prácticas" destinadas fundamentalmente a orientar la planificación en el proceso de desarrollo de nuevos destinos turísticos.

- El concepto de escala que implica la existencia de una estrecha interrelación entre los diferentes niveles geográficos y espaciales en los que el turismo actúa cuando se considera su perspectiva receptora. Así, y pese a que tal como establecen algunos autores (Vera et al., 1997) se produce una cierta ambigüedad a la hora de establecer los límites territoriales de una zona, región o espacio, de alguna manera es fácilmente perceptible cómo en una determinada región turística, especialmente 
en aquellas ubicadas en zonas litorales, se pueden apreciar diferentes núcleos de desarrollo turístico, que podrán corresponder, o no, con demarcaciones administrativas preexistentes.

- La distribución geográfica de los flujos y espacios turísticos donde se interrelacionan los lugares de origen de los turistas y sus lugares de destino, tipificando los distintos tipos de desplazamiento turístico y los factores que los condicionan ( Pearce, 1993; Burton, 1991). Conviene destacar en este punto que si bien existe una perspectiva mundial a la hora de establecer la distribución y características de los flujos turísticos, ello no debe conducir a olvidar el fuerte carácter interregional del turismo y que vendría determinado por las siguientes características: mayor importancia de los movimientos turísticos internos o domésticos, en comparación con los internacionales y de los continentales con respecto a los intercontinentales. Asimismo se constata la existencia de asimetría y desigualdad en la relación país emisor/país receptor de turismo.

- La clasificación de espacios turísticos y definición de las estructuras resultantes del desarrollo turístico (Pearce, 1981) en contraposición a las condiciones geográficas de partida del territorio antes del desarrollo turístico.

- El análisis dinámico del territorio, con la definición de modelos evolutivos, como el de Butler (1980) que suponen un avance fundamental en los procesos de planificación y gestión puesto que, de ellos, dependerá en buena medida la competitividad futura de estos espacios y que, a nuestro juicio, ofrecen una interesante perspectiva debido a que permiten 
establecer un nexo fundamental entre el territorio (ventajas comparativas y competitividad) y la capacidad de gestión de esas ventajas , planteamiento por el que abogaremos en páginas posteriores de esta investigación.

- Los enfoques más radicales de la geografía incluyen autores como Pearce (1993) que explica los flujos turísticos como la consecuencia de las relaciones de dependencia postcolonialista entre las grandes potencias económicas, quienes controlan los flujos turísticos a través de la propiedad de las grandes compañías hoteleras y de transportes, y los países menos desarrollados que poseen, a su vez, al igual que ocurría en la época colonial, las materias primas básicas del negocio, materializadas en este caso por los valores territoriales (clima, playas, naturaleza); otros autores llevan a cabo interpretaciones neomarxistas (Britton, 1991) destacando el papel del turismo como ejemplo claro del proceso de reorganización espacial de la producción y el consumo capitalistas.

\subsubsection{El Enfoque económico}

El turismo es una actividad económica que forma parte de los servicios susceptibles de ser comercializados y que, desde este punto de vista, posee una serie de especificidades propias, tal y como ponen de manifiesto De Rus y León (1997):

- Existe una disonancia entre los objetivos del consumidor y los de las

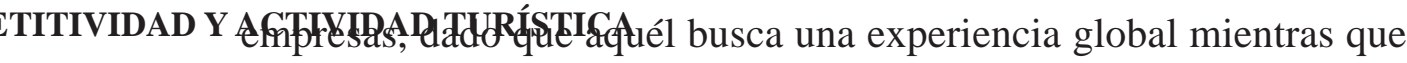
las empresas proporcionan servicios concretos que se alejan de lo que 
sería una contribución colectiva a la satisfacción del turista. No obstante, podemos añadir que, en la actualidad, el éxito de dichas empresas está indisolublemente ligado a la satisfacción global que obtenga ese visitante, por lo que, si bien las empresas turísticas tienen como primer e inmediato objetivo lograr que sus propios productos y servicios sean satisfactorios para sus clientes, son, asimismo, conscientes de su papel en la obtención de esa satisfacción final del consumidor.

- La complejidad del producto turístico debido a su carácter mixto, al estar integrado por la oferta de alojamiento, la oferta complementaria, las infraestructuras públicas combinado con recursos naturales de diverso tipo. Estos últimos pasan a formar parte de este resultado complejo que es el producto turístico.

- $\quad$ Es un sector con una estructura productiva poco flexible debido a su capacidad definida máxima, sus altos costes fijos, especialmente en inmovilizado material, la imposibilidad de almacenamiento del producto y la conjunción temporal y espacial de la actividad (estacionalidad) que, junto a las bajas barreras de entrada en el sector, conduce a una situación de gran dependencia comercial entre intermediarios oligopolistas y multitud de empresas oferentes de servicios turísticos indiferenciados.

- El turismo es una exportación con desplazamiento del consumidor al lugar de producción, lo que hace que determinados elementos de estabilidad política y social jueguen un papel primordial, siendo esenciales los impactos que ello produce sobre el medio ambiente y la población residente en los destinos turísticos. 
- El turismo no es inocuo, pese a que se le ha denominado "la industria sin chimeneas" y "la industria de los sueños", lo cierto es que provoca externalidades negativas, como son la congestión de los espacios naturales y la degradación del medio natural.

A la hora de clasificar las diferentes líneas de pensamiento o teorías que han analizado la posición de un país en los intercambios turísticos internacionales podemos hacerlo siguiendo el trabajo de Vellas y Bécherel, 1995) que los clasifica tomando como referencia cuatro determinantes:

A) La teoría de la dotación de factores, es decir la teoría de HeckscherOhlin para el comercio internacional en general. Se basa en el principio de que los países con unos determinados servicios se beneficiarían de ventajas comparativas para la producción y exportación de su output. La dotación de recursos se fundamenta en tres categorías:

- los recursos naturales y el patrimonio cultural, artístico y monumental,

- los recursos humanos,

- los recursos de capital y las infraestructuras,

En el caso del turismo los primeros serían sin duda los más importantes. Por una parte, la dotación de recursos naturales específicos para el disfrute del turista requiere una explotación que garantice el desarrollo a largo plazo del producto turístico, es decir, su sostenibilidad. La posesión de estos recursos naturales y de los recursos históricoculturales no será apta para el consumo turístico si no se realizan fuertes inversiones fundamentalmente en accesibilidad. 
En segundo lugar, la dotación de recursos humanos y sus habilidades y especialización es un elemento que juega cada vez más un papel primordial. Tradicionalmente, se ha afirmado que el desarrollo del turismo en determinadas zonas no ha sido el producto solamente de la posesión de recursos naturales y culturales. En este sentido, las elevadas densidades de población o la facilidad de los movimientos migratorios que facilitan una mano de obra, en general, poco cualificada han jugado también un papel significativo. En la actualidad, los cambios en el turismo y su modelo de desarrollo siguen dando importancia a la dotación de mano de obra pero en un sentido totalmente distinto. Sin una mano de obra cada vez más cualificada para trabajar en un sector con una fuerte dosis de desarrollo tecnológico y de exigencia por parte del consumidor será difícil desarrollar un sector turístico capaz de hacer frente a los retos del futuro.

En tercer lugar, el turismo es un sector intensivo en capital de forma creciente, tanto por el lado de las infraestructuras como del equipamiento en bienes de capital. Éste será un factor claramente limitativo tanto para las zonas turísticas maduras como para la consolidación de nuevos espacios turísticos en los países en desarrollo. Esto es especialmente cierto en un mundo en el que las tecnologías de la información y comunicación han tomado carta de naturaleza en el mundo de los servicios $y$, en especial, del turismo.

B) La teoría de los costes comparativos. La versión ricardiana de la teoría del comercio internacional nos dirá que un país se especializará en producir aquellos bienes y servicios que puede producir a mejor precio que otros países. Las fuerzas del mercado asignarán los 
recursos de una nación a aquellos sectores donde sea relativamente más productiva. Esta teoría se basa en las diferencias en la productividad de mano de obra entre unas y otras naciones.

Para el turista, el precio final que paga por el producto se compone, básicamente, del precio de los transportes utilizados, el precio del alojamiento y los gastos corrientes en oferta complementaria. En la actualidad, como consecuencia de la liberalización de los transportes y el comercio internacional, los precios de estos bienes y servicios han disminuido sensiblemente, permitiendo viajar a mayor número de personas y a más largas distancias. En general, los países desarrollados tienen menos oportunidades de competir vía precios con países menos desarrollados. En este contexto, no podemos olvidar el papel relevante que juega el tipo de cambio, que ha permitido, en el pasado, que determinados países como España mantuvieran y mejoraran su competitividad a pesar de tener tasas de inflación superiores a las de los países emisores. Sin embargo, en la medida que la relación calidad-precio le resulte favorable al cliente, la industria es competitiva. La evaluación calidad recibida- precio (no sólo económico, también esfuerzo físico y mental) pagado acaba siendo el elemento clave en la diferenciación de lo que ofrece una región turística en relación a sus competidoras y lo que realmente explica cómo zonas más caras pueden tener fuertes ventajas competitivas.

C) La teoría de la ventaja absoluta y el avance tecnológico cuyo origen se encuentra en los análisis de Adam Smith sobre el comercio 
internacional. Determinados países o regiones cuentan con recursos turísticos únicos y excepcionales, ya sean naturales o artísticos, cuya posesión les otorga una ventaja absoluta.

Las innovaciones tecnológicas ofrecen oportunidades de diferenciación que pueden reforzar las ventajas absolutas de un país o región. La tecnología es un instrumento básico para el desarrollo de cualquier forma de turismo y el hecho de poseerla proporciona la posibilidad de seguir compitiendo en el mercado ofreciendo servicios de calidad.

D) La teoría de la demanda pretende explicar las razones que justifican los flujos turísticos entre países y zonas turísticas. La demanda turística depende de la renta per cápita de la población y de sus motivaciones hacia el turismo exterior desde su región de origen. Vellas y Bécherel (1995) hacen hincapié en la importancia de este planteamiento siguiendo la formulación desarrollada por Linder, en el año 1961, en su obra "An Essay on Trade and Transformation" cuando señala que, en ocasiones, los intercambios internacionales no se explican por los niveles de dotación de factores. Por el contrario, éstos se dan fundamentalmente entre economías que poseen una dotación similar de factores.

En este sentido, el volumen de turismo internacional es mayor entre países que poseen estructuras turísticas similares. Aunque los productores ofrezcan un producto parecido, existirán siempre diferencias que justamente constituirán el atractivo del intercambio turístico entre países. En este sentido, se demanda la diferencia en determinados aspectos entre países próximos en niveles de desarrollo 
parecidos y con gustos y preferencias que sólo difieren levemente.

Esta teoría de la demanda, con aditamentos de las otras tres, permite explicar lo que serían las pautas espaciales del turismo mundial anteriormente expuestas, y que configuran la idea del predominio del turismo interior o doméstico y de los flujos continentales, con una fuerte asimetría, que conduce a una significativa concentración espacial de regiones emisoras y receptoras de turismo.

Sin embargo esta situación no se puede considerar estable en la actualidad, puesto que como han puesto de manifiesto Williams y Montanari (1995) se han producido cambios en la distribución regional del turismo por el proceso de transformación del turismo de masas hacia el turismo que ellos denominan posmoderno. Ello es debido a que este último está mucho más disperso desde un punto de vista geográfico, afectando a otros tipos de áreas, como las urbanas y rurales, produciéndose, por primera vez, una tendencia a la disminución de la polarización emisor-receptor.

Ahora bien, cuando se trata de reducir el enfoque de la cuestión a una perspectiva de menor tamaño, regional o local, surgen diversos interrogantes a los que no es factible dar una respuesta clara y taxativa.

Así, y aunque no es posible la generalización, se ha venido manteniendo la tesis, comúnmente aceptada, de que el turismo es un motor de desarrollo para áreas periféricas y con un escaso nivel de industrialización. Sin embargo, en la actualidad no es posible mantener esta idea, como se desprende de una simple lectura de la realidad estadística que ofrece la OMT y los propios 
organismos de turismo de numerosos países y regiones, dado que la transformación del modelo turístico en un mundo caracterizado por las nuevas tecnologías de la información coloca los efectos del turismo en la economía regional o local en una perspectiva diferente.

A la hora de considerar una serie de puntos de identificación del turismo como factor de desarrollo, y siguiendo lo manifestado por Vera y Marchena (1995) podemos establecer los siguientes:

1- La competitividad regional de los productos turísticos requiere de la conversión de las ventajas comparativas estáticas en dinámicas. El turismo obtiene rentas de los recursos medioambientales que posee la región. Para lograr avanzar en el desarrollo, los gestores locales deben buscar la creación de actividades más especializadas y la integración de mejoras tecnológicas y técnicas, en lugar de permanecer estáticos en la oferta de recursos naturales (sol, clima, playas). La tecnología, los recursos humanos y la existencia de una gestión flexible continuamente en contacto con los cambios del entorno serán fundamentales.

2- El turismo, más que otros sectores, necesita de una aportación pública sustantiva, que pasa a formar parte del producto turístico regional o local. Las administraciones han jugado un papel importante en la gestión de la actividad turística y deben seguir haciéndolo, tanto desde la perspectiva de la dotación y aportación de infraestructuras y servicios fundamentales en la configuración del producto turístico, como desde la gestión de los recursos de titularidad pública y de la coordinación y gestión de la cadena de valor de los destinos turísticos. 
3- El turismo aporta efectos multiplicadores a través de las relaciones insumo-producto de la región o zona. Para ello, es imprescindible desarrollar acciones que permitan que una buena parte del gasto turístico que llevan a cabo los turistas se quede en la zona.

4- El turismo como sector de creación de empleo en la zona. Tradicionalmente se ha considerado que la actividad turística, por su propia esencia, era altamente consumidora de mano de obra pero polarizada en dos grandes grupos. El grupo más numeroso formado por personal de base, prestador de la mayor parte de los servicios necesarios para el producto turístico, poco cualificado, precario y, en general, mal remunerado; y otro grupo, de mucha menor dimensión, y formado por los cuadros directivos de las empresas y organizaciones turísticas. Este panorama está cambiando progresivamente puesto que, la propia mejora de la competitividad de los productos turísticos pasa necesariamente por la existencia de unos recursos humanos mucho más especializados y cualificados en todos los niveles.

5- El turismo es una actividad capaz de captar ingresos de un residente y, en su caso, redistribuirlos sectorial y territorialmente en la zona. Se ha venido sosteniendo que el turismo podría tener efectos de arrastre en sectores productivos con una alta implicación en el proceso de creación de los productos turísticos, pero la influencia del turismo sobre el conjunto de la economía se manifiesta a través de la amplia red de servicios que de él dependan.

Tal y como señala Aguiló (1998) el modelo turístico de la sociedad del conocimiento ya no es una vía de escape para regiones subdesarrolladas que 
no han podido acceder a los beneficios propios de ser una región industrializada. Por el contrario, este nuevo modelo supone un conjunto complejo de actividades diversificadas que se articulan en torno al turismo y que se desarrollan por la aplicación de nuevas tecnologías, elevados niveles de formación e información con el objetivo de alcanzar altos niveles de calidad dentro de su especialización productiva.

\subsubsection{El enfoque de sistemas}

La Teoría General de Sistemas (TGS) es una de las metodologías científicas con mayor aplicación general y en áreas que, aparentemente, no guardan ninguna relación entre sí como son la biología, las ciencias sociales y las matemáticas, entre otras. Aunque existían trabajos previos, su primera formulación y denominación es atribuible al biólogo Ludwig von Bertalanffy (1901-1972), para quien la TGS debía constituirse en un mecanismo de integración entre las ciencias naturales y sociales y ser, al mismo tiempo, un instrumento básico para la formación y preparación de científicos.

Esta teoría se ha desarrollado con la finalidad de ofrecer una alternativa a los esquemas conceptuales conocidos en la tradición científica occidental, especialmente el enfoque analítico, caracterizado por la necesidad de reducir la causalidad compleja de un fenómeno a factores y variables simples. Si bien es cierto que hay elementos concomitantes en ambos métodos, puesto que el análisis de sistemas implica descomponer un sistema complejo en procesos elementales, el método analítico no es adecuado para el estudio de los sistemas que deben ser tratados holísticamente, dado que las propiedades del sistema no pueden inferirse de las propiedades de las partes. El principio clave en que se basa la TGS es, pues, la noción de totalidad orgánica y dinámica. 
Un sistema está formado por un conjunto de elementos, pero al mismo tiempo es "un todo no reductible a sus partes". Así pues, la Teoría General de Sistemas puede considerarse opuesta al reduccionismo y crítica ante el método exclusivamente analítico, sólo válido en los casos en que no existe interacción entre las partes de un objeto, lo que permite deslindarlas y volverlas a unir sin que sufran alteración alguna (Navalón, 2001).

La aproximación sistémica al estudio de la actividad turística con objeto de ejemplificar sus componentes y las relaciones entre ellos ha sido abordada ampliamente por diversos autores, bien como sistema complejo integral (Leiper, 1990; Mill y Morrison, 1992; Cooper et al. 1993), bien como individualidades de este sistema que generan, a su vez, su propia dinámica de componentes y relaciones internas y con el exterior del sistema (Guibilato, 1983; Middleton ,1988; McInthos y Goeldner, 1990; Laws, 1995; Vera et al., 1997). Por lo que podría parecer, como suele ser habitual en la mayoría de los estudios que abordan la problemática del turismo, que nos encontramos tantos modelos como análisis, estudios o investigaciones se hayan realizado, en función del enfoque del estudio.

Efectivamente, las distintas disciplinas científicas suelen observar la actividad turística como una aplicación de sus propias ideas y conceptos por lo que es frecuente que se adopten aproximaciones exclusivamente desde el ámbito de la geografía o la economía o en función de la escala de estudio y de los elementos del sistema turístico que se desee estudiar. Sin embargo, el turismo es una realidad compleja que permite la integración de distintas áreas de conocimiento ya que se trata de un sistema dinámico y abierto al entorno social, cultural, económico, político y tecnológico en que se inserta. 
Jafari (2002) ha identificado dieciocho áreas de conocimiento relacionadas con el turismo: agricultura, antropología, administración de empresas, animación socio-cultural, ciencias políticas, derecho, ecología y medio ambiente, economía, educación, geografía, historia, hostelería, marketing, psicología, planificación regional, religión, sociología y transportes. Esta variedad dota a la actividad turística de un extraordinario potencial puesto que le permite absorber simultáneamente los avances tecnológicos y la innovación que se van produciendo en cada una de estas materias particulares. Dada esta naturaleza múltiple de la actividad turística, Cooper (1993) propone, como alternativa interesante, la adopción de un enfoque interdisciplinar.

Esta visión coincide con la de la OMT $(1994,1998)$ para la que el turismo es, básicamente, un sistema interrelacionado de factores.

Sin embargo, desde el punto de vista académico y científico, esta concomitancia se convierte en una debilidad puesto que los conocimientos o bien se dispersan o bien se entremezclan, lo que no permite adoptar un enfoque unívoco, ni encontrar antecedentes científicos exclusivos de la materia "turística". La sistematización de sus componentes va a estar, por tanto, mediatizada por el enfoque adoptado por el investigador.

Uno de los modelos del sistema turístico que han sido pioneros y que además presenta una estructura muy comprensible de lo que es la dinámica turística, ha sido el formulado por Leiper en 1979 y actualizado en 1990 .

En este modelo encontramos tres elementos estructurales: 
1) Los turistas, que son los actores o eje principal del sistema y representan el elemento dinámico.

2) Los elementos geográficos, diferenciando tres componentes territoriales distintos (región emisora de turistas, regiones de tránsito o ruta de los turistas y región de destino de los turistas).

3) El elemento económico, la industria turística, imprescindible para la generación de actividad.

La industria turística está compuesta por un amplio número de empresas e instituciones, involucradas directa e indirectamente en la entrega del servicio turístico, situadas en ámbitos territoriales concretos de actuación o en sus áreas de influencia. Así, los operadores de mercado se encuentran fundamentalmente en la región de procedencia de los turistas, mientras que la industria del transporte juega su papel en las regiones de tránsito mientras que la industria de hostelería se sitúa en la región de destino. Esta industria forma parte de la oferta turística que se gesta principalmente en el destino territorial principal o complementario del turista, y que, al satisfacer demandas concretas, se configura como producto de consumo turístico.

El sistema turístico es abierto y, por tanto, en contacto permanente con la realidad y el entorno que le rodea que en el caso de la actividad turística Liu (1994) considera que es posible subdivirlo a su vez, en:

- Entorno interno, formado por el propio sector turístico donde se encuadran los ámbitos de gestión del turismo de un territorio 
determinado: planificación, políticas, marketing, organización, finanzas.

- Entorno operativo, que incluye el comportamiento del sistema turístico mencionado: turistas, proveedores, destinos competidores y empresas competidoras.

- Macroentorno de carácter general que hace referencia a la idea tradicional del mismo: macroentorno económico, político-legal, cultural, medioambiental y tecnológico.

El sistema turístico de Gunn (1994) se basa en la interrelación entre demanda $\mathrm{y}$ oferta, $\mathrm{y}$, dentro de esta última, entiende que hay cinco componentes interdependientes: atracciones, transporte, servicios, información y promoción.

Como es común en los enfoques sistémicos, el sistema territorial turístico y sus componentes tienen un carácter dinámico y abierto al entorno con el que interactúan. Los dos componentes esenciales, oferta y demanda, forman parte a su vez de un territorio y de un entorno más amplio que condicionan no sólo el flujo y características de éstos sino también el modelo de desarrollo turístico (Ivars, 2003). 

CAPÍTULO 3

CONCEPTO DE DESTINO TURÍSTICO 



\subsection{La idea de destino turístico}

Tal como hemos analizado en el capítulo anterior, en el ámbito del sector turístico no existe unanimidad, ni por parte de los investigadores ni por parte de los gestores privados y públicos, sobre lo que es o debe ser considerado como destino turístico. Si bien la idea que subyace en el concepto es compartida universalmente, la profusión de productos a los que se denomina "destino turístico" aconseja que nos detengamos conceptualmente en este punto para centrar el marco de nuestra investigación.

El problema surge porque este concepto se aplica a diferentes productos y en diferentes escalas de medida, desde la internacional a la local. En la actualidad, por destino turístico se entiende desde un continente, un país o una región hasta una población o un recurso artificial creado por el hombre. El concepto habitualmente se aplica indistintamente a una demarcación territorial de índole política o administrativa, o a una marca con potencial turístico que abarcara distintos países o regiones.

La aparición de los resorts turísticos integrados (Ivars, 2003) especialmente en países en vías de desarrollo, aunque no exclusivamente, complica aún más el panorama al recibir el calificativo de destinos turísticos de vacaciones en el lenguaje común y profesional, especialmente por sus características de entes autónomos capaces de generar esta actividad económica y absorber por sí mismos sus impactos, sin necesidad de establecer relaciones con el entorno ni con la comunidad local, más allá de la mera prestación de servicios en estas industrias. Estos resorts, aunque son, a menudo, un lugar cerrado, como islas dentro un destino más amplio, deberían ser considerados antes como micro productos turísticos que como destinos turísticos en sí mismos. 
Como hemos mencionado anteriormente, en el año 2002 la OMT llevó a cabo una primera aproximación al establecimiento de una definición de alcance internacional sobre el concepto de destino turístico.. Hasta ese momento, podemos encontrar definiciones muy variadas dependiendo del enfoque o disciplina que se considere. Así resulta interesante destacar las siguientes:

- Destino turístico es la concentración de instalaciones y servicios diseñados para satisfacer las necesidades de los turistas (Cooper, Fletcher, Gilbert y Wanhill,1993).

- Destino turístico es el país, región o ciudad hacia el cual se dirigen los visitantes que lo tienen como su principal objetivo (Bull, 1994).

- Destino turístico es el conglomerado de productos turísticos que actúan dentro de una demarcación geográfica determinada (Valls, 1996), a la que hay que añadir factores comunes tales como el clima, las infraestructuras, los servicios y los recursos naturales y culturales.

Para la Organización Mundial del Turismo un destino turístico local es "un espacio físico donde el turista pernocta al menos una noche. Se compone de diferentes productos turísticos como la estructura soporte, los atractivos y los recursos. Los destinos se definen a través de límites administrativos, los cuales ayudan a la gestión del mismo, siendo su imagen y posicionamiento factores clave para alcanzar la competitividad".

Si, tal y como establece la OMT, los destinos se configuran a través de 
límites administrativos que facilitan su gestión, en el ámbito políticonormativo destacamos la contribución conceptual de la Ley 3/ 1998 de Turismo de la Generalitat Valenciana, que establece un interesante enfoque de la cuestión al clasificar, con objeto de establecer criterios objetivos de distribución de recursos, los destinos turísticos radicados en su territorio:

- Destinos de atracción turística, aquellos que, por sus atractivos naturales, monumentales, socioculturales o por su relevancia en algún mercado turístico específico, reciben en un momento del año un número significativo de visitantes en relación a su población de derecho sin que estos visitantes pernocten necesariamente en este lugar.

- Destinos de vacaciones, en los que se engloban aquellos que en algún momento del año tienen una afluencia de visitantes superior al número de personas inscritas en su padrón municipal de residentes, que pueden tener como complemento de su economía otras actividades, y que la capacidad de sus alojamientos turísticos, unida a la de las plazas de alojamiento de segunda residencia, resulte superior a la de las plazas de alojamiento de primera residencia, y en donde el cómputo del número de plazas de alojamiento turístico debe representar, al menos, el uno por ciento de su oferta.

- Por último, considera esta ley que son destinos turísticos propiamente dichos aquellos que a lo largo de todo el año mantienen una afluencia de visitantes, que deben pernoctar en el mismo, superior al número de personas inscritas en su padrón municipal de residentes. Esta actividad es la base de su economía y la capacidad de sus alojamientos turísticos es superior a la de las viviendas de primera residencia. 
Al margen de que algunos aspectos de estas definiciones pudiera ser manifiestamente mejorable, nos parece muy oportuno destacar de esta concepción de destino turístico algunas consideraciones a los efectos de esta investigación:

a) Para ser considerado destino turístico (DT) el lugar en cuestión debe recibir una afluencia de turistas - que no de visitantes- superior al número de habitantes que posee. Es decir, se reconoce que si no hay alojamiento del turista en el lugar visitado no se optimiza el impacto del turista en la economía local.

b) La actividad turística -la recepción y gestión de la estancia de los turistas- debe hacerse de forma estable y regular, no esporádica o coyuntural. Por tanto, debe haber una gestión profesional, tanto pública como privada, orientada en esta línea.

c) Debe disponer de un número de alojamientos turísticos superior al de las primeras residencias, de tal modo que el producto ofrecido está en línea con la demanda que se recibe.

d) El turismo es la base de su economía, lo cual no excluye otras, pero sí fija claramente la escala de importancia que tiene en la economía territorial.

Nuestro trabajo parte de la concepción del turismo como un sistema abierto en el que interactúan diferentes elementos y que requiere de la cooperación y coordinación de todos los productores de bienes y servicios integrantes de la cadena de valor a través de unos 
procedimientos de gestión eficiente. En este sistema, uno de los componentes, el lugar de destino turístico, es un espacio físico localizado que cuenta con recursos naturales o artificiales capaces de generar un flujo de turistas hacia él y con capacidad para dar soporte a las necesidades humanas de bienestar, seguridad y ocio y cuya imagen turística debe ser adecuadamente comunicada para determinar el posicionamiento competitivo que se desea alcanzar en el sector de referencia.

Por tanto, a modo de resumen, nos parece claro, siguiendo este planteamiento, que los destinos turísticos deben estar caracterizados por una línea vertebral centrada en la vocación de ser destino turístico, esto es, los agentes responsables del desarrollo social y económico del lugar en cuestión deben hacer una apuesta clara e inequívoca para que el sector turístico sea el motor económico de ese desarrollo, con todo lo que ello implica.

El concepto de destino turístico adoptado comporta la asunción de las siguientes características esenciales del mismo: es un producto turístico de base territorial con límites definidos o definibles y que requiere una gestión integral.

\subsubsection{Producto turístico de base territorial}

Para Kotler (1997) "un producto es cualquier cosa que se puede ofrecer a un mercado para captar la atención, la adquisición, el uso o el consumo y que podría satisfacer un deseo o una necesidad. Incluye objetos físicos, servicios, sitios, organizaciones e ideas". 
El producto turístico basado en la conjunción oferta-demanda en un espacio territorial determinado, es el resultado de la combinación de recursos, bienes e instalaciones con los servicios necesarios que sirven para el intercambio en el mercado turístico. De hecho, existirá un producto turístico cuando el resultado final de esa combinación, convenientemente organizada, sea susceptible de ser vendido en uno o varios mercados para uno o distintos segmentos de demanda.

En turismo si no hay consumo no hay actividad, ni siquiera producto, dado que se requiere la presencia e intervención del consumidor para que se produzca algún tipo de resultado. De ahí que, junto al territorio, la demanda sea uno de los elementos esenciales del sistema turístico. Así, el turismo es una exportación con desplazamiento del consumidor al lugar de producción (De Rus, 2004), si bien, a menudo, existe divergencia entre los objetivos del consumidor y de las empresas y organizaciones que intervienen en las diversas fases de la cadena de valor del producto final entregado. Ello es debido a que la percepción del turista es una experiencia global, mientras que las empresas y las instituciones públicas proporcionan servicios concretos que, a menudo, no forman parte ni de un objetivo común ni de una estrategia conjuntamente diseñada.

Ahora bien, la presencia de la demanda y sus distintos grupos de consumidores o segmentos, obliga a los gestores del destino turístico a llevar a cabo una labor que permita el uso y disfrute de unos mismos bienes y servicios a diferentes tipos de consumidores, de forma armónica y satisfactoria. Además, no debemos olvidar que la confluencia en el mismo espacio y tiempo de, por un lado, diferentes clases de consumidores y, por otro, de los residentes locales, puede generar distorsiones importantes en el sistema que han de ser 
debidamente consideradas por los gestores del destino turístico.

Si bien, tal y como argumenta Ivars (2003), existen productos turísticos que no tienen base territorial, el producto turístico por naturaleza es el lugar de destino de la demanda ya que es aquí donde se sitúa una parte importante de la industria turística, en concreto la relacionada con el hospedaje y la restauración. Dicha actividad económica es la que da soporte al sector turístico y que forma parte y puede ser desagregada, del sistema productivo de una región o de una nación, produciendo efectos, tanto directos como indirectos, en otros sectores económicos.

Esta situación ha dado lugar a confundir destino y producto turístico, que si bien son términos muy relacionados no deben ser utilizados de forma ambivalente. Un espacio territorial al que se califica como lugar de "destino turístico" es en sí mismo un producto turístico que, a su vez, puede contener múltiples productos.

La concepción del producto turístico se adapta perfectamente a los proyectos empresariales pero es extraordinariamente difícil de adaptar a un territorio donde conviven turistas, población local, terceras industrias y donde surge un entramado de relaciones e intereses, en ocasiones enfrentados.

Así, el producto turístico considerado en su acepción de producto global e integrado en un espacio territorial requiere de un enfoque transversal en su concepción y gestión, en el sentido de que debe reunir y combinar una serie de productos individuales, habitualmente poco relacionados entre sí, a partir de los cuales, los intermediarios o el cliente directamente eligen el valor que desean bien para producir o ensamblar su producto o bien, en el caso del 
consumidor directo, para conseguir una experiencia vital. Esta situación provoca que, en el ámbito del destino, no exista un único responsable del producto sino que están implicados sector público y sector privado.

La delimitación del destino se realiza a partir de su función turística, es decir, de su vocación de especialización en la actividad económica del turismo para un territorio concreto. No obstante, debemos asumir que sus impactos $\mathrm{y}$ efectos pueden tener un efecto expansivo mayor de tal modo que afecte a otros núcleos, zonas o territorios que pueden verse afectados directa o indirectamente por la actividad turística.

La unidad política de base territorial dotada de competencias normativas, administrativas y de gestión pública más elemental, en la mayoría de los ordenamientos jurídicos internacionales, es el municipio. Cuando esta demarcación, fundamentada habitualmente en criterios de oportunidad histórica, coincide con la existencia de factores de atracción de la demanda, soportes de la industria turística y una posición en el mercado que permite gestionar una imagen turística diferenciada, la aplicación del concepto de destino turístico no presenta mayor dificultad. Estas circunstancias coincidentes permiten conjugar, con cierta autonomía, los elementos de mayor competencia municipal: la planificación territorial, los intereses de la población residente, entendida en sentido amplio, no sólo de las personas físicas sino también de las industrias y empresas radicadas en el municipio, y la ordenación de los flujos turísticos.

En este sentido se expresa la ya mencionada Ley de Turismo de la Comunidad Valenciana cuando enuncia: "el producto turístico tiene un gran componente municipal por cuanto los servicios, la escena urbana, la comunicación de la 
imagen de marca y otros aspectos de fuerte incidencia en la competitividad y comercialización del sector dependen en gran manera del grado de eficacia y compromiso asumidos por los ayuntamientos".

Sin embargo, este alcance (municipal) es el menos frecuente, dado que la propia dinámica de desarrollo de la actividad turística genera un consumo de recursos y una distribución de sus impactos, similar a ondas expansivas, desde el núcleo originario principal hacia otros puntos, creándose una suerte de núcleos adyacentes o complementarios que polarizan y, finalmente, integran el conjunto de la actividad turística. Es en este caso cuando suele acudirse a conceptos tales como espacio turístico (Boullon, 1985), zona turística (Gunn, 1997) o región turística (Dewailly, 1989; Lozato, 1990; Claval, 1995; Wall, 1997; Dredge, 1999) para explicar los componentes espaciales de los destinos turísticos supramunicipales con vistas a la concepción, planificación y diseño integral de una región turística.

Este espacio supramunicipal agrupa elementos tangibles e intangibles. Dentro de la primera categoría se encuentran los aspectos de naturaleza corpórea tales como los escenarios donde transcurre la actividad turística (entorno, recursos naturales y patrimoniales, empresas turísticas y de ocio, edificación, infraestructuras, pasillos de tránsito,etc.) que son elementos del sistema relativamente fáciles de identificar y agrupar. Junto a estos aspectos, determinantes de la caracterización del destino, se encuentran otros que, debido a su naturaleza intangible, sólo se pueden apreciar a través de los resultados o impactos que producen, tanto en los sujetos como en el medio o escenario físico. Este es el caso de la influencia que ejerce la política turística y no turística, la planificación integral del territorio como destino turístico, la gestión del patrimonio y la cultura, junto a la propia percepción 
de la actividad por parte de los residentes. Se trata, en definitiva, del potencial de relaciones internas y externas que se establecen entre los componentes de la industria turística y los sectores afines y conexos, las administraciones públicas, la población local, los turistas y los destinos competidores.

Así pues, aunque la comunidad científica encuentra grandes dificultades a la hora de definir y establecer los límites espaciales del concepto de destino turístico, es desde el ámbito de la planificación territorial turística donde más se ha avanzado al respecto. En este sentido, el trabajo de Gunn (1972, 1994, 1997) es uno de los más representativos. Este autor se adentra en el concepto de región turística e identifica cinco componentes del sistema que facilitan su acotación:

- Límites regionales definibles.

- Vías de acceso desde los mercados de origen (puertas de la región).

- Zonas de atractivos y servicios turísticos.

- Zonas sin atractivo turístico.

- Vías de circulación interior.

Dredge (1999) amplia la visión de Gunn, introduciendo elementos más dinámicos y sistemas de conexión entre distintas regiones otorgando relevancia al concepto de región turística. Enfatiza la relación con los mercados emisores del turismo y las rutas de circulación entre regiones e identifica en las zonas de atractivos y servicios turísticos una serie de nodos (cualquier lugar que un turista pueda visitar o contemplar) compuestos por tres elementos: el núcleo, los turistas y los marcadores o elementos de información. Clasifica los nodos en primarios, secundarios o terciarios en función de su capacidad de atracción y por el grado de conocimiento previo del turista. 
Otros criterios complementarios identificados por Gunn (1994) para la delimitación de las regiones turísticas arrojan valores de gran interés, así:

- La región debe tener un conjunto de características culturales, físicas y sociales que generen una identidad regional.

- Debe tener una adecuada infraestructura turística y oferta de servicios para permitir el desarrollo turístico y satisfacer las necesidades de los turistas.

- La región debe ser mayor que un destino o que una única atracción.

- La región debe poseer los suficientes atractivos para atraer turistas actual o potencialmente.

- La región ha de ser capaz de crear una agencia de desarrollo y acciones promocionales para fortalecer el desarrollo turístico.

- La región debe ser accesible para una masa importante de población.

Una matización interesante es la que introduce variables temporales, en la caracterización de los espacios turísticos. Así, se ha diferenciado "centros de estancia" que son aquellos que cuentan con un factor de atracción principal y en los que la estancia es igual o superior a cinco noches; "centros de distribución" que cuentan con factores de atracción fundamentalmente naturales y culturales y en los que la estancia oscila entre dos y cinco noches; "centros de escala" que, como su nombre indica, son puntos intermedios entre los lugares de origen de la demanda y el destino final con estancias 
variables, pero fundamentalmente cortas, entre una y tres noches; "centros de excursión" son lugares que mantienen cierta dependencia con respecto a los centros de estancia y, finalmente, "centros de recreación y ocio" que absorben demanda de los centros urbanos (Boullon, 1990).

Todos estos centros tienen en común el hecho de que, independientemente de su tamaño, observados aisladamente, cada uno constituye un destino turístico local (municipal, inframunicipal, o supramunicipal en terminología administrativa) pero que convenientemente puestos en conexión facilitan el desarrollo del concepto de región turística.

\subsubsection{Gestión integrada}

A lo largo de las páginas anteriores ha quedado expuesto que los gestores de los destinos turísticos deben tener un doble objetivo a lograr a través de su actuación: por un lado, lograr alcanzar un nivel de competitividad óptimo y, por otro, lograr mantenerlo optimizando al máximo los efectos positivos del turismo.

Para ello es imprescindible que la gestión de los destinos turísticos se articule de forma planificada, sistemática y coherente; lo que hace necesario la definición y puesta en gestión de una política turística que debería vertebrarse en torno a cuatro ejes básicos (Poon, 1993):

a) El predominio del respeto al medio ambiente debe estar en primer lugar, evitando que el turismo sea un factor que produzca desequilibrios territoriales por la vía del abuso en el uso de los recursos naturales, paisajísticos y culturales de todo tipo. En este sentido, el turismo debe 
guiarse por tres principios:

1.- Lograr un desarrollo turístico responsable a través de la fijación de límites muy claros al crecimiento y el diseño de las características y condiciones que deberá incorporar dicho crecimiento. En consecuencia, se tendrá en consideración un desarrollo integrado de las características ambientales y culturales que incorpora la región de destino y que, en resumen, consigan dignificar los valores que le son propios.

2.- Promover una cultura de conservación a través del establecimiento de una forma de vida que forma parte esencial de la sociedad y la cultura de la región. Es imprescindible la creación de una cultura orientada hacia el proteccionismo entre todos los agentes implicados en el desarrollo turístico y en el propio turista. En esta línea, los gobiernos deben actuar de forma tal que sirvan de modelo y referencia a través de sus propias actuaciones.

3.- Desarrollar núcleos de preservación medioambiental a través de la protección de Espacios Naturales y a la promoción de atractivos medioambientales. A su vez, estos desarrollos, junto a la promoción de áreas de ecoturismo, pueden generar oportunidades de empleo en una diversidad de tipos de ocupación. Igualmente, existe un potencial de riqueza en la aparición de sectores industriales que van desde el reciclaje a programas de interpretación e investigación en esta área, pasando por otras muchas actividades. 
b) Hacer del turismo un sector líder y un instrumento de crecimiento a través de :

1- Desarrollar su potencial como eje de desarrollo, puesto que en la sociedad de la información ningún sector como el turismo puede ofrecer tantas oportunidades de generación de nuevas actividades, sobre todo en el mundo de los servicios, que son directa o indirectamente activadas por el mismo. La presencia de miles de turistas creará mercados para la venta de productos que caracterizan a la especialización productiva de la región.

2- Adoptar nuevas estrategias de desarrollo que incentiven la flexibilidad de los procesos productivos, de tal modo que les permita una mayor adaptación a los cambios del entorno productivo, utilizando la innovación continua como palanca imprescindible de la competitividad. Los servicios ofrecen las mejores oportunidades para obtener efectos difusores a partir del propio turismo.

c) Desarrollar un nuevo modelo de gestión del marketing que abandone la concepción clásica basada en el desarrollo de producto como único referente válido. El marketing debe guiar todo el proceso del producto, desde la concepción y creación del mismo hasta la puesta a disposición del consumidor, por lo que el sector público tiene un papel a desarrollar en todas y cada una de las fases. Ahora bien, dicha participación no será de igual intensidad en todas ellas debiéndose mantener una colaboración estrecha con el sector privado. 
d) Estimular la aparición y desarrollo de un sector privado dinámico que sea capaz de afrontar de forma adecuada los continuos cambios del mercado. El gobierno, en este sentido, debe establecer políticas idóneas para proporcionar oportunidades de inversión y mejoras del producto, dotando de infraestructuras y servicios y aportando información a los agentes implicados en el proceso de desarrollo turístico que les permita a éstos conocer la realidad cambiante del sector.

Los cuatro ejes de actuación de la política turística señalados por esta autora (medioambiente, liderazgo sectorial, marketing, estímulo a la iniciativa privada) entendemos que pueden responder a líneas programáticas deseables que deben ser aplicadas, en parte o en su totalidad, a determinados modelos de destinos pero que están lejos de ser una fórmula universal. De hecho, creemos que algunos de estos ejes de actuación son excluyentes entre sí. En este sentido, la política gubernamental, turística, que se aplique en un destino puede limitar las economías de escala o incluso impedir el ingreso en el sector de determinadas empresas a través del establecimiento de límites y restricciones al desarrollo. Estas restricciones podrían tener beneficios sociales, pero a menudo tiene consecuencias económicas directas difícilmente soportables para regiones en desarrollo. En el mismo sentido, las reglamentaciones que inciden en aspectos tales como la preservación de la calidad medioambiental a través del establecimiento de gravámenes al consumidor final o a las empresas turísticas son, a corto plazo, impedimentos a la competencia, especialmente para las pequeñas empresas.

La planificación y gestión pública-privada del sistema de destino es un elemento fundamental para su desarrollo sostenible, puesto que, en la interacción de ambas iniciativas, conjuntamente con la representación de la 
comunidad local, en su caso, se puede articular un programa que responda a una visión global de todos los componentes del sistema: los mercados de origen, las relaciones de complementariedad y/ o competencia entre los integrantes de la cadena interna de valor, la relación competitiva con otros destinos, conjuntamente con las dinámicas territoriales, funcionales y sectoriales.

El plan Integral de Calidad del Turismo Español (PICTE, 2000-2006) ha introducido una de las dinámicas más innovadoras en materia de política turística en los últimos años. Plantea abiertamente una reflexión sobre cuáles deben ser los límites al crecimiento y al desarrollo turístico, máxime teniendo en cuenta que la demanda, no sólo sigue aumentando, sino que ha crecido la rentabilidad de la actividad debido tanto a la mayor capacidad de gasto de los visitantes como por los mejores márgenes con que operan las empresas turísticas españolas. Los límites al desarrollo turístico no deben plantearse, según este Plan, en términos generales, sino en relación a destinos concretos y en términos de sostenibilidad, relación con el medio ambiente natural y sociocultural. Es, en estos términos como se pueden definir modelos de desarrollo que determinen los límites cuantitativos y fijen pautas de desarrollo cualitativo, de ahí la importancia de un conocimiento más riguroso y científico de la oferta, para hacer posible definir modelos de desarrollo turístico en función de los recursos naturales y socioculturales y de las infraestructuras existentes o potencialmente disponibles. 


\subsection{Estructura competitiva de los destinos turísticos}

\subsubsection{Modelos de competitividad}

La diferencia sustancial entre cada destino turístico, basada en sus propios recursos y capacidades, el distinto entorno competitivo específico y general en que se desenvuelven las empresas y organizaciones, junto a la dinámica natural de cambio y evolución que sufre el producto con el transcurso del tiempo, dificulta enormemente el establecimiento de un modelo simplificado que permita la elaboración de una teoría específica para el desarrollo de estrategias competitivas propias de los destinos turísticos en general.

Uno de los primeros puntos sobre los que debe existir un cierto consenso es en la determinación de cuáles son los elementos estructurales que comparten, transversalmente, todos los destinos. Esta ha sido una materia ampliamente tratada, especialmente en la literatura académica, con desigual resultado, aunque poco a poco se ha ido consolidando una teoría de destinos básica para el establecimiento de posteriores modelos.

Tras analizar el estado de la cuestión hasta nuestros días, podemos encontrar dos líneas distintas en el análisis y la interpretación de estos elementos estructurales:

a) Modelos descriptivos. Se caracterizan por el análisis interno de los elementos más característicos que definen estructuralmente un destino con objeto de analizar sus ventajas comparativa y, a partir de éstas, determinar cuáles pueden ser sus ventajas competitivas (Cooper 1987, 1993, 2002; Ritchie y Crouch 1993,2000, 2003). Dentro de 
esta línea destacan, a su vez, las siguientes propuestas:

- Modelos centrados en las teorías de los recursos y atractivos, como elemento base de la diferenciación competitiva (Melián y García , 2003).

- Modelos cuantitativos que intentan determinar posiciones de competencia en el mercado entre destinos (Fayos, Fuentes y Muñoz 2003; Enright y Newton, 2004).

b) Modelos normativos. Estos modelos derivan, bien directamente de textos legales o bien de publicaciones de programas de las Administraciones Públicas. Los textos legales determinan indirectamente la estructura de los destinos turísticos al señalar el ámbito de competencia y de aplicación de las normas, determinando los sujetos sobre los que recae el mandato jurídico, en esta línea mencionamos, a modo de ejemplo, la Ley de Ordenación del Turismo de Canarias de 1995 o La Ley del Turismo de la Comunidad Valenciana de 1998. Las publicaciones administrativas habitualmente se refieren a criterios de planificación estratégica, valoración económica y gestión administrativa de los destinos, singularizando la estructura en la determinación de los límites espaciales de aplicación y en los sujetos activos de las iniciativas. Finalmente, los planes marco y estratégicos publicados por los gobiernos, especialmente en los últimos años, inciden, en la competitividad como objetivo alcanzar a través del despliegue de una serie de estrategias y/o instrumentos de actuación (Libros Blanco del Turismo de Cataluña 1983; Islas Baleares, 1987; Comunidad Valenciana, 1990; Rioja, 1991; Canarias, 1998; Plan Futures I, 1992-1995; Plan 
Futures II, 1996-1999; Plan Marco de Competitividad del Turismo Español 2000-2006).

No obstante el indudable valor de estos textos normados, vamos a desarrollar de forma más amplia los primeros, por su indudable repercusión en el ámbito científico.

\subsubsection{El modelo de Ritchie y Crouch}

Brent Ritchie y Geoffrey Crouch han sido los autores que más profusamente se han ocupado de la competitividad aplicada a los destinos turísticos en los últimos años. En una primera aproximación, a principios de los años noventa, basándose en las teorías de competitividad de Porter, desarrollaron un modelo con intención de proporcionar una herramienta que permitiera aplicar criterios cuantitativos a las decisiones de política turística.

Este modelo establecía que la función de competitividad de un destino turístico deriva las siguientes variables: Atractivo, Organización, Información y Eficiencia. Expresado de otra forma tenemos:

$\mathrm{TC}=f \mathrm{n}\left(\mathrm{A}_{\mathrm{n}},\right),\left(\mathrm{O}_{\mathrm{n}}\right),\left(\mathrm{I}_{\mathrm{n}}\right),\left(\mathrm{E}_{\mathrm{n}}\right)$

donde a su vez,

Atractivo $=f_{\mathrm{n}}$ (Atractivo del destino, Elementos disuasorios $)$ Gestión $=f_{\mathrm{n}}$ (Marketing)

Organización $=f_{\mathrm{n}}$ (Habilidades de organización del destino, Alianzas estratégicas)

Información $=f($ Sistemas de información interna, Investigación $)$ Eficiencia $=f_{\mathrm{n}}$ (Experiencia integral, Productividad) 
Este modelo inicial presentaba dos problemas fundamentales, por un lado la distinta naturaleza de las variables y, por otro lado, el gran número de variables independientes que deben hacerse operativas para poderse cuantificar.

En versiones posteriores los autores introducen nuevas variables (política turística, el desarrollo y la planificación) y desarrollan medidas operativas para cada componente del modelo de competitividad, pero sigue teniendo escasa capacidad de aplicación práctica como herramienta de medición de la competitividad internacional entre destinos.

En la última versión de 2003 (Figura 1) los autores depuran el modelo y realizan una construcción que identifica y analiza, de manera exhaustiva, la estructura de los destinos turísticos y sus elementos operativos hacia la competitividad y sostenibilidad.

El modelo analiza los aspectos o factores que contribuyen, en su opinión, al éxito de un destino turístico, si bien, como apuntan los propios autores, sería necesario que este modelo se completara con unos índices cuantitativos que facilitaran su aplicación a cualquier clase de destino y que permitieran situarlos en un ranking de competitividad. 
Figura 1 Competitividad y Sostenibilidad en Destinos

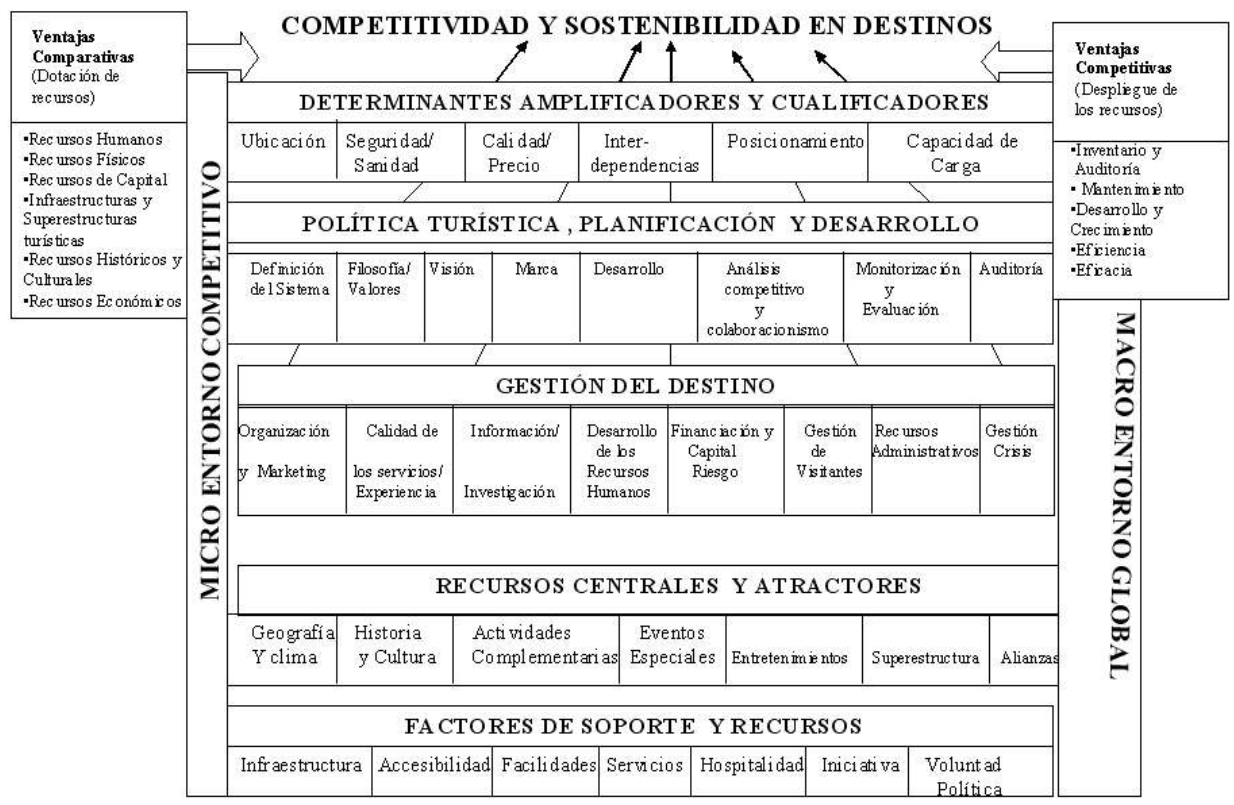

Fuente: adaptado de Ritchie y Crouch, (2003) 
En este modelo se reflejan tanto los recursos y atractivos que singularizan un destino (ventajas comparativas) como el conjunto de procesos de gestión tendentes a obtener ventajas competitivas a través, entre otros factores, de la eficiencia y la eficacia. Se trata, por tanto, de un marco conceptual que permite una mayor comprensión de las relaciones internas que se producen en los destinos.

El modelo establece, en primer lugar, nueve componentes principales de un destino y que son:

1) Las ventajas comparativas, aquellas propias del destino y que le vienen dadas bien por la naturaleza, bien por la acción de la sociedad sobre dicho destino.

2) Las ventajas competitivas, resultantes del despliegue de recursos o lo que es lo mismo, el uso que se le ha dado a los recursos disponibles.

3) El macro entorno de referencia, que remite a la consideración del sistema turístico como sistema abierto sujeto a dinámicas a menudo incontrolables del entorno social, económico o político.

4) El micro entorno competitivo, que forma parte intrínseca del sistema interno del destino en tanto que se refiere al conjunto de acciones y actividades que realizan todas las entidades que forman parte del mismo.

5) Los recursos y atractivos, son las palancas motivadoras del viaje turístico, la razón, en definitiva, de la elección del destino por parte de los turistas. 
6) Los factores y recursos de apoyo, aquellos elementos sin los cuales sería inviable el desarrollo turístico.

7) Los planes y estrategias de política turística, son los instrumentos que pueden ayudar a asegurar que el desarrollo turístico tienda a la sostenibilidad de la actividad, a la vez que se mantienen las aspiraciones de calidad de vida de aquellos que residen en el destino.

8) La gestión del destino, se refiere al conjunto de tareas diarias necesarias para poner en práctica las decisiones de política turística.

9) Los "determinantes calificadores y amplificadores" son factores cuyos efectos sobre la competitividad y sostenibilidad de un destino turístico se basan en definir su escala, límites o potencial. Estos calificadores y amplificadores moderan o magnifican la competitividad del destino filtrando la influencia de los otros componentes o factores.

En la última edición los autores introducen para el octavo determinante un nuevo concepto: la Auditoría de Destinos cuyo uso periódico arrojaría información sobre la situación actual del destino objeto de estudio (diagnóstico) y permitiría la fijación de objetivos de actuación preferente en el futuro, estableciendo indicadores de mejora continua del sistema. Esta auditoría estaría basada en la evaluación y la mejora de la eficiencia y la eficacia de las operaciones de una organización relacionándolas con su misión y sus objetivos y, tal y como los autores ponen de manifiesto, su principal objetivo sería la mejora de la gestión, de la sostenibilidad y, en definitiva, de la competitividad del destino mediante el mantenimiento de una visión compartida por parte todos los agentes implicados. 
Ritichie y Crouch determinan cómo debe ser el proceso de auditoría de un destino (fig.2) y otorgan relevancia a la figura de un auditor experto externo si bien reconocen la ventaja, tanto en costes como en valor añadido que supone la aplicación de un método de auto-evaluación, puesto que si los evaluadores, integrados en el órgano de gestión del destino, son lo suficientemente objetivos y críticos, son quienes, en definitiva, mejor conocen el destino. De hecho, reconocen que para pequeños destinos turísticos ."la auto-evaluación es la única opción viable".

\section{Figura 2 El proceso de Auditoría de Destinos}

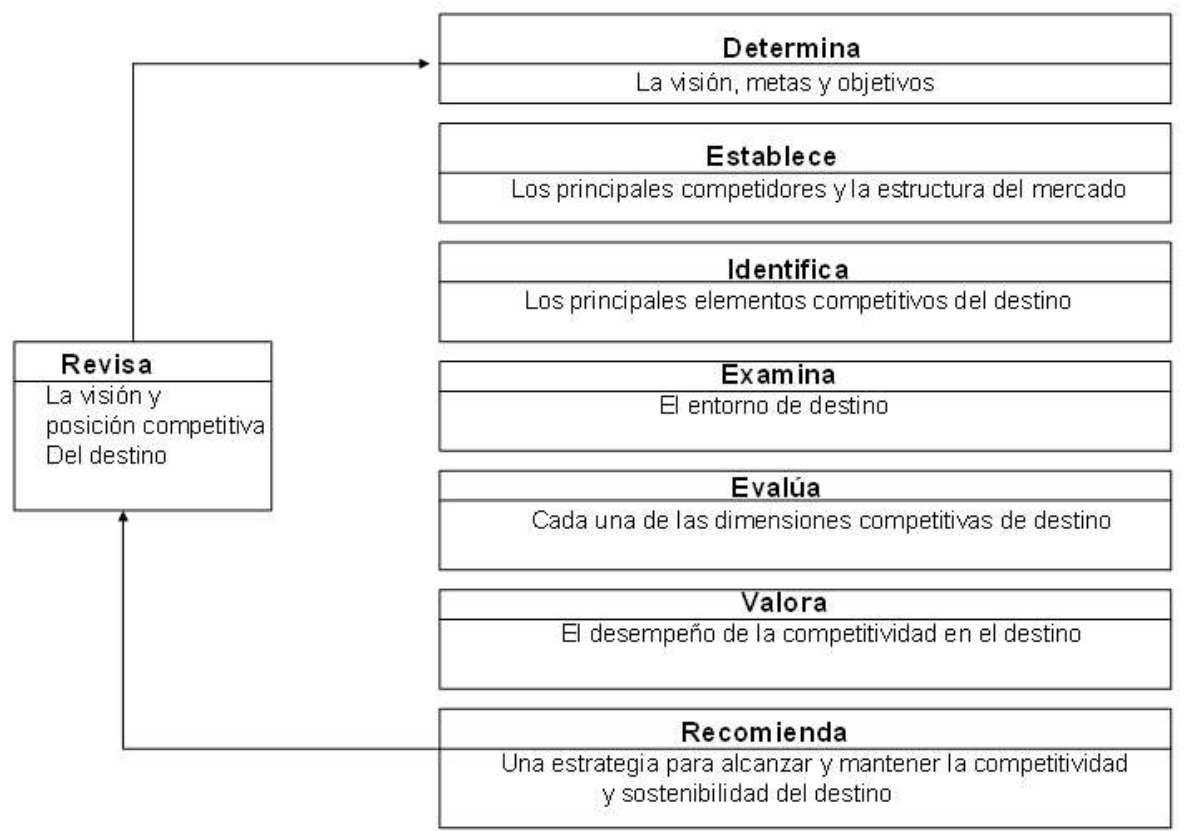

Fuente: adaptado de Ritchie y Crouch, 2003 
Estos autores finalmente desarrollan un índice (Índice de Competitividad y Sostenibilidad en Destinos, IDCS) que recoge doscientos setenta (270) indicadores para cada uno de los elementos que integran los distintos estamentos de su modelo (atractores y recursos principales, determinantes amplificadores y cualificadores; factores de soporte a la industria, política turística, planificación y desarrollo, gestión del destino), contraponiendo dos perspectivas diferentes pero complementarias: las medidas objetivas de la industria y las medidas subjetivas de los consumidores, basadas estas últimas en su percepción del destino.

En esta última idea, valoración del sector-percepción del consumidor, se basó el trabajo de Enright y Newton (2004) cuyo objetivo era medir la competitividad de la ciudad de Hong Kong situándola en un ranking comparativo con determinados destinos asiáticos que compiten en el mismo producto-segmento, para lo cual utilizaron algunos indicadores cualitativos de Ritchie y Crouch, especialmente de la construcción atractores y recursos principales. No obstante, la metodología empleada se aplicó exclusivamente a gestores y personal de primera línea de las empresas turísticas de esa ciudad, por lo que el contraste con la percepción del consumidor no queda fielmente reflejada.

Con respecto a las dimensiones de la competitividad en los destinos turísticos que mencionan estos autores en su modelo se refieren a las siguientes: económica, social, medioambiental, tecnológica, cultural y política.

\subsubsection{Teoría de los recursos y capacidades aplicada a los destinos turísticos}

Hasta finales de los años ochenta las opiniones predominantes estimaban 
que era la propia dinámica de oferta y distribución del producto la que determinaba el flujo de las corrientes turísticas internacionales, otorgando un papel protagonista al desarrollado por la industria (tour operadores y mayoristas) en lo que se ha venido a denominar la era "Fordiana" del turismo (Poon, 1989), caracterizada por un sistema de producción en masa de productos turísticos estandarizados.

Para Leiper (1990), en una toma de postura frente a estas opiniones, los turistas no son "llevados" hacia un destino, sino que son "atraídos" por su propia motivación hacia lugares y/o eventos donde esperan satisfacer sus propias necesidades. Richards (2002) investigó empíricamente este concepto de atracción a través de encuestas a turistas que visitaban destinos culturales, y demostró, efectivamente, los fuertes vínculos existentes entre la motivación, las necesidades de los turistas y las visitas de los destinos. Estos estudios inauguran la "nueva era del turismo" caracterizada por la supersegmentación de la demanda o, lo que es lo mismo, por la necesidad de ofrecer productos que se adapten a unas necesidades de demanda cada vez más complejas y diversas y que, a la vez, sean competitivos, en términos de precios, con los productos estandarizados (Fayos, 1994).

Estudios recientes identifican una nueva etapa en la caracterización del turismo del siglo XXI, con la etiqueta de turismo sostenible evaluado mediante el uso de indicadores para la gestión ( Plan de Excelencia Turística y Plan Agenda Local XXI de Calvià (1999). Plan de excelencia turística de la Costa Brava (Sardà, 2001); Plan Insular de Ordenación Turística de Lanzarote (1995, revisado en 2000) formulado a partir de la declaración de la isla de Lanzarote como Reserva de la Biosfera por la UNESCO en 1993; Fullana, P. et al. (2001); Sancho et al. (2002); Ministerio de Medio Ambiente (2003) 
Valls et al. 2004).

En esta línea, Clavé (2004) identifica tres tipos de estrategias que se han aplicado a destinos maduros y emergentes del litoral mediterráneo español e islas (Canarias y Baleares) y que responden a las tres etapas de turismo anteriores (era Fordiana, Nueva Era del Turismo, Turismo-Agenda XXI).

1) Estrategia de la renovación de los destinos y de la cualificación de los establecimientos articulada a través de las medidas desarrolladas por parte de la Administración Turística española mediante los planes de excelencia y los planes de dinamización que se vienen desarrollando desde 1993 en destinos turísticos de litoral e interior.

2) Estrategia de singularización a través de la incorporación de nuevas ofertas de ocio y diversión entre las que destacan el producto Golf, los Parques Temáticos y Acuáticos y las Actividades Náuticas. Junto a éstos otros productos divesificados en torno a los conceptos de salud, naturaleza, cultura, deportes, eventos y negocios.

3) Estrategia de sostenibilidad (desarrollada desde la mitad de los años noventa, especialmente a partir de la declaración institucional de Municipio Turístico Sostenible mediante la gestión de calidad medioambiental.

La teoría sobre los factores de atracción de un destino o "atractores" enlaza con las teorías sobre los recursos y capacidades. En definitiva, son los recursos naturales (clima, paisaje), culturales (arte, patrimonio, tradiciones, eventos) y artificiales (productos de naturaleza turística construidos por el 
hombre) de los que dispone de partida un destino el factor principal de atracción, combinados con la capacidad de gestionarlos convenientemente para que detenten un valor turístico susceptible de ser ofrecido al mercado.

Melián y García basándose en el modelo de los recursos de Penrose y Wernerfelt, evalúan el potencial competitivo de una modalidad deportiva de turismo en un destino turístico de sol y playa consolidado. En este estudio argumentan que el éxito de una forma particular de turismo en un destino depende, de forma determinante, de los recursos y capacidades que posee $y$, por tanto, la ventaja competitiva depende del control de estos activos que son valiosos, escasos, difíciles de imitar y sustituir e imperfectamente móviles (Melián y García, 2003). En este mismo sentido, Gray afirma que el éxito del turismo en un destino concreto depende, principalmente, de la existencia de recursos inmóviles y escasos (Gray, 1982). En esta misma línea se manifiesta Clavé (2004) al afirmar que en los destinos de litoral, concretamente en un estudio realizado sobre el litoral mediterráneo peninsular e Islas (Baleares y Canarias) los recursos sol y playa se consideran inagotables e inimitables.

\subsubsection{Modelos cuantitativos}

El mayor avance hacia la cuantificación de la competitividad de los destinos turísticos ha sido el modelo propuesto desde la OMT denominado genéricamente "modelo FAS" (Factores-Atractores-Soporte). Este modelo, pretende ser una aproximación a la especificación conceptual y cuantitativa cuyo objeto no es otro que llegar a medir la competitividad entre destinos 
turísticos de similares características. El alcance de este modelo es más amplio que la mera descripción de los elementos estructurales de un destino, puesto que, no sólo analiza esta estructura, sino que mediante la ponderación de estos elementos intenta determinar la adscripción de un determinado destino a un arquetipo propuesto como prototipo de referencia. Este planteamiento, teóricamente, facilitaría el camino hacia el establecimiento de rankings de competitividad entre destinos cuyas ventajas comparativas fueran similares (Fayos et al. 2002,2003).

El modelo se basa en un espacio de tres dimensiones iniciales que se van desagregando, cada una de ellas, en otras tres sucesivamente, dependiendo de la existencia o no de variables adicionales en el destino en cuestión. Las tres dimensiones iniciales son:

\section{Los Factores o Recursos en Turismo}

En este modelo el concepto de recursos es distinto al utilizado habitualmente desde el ámbito de la geografía asimilándose al concepto de input (factor de producción) propio de los sistemas industriales. En este sentido, los recursos de un destino turístico son la fuente de su proceso productivo. A partir de esta dimensión, realizan la siguiente disgregación:

1.1 Recursos naturales, que a su vez se dividen en:

- Agua

- Tierra

- Clima

1.2 Recursos humanos, que se componen de:

- Capital humano 
- Tradiciones culturales, mitos, leyendas.

- Condiciones (estructura y coyuntura) laborales del entorno de trabajo.

1.3 Recursos de Capital:

- Capital financiero existente

- Capital físico/ infraestructuras (aeropuertos, puertos, carreteras, ferrocarril,)

- Potencial para atraer capital foráneo

\section{Los Atractores}

Son las variables que se conforman como elementos de atracción turística del destino y cuya importancia relativa depende del tipo de destino de que se trate. Los atractores son los elementos centrales de cada producto turístico, donde se genera el valor que motiva la compra por parte del consumidor turístico. De ahí que la generación o destrucción de valor en torno a estos elementos va a ser determinante en la percepción que se tenga de este producto, situación que derivará tarde o temprano en cambios en las preferencias de la demanda.

El conjunto de atractores de un destino turístico puede ser clasificado del siguiente modo:

2.1 Atractores naturales,

- Espacios naturales

- Playas

- Actividades itinerantes en la naturaleza

2.2 Atractores culturales, - Legado histórico 
- Eventos

- Estilos de vida de la población local

2.3 Atractores artificiales,

- La oferta turística de ocio y entretenimiento

- Convenciones, exhibiciones

- Centro comerciales, tiendas

\section{Los Sistemas de Soporte}

Los sistemas de soporte son el tercer elemento que completa el modelo estructural de un destino turístico. En esta variable o dimensión se incluyen tanto la industria turística como los equipamientos que facilitan la prestación del producto turístico. Los elementos incorporados a la dimensión de sistemas de soporte constituyen los elementos clave para que la experiencia turística global pueda desarrollarse en condiciones de calidad. La existencia de infraestructura de alojamiento adecuada, de seguridad y sanidad y los sistemas de información en destino contribuyen en gran medida a la competitividad del destino. La clasificación de los sistemas de soporte es la siguiente:

3.1 Hostelería, hace referencia a la infraestructura de alojamiento y restauración del destino, incluyendo:

- Hoteles, de todas las categoría y modalidades

- Otros alojamientos, como por ejemplo, los apartamentos turísticos, casas rurales o pensiones

- Establecimientos de restauración, incluyendo cualquier posibilidad o alternativa gastronómica, ya sea de lujo, nivel medio, o los establecimientos de comida rápida 
3.2 Transporte, incluye todas las estructuras e infraestructuras necesarias para el uso de distintos medios de transporte hacia y dentro del destino.

- Transporte aéreo (líneas charter, líneas regulares, líneas de conveniencia o bajo coste)

- Transporte terrestre (transporte colectivo, taxi, alquiler de vehículos)

- Acuático (marítimos, fluviales)

3.3 Servicios complementarios,

- Distribución de la información y venta en el destino turístico (oficinas de información turística)

- Seguridad, salud, higiene

Por su parte, Enright y Newton (2004), con objeto de tipificar y medir la competitividad de un destino turístico, han desarrollado una propuesta inicial de modelo que une los factores genéricos de competitividad, aplicables a cualquier sector industrial, con los principales factores clásicos de atracción de un destino turístico. La mezcla de estos conceptos, provenientes de distintas fuentes académicas, es lo que permite, según los autores, “el desarrollo de un modelo más comprensivo de la competitividad de un destino que los desarrollados hasta este momento", en clara referencia a los trabajos desarrollados por Ritchie y Crouch. Según los autores, la principal contribución del estudio consiste en el desarrollo de una metodología operativa y, en particular, la inclusión en este método de los factores directamente relacionados con la competitividad empresarial, conjuntamente con los más convencionales que se vienen empleando en competitividad de un destino, como son la 
imagen percibida o los factores de atracción.

Realmente la metodología empleada por estos autores es interesante, especialmente el despliegue de parrilla de resultados, que permite visualizar puntos fuertes y débiles de un destino en relación a sus competidores directos, tanto en factores clásicos de atracción como en elementos de gestión. En definitiva, los resultados de su estudio indican, en opinión de los encuestados, en qué se considera que se es más competitivo y en qué menos, por lo que puede servir de orientación para la toma de decisiones de inversión. Sin embargo, el método empleado, encuestas a profesionales de la industria turística, podría ser completado con una serie de indicadores de carácter objetivo.

\subsection{Gestores del Destino Turístico}

Los elementos estructurales de un destino turístico no explican por sí mismo el conjunto de relaciones que tienen lugar en su interior y que derivan en una determinada posición competitiva en el mercado. Es necesaria la intervención de una serie de agentes que, utilizando los medios políticos y productivos a su alcance, desarrollan una serie de procesos, cada uno en su ámbito de competencias, tendentes a la obtención de un resultado final de naturaleza intangible.

Estos agentes, artífices del desarrollo turístico de un destino, son quienes a partir de sus propias capacidades gestionan sus respectivos ámbitos de competencia dentro de un contexto temporal y un entorno competitivo determinado. Además, en la medida que la cultura y el modo de hacer de 
los ciudadanos y las organizaciones implicadas en el territorio faciliten el proceso, más posibilidades existen de alcanzar con éxito los resultados esperados. Porter (2003) ha señalado que un entorno que fomenta la rivalidad empresarial es más propenso a la innovación y se adapta mejor a los cambios en el mercado, apoyándose en los avances tecnológicos. De esta manera se mejora la eficiencia y la productividad del conjunto del destino.

Sin embargo, un destino turístico no puede ser gestionado de la misma manera que una empresa u organización que dispone de autonomía absoluta para utilizar sus recursos y capacidades de la manera más eficiente posible en su sistema interno ejerciendo un amplio control sobre procesos y resultados. Tal y como indican Ritchie y Crouch los gestores de un destino turístico influyen, facilitan y coordinan pero "no son el destino".

Desde nuestro punto de vista, la capacidad para gestionar los recursos internos del destino descansa en los siguientes agentes:

1. Gestores con capacidad normativa, ejecutiva y sancionadora (Administración Pública).

- $\quad$ Gobierno Local.

- Gobierno Supra-local (regional, nacional, supra-nacional).

2. Gestores con capacidad ejecutiva (agentes económicos).

- Industria Turística.

- $\quad$ Proveedores.

- $\quad$ Industrias Conexas y de Apoyo.

3. Gestores con capacidad política (ciudadanos) 
- Población local.

- $\quad$ Asociaciones y organizaciones sociales.

\section{3. 1 Gestores con capacidad normativa}

La Administración Pública de nivel local participa activamente en el desarrollo turístico, dado que es quien tiene la capacidad normativa, a través de los instrumentos de planeamiento urbanístico, para establecer el alcance y los límites del modelo de desarrollo turístico que se quiere alcanzar.

El gobierno local es también el responsable directo de los servicios públicos, compartidos entre población local y turistas, que se ofertan en el destino. Aún en el caso de no ostentar la titularidad de las competencias de esto servicios (salud, policía, educación) que pueden recaer en instancias jerárquicas o territoriales superiores, es el garante, ante ciudadanos y visitantes, de la correcta coordinación para la prestación de estos servicios. Pero si se tiene en cuenta que uno de los indicadores por los que el municipio recibe el calificativo de turístico ${ }^{2}$ es porque el número de visitantes/turistas que recibe, es proporcionalmente mayor que el número de personas empadronadas (habitantes de derecho), las inversiones necesarias para garantizar la salubridad, seguridad y el bienestar de propios y visitantes, conjuntamente con la puesta en valor turístico o el mantenimiento de los factores de atracción del destino, supondrían, en la mayoría de los casos, afrontar un volumen de endeudamiento superior a las posibilidades financieras reales, aún a largo plazo, de estos entes locales. Por tanto, los criterios de eficiencia en la elección de inversiones y en el gasto público deberían primar por encima de criterios de eficacia política. 
El papel de las administraciones públicas de ámbito supra-local, con competencias en materia turística, se centra en la ordenación y regulación sectorial, la redistribución financiera de la recaudación impositiva y la estabilización del sistema mediante acuerdos horizontales y verticales de colaboración con otras administraciones sectoriales y territoriales. Asimismo, es importante su contribución al posicionamiento y comercialización de los destinos mediante la dotación de sistemas de redes de información y de promoción turística.

\subsubsection{Gestores con capacidad ejecutiva}

Los agentes económicos, si bien tienen capacidad de influencia, especialmente en decisiones políticas, se caracterizan esencialmente por su capacidad ejecutiva. Forman el tejido económico y productivo del destino y, su nivel de implicación en la gestión integral del destino suele ser directamente proporcional al volumen de sus intereses económicos particulares.

Tomando como referencia la mencionada Ley de Turismo de la Generalitat Valenciana, en la misma medida que un destino se califica como turístico por el volumen de población "turística" que recibe, estas organizaciones se considerarán "turísticas" en función tanto del volumen que los turistas representen en su cartera de clientes, como, especialmente en las pequeñas empresas, por la sensación de proximidad física en sus relaciones con éstos.

Así, podemos plantear como hipótesis que en la medida en que cuantitativamente el círculo más cercano al turista, las industrias de soporte, tienen una mayor presencia en el conjunto del espacio turístico de destino en relación al resto de empresas y organizaciones y, por ende, un mayor peso 
específico en la economía local, mayor es el nivel de competitividad turística del destino.

Los proveedores del sistema son las empresas y organizaciones que suministran a la industria turística los factores básicos de producción que necesita. Estos son, entre otros, la fuerza laboral, los equipamientos, la energía, construcción, materias primas y productos transformados. Los proveedores, tal y como Porter (1991) ha puesto de manifiesto en su "diamante" juegan un papel determinante en la competitividad del destino, puesto que el precio de sus productos y servicios determinará en buena medida el coste de partida que la industria deberá observar para determinar sus propios precios, siendo éste es uno de los factores estratégicos de mayor importancia. La proximidad de los proveedores con la industria, si bien no es uno de los criterios determinantes, sí favorece el abaratamiento de los costes relativos a la logística de distribución y permite una mayor precisión en la determinación de la calidad deseada para productos y servicios.

Las industrias relacionadas y conexas son aquellas que, si bien tienen puntos en común con la industria turística, su cliente principal no es mayoritariamente el turista o el visitante. Su presencia refuerza la industria turística en la medida que parte o toda su oferta de servicios puede ser añadida al producto total del destino. Es el caso de la oferta cultural (teatros, galerías de arte, museos, festivales de cine, eventos musicales), deportiva (campeonatos, torneos, premios, olimpiadas) y comercial (tiendas, centros y mega-espacios de ocio y compras). 


\subsubsection{Gestores con capacidad política}

Los ciudadanos, en sentido amplio, son todas aquellas personas y grupos organizados afectados por el desarrollo turístico y que tienen capacidad de influir políticamente en la gestión de los destinos. En contextos democráticos, la comunidad local participa indirectamente en la planificación y gestión de los destinos turísticos desde el mismo momento que elige su opción política preferente. Se convierte así en el cliente principal de los gobiernos locales, para los que la satisfacción de este público se convierte en su eje prioritario de actuación. Aunque se suele subvalorar la capacidad de actuación de la población, la sociedad civil organizada puede llegar a ejercer un control y una presión de gran alcance en los otros agentes del destino y en las decisiones relacionadas con el desarrollo turístico. En este sentido conviene remarcar la trascendencia de las decisiones de los grupos de acción local (GAL), ligados a las iniciativas LEADER y PRODER en la dinamización de las comarcas rurales.

\subsubsection{La comunidad local}

Es una constante en la literatura que trata la problemática de la gestión de los destinos turísticos el señalar la importancia de la actitud de los residentes locales para éxito del desarrollo turístico sostenible (Ap, 1992; Jurowski, 1994). El interés de los residentes en la gestión del destino es fundamental, puesto que proporciona la fuerza de trabajo, conforma el substrato cultural y es el componente social más influyente en las decisiones de política local. Adicionalmente, el ciudadano, aún sin desearlo, es un componente más, en cierta medida, del producto turístico entregado, al formar parte de la identidad socio cultural que despierta la atención del visitante. Su amabilidad, eficacia 
e imagen personal están directamente asociadas a la calidad percibida del destino. En este sentido, se ha afirmado (Gallarza y Calderón, 2002) que los residentes pueden desempeñar un papel tanto activo como pasivo en la imagen del destino, lo que ha dado pie a dos líneas de estudios. Por un lado, los residentes de un destino pueden tener imágenes de sus propios lugares de residencia que pueden ser investigadas de forma comparada con la de los turistas. Esta corriente se ha bautizado como "papel activo de los residentes en el estudio de la imagen del destino turístico". Por otro lado, el interés por la actitud de los residentes hacia el turismo ha dado lugar a otro grupo de estudios en los que los residentes son a menudo percibidos como una parte de los elementos de la imagen del destino y su respaldo a la industria turística afecta a las percepciones que los turistas tienen sobre el destino. Esta segunda línea de investigación se ha llamado "el papel pasivo de los residentes en el estudio de la imagen de los destinos turísticos". Ambos tipos de estudios suelen presentar implicaciones para la gestión, siendo pues herramientas muy útiles para las políticas de un destino.

Aunque se ha criticado (Ap y Crompton, 1998) la falta de un marco teórico previo sobre el que edificar una auténtica teoría del intercambio social turistaresidente, numerosas investigaciones han demostrado que la población residente percibe el turismo según las tres categorías básicas de impactos (económicos, medioambientales y sociales) que esta actividad produce en su entorno y éstos, a su vez, pueden ser tanto positivos, como negativos (Jafari, 1974; Mathieson y Wall, 1982 ; Murphy, 1985; Gee, et al., 1989; McIntosh y Goeldner, 1990; Archer y Cooper 1994; Fredline y Faulkner, 2000; Gursoy et al., 2002). 
Los efectos económicos del turismo han sido los primeros en ser verificados y sus impactos, especialmente los positivos, son claramente percibidos y deseados por la comunidad anfitriona en los estudios que se han realizado sobre este particular, si bien algunos investigadores encontraron variaciones en las reacciones en función de las características del destino estudiado (tipo de desarrollo turístico, grado de desarrollo, situación de la economía local, ámbito geográfico) y de la propia situación socioeconómica de los residentes.

El reconocimiento, más reciente, de los impactos medioambientales que el turismo produce sustenta los modelos de sostenibilidad de los destinos turísticos profusamente desarrollados en la actualidad. Según la OMT $(1996,1999)$ los principios de sostenibilidad se refieren a los aspectos ambiental, económico y sociocultural del desarrollo turístico, debiéndose establecer un equilibrio adecuado entre esas tres dimensiones para garantizar la sostenibilidad de un destino turístico a largo plazo y, con ello, su competitividad. Según este mismo organismo, el desarrollo sostenible del turismo exige la participación informada de todos los agentes relevantes del destino.

Los efectos sociológicos y culturales del turismo han sido analizados más frecuentemente desde el punto de vista de la sociología. Estudios en los que, en palabras de Pearce existe "una cierta añoranza sentimental por tiempos pasados" que pueden sesgar las conclusiones, trazando una línea que separa nítidamente a los actores. De una parte, al turista, depredador y, de otra, al nativo, víctima, brecha que será más o menos amplia en función de las diferencias sociales que separen ambos mundos y del estadio de madurez en el que se encuentre el producto turístico. No obstante, en este tópico, existe una amplia línea de investigación que, apoyada en la teoría del 
intercambio social de Homans, ha tratado de modelizar los parámetros determinantes de la actitud de los residentes hacia el turismo, centrándose en averiguar cuáles son las variables que determinan el que en una misma comunidad existan grados de mayor o menor apoyo al turismo (Dogan, 1989; Allen et al., 1988; Ap, 1990, 1992, Gursoy et al., 2002).

La argumentación basada en la teoría del intercambio social ha sido cuestionada por algún investigador (Pearce et al., 1991) quien propone un marco teórico alternativo basado en la teoría de la representación social desarrollada por Moscovici $(1984,1988)$ y definida por éste como "sistema de imágenes y valores preconcebidos que tienen su propio significado cultural independientemente de la experiencia individual". Estas ideas o representaciones mentales son compartidas por grupos dentro de una sociedad facilitándoles la comunicación. La clave para identificar la imagen social de una comunidad radica en identificar qué hay de común entre ellos, es decir, determinar, en nuestro caso, dónde está el consenso con respecto a la percepción del turismo entre los residentes. Se llega de esta manera a identificar patrones grupales de comportamiento dentro de una comunidad, repitiéndose estos patrones incluso entre distintos destinos (Davis, et al., 1998: Ryan y Montgomery, 1994; Madrigal, 1995; Fredline y Faulkner, 2000; Weaver y Lawton, 2001, Aguiló et al., 2003). (Tabla 2, anexos).

La metodología utilizada en la mayoría de estos estudios se ha basado en tratar de medir las percepciones, actitudes y comportamientos de los individuos residentes en una localidad determinada identificando los patrones predominantes y relacionándolos con distintas variables independientes (Fredline y Faulkner 2000). Los estudios se han centrado en la comparación entre residentes observándose dos dimensiones (Faulkner y Tideswell, 1997): 
la primera, de carácter extrínseca, referida a las variables que afectan a las reacciones de los residentes a nivel macro, en el sentido de que afectan a toda la comunidad y una dimensión intrínseca o individual que reconoce la diversidad y heterogeneidad de las percepciones en función de las características y circunstancias de cada individuo (Tabla 3, anexos).

El análisis de las potenciales conexiones entre la percepción de los impactos y la actitud personal con respecto al turismo se ha realizado a través de la comparación con las siguientes variables:

- Grado de participación en las actividades recreativas.

- Apego a la comunidad.

- Antigüiedad de residencia.

- Conocimiento sobre la actividad.

- Proximidad a su zona de negocios.

- Contacto que tenga con turistas.

- Posición social.

- Posición política.

- Tipo y forma del turismo.

- Beneficios económicos derivados del sector.

De las dimensiones intrínsecas sólo están probadas dos (Gursoy et al., 2002): (1) el grado de contacto que se tenga con los turistas; y (2) el interés económico personal. Estos mismos investigadores llegan a las siguientes conclusiones probadas y la confirmación de las siguientes hipótesis:

1.- Los residentes perciben el turismo como una actividad económicamente beneficiosa que genera empleo e ingresos, incrementando las oportunidades de ocio y recreativas de los habitantes. 
2.- Las actitudes de los residentes con respecto al turismo están fuertemente influenciadas por la percepción de la situación de la economía local: cuanto más negativa sea la constatación de la situación de la economía local, más positiva es la reacción local a favor del desarrollo turístico.

3.- Los residentes con más alto grado personal de interés por la preservación de la naturaleza y del medioambiente perciben que los costes asociados al turismo son mayores que los beneficios y se muestran más proclives a apoyar el turismo cultural y de eventos, en lugar del turismo basado en la utilización masiva de los atractivos naturales.

\subsection{Morella como destino turístico. La percepción de la comunidad local}

\subsubsection{Caracterización del destino turístico Morella}

Para encuadrar adecuadamente nuestra aportación empírica al estudio de la actitud de los residentes frente al turismo desarrollado en su localidad, hemos escogido un destino turístico de interior que aún no ha alcanzado su fase de madurez y que por sus características permitiera la realización de una investigación abarcable con los recursos disponibles. Es el caso de la localidad de Morella cuyas características territoriales y de producto se especificarán a continuación.

El área de estudio comprende la comarca de Els Ports de Morella. La comarca está situada en el noroeste de la provincia de Castellón (Comunidad Valenciana, España). Se trata de una comarca calificada de montaña (la altitud media es de 887 metros, con una extensión total de $1291 \mathrm{kms}^{2}$ ). Los municipios que 
forman esta comarca son trece: Zorita del Maestrat, Palanques, Herbés, Villores, Forcall, Todolella, Olocau, Mata de Morella, Morella, Vallibona, Cinctorres, Portell de Morella, y Castellfort cuya extensión oscila entre los $418 \mathrm{~km}^{2}$ de Morella y los $5 \mathrm{~km}^{2}$ de Villores con una población media en la comarca de 9.000 habitantes y una densidad de 7 hab. $/ \mathrm{km}^{2}$.

La delimitación anterior corresponde con la unidad administrativa comarcal, si bien se deben tener en cuenta otras agrupaciones de interés común, como son las Mancomunidades de Municipios, entre las que destacamos la denominada Mancomunidad Turística del Maestrazgo, formada por 59 municipios de las Provincias de Teruel (Comunidad de Aragón) y Castellón (anexo, tablas 4 y 5 ).

El área se encuentra en el sector oriental de la Cordillera Ibérica española, donde la altitud media se sitúa en los 987,8 m., con presencia de un relieve abrupto y montañoso que genera una extraordinaria riqueza geológica. El sistema ibérico es una zona de transición bioclimática en la que, debido a su altitud, el clima de la zona se puede clasificar de continental (anexos, tabla 6). Estos factores se han considerado tradicionalmente negativos para el aprovechamiento agrícola y el crecimiento demográfico (Noguera,1997) por lo que, pese a su notable legado histórico y rico patrimonio arquitectónico y cultural, la comarca se ha caracterizado por el éxodo rural, el envejecimiento de la población y un escaso tejido empresarial y asociativo que ha provocado un grave desequilibrio territorial entre estas zonas rurales y las zonas urbanas más próximas.

La base de la economía tradicional de la zona se centra en explotaciones agrícolas, ganaderas y agropecuarias de pequeño tamaño y en una modesta 
industria de productos cárnicos curados, conservas, quesos y repostería. Los cultivos y recursos principales son los cereales, olivos, almendros, vid, ganadería bovina y porcina, apicultura, las especies micológicas del territorio (trufas y diversos tipos de setas), y, en menor medida vestigios de la artesanía local, fundamentalmente trabajos en textiles, cerámica, cuero, madera y metal.

En el ámbito turístico, la zona objeto de estudio se encuadra dentro de la marca "Castellón- Costa Azahar" que tiene su origen en la marca "Costa del Azahar" (1965-1998). Originariamente comprendía las provincias de Castellón y Valencia. En 1998, se decidió simplificar la marca en "Costa Azahar". Este nombre, tal y como se ha puesto de relieve en el ámbito empresarial, puede servir de ejemplo de cómo un nombre difícil de pronunciar, de recordar y no asociable con ningún concepto turístico relevante, puede llegar a sobrevivir a cualquier valoración científica o técnica. Finalmente, desde 1999, la dificultad de situar la marca en su contexto geográfico ha llevado a anteponer el topónimo Castellón a la misma.

La marca Castellón Interior promociona aquellos lugares considerados de relevancia turística situados en el interior de la provincia (Morella, Sant Mateu, Benassal, Villahermosa del Río, Moncofa, Almenara, Cabanes, Segorbe, Navajas, Montanejos, Tinença de Benifassà, Vistabella), cada uno de los cuales dispone de su propio tratamiento de imagen.

El despegue turístico que ha tenido en los últimos años esta zona del interior de la provincia la sitúa como líder dentro de la Comunidad Valenciana, siendo ésta la tercera comunidad autónoma española en cuanto a número de plazas de alojamiento turístico rural ofertadas (Generalitat Valenciana, 2004), 
pasando de 716 plazas en 1996, a 6.743 plazas en 2003, lo que significa un crecimiento del $841,8 \%$. Esta situación, junto con la intensa apuesta por la diversificación del producto base "sol y playa" por parte de la Generalitat, ha llevado al reconocimiento en el mercado de dos marcas, no oficiales, pero con identidad propia: Morella y El Maestrazgo. Ésta última es gestionada por la entidad pública Mancomunidad Turística del Maestrazgo, constituida en 1972, que incluye los territorios de Castellón-Teruel.

Asimismo, la marca turística El Maestrazgo coincide, prácticamente, con las zonas de actuación de los programas europeos (Leader I y II) para el desarrollo rural sostenible (anexos, tablas 7 y 8 ) en el marco de los cuales se han llevado a cabo iniciativas de proyectos turísticos de distinta naturaleza (anexos, tablas 9,10 y 11), entre los que destacamos la creación de nuevos productos y el desarrollo de redes para la cooperación pública-privada, activados por los agentes locales e institucionales a través de los Grupos de Acción Local (GAL) que está siendo, en los últimos años, el auténtico motor del desarrollo turístico local.

Figura 3 Crecimiento anual del número de unidades y de plazas de alojamiento rural en la comarca de Els Ports (1996-2002)

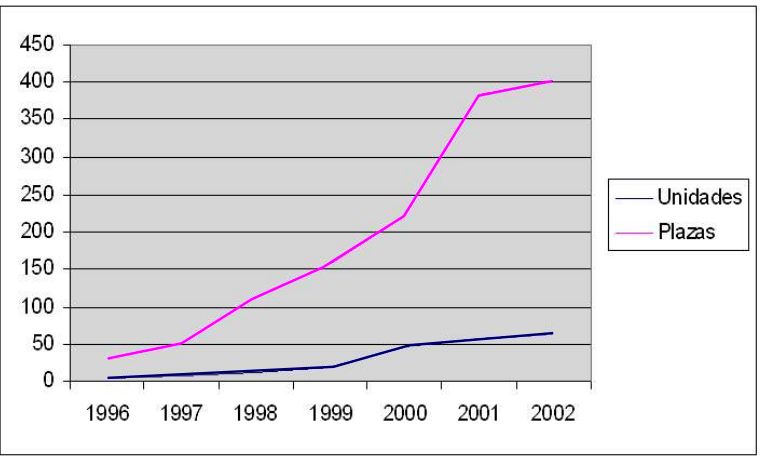

Fuente: elaboración propia a partir de estadísticas oficiales (IVE). 
Una vez situados en la comarca, el foco de la investigación se centrará en la capital de la misma, Morella, por ser el municipio turísticamente más desarrollado, siendo el máximo exponente y compendio de los recursos y productos ofrecidos en el resto del territorio: patrimonio, cultura, naturaleza y tradición. Así, esta ciudad, por sí misma dispone del $70 \%$ de los establecimientos hoteleros de la comarca de Els Ports, del 50\% de las plazas disponibles de alojamiento en casas rurales y del 57\% de las plazas de restaurantes (Anexos, Tablas 12,13,14). Destacamos en este punto el espectacular crecimiento experimentado por las plazas disponibles en alojamiento extrahotelero, concretamente en casas rurales, en toda la zona y en Morella en particular (fig. 2). Aspecto éste que, sin duda, se ha visto favorecido por las inversiones conjuntas público-privadas que han tenido lugar en los últimos años a partir de las iniciativas en turismo de los programas Leader (especialmente I y II) de estímulo a la diversificación agrícola

Con respecto a la situación demográfica en Morella, de igual manera que ocurrió en otras zonas rurales españolas, se caracterizó, desde los años 60 hasta finales de los 80 del siglo XX, por una constante emigración desde el interior hacia las zonas de crecimiento económico, es decir, las medianías y las zonas litorales. Como consecuencia de ello, se inició un grave proceso de deterioro de la estructura socio económica de estos espacios llegándose a alcanzar una densidad de población inferior a la mitad de la media de la Comunidad Valenciana (169 hab./ $\mathrm{km}^{2}$ en 1991), siendo de 5 hab./ km² para la comarca de Els Ports (Noguera, 1997).

Sin embargo, la tendencia actual, a finales del primer quinquenio del 2000, sigue una tendencia ascendente, en paralelo al progresivo desarrollo de la actividad turística (fig.3). Este último dato se corrobora, además de por la 
evolución experimentada por la oferta turística del sector, especialmente de alojamiento extrahotelero, con el contraste de los datos que arroja el saldo migratorio de la ciudad. De este último se aprecia que, si no se contemplara la inmigración de trabajadores extranjeros, (fig.4) muchos de los cuales están empleados en hostelería pero también en agricultura, el saldo migratorio sería aún negativo. El origen de esta situación se encuentra en que la población más joven, con un nivel de estudios superiores al de generaciones precedentes, necesita buscar alternativas laborales en el exterior, acordes con sus expectativas educativas.

Figura 4 Evolución de la población empadronada en la ciudad de Morella, período (1996-2004)

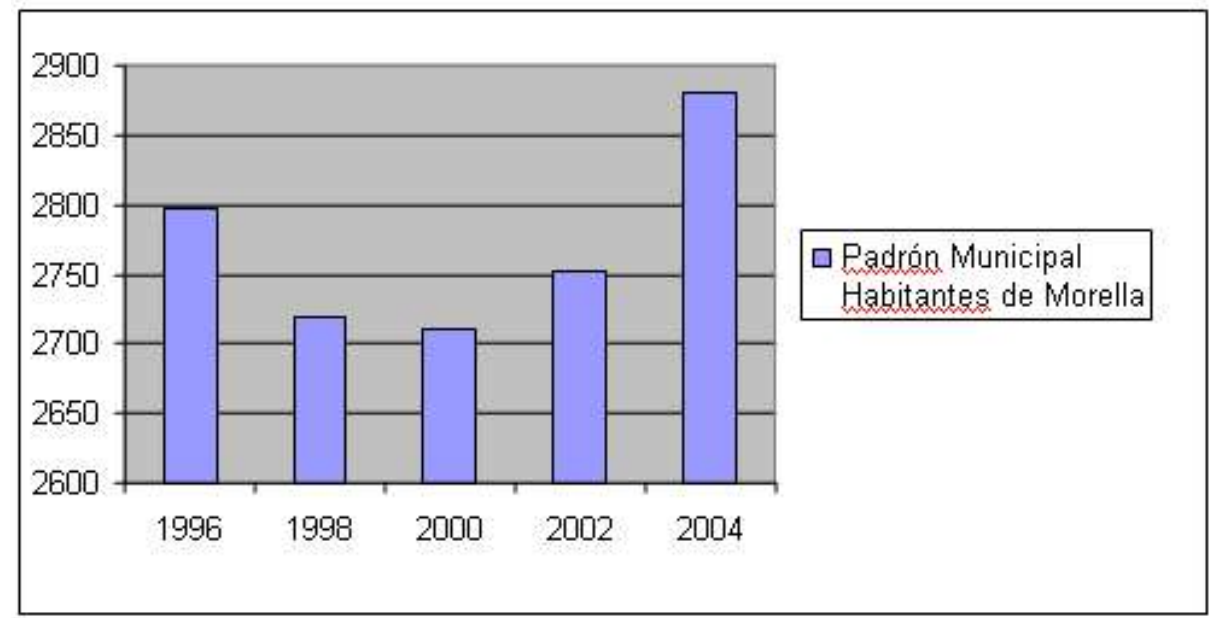

Fuente: elaboración propia a partir de estadísticas oticiales 
Figura 5 Inmigración en Morella (1995-2001)

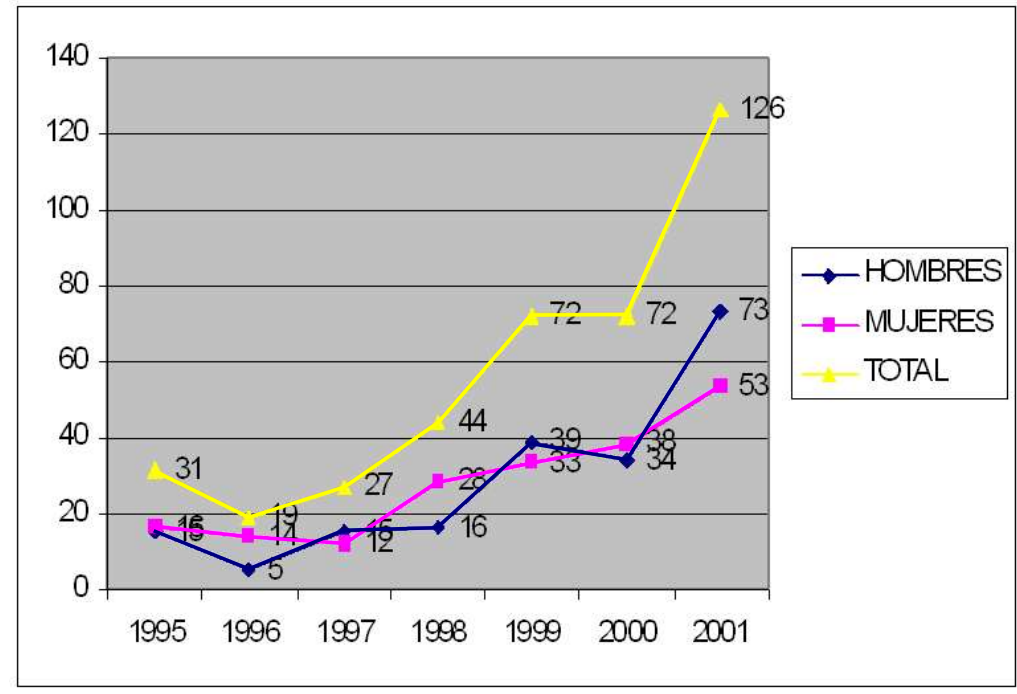

Fuente: elaboración propia con estadísticas oficiales (IVE)

En relación a la estructura de la población (fig.5), si bien el segmento de población de mayor edad, por encima de los 65 años, representa una importante cuota del total de población, la población activa, entre 18 y 65 años, no sólo se ha mantenido, sino que se aprecia un ligero incremento de su presencia en el conjunto de la población. La tendencia, sin embargo, con respecto a jóvenes y niños es descendente si bien este dato coincide con la inclinación a la baja correspondiente al descenso de natalidad que se viene observando, en los últimos años, en todo el país. 
Figura 6 Evolución de la población de Morella por tramos de edad

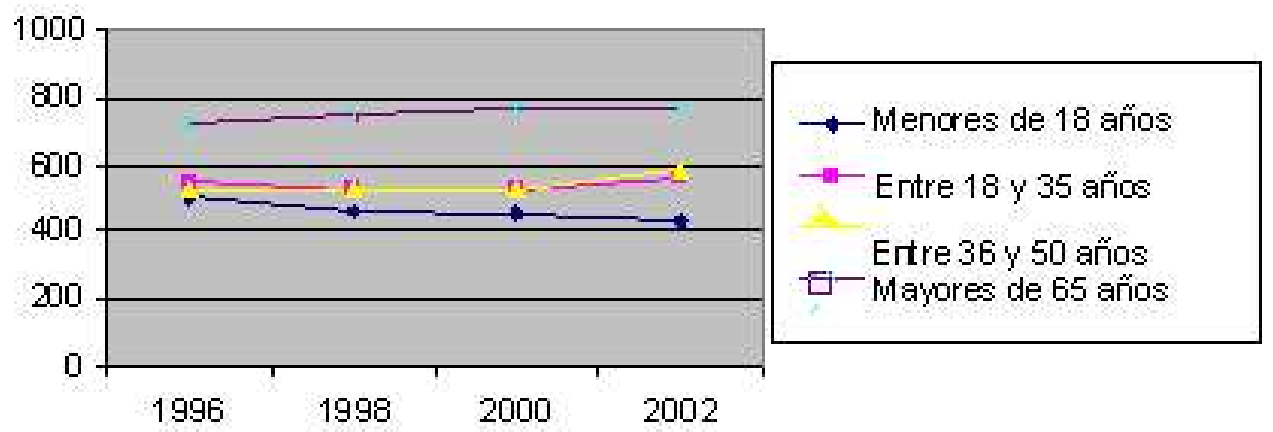

Fuente: elaboración propia con estadísticas oficiales (IVE)

\subsubsection{Actitudes de la población residente}

El diseño de la metodología aplicada en esta investigación guarda estrecha relación con uno de los objetivos planteados: investigar empíricamente el apoyo que el desarrollo turístico puede tener por parte de la comunidad residente en una localización determinada, a partir de su propia percepción de los impactos que esta actividad produce en su territorio. Adicionalmente, se ha querido comprobar el grado de consenso de la población en torno a su visión del posicionamiento actual del destino en el mercado turístico.

Se ha escogido para la investigación un destino turístico de interior, considerado dentro de la tipología de producto turístico cultural, que se encuentra al inicio de su etapa de madurez (Sancho et al., 2001). Pretendemos contrastar en él la aplicación de las hipótesis planteadas por investigaciones anteriores (Gursoy et al., 2002; Ko y Steward, 2001; Frekline y Faulkner, 2000; Weaver y Lawton, 2001) manifestadas en el siguiente sentido:

1.- Los residentes perciben el turismo como una actividad económicamente beneficiosa que genera empleo e ingresos y, 
adicionalmente, incrementa las oportunidades de ocio y recreativas de los habitantes.

Hipótesis (1) Existe una relación directa entre las percepciones de los beneficios del turismo y el apoyo de los residentes locales a su desarrollo.

2.- En relación con las variables intrínsecas que pueden condicionar la actitud de los residentes hacia el turismo, es decir, qué factores personales inciden o pudieran incidir en la formación de la actitud que mantienen los residentes en un destino turístico hacia el turismo. Para ello desestimamos variables personales (edad, nivel de estudios, etc.) y consideramos la variable objetiva implicación profesional en la cadena de valor del destino turístico.

Hipótesis (2) Existe una relación directa entre el grado de implicación profesional que se tenga en la industria turística con el apoyo manifestado al desarrollo de la misma y, a la inversa, una menor percepción de los impactos negativos de la actividad.

3.- $\mathrm{Si}$, tal y como se ha expuesto anteriormente, la medida local de la competitividad de un destino de base territorial viene referida al nivel de bienestar y/o satisfacción experimentado por sus habitantes, la base de la sostenibilidad, la frontera entre el desarrollo sostenible y la producción industrial competitiva se encuentra en el difícil equilibrio entre el beneficioso y deseable desarrollo de la economía local a través del turismo y la situación de rechazo y exclusión que llegan a experimentar aquellos que deseaban inicialmente la actividad. Hipótesis (3) Cuando un destino turístico de base territorial alcanza su plena madurez, se convierte en un cluster sectorial, 


\section{incompatible con el desarrollo de otras actividades productivas y con tendencia a la exclusión social de la población no directamente implicada con el cluster.}

\subsubsection{Método de obtención de la información}

La inexistencia de estudios anteriores cuyo ámbito territorial de análisis fuera la Comunidad Valenciana y, en concreto, un modelo de destino turístico de interior, nos condujo a tomar como referencia los trabajos publicados sobre esta materia en publicaciones científicas de carácter internacional. Siguiendo las pautas trazadas por estas investigaciones, el instrumento que se consideró idóneo para la obtención de la información ha sido el diseño de un cuestionario estructurado, auto-administrado, que permitiera el posterior análisis y tratamiento de la información mediante un sistema de análisis estadístico a través del programa SPSS ${ }^{3}$.

Dado el ámbito geográfico, la baja densidad de población, las características de la población y el coste de la técnica empleada se estimó el método postal convencional como el más idóneo para obtener la información. Para el envío personalizado de la encuesta se contó con la inestimable colaboración del Centro de Iniciativas Socio-Económicas (CISE) del Ayuntamiento de Morella.

Este método tiene dos dificultades fundamentales: su lentitud, en comparación con otros medios como son la entrevista personal o telefónica, y el nivel de participación o de respuesta que está situado en torno al 10\% (Grande y Abascal, 2001). Sin embargo, se sopesó el factor anonimato percibido como fundamental a la hora de responder libremente en una población donde el 
nivel de convivencia y reconocimiento entre vecinos es muy elevado. En este sentido, el envío postal personalizado de la encuesta auto-administrada permite una mayor calidad de la información dado que el encuestado puede ofrecer unas respuestas más meditadas y anónimas sin la injerencia de un encuestador o la rapidez derivada de la cuestación telefónica.

En relación al retorno de la información, se suministró, junto a la encuesta, una carta de presentación del estudio con instrucciones precisas, junto a un sobre en blanco para su devolución, una vez cumplimentadas, en unas urnas dispuestas al efecto en la Oficina de Turismo del Ayuntamiento. Para incentivar la participación de la comunidad se difundió la información sobre la investigación que se iba a realizar a través de la televisión local de Morella.

La población de la investigación se ha circunscrito a los habitantes empadronados en la ciudad de Morella. La población de derecho, según el padrón municipal de habitantes del año 2004, asciende a un total 2.911 individuos (1.465 mujeres y 1.446 hombres), de los cuales se seleccionaron los ciudadanos comprendidos en un intervalo de edad entre 18 y 65 años por considerarse el colectivo que podía proporcionar la información más adecuada que se necesita para la investigación. Este intervalo de edad coincide con el de población activa y una de las variables de interés para el estudio era contratar la hipótesis de la diferencia de actitud manifestada hacia el turismo en función de si existe o no vinculación profesional con la actividad turística. 
Tabla 15 Distribución de la población de Morella por género y edad (año 2004)

\begin{tabular}{|l|l|l|l|l|l|l|}
\hline & \multicolumn{2}{l|}{ HOMBRES } & \multicolumn{2}{l|}{ MUJERES } & \multicolumn{2}{l|}{ TOTAL } \\
\hline & $\mathrm{N}^{\mathrm{o}}$ & $\%$ & $\mathrm{~N}^{\mathrm{o}}$ & $\%$ & \multicolumn{2}{l|}{} \\
\hline -Hasta 15 años & 177 & $6 \%$ & 152 & $5 \%$ & 329 & $11 \%$ \\
\hline -Entre 16 y 30 años & 314 & $11 \%$ & 267 & $9 \%$ & 581 & $20 \%$ \\
\hline -Entre 31 y 64 años & 641 & $22 \%$ & 623 & $21 \%$ & 1264 & $44 \%$ \\
\hline - Mas de 65 años & 314 & $11 \%$ & 423 & $15 \%$ & 737 & $25 \%$ \\
\hline TOTAL & 1446 & $50 \%$ & 1456 & $40 \%$ & 2911 & $100 \%$ \\
\hline
\end{tabular}

Fuente: Ayuntamiento de Morella

\subsubsection{Elaboración del cuestionario}

El cuestionario estructurado comprende once páginas divididas en cuatro bloques temáticos en función de la naturaleza de las variables y el impacto de las mismas. (Anexo II.1) En el bloque primero se han medido los impactos económicos del turismo a través de 16 preguntas, de las cuales las 9 primeras y la número 16 están relacionadas con los impactos positivos, tal y como se ha recogido en la revisión bibliográfica anterior a su diseño. Las restantes se corresponden con los impactos negativos.

El segundo bloque (preguntas 17 a la 32) está centrado en los impactos sociales del turismo de las cuales las nueve primeras están asociadas a los impactos sociales y culturales positivos mientras que de la 26 a la 32 se corresponden con los negativos. Sin embargo, la pregunta 24 no está sometida al mismo criterio impacto positivo/negativo, en el sentido que pretende recoger una toma de postura personal con respecto a la afirmación planteada en ella. La pregunta 30 ("el desarrollo turístico actual requiere de trabajadores 
extranjeros") es de transición hacia la pregunta siguiente en la que se plantea la existencia o no de conflictos de convivencia con los trabajadores inmigrantes como posible impacto negativo.

El tercer bloque recoge la percepción individual sobre la repercusión del turismo en los impactos medioambientales, midiendo los ítems 33 y 34 posibles impactos positivos y el resto, preguntas 35 a la 38 , los negativos.

El bloque cuarto (preguntas 39 a la 46) pretende evaluar el nivel de conocimiento y el grado de implicación personal de los habitantes encuestados con respecto a la gestión turística desarrollada en la localidad. La pregunta 39, es de respuesta múltiple y en ella se pide una valoración, utilizando la misma escala de todo el cuestionario, sobre cuál considera el encuestado que es el factor de atracción primordial de Morella. La última cuestión plantea también una toma de postura personal con respecto al apoyo personal otorgado al desarrollo turístico.

Finalmente, los datos estructurales de carácter socio-demográfico se han establecido sobre las siguientes variables:

- Sexo

- Edad

- Ocupación

- Relación profesional con la actividad turística

- Nivel de ingresos mensuales

- Dependencia económica de la actividad turística

- Porcentaje de dependencia

- Nivel de contacto personal con los turistas 
- Residencia habitual de más de 6 meses al año en Morella

- Tiempo de residencia

- Propiedad de la vivienda

La escala utilizada para medir la valoración de las preguntas del cuestionario ha sido una escala no comparativa de Likert. Con objeto de ganar precisión en la escala se ha utilizado una distinción semántica de 7 categorías en las que el valor (1) implica estar "totalmente en desacuerdo" y el (7) "totalmente de acuerdo" en la que es posible un punto intermedio o neutro (4) "ni de acuerdo ni en desacuerdo".

Del total de 1.000 cuestionarios enviados, se recibieron un total de 151 cuestionarios completos lo que supone una tasa de respuesta del $15 \%$ y un margen de error del 5,5\%.

\subsubsection{Análisis de los resultados}

Con objeto de sintetizar, hemos agrupado las respuestas de cada uno de los cuatro bloques de estudio iniciales (impactos económicos, impactos socioculturales, impactos medioambientales, percepción del destino y apoyo personal al turismo) en grupos que recogen conceptos similares conforme a las hipótesis sostenidas en la literatura e investigaciones precedentes sobre esta materia.

\subsection{Impactos económicos}

Los resultados de los impactos económicos se analizan por su relación a las siguientes afirmaciones: 
1.- El turismo contribuye a la creación de empleo.

2.- El turismo fomenta la actividad empresarial (en la comarca).

3.- La actividad turística contribuye al aumento y mejora en la distribución de la renta .

4.- La actividad turística puede representar un coste de oportunidad para el desarrollo económico de la región.

5.- El turismo genera un coste de dependencia y distorsiona la economía tradicional local.

6.- El turismo produce inflación en los precios de los bienes de consumo y la vivienda.

La primera constatación que podemos establecer es que existe una clara percepción, por parte de los residentes de Morella, de los impactos económicos producidos por el turismo. Siendo, en general, más conscientes de los impactos positivos que de los negativos. En este sentido, el 75,5\% de los encuestados afirma estar totalmente de acuerdo o bastante de acuerdo en que el turismo contribuye a la creación de empleo, a los que se les puede añadir un 14,6\% que están algo de acuerdo. Así pues, un $90 \%$ de la muestra confirma este efecto positivo. Existe una ligera predisposición hacia la valoración positiva más acentuada en el grupo de hombres encuestados que en el grupo de las mujeres, siendo más negativamente valorado este aspecto entre la población que percibe menores ingresos y entre los que manifiestan no depender sus ingresos del turismo; en todos los casos mencionados estas diferencias son significativas al 95\%. Los restantes criterios de comparación realizados no arrojaban diferencias significativas en esta pregunta.

Con respecto a la contribución del turismo a la actividad empresarial en la comarca las respuestas son también prácticamente unánimes (el 94,7\%) al 
reconocer la activación económica que el turismo supone para los comercios locales. La mayoría de los encuestados manifiesta estar de acuerdo en la retención local de los beneficios económicos derivados de la actividad turística a través de la titularidad de los negocios que recae en empresarios naturales de Morella o la Comarca (93\%), aunque se aprecian diferencias en esta consideración en función de si los encuestados que trabajan en turismo son empleados o trabajan en calidad de empresarios, siendo éstos últimos los que manifiestan mayor grado de desacuerdo con la afirmación, presumiblemente por el mayor grado de percepción que puedan tener de competencia externa o no natural estrictamente de la zona; este grado de variación en la concordancia de respuestas coincide, adicionalmente, con quienes manifiestan un mayor nivel de ingresos económicos.

El nivel de acuerdo, aún siendo la media sensiblemente favorable, desciende, sin embargo, en relación a la potenciación de otro tipo de industrias (agroalimentación) o manufacturas (artesanía), con un $81 \%$. Son los más jóvenes y los adultos mayores quienes manifiestan mayor grado de desacuerdo en esta cuestión. Una interpretación posible de esta variación radica en la necesidad de diversificación de actividades, manifestada fundamentalmente por parte de los jóvenes, quienes desearían poder ejercer su vocación profesional en actividades y negocios radicados en la zona. Por su parte, el colectivo de mayor edad, cuyas rentas provienen de actividades distintas al turismo, probablemente expresan con este desacuerdo su disconformidad con el declive o desaparición de actividades y sectores productivos tradicionales. Obviamente, también hay diferencias significativas en esta cuestión en función de si los encuestados trabajan o no en actividades relacionadas con el turismo. 
La contribución de la actividad turística al aumento y mejora en la distribución de la renta es vista favorablemente por un $77 \%$ de la población, especialmente en lo que se refiere a la declaración genérica de que "el turismo ha mejorado la situación económica de la comarca", puesto que el $81 \%$ manifiesta algún grado de acuerdo con esta afirmación, siendo los adultos jóvenes, empleados en algún tipo de actividad relacionada con el turismo, quienes manifiestan una mayor valoración de esta cuestión. El incremento de posibilidades que implica el turismo para que los residentes realicen negocios en la comarca es también positivamente valorada, si bien existe un cierto grado de escepticismo con un significativo $14 \%$ de residentes que se mantienen neutrales en relación a esta cuestión. Las mayores diferencias apreciables con respecto a la percepción del aumento y mejora en la distribución de la renta están relacionadas con el nivel de ingresos de los grupos encuestados, siendo el segmento que percibe ingresos situados en torno a los $2.500 €$ mensuales (5,5 veces el salario mínimo interprofesional) los más satisfechos con la situación.

En relación a los impactos económicos negativos, la percepción del coste de oportunidad presenta, por primera vez, una notable discrepancia entre la población. Mientras que un 36\% de la población manifiesta algún grado de desacuerdo con la afirmación de que la inversión pública destinada a turismo podía haberse dedicado a otros sectores económicos, un 43,7\% apoya esta aseveración, mientras que un $27 \%$ se mantiene neutral al respecto. En el análisis del factor "vinculación profesional" con el turismo es donde los resultados presentan diferencias más significativas. Aquellos que reconocen su vinculación con el turismo tienden a mantenerse neutrales o estar algo en desacuerdo con la afirmación (3,39 de media en la escala de respuestas) mientras que los que no tienen vinculación profesional con el turismo tienden 
a valorar afirmativamente este aspecto, oscilando en torno a un 4,58 de media, esta diferencia es significativa al 95\%. Sin embargo, dentro del colectivo de profesionales turísticos, son los empleados quienes más apoyan la inversión realizada en turismo, mientras que la media de empresarios que consideran un uso alternativo de los fondos públicos se aproxima al 5 (bastante de acuerdo). Esta situación puede explicarse por la opinión de aquellos empresarios para los que el turismo no constituye su fuente de ingresos principal o consideran que les afecta indirectamente.

El coste de dependencia de la actividad turística en relación a la economía tradicional local es vista de la siguiente manera por los morellanos: un 66,2\% de la población afirma que la economía de la comarca no podría mantenerse sin el turismo, frente a un $20 \%$ que discrepa en alguna medida. En estos dos grupos no se aprecian diferencias entre los sexos pero sí en la edad. La dependencia es percibida en mayor medida por los adultos jóvenes, entre 36 y 50 años, que por los de menos y más edad. También por los que manifiestan percibir menores ingresos, siendo indiferente su vinculación profesional con el turismo.

Un amplio porcentaje de la población (el 77\%) considera que el turismo es una buena alternativa a las actividades agrícola y ganadera, si bien un 52,3\% considera que no son actividades excluyentes o, al menos, que el turismo no perjudica al sector primario. Por otra parte, un $23 \%$ manifiesta su disconformidad y un $22 \%$ de la población se mantiene neutral en su valoración. Las diferencias más significativas en las respuestas en relación al posible perjuicio que el turismo causa a las actividades tradicionales se muestra entre los empresarios vinculados a la actividad turística, quienes se inclinan a no considerar este impacto económico o al menos no considerarlo negativamente. 
Esta situación concuerda con el grupo que manifiesta percibir ingresos más elevados, aunque también con aquellos cuyos ingresos se sitúan en torno al salario mínimo profesional.

Los impactos económicos negativos tradicionales que el turismo produce son la subida en los precios de los bienes de consumo como consecuencia tanto de la estacionalidad de la demanda turística como de la necesidad de importar bienes que satisfagan las exigencias de los turistas. Por otra parte, el efecto compra de segunda residencia en las localidades turísticas lleva parejo un incremento del precio de la vivienda, como se ha puesto de manifiesto en los estudios realizados en la Comunidad Valenciana. Estos efectos no son ajenos a la población de Morella, quienes opinan categóricamente que los precios de los bienes de consumo son más elevados a causa del turismo (90\%), así como el precio de la vivienda $(80,8 \%)$ y, en menor medida, los impuestos locales $(57,7 \%)$. Con respecto a las diferencias entre grupos, el perfil más discrepante en relación a la inflación debida al turismo, especialmente la relativa a los bienes de consumo, se manifiesta entre los adultos de mayor edad (entre 51 y 65 años), y aquellos cuyos ingresos dependen total o mayoritariamente del turismo. Por otra parte, quienes culpan al turismo de la inflación son aquellos que manifiestan no estar vinculados a la actividad turística. Sin embargo, respecto al precio de la vivienda no se aprecian diferencias significativas en aspectos tales como edad o nivel de ingresos, posiblemente porque el $88 \%$ de los residentes encuestados manifiestan ser propietarios de su vivienda, frente a un $6 \%$ que no lo son. 


\subsection{Impactos sociales}

Los resultados de los impactos sociales se han estudiado en función de las siguientes afirmaciones:

\section{A. Impactos positivos}

1. Como consecuencia del turismo se mejoran las instalaciones y servicios de uso público en los destinos turísticos.

2. El turismo contribuye a la preservación y rehabilitación del patrimonio histórico.

3. El turismo fomenta la revitalización de las costumbres locales.

4. el turismo enriquece la vida cultural y social del destino.

5. La actividad turística contribuye al aumento de la población.

B. Impactos negativos

1. Como consecuencia del uso comercial de las tradiciones y símbolos culturales se produce una perversión de la identidad cultural. 2. La actividad turística genera conflictos y tensión entre los miembros de la comunidad.

3. El desarrollo del turismo contribuye a la creación de efectos colaterales no deseados.

Al contrario que los impactos económicos, los impactos sociales y culturales del turismo no son unánimemente percibidos por la población de la ciudad de Morella, ni en la misma medida entre los distintos segmentos de edad. En este sentido, las respuestas presentan un alto grado de dispersión, oscilando en todos los grados de la escala. 
En general, existe un mayor grado de consenso con respecto a los efectos culturales positivos (preservación y rehabilitación del patrimonio histórico), con el que está de acuerdo el $83 \%$, enriquecimiento de la vida cultural y social, con un consenso del $67 \%$, que hacia los efectos sociales, especialmente en relación a la afirmación de que, como consecuencia de la actividad turística, se mejoran las instalaciones y servicios de uso público en el destino turístico, estando en este caso en desacuerdo el $71 \%$ de la población.

La variable sexo no presenta diferencias significativas en las respuestas a las preguntas de este bloque de impactos socio-culturales. La variable edad, por el contrario, sí es significativa en relación a la menor valoración que efectúa, en general, el segmento de población más joven (hasta 35 años) en comparación a la media del resto de adultos. En este sentido, tienen peor opinión sobre los servicios públicos de la localidad, sobre el incremento de la población y sobre la afirmación de que el turismo favorece el mantenimiento de las tradiciones autóctonas.

Solamente un $18 \%$ de la población encuestada considera que el turismo ha generado una mayor unión entre los miembros de la comunidad; el 39\% está en desacuerdo, por lo que reconocen, en todo caso, que la actividad no ha producido una cohesión entre los miembros de la comunidad. Un alto porcentaje (43\%) se abstiene de pronunciarse en un sentido u otro. Las diferencias significativas se aprecian entre los adultos maduro, entre, 51 y 65 años, quienes manifiestan mayor grado de disconformidad con la afirmación de partida y, entre los que reconocen una dependencia económica directa con la actividad turística, está mejor valorada la situación por los empleados que por los empresarios. 
En la pregunta abierta que plantea, a la inversa, si el turismo ha generado conflicto entre los residentes en Morella, el 59\% considera que no se ha generado conflicto (un 30\% está totalmente en desacuerdo con esta afirmación), se recoge un discreto porcentaje de no pronunciamiento (20\%) y un $12 \%$ confirma la situación de conflicto entre los residentes, siendo, de nuevo, el grupo que manifiesta desarrollar una actividad empresarial quienes representan unas medias elevadas $(5,56)$ con respecto a la confirmación de las desavenencias internas.

A la vista de estos datos podemos concluir, por tanto, que si bien la actividad turística en Morella, en el estado de desarrollo actual, no genera conflictos percibidos al menos por la mayoría de los ciudadanos, tampoco es una actividad que haya favorecido la cohesión social.

Si se traslada el ámbito del posible conflicto al plano residente-turista, los resultados ofrecen la siguiente valoración: algo más de la mitad de la población considera que no existe tal conflicto, mientras que un $32 \%$ manifiesta algún grado de desavenencia (un $12 \%$ abiertamente reconoce la existencia de conflicto turista-residente) mientras que un $20 \%$ se mantiene indiferente. Con respecto a la pregunta "personalmente me agrada la presencia de turistas en Morella", la amplia mayoría de la población (64\%) se manifiesta positivamente, mientras se mantiene el grupo de oponentes en torno al $11 \%$, creciendo el porcentaje de indiferentes $(25 \%)$ con respecto a la pregunta anterior. En este punto, las diferencias más significativas se encuentran entre el segmento que manifiesta tener una relación profesional con la actividad turística con respecto al que no la tiene y, en mayor medida, en aquellos cuya dependencia económica del turismo es absoluta. 
La necesidad de incorporar trabajadores inmigrantes a la actividad hostelera, es reconocida por el $78 \%$ de la población. La percepción de que esta situación sea socialmente conflictiva es apoyada por el $32 \%$ de la población, con un $21 \%$ de indiferentes. No existen diferencias importantes entre grupos en este punto salvo en la valoración en función de la variable empleado/empresario turístico en la que son éstos últimos los que manifiestan un mayor grado de acuerdo con la conflictividad social derivada de la incorporación de trabajadores extranjeros.

Prácticamente la mitad de la población no considera que la seguridad en Morella se haya visto afectada por la actividad turística, frente a un 32\% que considera que sí lo ha sido. En este punto no hay diferencias significativas entre los distintos segmentos de población que hemos considerado.

\subsection{Impactos medioambientales}

El análisis de los impactos ambientales los hemos realizado en torno a dos cuestiones fundamentales:

1. El sostenimiento de la actividad turística requiere la preservación del medio natural como fuente de ventaja comparativa, por lo que aumenta la sensibilidad de los gestores del destino hacia la mejora del entorno urbano común (parques y jardines) y hacia la preservación del paisaje natural.

2. Los límites al desarrollo turístico vienen determinados por la capacidad de carga que puede soportar un destino turístico. La capacidad de carga es un elemento cualitativo derivado de la 
percepción que tienen turistas y residentes de las consecuencias que produce la saturación humana (contaminación visual, acústica y medioambiental).

Las preguntas que sustentan las afirmaciones anteriores reflejan que la percepción de la población de Morella se alinea en torno a dos factores que coinciden con las afirmaciones sobre impactos positivos y negativos del turismo sobre el medio ambiente, en el que los van referidos a las preguntas 33 y 34 de la encuesta y los segundos con las preguntas 35, 37 y 38 . La pregunta 36, planteada para evaluar el grado de saturación percibido, se alinea, sin embargo, en el ámbito de los impactos positivos. Esta situación se explica por dos motivos:

En primer lugar porque Morella no ha alcanzado un estado de desarrollo turístico equiparable al de un destino turístico maduro o consolidado por lo que aún no se ha alcanzado el estadio de rechazo o irritación manifestado por Doxey (1975).

En segundo lugar, el principal problema al que se enfrentan estas comarcas del interior es, precisamente, al abandono de la agricultura y ganadería como sistemas económicos tradicionales, habiéndose producido una emigración acusada en años anteriores, con la consecuente pérdida de población. Sin embargo, la tendencia actual es hacia el crecimiento. Tal y como se ha manifestado anteriormente, la causa principal de esta estabilización se debe, indudablemente, a la alternativa que el turismo ha representado para el sector primario. Por tanto, para la población, la vida que representa la actividad que producen las personas visitantes de la zona, lejos de ser un inconveniente, es percibido con cierta satisfacción. Esta situación se corrobora con las 
respuestas otorgadas a las preguntas 20, 22 y 24 del bloque socio-cultural.

En relación al balance entre los impactos positivos y negativos que el turismo produce sobre el medio ambiente, los resultados están bastante equilibrados, con una cierta inclinación hacia una mejor percepción de los positivos $(47,7 \%)$ sobre los negativos $(40,5 \%)$.

El impacto positivo mejor valorado por la población se refiere a la contribución realizada por los gestores públicos a la mejora de las infraestructuras locales en parques y jardines como consecuencia de la activación del turismo (un $63 \%$ de la población manifiesta algún grado de acuerdo, de los cuales un 38,5 lo manifiestan con mayor énfasis (bastante o totalmente de acuerdo).

Por otra parte, un impacto que suele alinearse en el ámbito de los negativos, especialmente cuando se hace referencia a los modelos turísticos basados en la utilización de los recursos sol y playa, es la polución visual. Los impactos que son producidos por la construcción de apartamentos, hoteles y segundas residencias para uso turístico y que, como es notorio, implican habitualmente la construcción de una muralla artificial de bloques (ladrillos) en paralelo a la primera línea de costa así como el consumo progresivo de recursos naturales para la construcción en torno a un núcleo determinado. Cuando se hace referencia al ámbito municipal de Morella, los resultados se invierten en el sentido de ser muy apreciado por la población (57\%) la integración en el paisaje lograda por las infraestructuras que dan soporte a la industria turística. Son las frecuencias absolutas de los extremos las que producen mayor diferencia entre los que manifiestan el total desacuerdo con que exista polución visual (26\%) y los que manifiestan que sí se produce $(5 \%)$. 
Con respecto a la saturación de la capacidad de carga de la localidad de la que se ha hecho mención anteriormente, no se manifiesta una clara percepción negativa, como suele ser habitual en estudios de este tipo. Al contrario, llama la atención que la situación está bastante equilibrada inclinándose a favor de quienes consideran que no se ha llegado o al menos no se ha superado la barrera de desarrollo turístico (el $44 \%$ ) frente a quienes sí manifiestan algún grado de acuerdo con la saturación (38 \%) por lo que se requerirá un considerable esfuerzo de coordinación por parte de los gestores públicos y privados en el debate sobre el modelo de desarrollo deseado con objeto de que estos términos favorables no se inviertan.

Finalmente, el mayor problema percibido y no resuelto, debido probablemente a la situación geográfica de la zona y a la particular orografía del terreno, se plantea con respecto al tráfico. El 58\% de los residentes manifiesta algún grado de acuerdo con la afirmación de que el turismo provoca congestión de tráfico en Morella, de los cuales un $48 \%$ están totalmente de acuerdo frente a sólo un $13 \%$ que no lo está en absoluto.

Relacionado con este bloque de cuestiones medioambientales no se aprecian diferencias significativas en las respuestas con respecto a los factores sexo, edad y contacto personal con los turistas de los encuestados. Sí hay diferencias muy significativas, por ejemplo, con respecto a la percepción del problema de congestión del tráfico que tienen el grupo de estudiantes frente a quienes manifiestan ser amas/os de casa.

Las personas que declaran trabajar en el sector tienden a valorar mejor los impactos positivos del turismo en el medio ambiente que quien manifiesta no trabajar en el mismo y, a la inversa, aquellos cuya ocupación no depende 
del turismo tienden a considerar en mayor medida los impactos negativos. Tendencia ésta más acusada en la medida que los ingresos personales dependen en su totalidad del turismo que cuando no dependen o lo hacen indirectamente.

\subsubsection{Percepción de Morella como destino turístico por sus residentes}

El último bloque de encuesta tiene por objeto medir la imagen cualitativa que tienen de Morella sus propios habitantes en lo que respecta a su vertiente de destino turístico. En este sentido, se ha efectuado un tratamiento diferenciado de la pregunta 39 con respecto al resto del bloque (preguntas 40 a la 46), dado que se ha querido delimitar, de entre los distintos recursos y productos relevantes de la zona, aquellos que se consideran que representan un valor diferencial y que pueden actuar como factores de atracción de la demanda hacia la zona. El contraste de las respuestas ofrecidas en esta pregunta con una pregunta idéntica planteada en un cuestionario dirigido a la demanda actual o potencial de la zona, arrojaría información de interés sobre cuál es el posicionamiento del destino en el mercado y de si esta idea coincide entre oferentes y demandantes del producto, conclusión que arrojaría información relevante tanto para el tratamiento de la imagen de marca, como para el desarrollo de productos.

Del análisis factorial de las respuestas a esta pregunta se desprende la percepción de tres tipologías de productos en el destino: 
a) Morella destino cultural, en el cual el interés principal es recorrer el patrimonio histórico-artístico y compartir la historia, tradiciones y cultura.

b) Morella destino de naturaleza, cuyo principal componente es el disfrutar del entorno y el interés que despierta el patrimonio paleontológico de la zona.

c) Morella destino de consumo hedónico, donde el ocio combinado con la compra y consumo de productos locales (artesanía, gastronomía) sería el mayor exponente.

Las medias obtenidas para estos productos han sido respectivamente:

1.- Turismo cultural (valoración media sobre siete de 5,5).

2.- Turismo hedónico (valoración media sobre siete de 4,6).

3.- Turismo de naturaleza (valoración media sobre siete de 3,99).

Las variaciones más significativas en las respuestas a esta pregunta con respecto a segmentos de población se producen en las siguientes variables: las mujeres tienden a valorar ligeramente mejor que los hombres la importancia que otorgan al patrimonio paleontológico y la compra de productos agroalimentarios y bastante más que éstos a la compra de artesanía.

Por grupos de edad, la diferencia más significativa se encuentra en la valoración superior que ofrecen los adultos entre 36 y 50 años del patrimonio paleontológico y de la artesanía con respecto al valor del resto de grupos. 
El segmento que manifiesta no depender sus ingresos en absoluto del turismo es quien peor valora la degustación de la gastronomía de la zona como factor de atracción turística con respecto al resto de los grupos. Para el resto de variables clasificatorias consideradas no se aprecian diferencias significativas con las medias del conjunto de la población encuestada.

En relación al resto del bloque (preguntas 40 a la 46), el análisis factorial arroja dos grupos diferenciados de preguntas con respuestas relacionadas:

El primer grupo recoge el apoyo personal al desarrollo turístico de Morella y Comarca, conjuntamente con la consideración de Morella como destino turístico alternativo al modelo de sol y playa y con la necesidad de promocionar Morella a nivel internacional.

El segundo grupo relaciona las preguntas de gestión turística: "la actividad turística está correctamente gestionada", "personalmente estoy informado/a de los nuevos proyectos e inversiones turísticas que se realizan en la comarca", "considero que Morella es muy conocida en toda España" conjuntamente con la pregunta que mide la consideración de Morella, no como destino alternativo, sino complementario al modelo de sol y playa desplegado en la costa cercana (triángulo Vinaroz-Peñiscola-Morella).

Prácticamente el $80 \%$ de los encuestados consideran que Morella es muy conocida a nivel nacional y un $73 \%$ considera que debería promocionarse a nivel internacional (de éstos un 35\% manifiesta estar totalmente de acuerdo con la necesidad frente a un $5 \%$ que no lo está en absoluto).

La valoración de la gestión turística realizada en Morella arroja los siguientes 
resultados distribuidos en tres grupos bastante homogéneos: un 39\% valora muy positivamente la gestión realizada, frente a un $27 \%$ que no está de acuerdo y un $31 \%$ que se mantiene neutral. Relacionamos esta pregunta con la percepción de control de la información disponible sobre el desarrollo turístico futuro del municipio y la zona y, prácticamente el $52 \%$ de los residentes no consideró que estuvieran informados sobre los nuevos proyectos e inversiones turísticas, mientras que un $28 \%$ manifestaron algún grado de acuerdo con la afirmación, de los que un 5\% están totalmente de acuerdo en el sentido de que disponen de dicha información.

A la pregunta ¿es Morella un destino complementario de la costa (Peñíscola) o por el contrario tiene identidad como destino alternativo? Los residentes se manifiestan a favor de las dos posturas: como destino alternativo lo valora un $80 \%$ de los encuestados y como complementario un $61 \%$. Estas respuestas, que no están enfrentadas, se explican fundamentalmente en razón del volumen de visitantes de un día y de paso (desde o hacia su lugar de origen) que desde la costa recibe anualmente Morella por una parte, y, por otra, en la medida que ha ido aumentando la oferta de plazas de alojamiento turístico disponible, ha aumentado también el volumen de turistas que, en distintas épocas del año, elige Morella como destino por sí mismo.

Los grupos categóricos considerados no introducen diferencias significativas, salvo casos poco concluyentes como es el del grupo más joven (entre 18 y 35 años) que tiende a valorar en menor grado la dependencia que tenga Morella del desarrollo turístico de la costa.

Asimismo, son quienes manifiestan tanto una relación directa con la actividad turística como una dependencia económica total los que, naturalmente, más 
firmemente apoyan el desarrollo turístico de la zona con medias muy próximas a la máxima puntuación, así como la necesidad de promocionar Morella a nivel internacional.

Finalmente, el apoyo expreso al desarrollo turístico de Morella y de la Comarca ha sido manifestado por el $75 \%$ de la población, de los que, para un $42,5 \%$ es un apoyo total, frente a un $5 \%$ que no lo apoya en absoluto, y un $32,5 \%$ en algún grado de acuerdo. 

CAPÍTULO 4

MODELO PARA LA GESTIÓN COMPETITIVA DE LOS DESTINOS TURÍSTICOS DE INTERIOR 



\subsection{Introducción}

En el capítulo primero de esta investigación se ha anticipado que el término "competitividad turística" viene siendo profusamente utilizado como referente para la consecución del objetivo final al que debe tender toda gestión profesional, bien sea en el ámbito de las organizaciones públicas con competencias en el diseño, aplicación y control de las políticas y estrategias turísticas, bien en el ámbito de las organizaciones privadas que buscan una rentabilidad creciente en el desempeño de su actividad comercial.

Igualmente, se ha hecho referencia a la convergencia que parece existir, desde distintos modelos sobre competitividad de destinos turísticos, hacia la consideración de que para el logro de una posición competitiva óptima no es suficiente con disponer de una serie de recursos y atractivos iniciales. Aunque estos recursos de partida son fuentes de ventajas comparativas la obtención de esa posición estará estrechamente vinculada a la capacidad que tengan sus gestores, públicos y privados, de controlar estos activos que son valiosos, escasos, difíciles de imitar y sustituir e imperfectamente móviles (Melián y García, 2003), logrando así conseguir ventajas derivadas de su habilidad como gestores, es decir, ventajas competitivas.

A partir de esta premisa, el dilema a resolver se podría resumir en la siguiente cuestión: si sabemos que la gestión tiene cada vez un mayor peso en el logro de la competitividad de los destinos turísticos, ¿sobre qué variables debe actuarse prioritariamente para conseguir ese objetivo? o, en sentido contrario, ¿qué variables de la gestión no pueden descuidarse por parte de los gestores de un destino que desee lograr un desarrollo turístico competitivo y sostenible? 
La cuestión no está resuelta en los estudios e investigaciones analizados. No existe, por tanto, consenso respecto a cuáles son las variables que, adecuadamente gestionadas, actuarán eficazmente en el logro de la posición competitiva deseada. Ahora bien, los términos eficiencia, calidad, innovación, posicionamiento, liderazgo, productividad aparecen de manera reiterada, aunque dispersa, a lo largo de la literatura científica revisada. En este sentido, consideramos que debían ser, inicialmente, la eficiencia, la calidad, la innovación y el posicionamiento estratégico las variables que han de ser adecuadamente gestionadas en un destino turístico. En este capítulo vamos a determinar qué contenido soportan, o deben soportar, estas variables.

\subsection{Dimensiones para la competitividad turística}

Entendemos por Dimensión cada una de las magnitudes que definen la gestión competitiva de un destino turístico, pudiéndose disgregar en unidades simples que permiten un mayor análisis e información, favoreciendo con ello su medición.

\subsubsection{Eficiencia}

La eficiencia aparece tradicionalmente vinculada a cualquier éxito organizacional o empresarial. De hecho, y desde el punto de vista de la teoría económica, la ausencia de eficiencia supondría simplemente la salida de la empresa u organización del mercado en el que compite. Esa posición, teóricamente central, en el desarrollo de la actividad de las organizaciones y la asunción de las consecuencia de su falta, condujo a no prestar excesiva atención a su significado real y, por supuesto, a su medición. De hecho, hasta la segunda mitad del siglo XX, no se desarrollan procedimientos específicos para su medición, tras un período de clasificación conceptual. 
Hasta entonces se habían utilizado medidas como la productividad que, admitida la presencia de la eficiencia, podríamos considerar como adecuada para realizar análisis comparativos entre empresas (Álvarez, 2001).

Productividad no es lo mismo que eficiencia como eficiencia no es lo mismo que competitividad. Sin embargo, no siendo sinónimos, ni siendo la competitividad la consecuencia inmediata de la eficiencia, podemos afirmar que la competitividad engloba ambos conceptos el de eficiencia y el de productividad (Álvarez, 2001).

Así, si productividad hace referencia exclusivamente al proceso productivo con objeto de obtener números índices que permitan comparar los costes de producción con los resultados, la eficiencia, a su vez, viene referida a la maximización de beneficios con los mínimos costes posibles. Pero este hecho, por sí mismo, no explica la competitividad puesto que empresas, sectores o países igualmente eficientes, pueden obtener distinto nivel de beneficios mediante la estrategia de diferenciación que permite introducir incrementos en el precio de venta del producto o resultado final (Krugman, 1994).

La ventaja en costes está muy relacionada con la eficiencia productiva puesto que para reducir los costes se debe actuar sobre todas las fuentes de ineficiencia. (técnica, asignativa de escala); el control de la eficiencia se convierte así en el primer objetivo operativo, mientras que, en la estrategia de diferenciación, lo importante es ofrecer un producto de calidad que satisfaga las necesidades del cliente mejor que lo hace el de la competencia, eso sí, a un coste razonable.

En consecuencia, la relación entre eficiencia productiva y competitividad 
tendrá un diferente nivel de importancia según sea la estrategia adoptada por la organización de tal modo que, en los supuestos de adopción de una estrategia basada en liderazgo en costes, el papel de la eficiencia será fundamental, mientras que en los supuestos de adopción de estrategias de diferenciación o especialización serán menos importantes sin que ello implique que no deban ser consideradas.

No quisiéramos detenernos, en este estadio de la investigación, en la discusión de este planteamiento, si bien nos parece oportuno llevar a cabo algunas breves consideraciones que reflejen adecuadamente cuál es el enfoque que proponemos para el análisis de la eficiencia.

\subsubsection{Medición de la eficiencia}

La primera consideración a realizar es la que pone de manifiesto que la medición de la eficiencia nace de la comparación entre lo que hace la organización y lo que debería haber hecho, de tal modo que se introduce la idea de un estándar u óptimo eficiente que actúa como horizonte. El problema reside en la determinación de cuál ha de ser ese óptimo, especialmente en los casos en que no toda la información está disponible.

Efectivamente, tal y como ya hemos puesto de manifiesto anteriormente, es muy difícil lograr la totalidad de datos necesarios para poder medir el grado de eficiencia interno $\mathrm{y}$, en caso de obtenerlos, realizar el análisis correspondiente para establecer los nuevos parámetros de futuro que, difícilmente, se mantendrán estables en entornos dinámicos y complejos.

El origen de los estudios en este campo se encuentra en los trabajos realizados 
por Farell (1957) quien, basándose en trabajos previos de Debreu (1951) y Koopmans (1951) introdujo el concepto de eficiencia relativa basada en la comparación de las actuaciones de una organización con las de las mejores empresas de su ámbito. De esta manera, surge el concepto de frontera o estándar que identifica el umbral óptimo de eficiencia a través de los índices obtenidos por las mejores empresas consideradas. Farell desarrolló el modelo matemático de obtención de esos índices de referencia separando el componente técnico (máximo output posible con la combinación de inputs empleada) y el componente asignativo (combinación de inputs en tal proporción que minimiza los costes de producción). La eficiencia técnica requiere un adecuado aprovechamiento de los recursos mientras que la eficiencia asignativa exige la elección del proceso productivo más económico, combinando los factores en las proporciones más adecuadas en función de sus productividades y de sus precios.

Una empresa será eficiente cuando lo sea desde la doble perspectiva técnica y asignativa, por lo que la eficiencia total es igual al producto de ambos. No obstante, la eficiencia asignativa pierde virtualidad bajo condiciones de incertidumbre sobre los precios de los factores de producción.

En relación a qué aspecto debe guiar la dirección de la eficiencia técnica, cuestión que está directamente relacionada con el tipo de empresa de que se trate y partiendo que toda empresa situada en la función frontera es técnicamente eficiente, existen dos formas básicas de medir esta eficiencia: las que se orientan al input y las que se orientan al output, siendo las primeras las que centran su estudio en el análisis del ratio de los inputs necesarios para producir un determinado nivel de output sobre los inputs empleados, mientras que las segundas calculan el cociente entre la producción real y la 
potencial. Por tanto, una organización con un coeficiente de eficiencia de uno indica que su comportamiento no se ve mejorado por otra. Una eficiencia menor de uno o mayor a uno, según el enfoque adoptado, indicará el grado de ineficiencia. Así, en un enfoque hacia los inputs, una eficiencia de 0,85 indicaría que se debe reducir el consumo de inputs en un $15 \%$ para ser eficiente, mientras que si es un enfoque orientado hacia los outputs un nivel de eficiencia de 1,20 implica que se deben aumentar los resultados un $20 \%$ para ser eficiente. La identificación equivalente entre ambos sistemas de medición de eficiencia productiva sólo puede tener lugar cuando la función de producción tiene rendimientos constantes a escala (Färe y Novell, 1978).

El concepto de frontera establece la relación entre el análisis empírico de la producción y la teoría económica, ya que las funciones de producción, coste y beneficio, son funciones frontera (Álvarez, 2001). Se pueden distinguir dos líneas de trabajo en este campo: las fonteras determinísticas y las fronteras estocásticas.

La primera de ellas, conocidas como fronteras determinísticas y reflejadas en los trabajos iniciales de Farell, atribuyen toda la desviación de la frontera a la ineficiencia técnica. Una función de producción frontera determinística puede expresarse como:

$\mathrm{Y}=f(\mathrm{x})-\mathrm{u}$

Donde y es el output, $\mathrm{x}$ es un vector de inputs y f es una función de producción en la que u es una perturbación aleatoria mayor o igual que cero que mide la distancia de cada empresa a la frontera de producción. Estas fronteras determinísticas al suponer que la distancia a la frontera es totalmente atribuible a la ineficiencia de la empresa, no tienen en cuenta que las empresas pueden ser afectadas por agentes externos, fuera de su ámbito de control, que no 
inciden de igual manera en todas las las organizaciones y que pueden actuar sobre el natural desempeño de su proceso productivo.

La formulación de las fronteras de producción estocástica aparecen por primera vez a finales de los años setenta en artículos de Aigner, Lovell y Sschmidt (1977) y fueron perfeccionados por Jondrow et al. (1982), quienes encontraron una medida de la eficiencia individual de las empresas en lugar de la eficiencia media de la muestra de los trabajos precedentes. Las fronteras estocásticas parten de la premisa de que los niveles productivos están limitados por la aparición de componentes aleatorios, no controlables por la empresa y que deben ser considerados para una correcta evaluación de la distancia a la frontera. La producción puede, modelizarse de la siguiente forma: $Y=f(x)+\varepsilon, \varepsilon=v-u$

Donde la perturbación aleatoria $v$ (sucesos, como el clima, no controlables por la empresa) es un término de error simétrico que se supone idéntica e independientemente distribuido con media 0 . El término de error $u$ se supone que es no negativo y que se distribuye independientemente de $v$ siguiendo una distribución de una cola. Así, $u$ recoge la distancia de cada empresa a su frontera estocástica, representando una medida de su ineficiencia técnica.

El cálculo de los índices de eficiencia necesita que se estime previamente la frontera de referencia. En este punto hay dos aproximaciones distintas: la paramétrica (programación matemática o técnicas econométricas) y la no paramétrica como es el modelo conocido como Análisis Envolvente de Datos (DEA) (Charnes, Cooper y Rhodes, 1978), cuya aplicación, en la actualidad, se ha generalizado. 


\subsubsection{Interpretación de los índices de eficiencia técnica.}

La cuestión central que surge de la comparación entre diferentes organizaciones es cómo justificar la existencia de empresas más eficientes que otras, siendo la explicación más utilizada la que establece una relación directa entre la eficiencia, o ineficiencia, con la capacidad de sus gestores (educación, experiencia, edad) pero la capacidad explicativa de estas variables es muy pequeña lo que indica que la cuantificación de el input gestión es bastante más complejo (Álvarez, 2001).

En el campo de la interpretación sobre las causa u origen de la ineficiencia técnica, los primeros estudios sobre la materia establecen que la eficiencia técnica depende del "conocimiento técnico, el esfuerzo y la suerte" (Marshack y Andrews, 1944), mientras que por su parte otros autores como Farell consideran que "la eficiencia técnica de una empresa debe reflejar la calidad de sus inputs", o introducen conceptos relacionados con el de eficiencia técnica, como es el caso de Leibenstein (1966) habla de "Ineficiencia X" haciendo referencia a los factores que están en la base de que determinadas empresas no logren alcanzar los niveles máximos de producción posible. En este sentido, las causas de que las organizaciones produzcan cantidades inferiores a las tecnológicamente posibles se encuentra en el comportamiento de los propios individuos que forman parte de la unidad productiva, quienes pueden limitar su esfuerzo o utilizar un mayor número de factores de producción que los estrictamente necesarios.

Por su parte, dentro del grupo de autores que "niegan la mayor", esto es, que no consideran válido el concepto de eficiencia técnica, podemos mencionar a Stigler (1976), para quien no es posible hablar de eficiencia técnica puesto 
que toda ineficiencia es asignativa e, incluso, niega el concepto de ineficiencia basándose en que no se puede conocer con precisión si la empresa objeto de estudio está maximizando beneficios o, por el contrario las razones que justificarían esa ineficiencia pueden ser debidos a elementos que no son conocidos en el proceso de investigación de la empresa en cuestión ( Forsund, Lovell y Schmidt (1980) .

La cuestión que subyace en el estudio de esta materia durante los últimos años se centra, fundamentalmente, en el análisis de los índices que permiten identificar la ineficiencia, pero lo cierto es que esta cuestión sólo permite actuar como elemento de alarma para el gestor de la empresa, de tal modo que le permite darse cuenta de que algo se está haciendo mal, pero ello no le da respuesta a la cuestión de qué se está haciendo mal, o cómo mejorar esa ineficiencia.

Efectivamente, la cuestión de la eficiencia debe ser planteada desde este ángulo de aproximación, adentrándose en el conocimiento de qué es lo que hacen las empresas, lo que producen y lo que consumen, es decir, un análisis cuantitativo de la cuestión, pero que debe incorporar, igualmente, un segundo ángulo complementario que permita conocer cómo lo hacen, es decir, una visión más cualitativa de la eficiencia, permitiendo poner en relación ambos aspectos. De otro modo, será imposible establecer modelos de gestión que sean realmente operativos.

\subsubsection{Eficiencia y sector público}

Uno de los elementos que caracterizan la actuación pública es que debe ser eficiente y eficaz (Musgrave y Musgrave, 1992), aunque el problema se 
plantea a la hora de definir cuál es el sistema más adecuado que permita el análisis y evaluación de las actuaciones que lleva a cabo la administración, máxime teniendo en cuenta las características que le son propias y le alejan de las reglas del mercado privado de producción de bienes y servicios.

Los ámbitos de actuación del sistema público que han despertado mayor interés en la literatura económica son los relativos a la eficiencia en los sistemas de recaudación, fundamentalmente en la limitación del exceso de gravamen (Pigou, 1928; Diamond y Mirrlees, 1971; Harberger, 1974; Feldstein, 1976; King, 1983; Auerbach, 1985) y en la eficiencia aplicada a la ordenación (Wiseman, 1990). Un sistema fiscal es eficiente cuando la asignación de recursos a que da lugar constituye un óptimo de Pareto. Un impuesto es óptimo si resulta admisible y no existe ningún otro impuesto admisible que sea Pareto-superior a él, es decir, un impuesto es Paretosuperior a otro si y sólo si da lugar a un exceso de gravamen menor, pero un impuesto será eficiente si y sólo si su exceso de gravamen es nulo. En el ámbito de la eficiencia de las normas, el debate es más ideológico que empírico. Así, frente al enfoque que plantea como criterio a aplicar el de Pareto, según el cual la oportunidad de emprender una acción pública debe medirse en función de valoraciones utilitaristas individuales, se encuentra el planteamiento denominado Wicksell-eficiente, según el cual una norma es eficiente en tanto ningún ciudadano se manifieste en contra.

Cuando se trata de medir la eficiencia de una unidad de gestión dentro de una organización pública o de ésta con otras organizaciones, el problema radica en los criterios de selección tanto de las organizaciones que representan las mejores prácticas, como de elección de los inputs y outputs que se utilizarán para la medición. Ello es debido a algunas de las características 
inherentes a la oferta de servicios públicos, que son las que introducen estas limitaciones en el estudio (Pedraja et al., 2001):

- Ausencia o escasa presencia del mercado (Downs, 1957; Niskanen, 1971; Wolf, 1979,1987 y 1988). El output público no se vende en el mercado, no tiene precio. Esta ausencia impide la cuantificación del mismo, dificultando su medición y, consecuentemente, su seguimiento y control.

- Carácter monopolístico de la producción. El carácter monopolístico de las organizaciones públicas libera de la presión competitiva que sanea el sector privado, propiciando el desarrollo de comportamientos eficientes frente a la amenaza de la quiebra de la organización, por lo que tanto el control externo de la institución como los mecanismos internos de adaptación son, si se producen, excesivamente lentos y costosos.

- Multiplicidad de criterios. Debido a la naturaleza de la función pública, la eficiencia puede no ser, necesariamente, el objetivo principal a alcanzar teniendo igual o más fuerza la equidad o la redistribución de la riqueza.

Teniendo en cuenta estas características es preciso encontrar el ámbito que permita el análisis empírico sin que los resultados resulten distorsionados por interferencias justificadas por razones de oportunidad social o política, situación que conduce al planteamiento sobre cuál ha de ser la técnica de medición más conveniente para el análisis de datos de los servicios públicos. Pedraja et al. (2001) consideran que no existe un tipo de aproximación que, 
en abstracto, resulte óptima. Serán las propias características del sector analizado, así como las restricciones de la información las que determinen cuál es la técnica de análisis que se revele como más apropiada. En cualquier caso, para estos autores, el método elegido debería cumplir las siguientes premisas:

a) Las técnicas utilizadas deberían ser aproximaciones de tipo frontera, en en las cuales la frontera de producción viene determinada por las mejores prácticas observadas, siempre y cuando la comparación sea homogénea entre unidades que actúan en un mismo mercado; incluso podrían ser unas públicas y otras privadas como ocurre en determinados ámbitos (sanidad, educación, algunos servicios locales). En España se ha avanzado en los últimos años en el establecimiento de indicadores de gestión pública para campos específicos como son la educación, la justicia o los servicios de policía.

b) La ausencia de mercado que imposibilita la medición del verdadero output y el carácter intangible de los resultados (mejora del bienestar de los ciudadanos, justicia social, valor añadido a la sociedad a través de la educación...), obliga a la utilización de outputs intermedios cuantificables (incremento de número de servicios por ciudadano, número de casos judiciales resueltos, número de alumnos graduados,etc.).

c) La técnica debería ajustarse a las características de incertidumbre y desconocimiento que roda a la tecnología de producción pública, lo que implica la utilización de técnicas que sean flexibles. 
Finalmente, estos autores se inclinan hacia la elección de las aproximaciones no paramétricas y, entre éstas, el Análisis Envolvente de Datos como la técnica de análisis más apropiada, puesto que el modelo se ajusta a las actividades realizadas por la mayoría de las Administraciones Públicas, modelo que se aproxima al análisis tradicional de ratios input/output.

\subsubsection{Eficiencia y sector turístico}

Una vez analizados los conceptos clave de la eficiencia y su medición, cabe plantearse si es posible extrapolar los métodos de medición de la eficiencia utilizados para la comparación entre unidades de negocio y de empresas, a la gestión para la competitividad de los destinos turísticos.

De acuerdo con el análisis efectuado en el capítulo anterior, el producto turístico de base territorial está formado por una serie de recursos naturales, culturales, patrimoniales y también artificiales que, generalmente, son de naturaleza y gestión pública y cuya imagen y posicionamiento en el mercado son determinantes para la efectiva atracción de la demanda hacia el destino en cuestión (Murphy et al., 2000).

Junto a estos recursos, fuente de ventajas comparativas, se encuentran los productos de naturaleza privada y los bienes y servicios públicos. Entre éstos últimos, podemos distinguir, asimismo, entre aquellos que son de carácter general, proporcionados por las administraciones centrales o autonómicas (sanidad, infraestructuras de acceso, aeropuertos, energía...) y aquellos cuya administración compete exclusivamente a la administración local (conservación urbana, medioambiente local, recogida y eliminación de residuos, seguridad ciudadana...). De ahí la amplitud y heterogeneidad 
de factores (inputs) que deben ser gestionados por los organismos competentes en el diseño e implantación de las políticas y estrategias de los destinos turísticos, muchos de los cuales, además, no se encuentran en su ámbito competencial, puesto que o bien son o bien de titularidad privada o bien corresponden a otras instancias públicas.

Por otra parte, al situarse estos bienes en el ámbito de las organizaciones públicas su cuantificación es sumamente compleja dado que su demanda no se valora a precio de mercado, sino que tratándose de bienes de uso compartido entre población y visitantes, se financian directamente a través de impuestos. Por lo tanto, el baremo para el cálculo de los costes no puede ser el precio de los factores, sino el volumen de ingresos públicos obtenido.

Por mandato constitucional el Estado detenta la potestad recaudatoria y distributiva de los impuestos fruto de la actividad turística generada en los destinos, concretamente a través del impuesto de sociedades, del impuesto sobre la renta de las personas físicas y el impuesto sobre el valor añadido. Por ello, la financiación del gasto público local se nutre de tres fuentes principales (Rubio, 2002):

1. Participaciones en los tributos del Estado y de las Comunidades Autónomas que financian el gasto municipal impropio y genérico. El gasto impropio es el realizado por los municipios para suplir o complementar servicios cuya competencia es de otras administraciones públicas.

2. Impuestos locales, que financian gasto municipal propio o autónomo con destino general y no divisible. El gasto propio es 
el que se realiza para prestar determinados servicios de su competencia y que, en ningún caso, presta ni el Estado ni las Comunidades Autónomas. El gasto autónomo es el resultante de decisiones políticas propias adoptadas en ejercicio de la autonomía municipal para gestionar sus respectivos intereses (arts. $137 \mathrm{y}$ 140 de la Constitución Española).

3. Las tasas, cuyo cometido es financiar determinados servicios públicos propios siempre y cuando sus costes y beneficios sean claramente delimitables.

Así, nos encontramos con que en los municipios turísticos se realiza o se debe realizar un gasto público constante para sufragar servicios que reúnan un nivel de calidad acorde con las necesidades y expectativas tanto de turistas y residentes como de la oferta privada desplegada en el destino, y todo ello con un sistema de financiación complejo y, esencialmente, limitado.

Ruiz y Guía (2004), en un estudio reciente que tenía por objeto la determinación del volumen de déficit de financiación de los municipios turísticos de Cataluña en relación con los no turísticos, calcularon la ratio ingresos/gasto por habitante en relación al componente tasas de la financiación local obteniendo así un indicador aproximado $(2,40)$ para la ponderación de los costes turísticos soportados debido a la presión turística de estos municipios. Asimismo, estos autores dedujeron que es imposible detectar, teniendo en cuenta el principio de equilibrio presupuestario, a la simple vista de los presupuestos, la existencia del déficit financiero municipal, puesto que el desequilibrio en el municipio turístico no aparece reflejado en las magnitudes presupuestarias, sino que, en todo caso, será consecuencia 
de una subprovisión de determinados servicios públicos. Es decir, manifiestan la imposibilidad a la vista de los datos económicos municipales de deducir de una ratio la información relevante sobre si los servicios públicos se prestan con la cantidad y calidad demandada o necesaria.

No parece ofrecer ninguna duda que una inadecuada gestión de los inputs que se utilizan en un destino turístico puede dar lugar a una deficiente posición competitiva del destino en cuestión, pero ¿cuál ha de ser el nivel de resultado esperado para poder determinar la ineficiencia en la gestión de los inputs?. ¿Cómo determinamos el nivel óptimo de producción?, ¿por el número de pernoctaciones en alojamientos turísticos controlados (hoteles, campings, apartamentos declarados de uso turístico)?, ¿a través del gasto turístico promedio realizado por los turistas y visitantes?, ¿según el rendimiento empresarial?. Consideramos que la solución a estas cuestiones está directamente relacionada con la capacidad de ocupación turística.

El objetivo de la capacidad de ocupación turística es determinar el número máximo de visitantes y el volumen de infraestructura asociada que puede absorber una zona sin que se vean menoscabados los valores del lugar desde el punto de vista económico, social y medioambiental al menos durante un tiempo determinado, hasta que se haya generado el suficiente cambio tecnológico que permita la asunción de una nueva frontera cuyo cambio sea aceptable y aceptado por residentes y turistas. Esta cuestión está, por tanto, relacionada con la determinación del cuál es el volumen óptimo de producción de cada destino turístico a partir del cual se producirían rendimientos decrecientes no exclusivamente económicos, también psicológicos.

En este contexto y en el estado actual de la cuestión, no creemos que se 
pueda llegar a determinar con facilidad fronteras externas al destino con objeto de establecer estándares comparativos (¿qué destinos turísticos competidores son más eficientes?). En primer lugar porque se debería disponer de una información de partida lo suficientemente homogénea para todos los destinos que no introdujera distorsiones significativas en los resultados o, en su caso, poder llegar a estimar factores correctores de ponderación. Adicionalmente, sería también muy compleja la estimación de los valores de corrección para la cuantificación de factores exógenos de entorno, como pudieran ser la climatología, las catástrofes naturales o la distorsión que producen las acciones terroristas en los destinos turísticos.

Por tanto, entendemos que la definición de las fronteras que deben marcar la eficiencia en la gestión de los destinos turísticos debe nacer desde dentro, esto es, desde el propio destino, de tal modo que deben ser los actores críticos del proceso, grupos de interés, los que deben establecer, a la vista de su propia realidad, dicha frontera en función del objetivo interno predominante y en la que, obviamente, la orientación estratégica al cliente (interno: la comunidad y externo: los visitantes) debe de ser una de las guías fundamentales en ese proceso de reflexión.

Desde esta óptica, no parece probable que la definición de fronteras de eficiencia técnica sea fácilmente aplicable en la gestión de los destinos turísticos, especialmente en aquellos que son de pequeña dimensión y que se encuentran en fase de desarrollo incipiente. Ahora bien, no por ello se debe desprender que el logro de la eficiencia no sea objeto prioritario de la gestión de los destinos turísticos, al contrario.

Una interpretación perfectamente aplicable a la gestión de los destinos 
turísticos es la visión que ofrece Stigler, no para negar la validez o existencia de la eficiencia técnica aunque entendemos que resulta extraordinariamente complejo su cálculo, pero sí para poner de manifiesto la mayor importancia que para el logro de la competitividad en los destinos turísticos tiene la eficiencia asignativa. Esto es, la correcta distribución de los siempre escasos recursos que este tipo de municipios y localidades tienen a la hora de diseñar sus procesos de planificación y desarrollo turísticos, así como la intervención de las diferentes administraciones que participan en el proceso de desarrollo turístico.

A similar conclusión llegan Ruiz y Guía (2004, pag.74) al señalar que "en el caso de los municipios turísticos, esencialmente si son municipios de pequeñas dimensiones y por lo tanto con una limitada capacidad financiera y técnica compartir competencias y recursos sería clave, tanto para la posible obtención de recursos financieros adicionales, como para la planificación y aplicación de las diferentes medidas a adoptar en la gestión sostenible del destino turístico [...] con la finalidad de mejorar la capacidad organizativa, técnica y financiera que requiere la prestación de unos servicios de calidad en el actual escenario de alta competencia turística”.

Por ello, y en conclusión a lo hasta aquí expuesto en este apartado de eficiencia, consideramos que la existencia de un instrumento metodológico que implique la elaboración de un cuadro de indicadores a la medida del destino, que permita conocer a los gestores del destino turístico la situación de partida y la evolución de los factores clave del éxito, sus variables y subvariables, es la forma adecuada de plasmar la dimensión de la eficiencia en el logro de un desarrollo sostenible y a, la larga, determinará cuál es su posición competitiva en el mercado. 


\subsubsection{Calidad}

\subsubsection{Valoración de la calidad percibida y satisfacción del consumidor}

La segunda dimensión que nos ocupa: calidad, recoge una palabra que es profusamente utilizada con intenciones comerciales para asegurar la excelencia de todo tipo de productos y servicios. Indiscutiblemente, el término está asociado, universalmente, a un sentimiento positivo, por lo que, "teniendo calidad" parece ser que se es mejor y más competitivo. Pero ¿qué significa realmente tener calidad?

Las primeras aportaciones conceptuales al término, provenientes del ámbito de la industria, enfatizan principalmente la importancia de la conformidad del producto con las especificaciones del suministrador. Se habla así de definiciones objetivas de la calidad y sus principales valedores son Crosby (1979), Gavin (1984), Juran y Gryna (1988), Tellis y Gaeth (1990).

En este sentido, para Crosby (1984) la calidad, en su concepto más básico, significa conforming to requirements (conformidad con las especificaciones). Juran (1990), sin embargo, parece querer huir de la simplificación de las definiciones cortas y propone dos significados distintos para este concepto: por una parte, relacionadas con los atributos del producto, es decir, con aquellas características que proporcionan satisfacción y que le permiten competir en el mercado y, por otra parte, se refiere también a la ausencia de deficiencias en su entrega y que podrían repercutir en el producto creando insatisfacción (concepto de no calidad).

Posteriormente, la creciente importancia que fueron adquiriendo las actividades 
de servicio en la economía y su progresiva incorporación, como elementos del producto, por los fabricantes de bienes tangibles, hizo que el interés por la calidad se propagase poco a poco a los servicios, dando lugar así a una corriente específica.

Grönroos (1984) presentó un enfoque de la calidad orientada a los servicios en el que introdujo el concepto de calidad percibida en los servicios y el modelo de la calidad total de los servicios. Este enfoque se basó en investigaciones sobre el comportamiento de los consumidores y la influencia que tenían en las evaluaciones después del consumo, las expectativas que los consumidores se habían hecho respecto a los productos investigados, dando pie a la corriente denominada definiciones de la calidad subjetiva, basada en el punto de vista del cliente. En esta línea Buzzell y Gale (1987) realizan una de las afirmaciones más sencillas y a la vez más exactas que se conocen sobre lo que es la calidad: la calidad es lo que los clientes dicen que es y la calidad de un producto o servicio determinado es lo que el cliente percibe que es.

Para Zeithaml (1988) la calidad percibida supone una evaluación global, similar a una actitud, que el consumidor realiza sobre el nivel de excelencia o superioridad del servicio ofrecido por una determinada organización. Dentro de un enfoque subjetivista de la calidad, la calidad percibida sería el resultado de la comparación entre las percepciones del cliente sobre el nivel de servicio prestado por una organización y las expectativas sobre el nivel de prestación que se debería esperar de esa categoría de servicio. Según este planteamiento, en igualdad de condiciones, cuanto más altas sean las expectativas de los consumidores, menor será el nivel de calidad percibida. Para esta autora, la calidad percibida es diferente de la calidad objetiva 
porque supone un alto nivel de abstracción, es una forma de evaluación global que, en algunos casos, es parecida a la actitud y que es un juicio hecho normalmente dentro de un conjunto evocado.

Churchill y Surprenant (1982) y Cronin y Taylor $(1992,1994)$ han enfatizado la importancia de la calidad percibida sobre la discrepancia existente entre expectativas y percepciones a la hora de entender la satisfacción de los usuarios. También se han centrado en la intención de volver a utilizar el servicio por parte de los consumidores como indicador del grado de satisfacción alcanzado con respecto a la calidad del servicio.

De estas consideraciones se desprende que la calidad percibida y la percepción de la calidad son dos conceptos muy relacionados aunque no equivalentes. La calidad percibida es una construcción teórica que señala el nivel de excelencia que el individuo atribuye a un producto o servicio, mientras que la percepción de la calidad hace referencia al proceso a través del cual el consumidor recoge, procesa e interpreta los estímulos sensoriales que genera su entorno (Cruz Roche, 1990) y que da como resultado la creación de la imagen que el individuo tiene acerca de la calidad del servicio.

La aproximación al concepto de la calidad percibida de los servicios, realizada por Parasuraman, Zeithaml y Berry $(1985,1988)$ representa la aportación fundamental de la llamada escuela americana, que es la que ha recibido mayor aceptación por parte de diversos investigadores al utilizar ampliamente el modelo creado por estos autores. Según esta escuela, se define la calidad de los servicios como "la amplitud de la discrepancia o diferencia que existe entre las expectativas o deseos de los clientes y sus percepciones”, de tal manera que un servicio será de calidad cuando su realización iguale o supere 
las expectativas del cliente, mientras que será calificado de baja calidad cuando la prestación no consiga cubrir estas expectativas. Esta escuela americana, por tanto, se ha centrado en los aspectos relacionados con la calidad del servicio ofrecido. Una de las grandes virtudes de estos investigadores ha sido el desarrollar la escala Servqual para medir la calidad percibida del servicio y que, adicionalmente, facilita la comparación de la calidad ofrecida entre distintos subsectores de la industria de servicios.

Paralelamente, en sintonía con la línea de pensamiento anterior, se ha identificado a la escuela nórdica, liderada por Grönroos y Gummesson (1988), quienes enfocan la calidad de servicio desde el punto de vista de "la diferencia entre la calidad esperada y la calidad experimentada". Según estos autores la formación de las expectativas previas de los consumidores vienen influenciadas por dos niveles cognitivos: lo que los clientes creen que ocurrirá durante el momento del servicio y lo que realmente desean que ocurra. En la misma línea se manifiestan Parasuraman, Zeithaml y Berry (1988) quienes conciben las expectativas como "deseos o necesidades de los consumidores, por ejemplo, lo que sienten que debe ser entregado por un proveedor de servicio antes que lo que éste podría ofrecerles".

Las expectativas que se forman a partir de las acciones del productor, a través de la publicidad o los vendedores, son el origen de la gestión de las expectativas que incluye el conjunto de acciones que realiza la empresa para ajustar las promesas a la realidad del producto. En todo caso, influenciado por las promesas de ventas, la hipótesis de que el cliente es el único que realmente sabe qué es lo que desea es la que se tiene por válida, frente a otra posible alternativa que fuera que quien mejor conoce las expectativas del cliente es el vendedor, productor u oferente del servicio. Grönroos (1983), Nightinggale 
(1985), Brogowiz et al. (1990) consideran que la calidad de los servicios puede ser definida tanto desde la perspectiva del proveedor del servicio como desde la perspectiva del cliente, y señalan que es un mecanismo dinámico puesto que la calidad proporcionada por el proveedor del servicio es diferente a la percibida por el cliente, debido a que las características del proveedor del servicio están continuamente readaptándose en función de la retroalimentación de información que recibe de los clientes y, a su vez, las percepciones de los clientes se van modificando debido a sus experiencias anteriores.

Según Deighton (1992) los individuos compran productos y servicios, pero lo que consumen es la realización (performance) que estos ofrecen. La realización o performance se define como la percepción que tiene un individuo de un acontecimiento presenciado en relación con su obligación en una transacción, y es considerado como un estándar de evaluación. King (1984) asegura que en aquellas situaciones en las cuales se produce una participación del cliente en la realización del servicio, las expectativas del mismo son más elevadas que las de otros clientes que no intervienen en el proceso. Así, la satisfacción con un producto o servicio está ligada tanto a juicios cognitivos previos como a reacciones afectivas derivadas de su consumo (Oliver, 1981, 1989).

En el área del marketing que estudia el comportamiento del consumidor, el término performance se aplica para definir la evaluación de los beneficios o resultados de un servicio como consecuencia de su uso. Cronin y Taylor (1994) sugieren que la satisfacción es una evaluación acumulativa y, por tanto, representa más un juicio global que una medida de una transacción específica. Según Jones y Suh (2000) la satisfacción definida desde ese punto 
de vista explicaría mejor las intenciones de recompra.

Diferentes investigaciones han defendido la convergencia entre el enfoque cognitivo y el afectivo, integrando ambos tipos de variables en el proceso de formación de la satisfacción (Price, Arnould y Tierney, 1995; Zeithaml, Berry y Parasuraman, 1996; Oliver, 1997). El componente cognitivo implica un proceso mental de pensamiento y evaluación de una experiencia de consumo formado por los elementos de comparación, mientras que el componente emocional se refiere a las respuestas afectivas positivas o negativas que aparecen de esa valoración. Para Oliver (1993) es precisamente ese componente emocional lo que diferencia el fenómeno de formación de la satisfacción de otros conceptos afines como puede ser la calidad percibida del servicio.

La calidad percibida puede definirse como un juicio global del consumidor sobre la oferta de una empresa (Steenkamp, 1989) o la excelencia o superioridad de un producto (Garvin, 1983; Zeithaml, 1988) debido a la adaptación del producto/servicio a las necesidades y exigencias del individuo y a la ausencia de deficiencias (Juran, 1988).

Para algunos autores la satisfacción va unida a una experiencia específica de consumo, mientras que la calidad puede ser percibida sin ninguna experiencia (Oliver, 1993; Rust y Oliver, 1994) de tal manera que la calidad percibida es una antecedente de la satisfacción y ésta última vendrá condicionada por el cruce entre la calidad percibida y los costes incurridos, entre ellos el precio. Sin embargo, el grado de satisfacción/ insatisfacción modificará el concepto de calidad percibida en el individuo proporcionándole un carácter dinámico y acumulativo a lo largo del tiempo. Si la satisfacción 
es el resultado final de la evaluación de la calidad de servicio, las empresas deben ser capaces no sólo de detectar aquellos atributos que puedan mejorar la calidad de este servicio, sino también los factores que contribuyen a mejorar el nivel de satisfacción (Lee, Lee y Yoo, 2000).

Aunque el objetivo último sea lograr clientes con el cien por cien de satisfacción, y, de hecho, hacia este objetivo es al que debe tender la organización, es muy difícil su logro. Incluso, en este caso, no hablaríamos de expectativas, sino de exigencias; de plena conformidad del producto con sus especificaciones y, en relación a los servicios, es, prácticamente, inviable. No todos los clientes son iguales, no todos esperan lo mismo de un determinado servicio, ni lo perciben de igual forma. En lugar de ello, hay que considerar justificable que se cumplirá la propiedad de que la esperanza matemática coincide con la media. Es decir que la mayor parte de los consumidores se comportarán según lo hace la media y, por tanto, resulta posible conocer cuáles son sus expectativas y evaluar los resultados de las acciones que se tomen con respecto al nivel de calidad de los servicios.

El planteamiento anterior nos conduce a una cuestión que siempre va de la mano de las expectativas y es el momento de la confrontación de éstas con la realidad ofrecida, con la calidad experimentada. Grönroos (1988) la define según la calidad técnica de los resultados y la calidad funcional del proceso (el "qué" y el "cómo"). La calidad técnica (resultados) equivale a lo que Lehtinen y Lehtinen (1991) consideran como calidad física y Mels, Boshoff y Deon (1997) definen como calidad extrínseca. Sin embargo, la calidad técnica no es suficiente para asegurar la calidad total percibida en las empresas a menos que éstas tengan los servicios altamente estandarizados y no exista interacción humana, por lo que también es necesaria la medición de los 
aspectos funcionales del servicio (el proceso de prestación).

En los últimos tiempos se ha sugerido que la simple calidad del servicio no es suficiente para explicar la forma en que esta calidad de servicio influye en la toma de decisiones futuras del consumidor por lo que se ha unido al estudio el concepto de valor. Aunque desde el ámbito de los servicios no ha sido un tema ampliamente estudiado (Caruana et al., 2000); Woodruff y Gardial (1996) proponen que "el valor del consumidor es la percepción del individuo sobre las consecuencias que desea que ocurran en una determinada situación de uso para que se ajusten a sus deseos". Por su parte, Zeithaml (1988) definió el concepto de valor como "la evaluación global que hacen los consumidores respecto a la utilidad de un producto, según su percepción de la diferencia entre lo que reciben y lo que dan". Según este concepto el valor es la distancia que media entre los resultados y beneficios obtenidos y el coste en tiempo dinero y esfuerzo invertido por el individuo. Day y Crask (2000) consideran que el valor puede medirse antes, durante y después de la experiencia del consumidor mientras que la satisfacción es siempre una evaluación post-consumo.

Estos planteamientos sugieren que el concepto de valor tiene mayor extensión que la calidad percibida; por tanto, la calidad puede ser un antecedente del valor y, a su vez, el valor influye en los juicios de satisfacción, identificándose el rol mediador del valor entre el efecto de la calidad percibida sobre la satisfacción (Caruana et al., 2000).

Los factores que tradicionalmente forman el concepto de valor son el precio de venta y la calidad del producto (Monroe, 1990), aunque otros autores (Shechter, 1984; Bolton y Drew, 1991) han sugerido que el factor precio 
puede no ser suficiente en sí mismo y que se deben considerar otras variables como son la calidad del servicio, el riesgo percibido y la imagen. Sheth et al. (1991) han sugerido que el valor es un concepto con múltiples dimensiones (sociales, emocionales, funcionales, condicionales) que pueden impactar de forma diferente según las situaciones, de tal manera que este concepto es una variable que media entre la calidad del servicio y la satisfacción.

Esta teoría sobre el valor, como variable intermedia, puede tener importantes implicaciones, ya que, la satisfacción del consumidor no vendría dada directamente por la calidad del servicio, sino que se verá influenciada por cualquiera de las variables del valor percibido. Por tanto, a nivel de gestión, es relevante entender cuáles son las claves y los mecanismos del segmento de mercado considerado para actuar no sólo sobre la calidad del servicio ofrecido sino también sobre aspectos sociales y emocionales que pueden jugar un papel muy importante en la percepción del turista. En ese sentido, las últimas investigaciones de Sweeney et al. (1999) sugieren que la más importante contribución de la calidad del servicio podría ser realmente indirecta. En el sentido de que si la buena calidad de servicio reduce el riesgo percibido, incrementa indirectamente el valor.

El concepto de cadena de valor desde el punto de vista de la organización fue desarrollado por Porter (1985), concluyendo que toda organización no es más que un conjunto de actividades encadenadas que se llevan a cabo para diseñar, producir, comercializar, distribuir y apoyar sus productos o servicios. Todas estas actividades están organizadas con el objetivo de crear valor, entendiendo como tal la diferencia entre lo que el cliente está dispuesto a pagar por un producto o servicio y el coste para la empresa de generar el mismo, por lo que, no sólo es necesario que cada actividad sea llevada a 
cabo eficientemente, sino que todas ellas deben estar perfectamente integradas si se pretende alcanzar unos resultados globales aceptables.

El principio básico en el que se fundamenta la cadena de valor propuesta por Porter es que todas las actividades realizadas por una unidad de negocio pueden ser clasificadas dentro de nueve categorías diferentes. Las cinco primeras son consideradas como actividades primarias y están comprometidas con la obtención, producción y venta posterior de los productos/servicios ofrecidos por cada unidad de negocio. Estas actividades son: logística interna, producción/operaciones, logística externa, marketing/ventas y servicio postventa. Las cuatro restantes son consideradas como actividades de apoyo o soporte y su finalidad es conseguir un mayor grado de eficiencia y eficacia en las actividades realizadas tanto en los centros primarios como en los de apoyo. Estas actividades son: abastecimiento, desarrollo tecnológico, recursos humanos e infraestructura. Las actividades secundarias son necesarias para controlar y apoyar el desarrollo de las actividades primarias; añaden valor al negocio, pero sólo a través de su contribución a mejorar los resultados de las actividades primarias.

Este modelo consideramos que es también un excelente instrumento para el análisis pormenorizado de la organización de un destino turístico en conjunto. En la figura 7 mostramos la adaptación del modelo a los destinos turísticos

Las actividades denominadas principales son aquellas que tienen al clienteturista como eje central de su estrategia y actuaciones. Algunas de las cuales comienzan con anterioridad al desplazamiento de éste, como son las actividades de marketing tendentes a captar su atención, crear unas expectativas y reforzar su impulso de compra. La logística de acceso implica todas las actuaciones 
necesarias para hacer factible el establecimiento de la conexión física entre el cliente y el destino. En este punto se incluyen tanto las plataformas y servicios de información para gestión de reservas y ventas como las propias facilidades para el acercamiento y distribución física (infraestructuras de acceso, transportes, facilidades de entrada, etc.). Las operaciones relacionadas con las industrias de soporte y apoyo son autogestionadas por los titulares de las mismas, privados en su mayoría, quienes a su vez aplican o deben aplicar las dimensiones que propugnamos (calidad, eficiencia, posicionamiento, innovación) en su negocios a nivel micro, contribuyendo con sus aportaciones a la imagen general del destino. Por su parte, las operaciones de comunicación y postventa en destino, generados mayoritariamente, aunque no necesariamente, por los actores públicos son fundamentales para reforzar sentimientos positivos de satisfacción que reduzcan o neutralicen el riesgo percibido y fomenten, en la medida de lo posible, un cierto compromiso relacional a largo plazo entre el turista y el destino turístico.

Figura 7 Cadena de valor de un destino turístico

\begin{tabular}{|c|c|c|c|c|}
\hline $\begin{array}{l}\text { ACTIVIDADES } \\
\text { PRIMARIAS }\end{array}$ & \multicolumn{4}{|c|}{$\begin{array}{l}\text { ACTIVIDADES } \\
\text { SECUNDARIA }\end{array}$} \\
\hline MARKETING & & & & \\
\hline LOGISTICA DE ACCESO & $\sum_{\substack{m \\
\infty}}^{m}$ & 思 & $\begin{array}{l}0 \\
\text { 员 } \\
\text { 男 }\end{array}$ & $\frac{\omega}{\omega}$ \\
\hline $\begin{array}{c}\text { OPERACIONES DE SOPORTE } \\
\text { (industria turistica) }\end{array}$ & 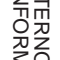 & $\begin{array}{l}z \\
\alpha \\
0\end{array}$ & б & $\begin{array}{l}\text { क } \\
\text { 吕 }\end{array}$ \\
\hline $\begin{array}{l}\text { OPERACIONES DE APOYO } \\
\text { (industrias conexas y afines) }\end{array}$ & 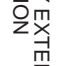 & $\sum_{\substack{n \\
\underline{a}}}$ & $\stackrel{\Omega}{\complement}$ & $\frac{1}{\partial}$ \\
\hline $\begin{array}{l}\text { OPERACIONES DE COMUNICACION } \\
\text { Y POSTVENTAEN DESTINO }\end{array}$ & 里 & & & \\
\hline
\end{tabular}

Fuente: elaboración propia 
En relación a las actividades secundarias, los sistemas internos y externos de información permitirán la generación de un output que será el establecimiento de unos indicadores, incorporables al cuadro o mando de control, para cada uno de los procesos internos que se consideren críticos. Algunos de estos procesos pueden estar referidos a los recursos, las actividades y procesos, las relaciones internas en destino y los resultados económicos, sociales y medioambientales. Esta información es determinante para la toma de decisiones y planificación conjunta de acción por los agentes directamente implicados en el destino a través del organismo de gestión que se haya considerado. Finalmente, los resultados alcanzados y las mejoras introducidas en el sistema serán la base para el desarrollo de nuevos recursos o la mejora de los existentes, que permitan, a su vez, la generación de mayor valor para el destino. El sistema de financiación de los municipios turísticos es clave para el sostenimiento del sistema y para la generación de mejoras a través de inversiones que no comprometan los recursos naturales en el futuro, ni dañen la calidad de vida de los residentes debido a la congestión asociada al crecimiento turístico (De Rus, 2004).

\subsubsection{Modelos de gestión de calidad}

Desde los años noventa del pasado siglo hasta nuestros días, se vienen desarrollando metodologías basadas en sistemas de calidad que pretenden servir como guía de actuación para que las organizaciones, basándose en la utilización de sus principios, métodos e instrumentos, incrementen sus niveles de calidad y que ello contribuya a una mejora global de su competitividad en el mercado.

Han surgido así unos sistemas estratégicos de gestión basados en la llamada 
filosofía de la "Calidad Total", que son considerados por diversos autores (Camisón, 1996) como enfoques “de segunda generación”, caracterizados por su naturaleza multidimensional y dinámica, puesto que el despliegue de acciones abarca todos los procesos decisivos de la empresa, basándose en un ciclo de mejora continua.

Cualquier modelo o sistema de gestión de la calidad total que se quiera implantar en una organización está basado en unos principios de gestión formalmente aceptados. Estos principios se refieren al conjunto de conocimientos teóricos que conforman el paradigma: comprenden conceptos, objetivos, estrategias y enfoques. Por otra parte, junto a los principios, se encuentran las herramientas que comprenden el cuerpo de conocimientos técnicos necesarios para poner en práctica la metodología.

Los modelos de Gestión de la Calidad Total son el resultado de una evolución natural desde la calidad entendida como una actividad de "control", es decir, como una operativa de inspección sobre el producto para estimar su grado de conformidad con los estándares previamente definidos o diseñados, hacia un concepto mucho más amplio, que entiende la calidad como objetivo de la organización, en tanto que es un instrumento que le permite obtener una meta estratégica más ambiciosa. Para lograr este objetivo toda la organización debe conducirse de acuerdo a la obtención de la excelencia a través de la mejora continua. Esta situación es la base para la constitución del modelo de gestión de la calidad definido por Membrado (1999) como el “conjunto de criterios agrupados en áreas o capítulos que sirven como referencia para estructurar un plan de Calidad Total en una empresa u organización, o en una parte de la misma". 
La gestión de la calidad total representa una política de empresa sustentada en cinco pilares básicos: liderazgo, orientación al cliente, prevención, mejora continua y participación; y se fundamenta en tres coordenadas de gestión: mejora continua (dirección día a día) en cada unidad organizativa, trabajo en equipo (dirección por procesos) enfocada a la integración horizontal de la organización, y planificación de la gestión (dirección por políticas). La metodología incluye el despliegue de las herramientas necesarias que permitan la medición sistemática y el control de los procesos, cuyos resultados sirven de información para retroalimentar el sistema. A su vez la existencia de un sistema de certificación se convierte en una referencia que clarifica el objetivo de transformación de la empresa y que sirve para comunicar al mercado los logros de calidad conseguidos.

Con respecto a las herramientas de gestión de la calidad, éstas se usan de forma cíclica (iniciando un nuevo proceso de mejora cada vez que se completa el ciclo anterior) e incluye manuales para el desarrollo documental del sistema, creación de sistemas de recogida y procesamiento de la información, una guía para la autoevaluación conforme a los requerimientos de cada unidad organizativa evaluada, y el uso de las herramientas clásicas del control de calidad (hoja de recogida de datos, diagrama de Pareto, diagrama de Ishikawa, diagrama de flujo, gráfico de correlación, etc.), así como otras relativas a la planificación y gestión (diagrama de afinidad, diagrama de árbol, diagrama matricial, ciclo PDCA) o herramientas relativas a la resolución de problemas (brainstorming, matriz de criterios, técnica grupo nominal, blueprint, métodos Taguchi, método Delphi) entre otras.

En la actualidad, en el ámbito del sector turístico de nuestro país, se pueden distinguir básicamente dos aproximaciones compatibles entre sí: el enfoque 
de la normalización basado en el aseguramiento de la calidad según los estándares ISO, cuyos rasgos principales se expondrán a continuación, y el enfoque sectorial, creado específicamente para el sector turístico como planteamiento estratégico global y que abarca tanto el aseguramiento de los requerimientos del mercado como el control del proceso productivo. Este último enfoque será objeto de análisis en un apartado diferenciado por su importancia para la gestión de los destinos turísticos.

La norma ISO 9000 (cuyo equivalente español es la UNE 66.900) define el aseguramiento de la calidad como: Conjunto de acciones planificadas y sistemáticas que son necesarias para proporcionar la confianza adecuada de que un producto o servicio satisfará los requisitos dados sobre la calidad. Esta norma se basa en el establecimiento de estándares mínimos que son acordados y publicados como normas emanadas por la International Standard Organisation (ISO).

El aseguramiento de la calidad es una actividad que no actúa directamente sobre el proceso de producción, sino que tiene como objetivo confirmar si un producto, servicio o sistema de calidad responde o no a los requerimientos del mercado. En principio, el aseguramiento de la calidad, a través de la certificación de una entidad acreditada, ofrece al cliente, en el momento de la compra, un elevado nivel de confianza sobre el producto o servicio que desea adquirir, si bien es evidente que si el resultado final de éste no refleja las características esperadas por el cliente, el aseguramiento de la calidad resulta totalmente ineficaz y debe reconducirse a una garantía de satisfacción de las expectativas no cumplidas.

El sistema de aseguramiento actúa fundamentalmente en dos frentes: en el 
establecimiento de los estándares mínimos a cumplir, recogidos en unas normas, y en el sistema de certificación y cesión del uso del distintivo de calidad. La norma de calidad es una especificación técnica, cuya observancia no es obligatoria. Es establecida en comisiones técnicas en las que intervienen representantes de todas las partes interesadas en su desarrollo, y que aprueba un Organismo que disfruta de reconocimiento nacional o internacional. El contenido de las normas puede variar desde normas que recogen específicamente terminología sectorial hasta aquellas que recogen criterios ecológicos, sistemas de seguridad o descripciones de métodos analíticos o de ensayo, entre otras. En España, las actividades de normalización son competencia de la Asociación Española de Normalización y Certificación (AENOR) quien las aprueba una vez que han sido desarrolladas por los correspondientes Comités Técnicos de Normalización (CTNs) y reciben el nombre de normas UNE (Una Norma Española).

En España, tras su publicación en el BOE de marzo de 2001, se creó un nuevo Comité Técnico de Normalización en AENOR: el AEN / CTN 167 de Servicios de Hostelería a iniciativa de la Federación Española de Hostelería (FEHR), quienes, en 1997, presentaron un proyecto para la creación y desarrollo de las normas de calidad en la restauración, tomando como referencia la norma IRQ700. A lo largo del año 1998 elaboraron un estudio que sirvió para la posterior redacción de las normas de calidad turística.

Este hito es importante puesto que, en el ámbito turístico, hasta fecha muy reciente, las únicas iniciativas de normalización habían correspondido al Comité Europeo de Certificación (CEN), a través de sendos proyectos que han tenido objeto la "la normalización de la terminología y especificaciones de las instalaciones y servicios, incluyendo las actividades recreativas 
relacionadas con el turismo y ofrecidas por la industria turística, que puedan ser utilizadas en los sistemas de información y reservas para dotar a los usuarios con criterios para la toma de decisiones y la definición de conceptos turísticos para turoperadores y agencias de viajes. Por su parte, en el seno de la Organización Internacional de Normalización (ISO) se creó el grupo de trabajo denominado "Accommodation Facilities", dependiente directamente del Consejo Técnico, con la misión de estudiar las necesidades de normalización internacionales en el sector de los servicios turísticos y proponer un programa de trabajo. La propuesta de creación de este grupo de trabajo parte de la Asociación Internacional del Automóvil (AIT/FIA), al solicitar, en 1996, una clasificación hotelera internacional. Esta iniciativa, no ha prosperado.

La diferencia fundamental entre las normas emanadas de un organismo $\mathrm{u}$ otro es que las normas EN son de obligada adopción para los países miembros del $\mathrm{CEN}^{4}$ lo que implica que los países deben anunciar públicamente su existencia y retirar las normas nacionales que puedan entrar en conflicto con la europea. Las normas ISO, por el contrario, no implican la obligatoriedad de su adopción, siendo normas internacionales de referencia y consulta; si bien, favorecidas por el proceso de globalización de los mercados, están siendo cada vez más extendidas.

La norma ISO 9001:2000 es la base normativa del aseguramiento del sistema de gestión de la calidad por parte de la empresa u organización y se complementa con la norma ISO 9004:2000 que hace referencia a la guía metodológica para la mejora continua. Estas son las únicas normas de este tipo que se están aplicando al sector turístico, además de la serie 14001 de gestión medioambiental.

${ }^{4} 19$ países: Alemania, Austria, Bélgica, Dinamarca, España, Finlandia, Francia, Grecia, Holanda, Irlanda, Islandia, Italia, Luxemburgo, Noruega, Portugal, Reino Unido, República Checa, Suecia y Suiza. 
Por su parte, AENOR es el organismo que ha sido acreditado por la Entidad Nacional de Acreditación (ENAC) para certificar sistemas de aseguramiento de la calidad según las normas UNE-EN ISO 9000. Pero mientras el aseguramiento de la calidad tiene una aplicación sencilla en el ámbito de la empresa industrial, donde empresa y productos son fácilmente separables, en las empresas de hostelería, empresa y servicios son indisolubles, por lo que se plantea un dilema: por una parte, este sistema es adecuado para la certificación de la organización empresarial pero, por otra, aún hoy, no es aplicable al aseguramiento de la calidad en los servicios prestados, por lo que pueden haber serias discrepancias entre las expectativas creadas por el distintivo otorgado por AENOR y la calidad de los servicios percibidos.

\subsubsection{El enfoque sectorial: el modelo de calidad del sector turístico español}

La política turística española, en la última década, se ha caracterizado por su labor de sensibilización y apoyo a la iniciativa privada con objeto de lograr una mejora de los niveles cualitativos del conjunto de la oferta turística mediante la implantación de estrategias de diferenciación que permitan, al conjunto del país, diversificar su atractivo principal, sol y playa, y distinguirse de productos similares ofertados por destinos competidores, manteniendo su cuota como segundo destino mundial en relación al número de llegadas internacionales de turismo, e incluso impulsando el crecimiento de esta cuota. Para ello, se ha apoyado en tres programas consecutivos: FUTURES I, FUTURES II y PICTE (fig. 7). El primer programa se centró en el apoyo a la consecución de la excelencia turística en entornos naturales urbanos. El segundo programa de destinos turísticos impulsó una dinámica de confluencia de actuaciones públicas y privadas tendentes a mejorar la oferta turística del 
turística del destino y, finalmente, el tercer programa, PICTE, se centra en el liderazgo de la administración local y su necesaria aportación al concepto de desarrollo sostenible mediante el mantenimiento de los beneficios económicos derivados de la actividad turística, sin menoscabar ni los valores socio-culturales propios de lugar ni los recursos medioambientales. En los apartados siguientes se desarrollan con mayor amplitud los aspectos esenciales de cada uno de estos programas.

\section{Figura 8 Evolución de la Política Turística Española}

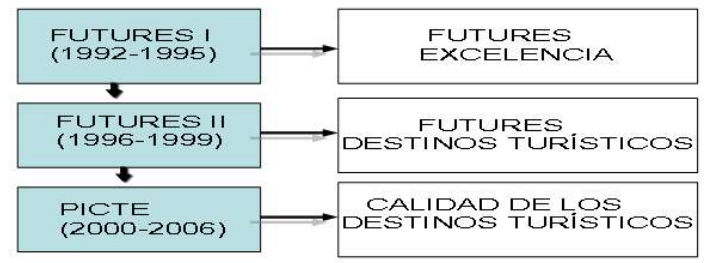

Fuente: Secretaría General de Turismo, 2004

\subsection{Plan marco de competitividad del turismo español , FUTURES (1992-1995)}

La pérdida de importancia relativa del turismo en la economía española se produjo a partir de 1989, año en que tiene lugar un descenso importante del número de turistas, tras unos años (1980-1988) de fuerte crecimiento. De tal manera que a principios de la década de los años 90, la Secretaría General de Turismo (SGT) observando que una serie de destinos turísticos del Mediterráneo y de los Archipiélagos sufrían desordenes urbanísticos y contaban con infraestructuras hoteleras y de servicios obsoletas, planteó, conjuntamente con las Comunidades Autónomas, la creación y puesta en marcha del Plan Marco de Competitividad del Turismo Español (FUTURES) cuyo objetivo genérico era establecer las estrategias necesarias para que el 
turismo consolidara su posición competitiva como sector líder en la economía española y uno de los principales destinos del Mediterráneo. El ámbito espacial de aplicación del Plan Marco era nacional, y su ámbito temporal estaba pensado para cuatro años (1992-1995). La apuesta principal del plan consistía en la coordinación de todas las Administraciones turísticas, de distinto ámbito regional, para concentrar esfuerzos y rentabilizar los costes con vistas al desarrollo de la excelencia turística en entornos rurales y urbanos de los destinos más desarrollados. Los principios de actuación se basaban en tres ideas: inmediatez en la ejecución, cooperación y co-financiación con las distintas Administraciones turísticas (autonómicas y locales) e implicación de los distintos agentes sociales, tanto beneficiarios como promotores de los planes.

El plan marco estaba integrado por cinco planes operativos:

P.1.- Plan de coordinación y cooperación institucional, FUTURESCOORDINACIÓN.

P.2.- Plan de modernización e innovación turística, FUTURESMODERNIZACIÓN.

P.3.- Plan de nuevos productos turísticos, FUTURES -NUEVOS PRODUCTOS

P.4.- Plan de promoción, marketing y comercialización, FUTURESPROMOCIÓN

P.5.- Plan de excelencia turística, FUTURES-EXCELENCIA

El plan de coordinación y cooperación institucional (FUTURESCOORDINACIÓN) pretendía establecer una estrategia común para todo el sector, sobre sector sobre la que se podían apoyar las políticas turísticas de las Comunidades Autónomas y de los entes locales. Esta estrategia se 
desarrollaba a través de cuatro programas. Entre los que destacaba el programa de coordinación de la Administración del Estado, en el que se manifestaba, expresamente, que los proyectos de carácter turístico que se financien con fondos públicos de la Administración del Estado o con fondos comunitarios, se enmarcarían dentro de los objetivos y líneas de actuación establecidos en el Plan Marco de Turismo. En este sentido se contemplaba la "colaboración en la concesión de apoyos financieros a proyectos turísticos que se benefician de incentivos públicos gestionados por otros Departamentos tales como Incentivos Regionales, subvenciones FEDER, RECHAR, RESIDER y RENAVAL, subvenciones del FSE o del FEOGA-Orientación”, abriendo así una línea directa de cooperación con aquellos programas comunitarios que pudieran estar basados en el desarrollo rural.

En su declaración de intenciones, el plan de modernización e innovación turística manifestaba su voluntad de consolidar la competitividad y rentabilidad de las empresas turísticas, en particular, las empresas de reducido tamaño y las asociaciones o colectivos de empresas turísticas. Tras el análisis del conjunto de medidas previstas al respecto destacan dos puntos clave: la mejora de la competitividad a través de la formación de los recursos humanos y el apoyo a la implantación y desarrollo de programas de calidad en las empresas.

El plan de nuevos productos turísticos era particularmente interesante puesto que establecía dos ámbitos de actuación: por un lado, la consolidación de la oferta turística tradicional española basada en los recursos de sol y playa mediante el apoyo a la creación de oferta complementaria, y, por otra parte, el apoyo al desarrollo de nuevos productos en destinos alternativos, en particular en las zonas de interior y de montaña. El desarrollo de este programa 
se efectuaba a través del acceso a fondos comunitarios FEDER, FEOGA y de las acciones LEADER.

El Plan de promoción, marketing y comercialización apoyaba el desarrollo de un sistema operativo común que orientara las actuaciones promocionales empresariales e institucionales con el objeto de aminorar los costes individuales derivados de la comercialización. Las medidas adoptadas para lograr este objetivo se situaron en el ámbito de la asistencia técnica y asesoramiento a través del Instituto de Turismo de España (TURESPAÑA).

El último plan operativo, el Plan de Excelencia Turística nació con la idea de promover iniciativas que mejoraran la satisfacción general de los turistas en España y elevaran el prestigio del turismo español. La idea era configurar programas específicos para zonas turísticas que permitieran un tratamiento global del destino. Estos programas estarían, a su vez, condicionados a la existencia de planes municipales que contemplaran medidas de desarrollo turístico. Un incentivo del programa era que propiciaba la creación de una marca: "Destino Turístico Excelente", cuando concurrieran circunstancias de criterios medioambientales respetuosos y establecimientos modernos adaptados a las exigencias de calidad del mercado en un mismo destino.

Con respecto al sistema y a la cuantía para la financiación de estos planes, se trataba fundamentalmente de completar las aportaciones de planes europeos más amplios que contemplaran el desarrollo de proyectos turísticos, fundamentalmente dentro del ámbito de los fondos de desarrollo regional (FEDER) que para ese período se encontraba en vigor (1989-1993), y los programas comunitarios de desarrollo de zonas rurales (LEADER). La financiación estaba prevista en un único presupuesto de tracto sucesivo. 
Las medidas de estímulo a las iniciativas empresariales se relacionaban con incentivos fiscales, económicos (subvenciones hasta el 50\% de la inversión) y financiación preferente. Una línea importante que se abre también es la conversión de deuda del Estado para proyectos de inversión turística en el exterior, en zonas de interés estratégico, y cobertura de los riesgos de inversión en proyectos turísticos en el exterior.

Tabla 16 Presupuestos del Plan Marco de Competitividad del Turismo Español (mill.ptas.)

\begin{tabular}{|l|l|l|l|l|l|}
\hline & 1992 & 1993 & 1994 & 1995 & TOTAL \\
\hline $\begin{array}{l}\text { P1. Futures- } \\
\text { Coordinación }\end{array}$ & 190 & 240 & 270 & 310 & 1.010 \\
\hline $\begin{array}{l}\text { P2. Futures- } \\
\text { Modernización }\end{array}$ & 2.450 & 2.930 & 3.150 & 3.440 & 11.970 \\
\hline $\begin{array}{l}\text { P3. Futures- } \\
\text { Nuevosproductos }\end{array}$ & 460 & 560 & 710 & 780 & 2.510 \\
\hline $\begin{array}{l}\text { P4. Futures- } \\
\text { Promoción }\end{array}$ & 6.469 & 7.125 & 7.850 & 8.635 & 30.079 \\
\hline $\begin{array}{l}\text { P5. Futures- } \\
\text { Excelencia }\end{array}$ & 450 & 650 & 720 & 820 & 2.640 \\
\hline
\end{tabular}

Fuente: Ministerio de Industria, Comercio y Turismo, 1992 
Tras la evaluación positiva que, en líneas generales, supuso el Plan Marco de Competitividad del cuatrienio anterior, y en el seno de un nuevo contexto político, tras las elecciones de 1996, surge formalmente lo que se denominó como "una nueva política turística".

Si bien la inquietud de los años precedentes se centraba en la preocupación por la posible pérdida de competitividad del turismo español y las estrategias tendían a recuperar valor turístico para destinos y empresas, el escenario económico, social y competitivo de los siguientes años da un giro radical: en el ámbito turístico no sólo no se pierde cuotas de competitividad sino que se alcanza un éxito sin precedentes en cuanto al número de llegadas de turistas internacionales.

\subsection{Plan marco de Competitividad del Turismo Español, FUTURES II (1996-1999)}

La nueva política turística nacional propulsada por TURESPAÑA (1996) incide en determinados principios rectores que si bien han estado presentes en los últimos años, van a cobrar ahora una especial relevancia, y son la sostenibilidad (económica, socio-cultural y medioambiental), la corresponsabilidad de todos los agentes públicos y privados y de las sociedades receptoras implicadas en el desarrollo turístico, concentración de las ayudas que permitan una mayor rentabilidad y multiplique su efecto demostración e integración de las iniciativas empresariales en proyectos conjuntos con las administraciones públicas.

Un eje estratégico que persiste en esta nueva iniciativa es el fortalecimiento de las llamadas ofertas turísticas alternativas, oferta turística de naturaleza 
y oferta turística cultural, cuyo desarrollo puede impulsar la economía de algunas zonas menos favorecidas. Para ello se acordó la potenciación de los Planes de Excelencia y Dinamización cuyo propósito fue incorporar a la actividad turística los destinos culturales rurales o del litoral que dispusieran de recursos con un buen potencial de atracción y susceptibles de organizarse como destino turístico.

Según Tea Cegos Consultur (2005), las inversiones realizadas como consecuencia de la ejecución de los planes se han dirigido hacia:

1. Infraestructuras y obras de mejora (51\%).

2. Creación y equipamientos $(23 \%)$.

3. Gestión (9\%).

4. Promoción (9\%).

5. Planes estratégicos y estudios $(8 \%)$.

El hecho de que un 9\% de las inversiones realizadas en los Planes de Excelencia y Dinamización se hayan dirigido a la mejora de la gestión turística de los destinos ha permitido que las futuras inversiones y el seguimiento de las actuales se realicen teniendo en cuenta aspectos relacionados con la planificación y la optimización de recursos (eficiencia).

A pesar de la declaración anterior de nueva política turística lo cierto es que se trata de una línea de acción fundamentalmente continuista, con algunos rasgos diferenciadores: mayor flexibilidad en la aplicación de los planes operativos - que pueden estar dirigidos indistintamente a subsectores, productos y destinos -, la intervención de una Secretaría General de Turismo reorganizada o la potenciación de Turespaña como ente asesor. Esta continuidad se refleja también en el nuevo contenido de los planes operativos que 
modernización (ahora denominado tecnificación e innovación), FUTURES excelencia (Futures destinos turísticos). FUTURES Coordinación y Cooperación se disgrega en dos: FUTURES coordinación y FUTURES cooperación internacionalización. Dos nuevos planes surgen de líneas de programas anteriores: FUTURES calidad y FUTURES formación. Desaparece el plan FUTURES promoción y surge FUTURES I+D.

Por otra parte, la oferta pública de servicios en su línea de calidad ${ }^{5}$, convocaba concurrencia pública entre asociaciones y entidades turísticas para optar a las líneas aprobadas en la misma en aplicación del Plan Marco de Competitividad del Turismo Español (1996-1999). Entre los proyectos seleccionados destacó, por su carácter estratégico para el sector turístico español, el de la planificación y desarrollo de un sistema de calidad en el sector hotelero español articulado en distintos períodos. Los proyectos fueron presentados por iniciativa de la Federación Española de Hoteles (FEH) y la Asociación de Zonas Turísticas de España (ZONTUR).

Las primeras auditorías de calidad tuvieron lugar en los meses de febrero y octubre de 1996 y, en noviembre del mismo año, se constituyó, por acuerdo de las asociaciones hoteleras implicadas en el proyecto, el Instituto para la Calidad Hotelera Española (ICHE) con el objetivo de impulsar el desarrollo cualitativo del sector hotelero español y constituyendo la infraestructura básica del nuevo Sistema de Calidad del sector hotelero español. Al mismo tiempo, se creó la Marca de Calidad y se inició el proceso de promoción y difusión de ésta que abarcó todo el año 1997.

El Instituto, en su calidad de órgano de representación del sector hotelero 
en materia de calidad, asume como funciones propias dos importantes tareas: por una parte, el desarrollo y gestión del Sistema de Aseguramiento de la Calidad y, por otra, la implantación de la Calidad Total.

Respecto al sistema, el Instituto asume la función de desarrollar y gestionar el marco normativo y reglamentario de funcionamiento, lo que implica la elaboración y/o verificación de las normas o estándares de calidad; los reglamentos de auditoría, certificación y control; el reglamento de uso de la marca de calidad y el reglamento de coordinación, homologación y acreditación de entidades adheridas o asociadas al sistema. Asimismo, verifica el cumplimiento del nivel de servicio requerido para la certificación de establecimientos y controla y garantiza su cumplimiento posterior.

Respecto a la Implantación de la Calidad Total, se compromete a (1) liderar la adhesión de todo el sector hotelero español al sistema de gestión de calidad. Se trata, por tanto, de diseñar e impulsar la estrategia nacional de implantación del sistema poniendo en práctica programas de trabajo vinculados a los diversos colectivos empresariales con el fin de sensibilizar y favorecer la integración de éstos en el sistema; (2) promocionar, con la financiación de la Administración Central, la marca de calidad entre los clientes finales y los intermediarios del sector hotelero; y (3) impulsar el intercambio de experiencias entre el sector hotelero comprometido con la calidad y otros colectivos sectoriales con el objetivo estratégico de la mejora global de la imagen del producto turístico español en el ámbito internacional.

Para facilitar la operatividad del Instituto, la estructura organizativa descansa en la idea de la descentralización mediante la cesión de ciertas facultades de representación a las asociaciones hoteleras locales, que deben, a partir 
de la firma del acuerdo de delegación, liderar la implantación del Plan de Calidad en su zona, constituyéndose como entes gestores del Plan.

En una segunda fase (1998-1999) que se podría denominar de expansión, el objeto del Plan de Calidad consistió en la consolidación de las normas anteriormente desarrolladas, extensión a otros productos específicos de alojamiento y desarrollo de nuevas herramientas para la implantación del sistema y de la gestión de la calidad, así como la creación del soporte estructural necesario para la extensión del Plan a todos los destinos turísticos nacionales que solicitaran su inclusión, además de a las cadenas hoteleras y a las asociaciones hoteleras independientes. En total se puede cifrar en unos 1.200 establecimientos en todo el territorio adheridos al sistema durante este bienio, si bien, con un porcentaje de certificación aún no demasiado elevado (un total de 42 establecimientos en 1998) ${ }^{6}$.

Como consecuencia de la sucesiva extensión horizontal del Plan de Calidad a los distintos subsectores turísticos (restauración, agencias de viajes, estaciones de montaña, casas rurales, campings) quienes aplicaban en la implantación del sistema en las empresas una metodología similar pero con normas específicas para cada subsector, surge en el seno de las distintas asociaciones promotoras, habitualmente las más representativas de cada uno de los subsectores de referencia, la idea de unir esfuerzos para un mejor aprovechamiento de los recursos disponibles, fundiendo todos los institutos creados específicamente para la gestión de la calidad (ICHE, INCAVE, ICRE, ICCE, ACTR y ATUDEM) en un único ente gestor denominado Instituto para la Calidad Turística Española (ICTE). Se trata de una entidad

${ }^{6} \mathrm{~A}$ principios del año 2002, el número total de empresas turísticas certificadas asciende a 252 , de las cuales 60 son hoteles.

${ }^{7}$ Instituto para la Calidad Hotelera Española (ICHE), Instituto para la Calidad de la Restauración Española (ICRE), Instituto para la Calidad en los Campings Españoles (ICCE), Asociación para la Calidad del Turismo Rural (ACTR), Instituto para la Calidad en Agencias de Viajes Españolas (INCAVE), Asociación Turística de Estaciones de Esquí y de Montaña (ATUDEM). 
Instituto para la Calidad Turística Española (ICTE). Se trata de una entidad privada, sin ánimo de lucro, creada a iniciativa del sector empresarial turístico con el apoyo financiero de la entonces denominada Secretaría de Estado de Comercio y Turismo. El acta fundacional fue firmada el 14 de abril de 2000.

Figura 9

\section{Sistema de calidad del ICTE}

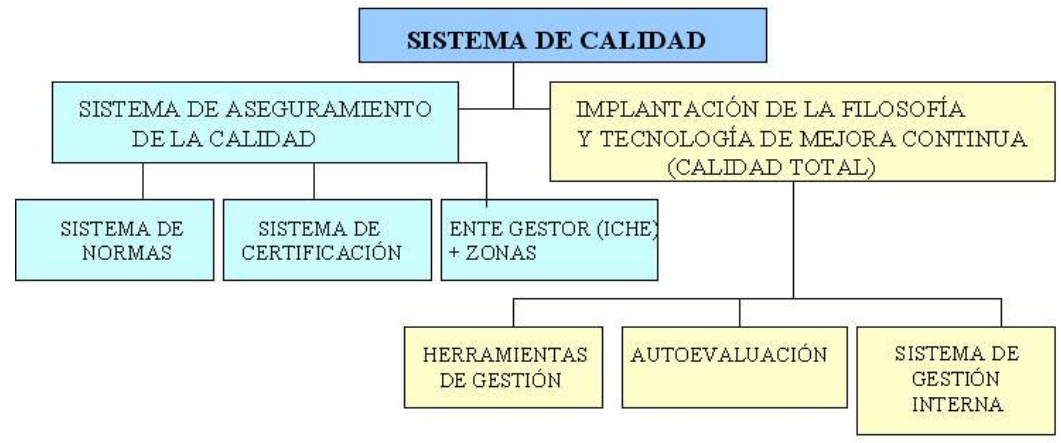

Fuente: ICTE, 2000

El ICTE es un Instituto cuyos objetivos son: (1) la normalizacion, que implica la creación, desarrollo, actualización y revisión del conjunto de normas de calidad turística; (2) la certificación, mediante la concesión de un sello de Calidad Turística Española; (3) la gestión del Sistema de Calidad Turística Española (SCTE), mediante el apoyo a las empresas turísticas en aspectos tales como formación y sensibilización en el sistema; (4) publicaciones; (5) el soporte técnico a través de las correspondientes delegaciones territoriales; (6) la difusión y promoción de la calidad en todo el sector turístico a través de la promoción de la marca y de las empresas certificadas. 
Con respecto a la representación en la Asamblea General, los distintos Institutos fundadores ostentan diferentes cuotas que pueden, según los estatutos, ser modificadas anualmente. Para el primer ejercicio se fijó de la siguiente manera: $40 \%$ hoteles y apartamentos turísticos, $15,5 \%$ agencias de viaje, $15,5 \%$ restaurantes, $15,5 \%$ campings, 8,5 alojamientos rurales, $5 \%$ estaciones de esquí y de montaña. Lo que implica un predominante peso específico del sector de alojamiento especialmente si se unen en votación todas las cuotas concernientes al alojamiento hotelero y extrahotelero de cualquier tipología.

El sistema de calidad ideado en un principio por el antiguo ICHE y extendido en la actualidad en torno a la idea integradora vista anteriormente, tiene dos frentes simultáneos: el aseguramiento de la calidad y la gestión de la calidad total mediante la implantación de la filosofía de la mejora continua.

Las normas de calidad se desarrollan bajo los dos principios complementarios de la autorregulación subsectorial y de la coherencia intersectorial. Por el primero de estos principios, son los responsables de cada subsector los que fijan los compromisos que asumen frente a sus clientes, siempre basados en diagnósticos sectoriales sobre las expectativas de la demanda. Por el segundo principio, todas las normas deben estar sujetas a un enfoque, alcance, metodología, estructura y un nivel de exigencia común en los aspectos homogéneos y un nivel coherente en los aspectos heterogéneos. Los órganos técnicos del ICTE, en concreto, el Comité Técnico Normativo Intersectorial, son los responsables de garantizar estos aspectos. Las exigencias de coherencia deben ser impuestas siempre desde los órganos intersectoriales. 


\subsection{Plan Integral de Calidad Turística Española, PICTE (2000- 2006 )}

Como consecuencia de la fuerte expansión y desarrollo obtenida en los años anteriores, la Secretaría General de Turismo (SGT) de España, propietaria de la tecnología del Sistema Calidad Turístico Español (SCTE), decidió estructurar y organizar el SCTE para lograr una mayor eficiencia y cobertura de todas las necesidades de la industria turística española, situación que se concretó en el Plan Integral de Calidad Turística Española (PICTE).

La multiplicidad del sector turístico como actividad económica capaz de generar notables beneficios en la renta de las comunidades locales, tanto en los sectores tradicionalmente turísticos (industria de soporte) como en aquellas otras industrias conexas o afines, requiere de la motivación y colaboración de todos los agentes del destino que, de una forma u otra, proveen servicios consumidos por los turistas, ya sean de carácter público o privado, turísticos o no turísticos. Esta situación plantea un nuevo objetivo: alcanzar un nivel de calidad homogéneo dentro de un mismo destino, de tal manera que no se lleguen a generar deficiencias que comprometan ni la percepción de la calidad del destino por parte del turista ni su satisfacción como consumidor. 
El PICTE estructura el SCTE en tres áreas o ámbitos de actuación.

\section{1- SCTE Sectores}

En esta área de actuación se incluyen cada una de las ramas de la actividad turística que disponían ya de su propia estructura de calidad, concretada en unas normas y un ente gestor, el correspondiente instituto sectorial de la calidad. Bajo este esquema se engloban los 13 sistemas de calidad subsectorial:

Bajo este esquema se engloban los trece sistemas de calidad subsectorial:

- hoteles y apartamentos turísticos

- restaurantes

- $\quad$ agencias de viajes

- campings

- casas rurales

- $\quad$ estaciones de esquí y montaña

- $\quad$ empresas de autocares de turismo

- $\quad$ empresas de tiempo compartido

- $\quad$ oficinas de turismo

- palacios de congresos

- convention bureaux

- $\quad$ espaciones naturales protegidos

- playas

Los productos del SCTE Sectores forman el conjunto de instrumentos metodológicos que permiten a una organización la implantación del sistema de calidad dentro del subsector en el que desarrolla su actividad, y que son: 
P1: Nuevo enfoque del modelo SCTE

P2: Estructura para la gestión de la calidad

P3: Normas de calidad turística

P4: Método de autoevaluación

P5: Solución inmediata de aspectos críticos

P6: Procedimientos operativos

P7: Satisfacción del cliente

P8: Quejas y sugerencias

P9: Indicadores de servicio

P10: Cuadro de mando para medición del servicio

P11: Manuales de la calidad y de los procedimientos

P12: Proyectos de mejora

P13: Revisión del sistema de calidad

P14: Directrices para la auditoría de certificación

P15: Implicación y capacitación del personal en la Mejora continua P16: Mantenimiento y mejora del Sistema de Calidad P17: Directrices para la auditoría de renovación

Estas herramientas para la mejora de la calidad se llevan a cabo a través de un proceso que consta de cuatro etapas: lanzamiento, desarrollo, consolidación y mejora continua.

\section{2- SCTE Buenas Prácticas}

Este instrumento surgió para poder satisfacer las necesidades de organizaciones y empresas de pequeño tamaño, que por sus características propias les era imposible alcanzar los niveles de exigencia contemplados en el SCTE Sectores. Conviene recordar, en este sentido, que la mayor parte de la industria turística española está configurada por empresas de pequeño y mediano 
tamaño, lo que lleva aparejada, como inevitable consecuencia, el que sean éstas las que determinan la percepción final de calidad que un turista obtiene respecto de un destino turístico.

La Secretaría General de Turismo lo cede para su aplicación en aquellos destinos turísticos que, estando llevando a cabo la implantación y desarrollo de un Plan de Excelencia Turística o de Dinamización Turística, deseen aplicar este instrumento en su ámbito territorial, con el objetivo de estimular al sector privado en el conocimiento e implantación de los sistema de calidad turística.

El SCTE Buenas Prácticas, está caracterizado por:

- Estar dirigido a 23 subsectores: albergues, artesanos, alquiler de vehículos, bares y cafeterías, comercios turísticos, empresas de actividades deportivas y de ocio, guías turísticos, museos, centros de iniciativas turísticas, policía turística, puertos deportivos, taxis, agencias de viajes, campings, casas rurales, convention bureaux, espacios naturales, estaciones de esquí, hoteles y apartamentos turísticos, oficinas de información turística, palacios de congresos, playas y restaurantes.

- Estar basado en la sistematización y evaluación de calidad de las prácticas normales y ordinarias que lleva a cabo el personal de las empresas y negocios turísticos en contacto directo con el cliente.

- Las normas se elaboran a partir de las consideraciones y recomendaciones llevadas a cabo por el propio personal en contacto 
con los clientes, mediante sesiones colectivas de trabajo lideradas por personal técnico contratado por la SGT a tal efecto.

- $\quad$ Es de fácil aplicación y muy flexible, pudiéndose adaptar por tanto a las diferentes realidades empresariales (tamaño, ubicación, tipología de producto, demanda) que pueden darse dentro de un mismo destino turístico.

- Su implantación se lleva a cabo de forma progresiva en tres etapas: 1. Etapa de lanzamiento

P1: El destino, la empresa y el profesional turístico.

P2: Manual de Buenas Prácticas para cada uno de los subsectores intervinientes en el proceso.

2. Etapa de desarrollo

P3: Satisfacción del cliente

P4: Plan de mejora

3. Etapa de Consolidación y Acceso al SCTE Sectores

- Consolidación, para aquellos subsectores que no dispongan de una norma específica en el SCTE Sectores, que incluya la formación en calidad y cualificación turística, según las necesidades y características que los actores del destino hayan considerado oportuno previamente en las dos fases anteriores. Acceso al SCTE Sectores, para aquellos subsectores que sí

- disponen de una normativa específica:

○ P5: Normas de calidad turística

o P6: Método de autoevaluación 


\section{3- SCTE Destinos}

El PICTE señaló la necesidad de disponer de un instrumento conceptual y metodológicamente adecuado para poder definir y gestionar adecuadamente la calidad de un destino turístico de forma permanente, estableciendo a su vez las necesarias vinculaciones con los sistemas de calidad que pudieran estar siendo implantados por la industria turística a través de la iniciativa privada. Este sistema de calidad turística en destinos constituye uno de los proyectos más ambiciosos dentro del PICTE puesto que además de requerir un enfoque orientado hacía la mejora continua y hacia la recuperación y puesta en valor de los recursos turísticos empleados en el proceso productivo, se caracteriza por la gestión coordinada del destino.

Los destinos turísticos interesados deben remitir su solicitud a la Federación Española de Municipios y Provincias (FEMP), quien llevará a cabo una primera valoración, para posteriormente proponer a la SGT los destinos candidatos a obtener la asistencia técnica necesaria con la aportación correspondiente de la SGT. En el período 2000-2003, inicio de su fase de desarrollo, se integraron nueve destinos de muy diferentes características, lo que permitió crear un modelo adaptado a las distintas tipologías. A lo largo de 2003-2004 se implantó en quince nuevos destinos, siendo, en la actualidad, medio centenar los destinos que trabajan en la implantación del SICTE-Destinos (fig. 10). 
Figura 10 Tipología de destinos SICTE

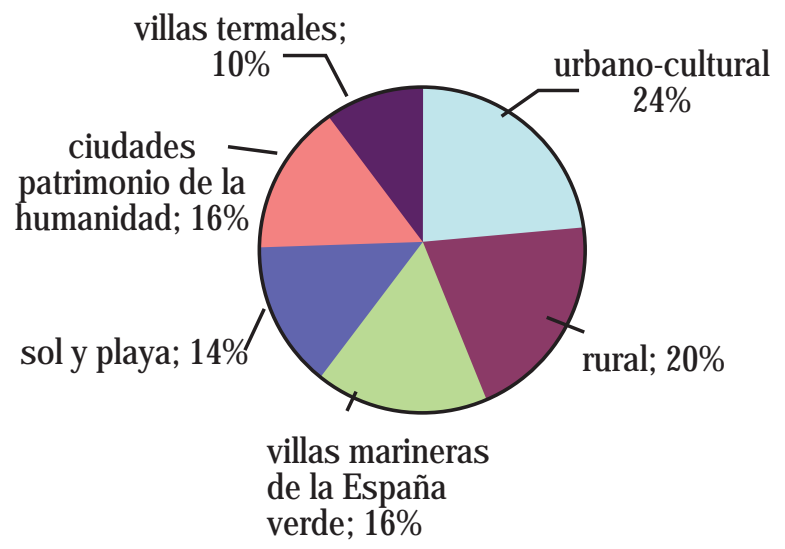

Fuente: Tea Cegos Consultur, 2005

Para la implantación del SCTE Destinos se requiere un total de cinco productos metodológicos que reúnen los procedimientos para la implantación de las tres herramientas que componen el sistema: el ente gestor, los estándares intersectoriales y sectoriales, y el cuadro de indicadores de calidad. Conjuntamente, se disponen de un total de ocho textos básicos que contienen la norma de funcionamiento o contenidos mínimos:

- Productos:

o Módulo de gestión integral del destino: el ente gestor de la calidad turística.

- Manual para la implantación de los estándares de calidad sectoriales eintersectoriales.

- Manual para la implantación del cuadro de indicadores de la calidad en el destino.

- Manuales de buenas prácticas. 
○ Módulo de sensibilización.

- Textos:

- Reglamentos de funcionamiento del ente gestor.

- Plantilla para la planificación de la mejora.

- Requisitos para la adhesión al SCTE Destinos.

- Protocolo de adhesión al SCTE Destinos.

- Procedimiento para la autorización del uso del distintivo.

- Normas de uso del distintivo.

- Manual para la implantación del cuadro de indicadores de calidad en el destino.

- Modelo de encuesta tipo para la demanda del destino.

○ Hojas de introducción de datos: aspectos generales del destino, subsectores y demanda.

○ Hojas de resultados: aspectos generales del destino, subsectores y demanda.

A continuación citaremos una serie de iniciativas llevadas a cabo en distintos ámbitos territoriales de España dirigidas a la implantación y mejora de la calidad en productos turísticos con objeto de lograr una clara diferenciación de sus productos en el mercado. Destacamos las siguientes:

\section{1- Club de Calidad Cantabria Infinita}

Este club de calidad surge en el año 2000 por iniciativa del Gobierno de la Comunidad de Cantabria con el objetivo de crear un producto de alojamiento de calidad y diferenciado de otros posibles competidores. En el futuro se complementará este programa con uno similar para restaurantes.

Pueden optar a este programa aquellos establecimientos de alojamiento que 
reúnan las siguientes características:

- No superar las 25 habitaciones.

- Disponer de una arquitectura singular y/ o tradicional.

- Estar ubicado en zona rural o entorno natural de Cantabria.

\section{2- $\quad$ Plan de Calidad de Destino Gijón}

Este plan se crea en el año 2002 dentro del Plan de Excelencia Turística, con el objetivo de lograr establecer unos estándares de calidad para las empresas del sector turístico del municipio. El plan consta de dos partes, habiendo finalizado la primera de ellas en septiembre de 2003, y estando en estos momentos en fase de desarrollo la segunda.

Por su parte, y dentro de los programas de estímulo o apoyo a la implantación de la calidad, encontramos una serie de iniciativas que han sido desarrolladas dentro del marco autonómico por los respectivos organismos competentes con el objetivo de estimular y apoyar el conocimiento e implantación de la calidad en el sector turístico dentro de sus respectivos ámbitos territoriales.

1- Instituto de Calidad Turística (IQT) del Gobierno de las Islas Baleares, tiene como objetivo ofrecer al sector turístico una nueva herramienta que permita hacer efectivo el paso hacia un modelo de calidad turística que permita un aseguramiento de la misma a través de las funciones informativas, formadoras, de mediación, de asesoramiento y creación de productos turísticos diferenciados, ejecutándose este objetivo a través de dos líneas de actuación:

- Apoyo a la implementación de los sistemas de calidad, sostenibilidad y medio ambiente de los destinos turísticos.

- Promoción de la calidad en los destinos turísticos y en los 
sectores adheridos a los proyectos de calidad, potenciando el asociacionismo y el desarrollo de las innovaciones tecnológicas.

2- Madrid Excelente, es un programa surgido a iniciativa de la Comunidad de Madrid en el año 2000, orientado a ofrecer una herramienta de apoyo a los empresarios para fomentar la cultura de la calidad y la excelencia en las organizaciones (empresas, consumidores, colectivos empresariales y profesionales) de la región.

3- Qualitur, programa constituido en el año 1999 por la Agencia Valenciana del Turisme, de la Generalitat Valenciana, con el objetivo de difundir e impulsar la cultura de la calidad entre las empresas y entidades turísticas de la Comunidad Valenciana. Entre sus objetivos específicos, se citan los siguientes:

- Sensibilizar y promocionar la cultura de la calidad entre los agentes del sector turístico.

- Resaltar la importancia de la competitividad de las empresas y destinos turísticos.

- Promocionar a las empresas y entidades turísticas que apliquen criterios de calidad en su gestión mediante actos de entrega pública de los certificados obtenidos (ISO o ICTE).

- Cualificar a los empresarios y profesionales del sector turístico en los principios básicos de la gestión de la calidad y el medio ambiente a través de la Red de Centros de Turismo (CdTs).

Un requisito imprescindible para la implantación y mantenimiento a lo largo del tiempo de SICTE Destinos es la creación y mantenimiento de un ente gestor que tenga una visión estratégica más allá de la mera promoción del destino, función habitual de los entes gestores y cuya misión principal 
consiste en la dinamización y control del proyecto en su destino. En este punto cada destino decide cuál es la identidad y forma jurídica idónea que debe adoptar ese ente gestor, pero es imprescindible la existencia de la figura de un gerente responsable que coordine las actuaciones que se solicitan. Un reciente estudio realizado por el centro de dirección turística de ESADE, en colaboración con la Federación Española de Municipios y Provincias (2005), que recoge la evolución comparada de la gestión de los municipios españoles, ofrece los siguientes datos de interés:

- Se constata la evolución positiva con respecto al número de entes gestores de que disponen los municipios españoles, incrementándose en 2005 un 14\% con respecto a las cifras obtenidas en un estudio similar realizado en 1997.

- Más de la mitad de la muestra (1.531 municipios) dispone en la actualidad de una concejalía propia de turismo como centro neurálgico de la gestión $(58,04 \%)$.

- La presencia de los patronatos municipales se sitúa en torno al $12,59 \%$.

- Los consorcios se mantienen en un 5,59\% y el resto de organismos son mancomunidades (3\%), entes públicos diversos $(12 \%)$, oficinas de turismo (3\%) y agencias de desarrollo $(1 \%)$.

- La gestión pública prevalece sobre la privada y la mixta, aunque se observa un incremento importante de esta última fórmula a través de entidades sin ánimo de lucro, los propios consorcios, los patronatos y otros organismos. 


\subsubsection{Innovación}

\subsubsection{Marco conceptual de la Innovación}

La Teoría Evolucionista (Nelson y Winter, 1982) pone de relieve la gran variedad y diversidad existente en el proceso de innovación en las organizaciones. Las entidades, partiendo de múltiples bases iniciales, van evolucionando con el tiempo, generando diferentes capacidades genéricas y tecnológicas que se combinan de múltiples formas. Se trata de distintos procesos de innovación, lo que determina que cualquier generalización sea errónea (Pavit, 1984).

Aún así, en coexistencia con la variedad y el cambio, la dinámica industrial se caracteriza también por un cierto grado de persistencias, lo que hace posible identificar regularidades (Dosi et al., 1994). Como señalan Buesa y Molero (1998), surge así un nuevo enfoque sobre la innovación que, frente al tradicional, consistente en buscar un conjunto de factores determinantes de esta actividad, intenta conocer la estructura interna del proceso innovador y destaca especialmente la diversidad de situaciones innovadoras existentes en la realidad. Se pretende buscar asociaciones más que relaciones causales, de contenido muy diverso, mediante un análisis de interdependencia (Galende y de la Fuente, 2003).

Los patrones de innovación definen agrupaciones de empresas que comparten ciertas características básicas que delimitan su comportamiento y tratan de reflejar las diferencias existentes en las formas en que se producen y organizan las actividades innovadoras. Las organizaciones son consistentes en el desarrollo de actividades innovadoras que sean compatibles con el núcleo 
central de capacidades tecnológicas que dominan, y en el momento en que estas capacidades se diferencian de unas entidades a otras, surgen también patrones de innovación diferenciados (Nelson, 1991).

La revelación inicial de que el proceso de innovación en las empresas no es uniforme y de que por tanto se pueden distinguir patrones de innovación se debe a los estudios de Schumpeter, en los que se estudian dos marcos tecnológicos. El primero, propuesto en el trabajo "The Theory of Economic Development" (Schumpeter, 1934), se denomina destrucción creativa y se caracteriza por una gran cantidad de empresas innovadoras que se suceden unas a otras en la posesión de ventajas tecnológicas. El segundo es propuesto en el trabajo "Capitalism, Socialism and Democracy" (Schumpeter, 1942) y se denomina acumulación creativa, caracterizado por el predominio de unas pocas grandes empresas que realizan su labor innovadora de forma continua e impiden con ello la entrada de nuevas entidades.

Como se observa, la mayor parte de las aportaciones que han marcado un hito en el estudio de la innovación centran su atención en la componente tecnológica, hasta el punto que se suele asociar el concepto de innovación con el de innovación tecnológica. En efecto, el cuerpo doctrinal mayoritario sobre el concepto de innovación hace referencia casi exclusivamente a la dimensión tecnológica como fuente principal de cambio en las organizaciones, por lo que se hace necesario abordar de forma especial el ámbito tecnológico aplicado al turismo.

Es mucho lo que se ha escrito sobre innovación estando, como se ha comentado, el énfasis puesto casi siempre en la dimensión tecnológica que rodea a la innovación y, sobre todo, lo que ésta implica en cuanto a cambios 
en los productos o servicios. Sin embargo, hablar de innovación es algo más, pudiéndose generalizar como la capacidad de ofrecer valor al cliente, o lo que es lo mismo, que el cliente encuentre nuevos atributos por los que esté dispuesto a pagar. En la búsqueda de este objetivo se encuentra implícito el logro de ventajas competitivas, de cambios en las reglas del juego de la competencia entre organizaciones $\mathrm{y}$, fundamentalmente, de estrategias de negocio (O’Hare, 1988).

Para muchas organizaciones y sectores de actividad la alternativa más idónea para mantener o recuperar competitividad es la de ser innovadores, pero frecuentemente no entienden qué es lo que esto significa realmente. Como consecuencia de ello podemos encontrarnos con una desviación en lo que se hace con respecto a lo que se debería hacer, cabiendo la posibilidad de obtenerse como resultado un fracaso.

Al igual que con otros muchos conceptos la idea más extendida y popular no suele ser la más correcta, lo que da lugar al surgimiento de equívocos y mitos difíciles de superar. En este sentido, la imagen más popularizada del concepto de innovación gira habitualmente alrededor de tres variables (O’Hare, 1988):

1. Tecnología. Para muchas personas innovar significa necesariamente desarrollar una nueva tecnología o su aplicación para un uso específico.

2. Producto o servicios. Está muy extendida la idea de que la innovación supone la generación de un nuevo producto o servicio, o lo que es lo mismo, el proceso de innovación culmina con el lanzamiento al mercado de un nuevo concepto. 
3. Aleatoriedad. A menudo se cree que la innovación se basa en la inspiración de un genio creativo que trabaja de forma independiente y sin el cual ésta no sería posible. Es decir, se puede ser innovador si tal genio se encuentra en la organización, en caso contrario sería imposible.

Estas percepciones, compartidas en mayor o menor medida por gran parte de los directivos y de los empresarios en general, conllevan una serie de implicaciones que son las que, a la postre, generan la visión intuitiva y normalmente errónea que generalmente se tiene del concepto de innovación.

Dichas implicaciones, que se recogen en la Figura 10, se explican brevemente a continuación.

1. Sectores maduros. Si la innovación es sinónimo de tecnología entonces parece que no tiene sentido hablar de innovación en sectores maduros o de bajo desarrollo tecnológico, razón por la que habitualmente se considera que es un esfuerzo no fructífero y los directivos asumen que no se trata de algo importante para el éxito futuro de sus organizaciones.

2. Tecnología. Si la innovación está ligada estrechamente a la tecnología ello implica que ha de ser el departamento de investigación y desarrollo (I+D) el que asuma exclusivamente la responsabilidad de innovar, de forma autónoma con respecto al resto de áreas de la organización. 
3. Responsabilidad de la innovación. Si se considera que únicamente un departamento, habitualmente el de I+D, se responsabiliza del proceso de innovación, el resto, es decir, finanzas, recursos humanos, o producción, sólo actúan como meros apoyos sin ejercer ninguna acción creativa, por lo que deben adaptarse a los planes de innovación del departamento líder.

4. Integración. Si la innovación consiste solamente en el desarrollo de nuevos productos o servicios liderados por un único departamento, no parece que la búsqueda de nuevas formas de realizar procesos tenga sentido, por lo que el impacto global de la innovación sobre la organización es limitado en alcance.

Figura 11

Las percepciones básicas determinan cómo contemplan las personas a la innovación
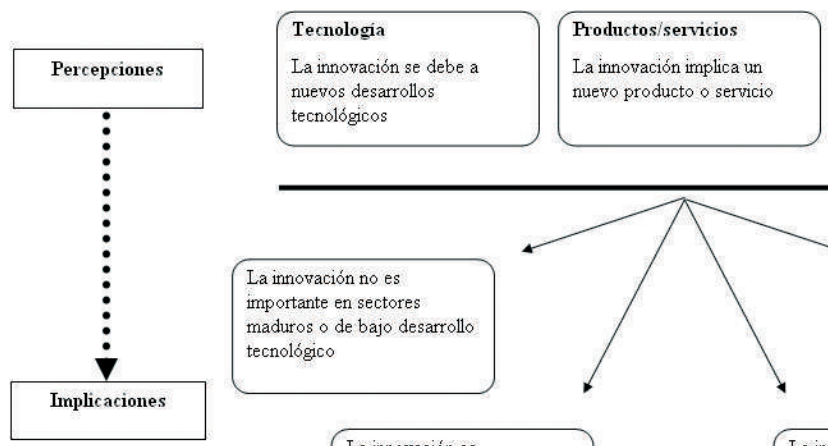

Aleatoriedad

El proceso innovador es

aleatorio por naturaleza

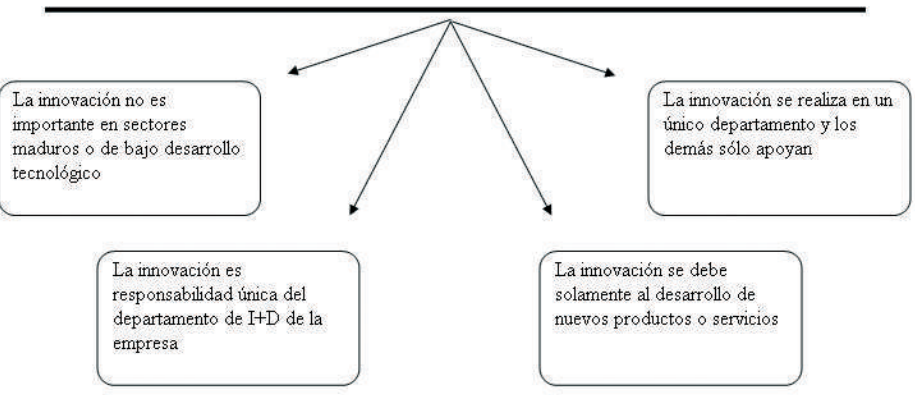

Fuente: O’Hare (1988) 
Los anteriores son ejemplos típicos de implicaciones equívocas sobre lo que supone la innovación para la organización, fruto, como se ha comentado, de una serie de percepciones que se han ido instalando en la imagen colectiva compartida por muchos directivos y empresarios. Por esta razón, y con objeto de que no se confine la innovación a una práctica meramente testimonial o de bajo impacto para la organización, se hace necesario establecer una definición precisa de lo que ésta supone realmente. No se trata tanto de un ejercicio académico para establecer términos empresariales, sino de utilidad práctica, pues las definiciones determinan las percepciones y éstas, en última instancia, son las que conducen a la acción (Gallego y Osorio, 2005).

Por tanto, siguiendo a O'Hare (1988) adoptamos la siguiente definición de innovación: "nuevas formas de ofrecer valor al cliente", definición en la que todos sus términos tienen relevancia:

1. Nuevas. La innovación requiere de la identificación de maneras alternativas de solucionar problemas existentes en la organización y de satisfacer las demandas de mercado, de forma que sea algo más que una mera optimización de recursos. Por tanto, la innovación debe consistir en nuevas formas de satisfacer las necesidades básicas y no solamente en realizar mejor las tareas. Esta generación de ideas novedosas requiere romper con viejos moldes y patrones de conducta, es lo que se denomina pensamiento o reflexión lateral.

2. Ofrecer. Resulta necesario que la innovación no esté relacionada únicamente con el producto o servicio en sí, sino con todas las actividades del negocio, tales como la distribución, la administración interna o el marketing, cuya coordinación e integración es la que, 
en suma, permite lograr la razón de ser de la organización, que es la de ofrecer algo por lo que el cliente esté dispuesto a pagar.

3. Valor. La búsqueda de la innovación debe estar guiada por el deseo de ofrecer al cliente aquello que le haga valorar más lo que recibe. En ocasiones esto supone ofertar algo con mayor capacidad y/o atributos, mientras que en otras ocasiones implica, por el contrario, ofrecer menos atributos pero más sencillez, fiabilidad, accesibilidad técnica y económica. . En resumen, el denominador común es la identificación de necesidades insatisfechas, tanto en el mercado como conjunto o, de forma más habitual, en un determinado segmento del mismo.

4. Cliente. Frecuentemente la búsqueda de la innovación es dirigida desde un punto de vista estrictamente interno, guiada por el logro de un mayor nivel de eficiencia. Sin embargo, si no está específicamente orientada hacia el cliente tal optimización resulta de poco valor. El verdadero éxito de la innovación radica en la cuidadosa atención a las necesidades de los clientes más que en la solución de la problemática interna. Conviene indicar aquí que, en ocasiones, la innovación puede suponer menores niveles de eficiencia, aunque ello no significa un problema si la innovación resuelve necesidades reales del cliente de forma mejor que las soluciones actualmente disponibles.

Como se puede deducir de la definición, la innovación es un campo muy amplio que abarca todos los aspectos de la organización, desde cómo funciona ésta hasta sus relaciones con los clientes. Muchas de las innovaciones más 
significativas han tenido escasa o nula participación por parte de las nuevas tecnologías. Otras han tenido lugar en sectores maduros o de bajo nivel tecnológico. Sin embargo, todas comparten una característica común, y es que suponen nuevas formas de ofrecer valor a los clientes.

\subsubsection{Modelos de innovación}

En el ámbito académico existen numerosos modelos teóricos que explican las formas en que una innovación puede ser introducida en una organización y cómo puede, a su vez, influenciar la relación con los clientes. De todos ellos, probablemente, el más fácil de asimilar es el que distingue entre dos tipos de innovación, describiendo cómo pueden ser desarrolladas y gestionadas, así como sus implicaciones frente a los clientes. Tal categorización diferencia entre innovación incremental y radical (Fernández, 1996). La primera, como su nombre indica, es aquella que supone cambios relativamente menores en los productos, servicios o procesos de la organización, frente a la radical, caracterizada por significar una forma totalmente nueva de operar, tanto desde el punto de vista de la empresa como de la competencia.

Figura 12 Modelos de innovación

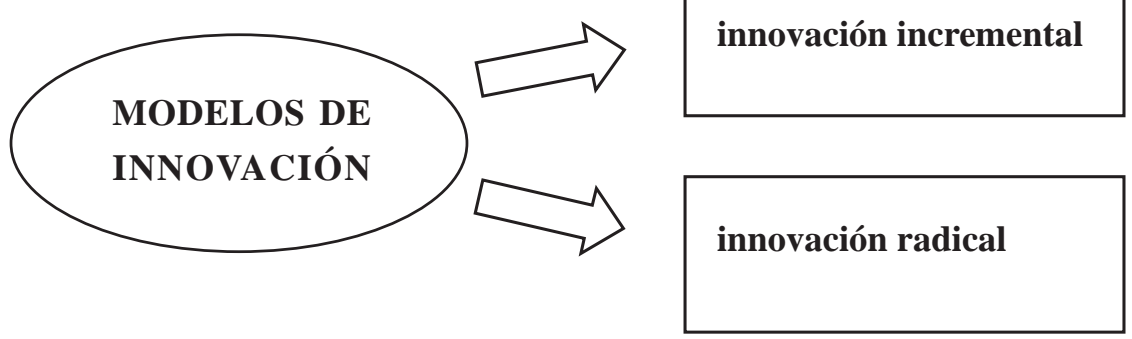

Fuente: Adaptado de Fernádez (1996). 
La innovación incremental suele ser fruto de la utilización de tecnologías y formas de trabajo ya conocidas a las que se les confiere algún tipo de novedad o, simplemente, se mejoran respecto a su forma habitual de utilización, de manera que suponga una alternativa nueva. Muchas veces es resultado también de la adaptación de innovaciones que han hecho otras empresas competidoras o de organizaciones que realizan sus actividades en otros sectores.

En lo que se refiere a su desarrollo, la innovación incremental puede ser resultado de un proceso interno de promoción de ideas procedentes de los empleados, bien como resultado de su conocimiento de los productos, servicios y procesos realizados en la organización, o bien a través de su interrelación con otros agentes externos, como pueden ser los propios clientes, con sus sugerencias y quejas, los proveedores o los distribuidores. También suele ser resultado de los esfuerzos de la dirección por controlar la actividad de otras empresas, y estar al corriente de sus innovaciones para responder rápidamente a las mismas copiándolas o mejorándolas (Malhotra et al., 2001).

Una u otra vía es igualmente válida como forma de ofrecer nuevas alternativas de valor para los clientes. Ahora bien, en ambos casos es preciso que la dirección de la organización marque objetivos y criterios, porque ambas vías implican la necesidad de mecanismos que permitan que puedan ser llevadas a cabo. Así, a título de ejemplo, para promover la innovación a partir de las ideas de los empleados es necesario crear en la cultura de la empresa las condiciones que favorezcan la afluencia de propuestas. Alternativamente, la copia y mejora de innovaciones externas precisa de la existencia de personas y medios para hacer un seguimiento de las prácticas del mercado. 
Finalmente, desde el punto de vista de las implicaciones sobre los clientes, destinatarios últimos de la innovación, el modelo incremental supone normalmente pequeñas mejoras en la rentabilidad o en la cuota de mercado que, sin embargo, son rápidamente neutralizadas cuando otras empresas advierten el cambio y lanzan la misma alternativa o similar a precios más competitivos o con características que la hacen más atractiva a los ojos de los clientes. Una forma de impedir que esto suceda consiste en introducir a la organización en una corriente continua de innovaciones incrementales. En este caso, no tanto por su magnitud sino por su elevada cantidad, supone como resultado una valoración mayor por parte de los clientes, que terminan percibiendo algo más que pequeños cambios y que, además, para los competidores resulta difícil copiar dada la gran cantidad de nuevas alternativas que sería necesario imitar.

En lo que se refiere al otro modelo de innovación, el radical, éste se basa en la adopción de desarrollos tecnológicos hasta ahora desconocidos o inaccesibles para el gran público y para la mayoría de las empresas del sector. Normalmente constituyen el resultado de los departamentos de I+D de las grandes organizaciones o de la compra y puesta en funcionamiento de patentes desarrolladas por terceros (Malhotra et al., 2001). Esta característica supone, a los ojos del consumidor, que se encuentra ante un nuevo concepto por el que puede sentir una elevada atracción.

No cabe duda que la gestión de una innovación radical plantea desafíos y complicaciones que, en un momento puntual, son muy superiores a los asociados a las innovaciones incrementales. La incertidumbre y el riesgo inherente a las mismas, así como los habitualmente elevados costes económicos hacen de este tipo de actividad un reto que pocas organizaciones se deciden 
a abordar. Por otra parte, los problemas de tipo organizativo y comercial que pueden suponer estas innovaciones constituyen también frenos a este tipo de acción, porque los cambios pueden tener importantes repercusiones internas, tales como cambios en la estructura organizativa, con lo que ello supone de modificación en las relaciones de poder intra-empresa. También es posible encontrarse con la necesidad de ejecutar modificaciones en la forma de comercializar los productos o servicios, con cambios en los canales o la propia actividad y/o razón de ser de la fuerza de ventas.

Por último, y en lo que respecta a las implicaciones sobre los clientes, como todas las grandes apuestas, las ganancias o las pérdidas pueden ser de proporciones muy elevadas. En caso que la innovación radical tuviera éxito, con una buena acogida entre los clientes, la ventaja de ser el primero podría suponer que, con una buena gestión, se mantuviera una posición de liderazgo en el tiempo, pues está comprobado que existe una lealtad hacia la primera marca si ésta logra mantener la calidad frente a las respuestas que, inevitablemente, ofrecerán los competidores. Es esta una de las razones por las que tanto se argumenta que la única forma de competir en los turbulentos entornos actuales es mediante la innovación y la gestión del conocimiento adquirido con la misma, pues puede suponer esa ventaja de inicio que, con tesón y buenas estrategias se puede mantener e incrementar en el tiempo (Grant, 1996).

Sin embargo, en el lado opuesto, no hay duda que un fracaso en la introducción de una innovación radical puede tener implicaciones igual de importantes que un éxito, pero esta vez desde un punto de vista negativo, es decir, los perjuicios económicos y de credibilidad pueden suponer un lastre del que, tal vez, la organización no logre recuperarse. Por esta razón es necesario 
incidir en que la innovación debe ser un proceso gestionado, es decir, no se trata de algo aleatorio fruto de una inspiración momentánea, sino que debe ser resultado de un proceso coherente en el que exista unas estrategias y mecanismos de evaluación que permitan asegurar que la innovación está en consonancia con el camino marcado por la organización y que ha sido evaluada convenientemente para minimizar los riesgos de fracaso; y si éste se produjera que sirva para aprender de los errores y seguir firme en el desarrollo de nuevas innovaciones (O’Hare, 1988).

\subsubsection{Innovación en turismo}

Tradicionalmente el estudio de la actividad innovadora se ha centrado en las empresas de manufactura, dado que éstas tienen más versatilidad para la generación de nuevos productos y, además, al basarse en tecnologías que facilitan la fabricación también abren la puerta a la innovación mediante cambios en los procesos productivos. Sin embargo, en las empresas de servicios la investigación sobre patrones de innovación no ha sido tan amplia, al ser, generalmente, menor la utilización de la tecnología en sus actividades. La excepción más significativa la encontramos en la adopción de las tecnologías de información, en la que muchas empresas de servicios han sido punteras, por delante de las de manufactura. En nuestro caso, el sector turístico, eminentemente de servicios, también ha sido poco estudiado desde el punto de vista de la innovación, si bien existen estudios muy interesantes que han arrojado luz sobre las características propias que adquiere la innovación en él (Jacob y Bravo, 2001; Sirilli y Evangelista, 1998).

El sector turístico se caracteriza por un notable nivel de evolución fruto de los continuos cambios sociales, políticos y económicos que se producen 
tanto en el ámbito nacional como internacional. Como respuesta a los incesantes desafíos que van surgiendo se hace preciso responder con nuevas alternativas en la forma de ofrecer servicios. Además, se trata de un sector bastante transparente, en el que resulta relativamente sencillo identificar las innovaciones realizadas por la competencia e imitarlas rápidamente. Esta imitación se ve facilitada por la práctica imposibilidad de patentar los servicios o productos ofrecidos, que es la única garantía legal que preserva los derechos al inventor (Fernádez, 1996).

Cabe indicar que al referirnos a la unidad de análisis objeto de la innovación en el turismo podemos hacerlo desde dos perspectivas. La primera, de ámbito amplio, está relacionada con el concepto de destino turístico, y engloba a todas aquellas organizaciones y empresas turísticas que se encuadran dentro de un referente territorial homogéneo. La segunda perspectiva, de ámbito más particular, se refiere a las organizaciones que, a título individual, constituyen el tejido turístico de un destino o de una entidad geográfica mayor, como es una región o país. Si bien en ambos casos hablar de innovación tiene el mismo denominador común, que no es más que la búsqueda de nuevas formas de ofrecer valor a los clientes, la forma de abordar este objetivo varía. Por así decirlo, al destino turístico corresponde una actuación agregada o macro, mientras que la organización responde a una iniciativa individual o micro.

En los dos casos será necesario articular los mecanismos que permitan lograr el objetivo mencionado. No obstante, no cabe duda que en la búsqueda de niveles elevados de innovación por parte de un destino turístico intervienen numerosos agentes, que deben coordinar sus actuaciones para que éstas den resultados positivos. Entre estos agentes podemos citar a los gobiernos (en 
sus distintas categorías; supranacional, nacional, regional, provincial y local), agentes sociales (partidos políticos y asociaciones ciudadanas), representantes empresariales (confederaciones de empresarios, sindicatos) y otros grupos (colectivos ecologistas, académicos). Dada la diversidad de objetivos distintos que, en un momento dado, pueden perseguir estos agentes, se hace necesaria la existencia de instituciones de referencia que marquen la pauta a seguir y con capacidad de aglutinación y de hacer cumplir las directrices que de ella emanen.

Cuando nos referimos al sector turístico en sentido empresarial podemos identificar una serie de agentes relacionados, pero al mismo tiempo autónomos, de tal forma que no podemos afirmar que el nivel de innovación en todos ellos es homogéneo. Algunos de ellos son más susceptibles de adoptar innovaciones, especialmente de tipo tecnológico, mientras que otros operan en segmentos más estables en los que aparentemente no parece tan necesaria la innovación como mecanismo de supervivencia. Estos agentes, protagonistas de la actividad turística podemos agruparlos en las siguientes categorías:

1. Alojamiento (hoteles, apartamentos, recintos de camping, etc.).

2. Restauración (bares y restaurantes).

3. Ocio y cultura (parques temáticos y de atracciones, locales nocturnos, museos, instalaciones deportivas, etc.).

4. Organización (agencias de viaje, operadores turísticos).

5. Transporte (compañías aéreas, navieras, terrestres, alquiler de vehículos, etc.).

De esta lista indicativa de agentes que participan en la actividad turística se deduce rápidamente las grandes diferencias que pueden aparecer entre grupos 
al referirnos a la innovación, pues resulta patente que los cambios que debe efectuar una compañía aérea para sobrevivir en el competitivo mercado del transporte aéreo no es comparable con los niveles de innovación que debe llevar a cabo un museo antropológico local para captar turismo cultural. Además, dentro de un mismo tipo de actividad, por ejemplo la de hospedaje, la dimensión del hotel o de la cadena a la que pertenece es un indicador del esfuerzo en innovación que se efectúa. Cuanto mayor es el tamaño más elevado es el número de innovaciones, lo cual también es lógico por cuanto las grandes cadenas hoteleras nacionales e internacionales basan su competencia en la oferta de nuevos servicios y procesos en un mercado también muy competitivo (de Burgos et al., 2003). Un pequeño hotel rural necesita innovar, sin duda alguna, aunque su segmento de mercado tiene unas características tales que le permiten mantenerse al margen de la elevada competencia existente entre las grandes cadenas y no precisar de la misma proporción de acciones innovadoras.

Por otra parte, aunque de forma muy similar a otros sectores de actividad, al hablar de innovación en la organización turística el abanico incluye las siguientes posibilidades:

1. Producto o servicio. Constituye una nueva oferta al cliente o una modificación sobre las ya existentes, de tal forma que se valore no sólo la novedad sino también el incremento de utilidad que se obtiene.

2. Procesos. Referido a los medios utilizados para la provisión de un producto o servicio, así como la forma en que se organiza la generación del mismo. 
3. Comercialización. Aspecto de la innovación relacionado directamente con la forma de hacer llegar al cliente el producto o servicio mediante la identificación de nuevos mercados, técnicas publicitarias y entrega del mismo.

4. Organización. Relacionada con la forma de estructurar jerárquica y departamentalmente la empresa y sus relaciones internas, así como las externas con proveedores y distribuidores.

Cabe indicar que, en los últimos años, la mayor parte de las innovaciones en el sector turístico se basan en desarrollos tecnológicos, especialmente procedentes del campo de la tecnología de información, si bien todas las áreas significativas, especialmente en la hostelería, se ven favorecidas por la innovación tecnológica general. Entre estas áreas se puede citar cocinas, gestión energética y medioambiental, seguridad, limpieza y, también todo lo relacionado con la gestión administrativa. Dado que la mayor proporción de innovación tecnológica viene de la mano de las tecnologías de información, y al ser éstas de acceso generalizado por parte de la inmensa mayoría de las organizaciones, podemos concluir que el tipo de innovación más frecuente en el sector turístico es el incremental, siendo mínima la fracción de innovaciones que pueden denominarse radicales.

En las tablas 17,18 y 19 (anexos) se ofrece una lista de ejemplos de posibles innovaciones en el sector turístico, clasificándolas según sean de base tecnológica o no y, en el primer caso, si se refiere a la tecnología de información (TI). También se incluye la categoría de innovación de que se trata y han sido clasificadas según su utilidad potencial antes, durante y con posterioridad a la estancia del cliente en un destino turístico. 
posterioridad a la estancia del cliente en un destino turístico.

En relación directa con lo mencionado anteriormente, se puede citar una serie de circunstancias o factores de sensibilidad que afectan al éxito de la innovación tecnológica en los productos y servicios turísticos. Dichos factores tienen una especial relevancia porque determinan en amplia medida el éxito de la transferencia y del desarrollo tecnológico en las empresas turísticas. Estos elementos se pueden categorizar de la siguiente manera (Viceriat y Treboul, 2003):

1. La falta permanente de datos sobre las necesidades de nuevos servicios por parte de los consumidores turísticos y de los profesionales del sector. Preguntas como cuáles son las necesidades de nuevos servicios a los que la tecnología debe dar respuesta, con qué nuevas funcionalidades o para qué usos específicos aplicarla, son ejemplos de cuestiones que muchas veces no encuentran una respuesta rápida, puesto que existe una tendencia a situar la tecnología en sí como fin y no como medio, dejando de lado una cuestión primordial, como es la satisfacción de una necesidad o una demanda del mercado. Por esta razón, una mejor comprensión de las necesidades de los consumidores debería permitir adaptar las innovaciones a los clientes. Tal conocimiento procedería de datos obtenidos directamente de los consumidores, motivo por el cual esta cuestión se erige como un factor de sensibilidad de primer orden.

2. Omnipresencia de las tecnologías de información en la generación y venta de productos turísticos. Efectivamente, el sector turístico constituye uno de los primeros ámbitos de aplicación de las tecnologías de información, algo que se hace patente en Internet, en donde el turismo, 
especialmente los viajes, constituyen el sector más representado tanto en número de sitios Web como de transacciones. Otros medios, como las bases de datos, programas informáticos de gestión, comunicaciones entre ordenadores, por poner algunos ejemplos, también ocupan un importante papel en este panorama. En este apartado el factor de sensibilidad o de éxito lo constituye la capacidad de integrar tecnologías y aplicaciones informáticas en procesos cada vez más complejos de generación de oferta turística.

3. La cadena de generación, gestión y venta de productos y servicios turísticos está cada vez más integrada, como respuesta a una demanda muy volátil, personalizada, exigente, sujeta a numerosas reglamentaciones y en la que crece continuamente la preocupación por el medio ambiente. Todo ello impone la necesidad de interaccionar y coordinar las diferentes funciones que se llevan a cabo en el seno de una empresa turística. Dicha evolución se apoya en desarrollos tecnológicos considerables que, a su vez, conducen a que las organizaciones rediseñen su organización. La tecnología, en este caso, está orientada a gestionar la información necesaria para poder integrar todas estas funciones convenientemente. Por esta razón, el factor de sensibilidad consiste en la capacidad de encontrar, primero, y de dominar, después, las aplicaciones informáticas que permitan lograr los objetivos de integrar información procedente de las distintas funciones de negocio.

4. Un factor de sensibilidad que afecta al éxito de la transferencia e innovación tecnológica reside en la conciencia sobre la importancia que la tecnología tiene sobre el sector. Como no se conoce o, sobre todo, no se percibe el peso que tiene la tecnología raramente se toma en plena 
consideración, por parte de los agentes que intervienen, la importancia que juega esta variable en el contexto turístico. Como muestra para cuantificar el valor añadido que aporta la tecnología pensemos, por ejemplo, en la repercusión que para el sector turístico supondría que Internet dejara de operar como red durante 24 horas, o bien que el ordenador servidor de un hotel se estropease por idéntico periodo de tiempo o, por poner otro ejemplo, que las máquinas canceladoras de tickets en un parque temático se averiaran también por el mismo espacio de tiempo. La cuestión reside aquí en la importancia que para todos los agentes relacionados con la innovación en el turismo (empresas turísticas, empresas tecnológicas, poderes públicos, entidades financieras, etc.) tiene la concienciación sobre el creciente valor añadido que para este sector de actividad supone la innovación tecnológica.

Figura 13. Factores de sensibilidad en la innovación tecnológica en el sector turístico

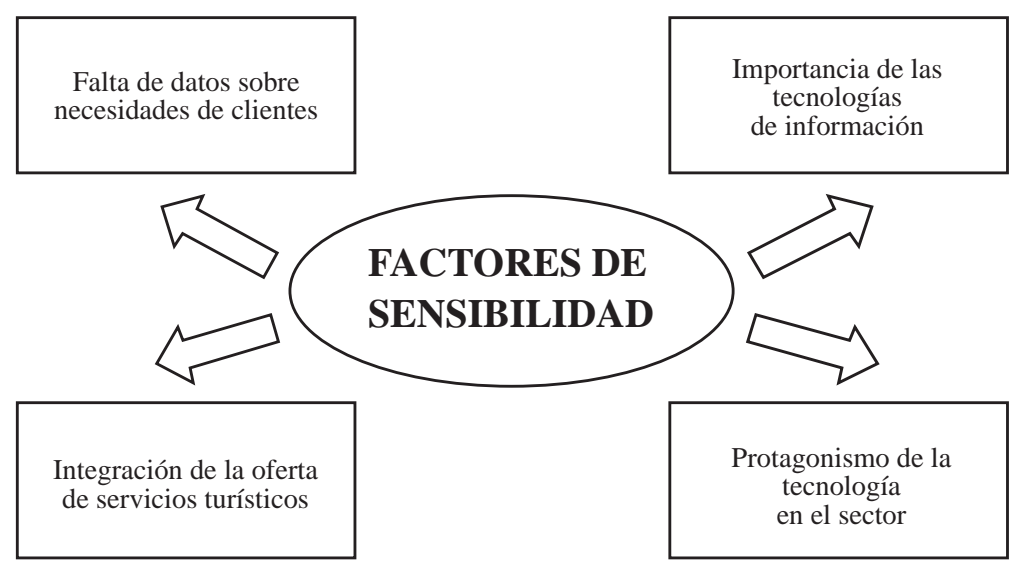

Fuente: Viceriat y Treboul (2003) 
5.- La tecnología se ha convertido progresivamente en uno de los principales vectores de desarrollo en el campo del ocio y del turismo para el gran público y de cambio en las formas de organización de los territorios y de las organizaciones. En el curso de los próximos años el paisaje turístico se transformará profundamente por la previsible multiplicación de innovaciones en los productos y servicios asociados a la tecnología (Viceriat y Treboul, 2003) debido tanto a las crecientes exigencia de los clientes como a la presión hacia el cambio ejercida tanto por turistas, como las organizaciones que necesitan ser más rentables, más productivas, rápidas, eficaces y, a la vez, más simple y fácilmente administrables, como por los destinos, cada vez más completos y competitivos en relación a la gama de ofertas disponible en su territorio.

\subsubsection{Posicionamiento}

\subsubsection{Introducción}

Siguiendo las definiciones más comunes en la materia, podemos afirmar que posicionamiento es: “ La toma de una posición concreta en la mente de los sujetos a los que se dirige una determinada oferta u opción, de tal manera que, ante una necesidad que dicha oferta u opción puedan satisfacer, se dé preferencia a ésta frente a otras similares" ( Ries y Trout, 1991) o "el acto de diseñar una imagen de organización, unos valores y unas ofertas, de manera tal que los consumidores comprendan, valoren y se sientan más atraídos por lo que propone la organización que por lo que proponen sus competidores" (Kotler,2001). 
De estas definiciones, se desprenden una serie de consideraciones importantes para poder determinar cuando una organización dispone de alguna ventaja competitiva en la que basar su estrategia:

- Son los clientes quienes deben valorar si esta diferencia es significativa o no.

- Debe ser claramente distinta de la que oferte la competencia.

- Esta distinción/ diferencia ha de ser claramente percibida por los consumidores.

- Debe ser difícil de imitar.

- Ha de ser rentable para la organización que la gestiona.

- Ha de ser rentable, y percibida como tal, por los consumidores.

El proceso estratégico que debe guiar la organización a la hora de establecer su posicionamiento en el mercado, la toma de una posición en la mente del consumidor o el acto de diseñar una imagen de organización, unos valores y unas ofertas, debe estar fundamentado en los tres pilares básicos: análisis estratégico (externo e interno), elección estratégica, ejecución y seguimiento de la estrategia (Learned et. al., 1965) ya que, la posición estratégica depende tanto de los recursos y capacidades de la organización como del entorno competencial que la rodea, unido a sus valores, creencias, deseos y objetivos. (Garrido, 2003).

Será, por tanto, desde el campo de la planificación estratégica desde donde habrá que abordar el estudio del posicionamiento como dimensión fundamental para el logro de la competitividad. El planteamiento estratégico, según Serra (2000), comprende el marco estratégico, constituido por la misión, visión, el posicionamiento y la estrategia de la organización y, su relación con el 
comportamiento organizacional, formado por las interactuación que se produce entre la estructura, la cultura, las políticas y el liderazgo.

El marco estratégico identifica su propósito estratégico (Hamel y Prahalad, 1995), estableciendo el campo de actuación futura en el que va a moverse la organización, su sentido de destino, al establecer una misión compartida que genera el compromiso emocional de los recursos humanos con la organización y su sentido de orientación que identifica el posicionamiento que se desea obtener en un horizonte de medio y largo plazo. El Posicionamiento se refleja en el lugar que la organización quiere ocupar junto con sus productos o servicios en la mente de los actores críticos, esto es, cualquier individuo o grupo que puede ser afectado por las acciones, decisiones, políticas y prácticas u objetivo de la organización (Carroll, 1989) y de los consumidores de esos bienes o servicios (Iglesias y Arriola, 2004).

Por su parte, la estrategia de negocio hace referencia a las actuaciones que deben llevarse a cabo para mejorar el posicionamiento competitivo de cada una de las unidades de negocio de la empresa en sus respectivos entornos (Falcón y Osorio, 1998), partiendo de la misión y de la organización y de sus competencias o capacidades básicas distintivas, examinando la cadena de valor y analizando las opciones que ofrecen los recursos y capacidades disponibles ( Garrido, 2003).

A los efectos de esta investigación, aplicamos esta idea de estrategia al considerar que, los grupos de interés en un destino local, deben plantearse la gestión integral del destino turístico utilizando los principios de la estrategia organizativa. En definitiva, tanto el reconocimiento de un municipio como destino turístico como la decisión, estratégica, del desarrollo mediante la vía 
de la actividad económica que llamamos turismo, implica que sus recursos y capacidades deben ser gestionados bajo una misma visión compartida y mediante el reconocimiento explícito de unos objetivos formalmente establecidos cuyo alcance pudiera medirse en términos de eficiencia. Considerar el destino, en definitiva, como una, o varias, unidades de negocio.

Centrándonos, por tanto, en la aplicación de la estrategia de negocio como la forma concreta de competir en un determinado sector con el fin de alcanzar unas mayores ventajas competitivas sostenibles a largo plazo (Porter, 1980; 1985) el proceso de planificación estratégica aplicable a un destino turístico comprendería las siguientes fases:

1- La identificación de las unidades de negocio y unidades estratégicas de negocio que conforman la cadena de valor en la entrega del producto.

2- La selección de objetivos estratégicos y operativos que deben cumplirse.

3- Análisis del entorno general.

4- Análisis del entorno competitivo.

5- Análisis de recursos disponibles en la "unidad de negocio" (marketing, producción/ operaciones, finanzas, recursos humanos) para proceder a la identificación de sus fortalezas y debilidades.

6- La formulación de estrategias. 
Por tanto, el proceso de planificación estratégica pivotaría sobre estos tres ejes: análisis, elección de estrategias y ejecución. Considerando los objetivos de esta investigación, delimitaremos , a continuación, los aspectos más relevantes de los dos primeros ejes (el análisis y la elección de estrategias) para, finalmente, llevar a cabo una reflexión sobre la fijación de objetivos y concreción de lo que debería ser el posicionamiento estratégico en las organizaciones de carácter mixto público- privado aplicable al ente gestor que, como ya hemos mencionado en el apartado dedicado a la dimensión "eficiencia", consideramos imprescindible en la gestión de un destino turístico.

El análisis del entorno general tiene como objetivo poder establecer un cuadro de indicadores que permitan el diagnóstico, evaluación y previsión de aquellos factores que tienen potencial para afectar a la organización en su conjunto, y permite construir tendencias de tal modo que la organización pueda prepararse adecuadamente para afrontarlas con garantías de éxito (Hax, y Majluf, 1991). En este sentido, los ajustes al entorno, por su propia naturaleza, no pueden ser tan flexibles y rápidos en el conjunto del destino turístico como lo puede ser dentro de las empresas que lo configuran. Por lo que el establecimiento de observatorios permanentes sobre un conjunto de variables relevantes ofrecería una valiosa información para el rápido establecimiento de estrategias de adaptación.

Si bien el objetivo final de la evaluación del entorno general tiene que ser el de determinar las oportunidades y amenazas que éste ofrece, o se considera que puede llegar a ofrecer también es posible identificar otros beneficios directos de este proceso de análisis de entre los que destaca el fomento del pensamiento estratégico en toda la organización (Duncan, et al., 1992). 
La situación de los destinos turísticos con presencia de mercados internacionales en su territorio requiere de un análisis más complejo y pormenorizado que el correspondiente a un destino en fase inicial de su desarrollo y el de aquellos cuyo tipo de demanda sea, normalmente, interna. En este punto cabría considerar en el análisis del entorno general no sólo los aspectos relativos al territorio receptor sino el que se refiere al ámbito específico del consumidor turístico. Es decir, en el caso de un destino turístico que disponga de flujos de demanda internacional su planificación estará condicionada por el entorno general que afecte a esos países-mercados, por lo que es hacer una consideración específica respecto de cada uno de los entornos generales de cada país de origen de los respectivos flujos de demanda.

Igualmente, tampoco parece cuestionable el afirmar que el conjunto de organizaciones públicas y privadas que integran el producto turístico se verá afectada por su propio entorno general de país y que tendrá una incidencia directa en el desarrollo de su actividad profesional. Naturalmente si las principales corrientes de flujo turístico son internas, el llamado turismo doméstico, el entorno general será el mismo para tanto para oferentes como para consumidores.

Aceptada la necesidad de llevar a cabo un análisis adecuado de los entornos generales para poder tomar las decisiones oportunas en el ámbito de la organización, los inconvenientes que conviene solventar son los relativos a la dificultad de disponer de la información y los recursos adecuados para cuantificar y medir convenientemente las variables o factores clave que determinan y caracterizan ese entorno, así como el coste económico que implica para las organizaciones este análisis, no siempre justificado desde 
el punto de vista de la eficiencia interna. Incluso en el supuesto de disponer de la información a través de fuentes secundarias, la dificultad que implica el poder llevar a cabo previsiones o estimaciones a medio y largo plazo (Garrido, 2003).

Por otra parte, de entre todos los modelos de análisis del entorno específico, probablemente, el más conocido y aplicado es el propuesto por Porter (1980) que parte de la existencia de cinco fuerzas competitivas que, a su vez, pueden ser evaluadas a partir de una serie de variables que contribuirán a identificar como oportunidad o amenaza la naturaleza de los eventos externos.

\subsubsection{Posicionamiento $\mathrm{y}$ ente gestor}

Desde el punto de vista conceptual, algunos autores sostienen que debe abordarse una perspectiva más amplia que la de la de los clientes o beneficiarios directos del producto como destinatarios finales de las estrategias públicas de posicionamiento proponiendo enfoques más abiertos con inclusión de más actores en este proceso, de tal modo que se logre una mayor interacción entre la sociedad, los individuos y las organizaciones públicas (Arellano, 1997) . Así, el posicionamiento participativo debe ser el objetivo a lograr por una organización pública moderna y acorde con el sentir de las civilizaciones desarrolladas, en las que se intenta transmitir la posibilidad de participación de los agentes críticos, introduciendo en el proceso de decisiones públicas los intereses colectivos o difusos que emergen de la sociedad, articulándolos a través del debate racional y la lógica discursiva ( Sánchez, 1991). No obstante, esta participación debe vertebrarse en torno a la regulación de unos procedimientos que garanticen un discurso racional, limpio, abierto y en condiciones de igualdad entre todas las partes afectadas 
por las decisiones (Villoria, 1996), aspecto éste que refuerza el aspecto garante de la Administración Pública.

Mediante la combinación de las variables flexibilidad y nivel de garantías, Iglesias y Arriola (2004) defienden la existencia de cuatro modelos de posicionamiento para las organizaciones públicas:

a) Posicionamiento marginal, donde la organización está enmarcada por unos niveles de flexibilidad y de garantías ofrecido muy escasos, siendo la consecuencia de ello una organización ineficiente y con escasa legitimidad tanto a nivel institucional como a nivel de resultados.

b) Posicionamiento Eficaz/ Eficiente, caracterizada por un elevado nivel de eficiencia/ eficacia pero escaso en lo referente al nivel de garantías ofrecido, lo que da lugar a una organización muy orientada a la obtención de rendimientos como fuente de obtención de su legitimidad.

c) Posicionamiento Garantista, definida por una línea de protección garantista elevada y poca capacidad de flexibilidad donde, por tanto, serán los procedimientos y cauces normativos y reglados los que definan su línea de actuación, lo que redundará en una legitimidad de la organización como sinónimo de legitimidad institucional.

d) Posicionamiento Participativo en el que la organización pública correspondiente combina, en altas dosis, el nivel de garantías y el nivel de flexibilidad, lo que hace que su legitimidad derive tanto de su carácter institucional como de sus logros de gestión. 
Por su parte, su flexibilidad se pone de manifiesto en la capacidad de que dispone la propia organización de optar entre diversas alternativas de decisión a la de actuar, pudiendo en consecuencia, valorar y ponderar el interés público primario con otros de carácter secundario, ya sean públicos o privados (Giannini, 1988) , y donde la búsqueda de la eficiencia no debería quedar constreñida al ámbito de lo estrictamente económico sino que otros intereses sociales, culturales y medioambientales deben ser igualmente contemplados.

De ambas características (alto nivel de garantías y alto nivel de flexibilidad) derivará una legitimidad de gran valor para la organización pública por cuanto se percibe la existencia de un código de valor compartido por la organización, la sociedad y los actore. Unos procedimientos conocidos y la imagen transmitida acorde con ellos (reforzado todo ello por la existencia de una valoración positiva de los rendimientos de la administración y gestión de esos procesos (Bañón y Carrillo, 1997).

Por tanto, y como conclusión de lo anteriormente expuesto, la organización pública tiene que articular de forma clara a quién se va a dirigir, cómo y por qué (Iglesias y Arriola, 2004) para lo que debe:

- Definir una visión concreta y bien delimitada en cuyo proceso de elaboración hayan participado todos los actores implicados que, o bien deban estar implicados en el posterior desarrollo e implementación de las acciones, o bien puedan verse afectados por los resultados directa o indirectamente por dichas acciones.

- Definir un marco de actuación estratégico idóneo, en función de los objetivos asignados y los recursos y capacidades disponibles, que actúe como guía y referencia de la organización. 
- Fijar un objetivo de posicionamiento a alcanzar y establecer los mecanismos idóneos para controlar la evolución en el cumplimiento o desviaciones en ese objetivo, evitando en todo momento la actitud de "laissez faire, laissez paser", basado en el convencimiento de que el posicionamiento se obtendrá de forma automáticamente derivada de la legitimidad institucional.

- Gestionar el conocimiento en el ámbito interno de la organización $\mathrm{y}$, muy especialmente, en los recursos humanos para que actúen de forma coordinada y coherente con el marco estratégico diseñado por la organización.

\subsection{Modelo para la evaluación de la gestión competitiva de destinos turísticos en su fase inicial de desarrollo. Auditoría de Gestión Turística Competitiva (AGTC).}

El conocimiento teórico-conceptual de las dimensiones que determinaban la competitividad debe complementarse con un instrumento que nos permita medir, en un destino turístico, el despliegue de la función de gestión como fuente de ventajas competitivas.

Con este instrumento, los gestores de un destino turístico podrán, en primer lugar, medir su posición competitiva inicial o de partida y, en segundo lugar, marcar una pauta o conjunto de pautas de actuación que sea una referencia cierta para establecer las actuaciones a desarrollar para mejorar esa posición 
inicialmente detectada. Adicionalmente, y en la medida que este instrumento se aplicara a otros destinos, podría servir como elemento referencial para establecer una comparación objetiva entre los diferentes destinos turísticos analizados.

En el proceso metodológico para definir adecuadamente dicho instrumento procedimos a establecer, en primer lugar, para cada una de las dimensiones consideradas, cuáles podrían ser los factores clave para determinar su nivel de desarrollo y, a su vez, para cada uno de estos factores, cuáles podrían ser las variables fundamentales que inciden en esta evolución. Por último, a cada una de estas variables se le establecieron un conjunto de subvariables.

Para determinar de forma objetiva cuáles podrían ser los tres últimos grupos (factores clave, variables y subvariables) se llevaron a cabo sucesivas sesiones de trabajo con un grupo de gestores públicos internacionales especializados en desarrollo turístico local provenientes de los cuatro ámbitos o niveles que intervienen en un destino turístico municipal, es decir, nivel local, regional, nacional y supranacional.

Los objetivos perseguidos con la realización de estas sesiones de trabajo fueron:

1- Fomentar un debate abierto e interactivo para poder perfilar, desde un punto de vista práctico y operativo, cómo se podía aplicar el concepto de competitividad a un destino turístico y cuáles eran los elementos y características que lo podrían definir, validando o no nuestra hipótesis de partida sobre cuáles son las dimensiones de la competitividad. 
2- Establecer si, tal y como nosotros manteníamos inicialmente, la adecuada actuación por parte de gestores competentes sobre una serie de factores clave y variables en la gestión de los destinos turísticos podría ser o no fuente de ventajas competitivas para un destino turístico.

3- En caso afirmativo, es decir, en caso de que la hipótesis anterior se validara, determinar cuáles eran esos factores clave y variables de cada dimensión.

4- Por último, establecer una ponderación en cuanto a la importancia que, a su juicio, podían o debían tener cada uno de los factores clave y de las correspondientes variables.

En la primera reunión con los expertos se desarrollaron cuatro sesiones monográficas que estaban orientadas a la obtención de conclusiones sobre qué es la competitividad, cómo se define, qué dimensiones engloba y qué valor debería otorgarse a cada una de ellas. El resultado fue altamente enriquecedor ya que, dada la configuración del grupo de expertos (diferentes niveles de competencias, diferentes países, distinto nivel de representación pública y privada), se pudieron alcanzar varias conclusiones:

a) La absoluta necesidad de que la gestión de los destinos turísticos se lleve a cabo siguiendo unas pautas de actuación que orienten y enmarquen adecuadamente la acción conjunta de los sectores públicos y privados.

b) Que dicha actuación conjunta tenga como necesaria referencia la 
búsqueda permanente de competitividad y que ésta pueda ser, a su vez, sostenida en el tiempo para lograr que el desarrollo turístico local sirva como motor de desarrollo social y económico de la comunidad local.

c) Que las dimensiones que determinan la competitividad, tal y como nosotros considerábamos inicialmente, eran la eficiencia, la calidad, la innovación y el posicionamiento. En este sentido, no obstante, los expertos consideraron que la innovación no debía considerarse en sí misma una dimensión de la competitividad, sino que debía considerarse como una consecuencia de la implantación de un proceso integral de gestión de la calidad, de tal modo que aquella formaría parte, en realidad, de la dimensión de la calidad.

A la vista de estas conclusiones, se desarrolló un documento simplificado, en formato de encuesta que, partiendo del documento original, nos permitiera cumplir con el resto de objetivos, es decir, definir cuáles eran los factores clave y las variables fundamentales que deberían, a su vez, englobarse en cada una de las dimensiones mencionadas - eficiencia, calidad y posicionamiento - para, a continuación, establecer un valor o ponderación para cada una de ellas. Estas encuestas se realizaron de forma sucesiva centrándonos en cada una de las sesiones en una de las dimensiones establecidas (Anexo 3).

En total, se desplegaron quince preguntas con un promedio de ocho ítems de valoración (subvariables) cada una. La escala utilizada para medir la valoración de las preguntas del cuestionario ha sido una escala no comparativa 
de Likert de cinco categorías en la que (1) representa "sin importancia", (2) "poca importancia", (3)"neutro", (4) “importante" y (5) "muy importante".

La estructura de las preguntas del cuestionario corresponde, en síntesis, al siguiente planteamiento:

\section{Dimensión 1. - Eficiencia}

- La eficiencia es el reflejo interno de la calidad, de tal modo que el objetivo estratégico de la misma debe ser lograr la satisfacción óptima de los clientes internos del destino turístico, esto es, la industria turística local y de la propia comunidad residente. De este modo, el desarrollo turístico será un instrumento eficaz para lograr un mejor bienestar y una mayor calidad de vida de los integrantes de esa comunidad local.

\section{Factores Clave:}

(1) Órgano de Gestión, se parte de la premisa de que el destino turístico (DT) debe disponer de un órgano de gestión basado en la cooperación público-privado cuya misión sea la definición, aplicación y control de la política turística local. Sus variables son :

- Organización y estructura.

- Programas de actuación.

(2) Desarrollo de la industria turística local, en tanto que los clientes internos directos de la política turística local y motor del crecimiento 
económico de la zona, la industria turística local debe lograr unos niveles de desarrollo óptimo para, de este modo, generar el valor añadido necesario para el progreso de la sociedad. Sus variables son:

\section{- Vertebración /estructuración de la industria turística.}

- Desarrollo de la industria turística.

(3)

Bienestar de la comunidad local, considerando el carácter instrumental que el turismo debe tener en el logro de la mejora del bienestar y calidad de vida de la comunidad local en los destinos en los que actúa, el órgano gestor debe considerar siempre la satisfacción de la comunidad local como el marco de obligatoria referencia de todas sus acciones en política turística. Sus variables son:

\section{- Desarrollo económico.}

- Desarrollo sociocultural.

- Sostenibilidad medioambiental.

\section{Dimensión 2.- Calidad}

- $\quad$ El objetivo estratégico de esta dimensión debe ser la de lograr el aseguramiento de la calidad de producto ofrecido mediante la constatación sistemática y continuada de que éste responde adecuadamente a las necesidades y expectativas de la realidad social, económica, política y cultura en la que actúa, logrando así la satisfacción del consumidor final, el turista.

\section{Factores Clave:}


(1) Calidad de Diseño se entiende por calidad de diseño el conjunto de acciones que el destino turístico, a través de su organismo de gestión correspondiente, lleva a cabo para conocer de forma continua y sistemática las necesidades y expectativas que tienen sus mercados de referencia. Sus variables mínimas a considerar son las siguientes:

- Investigación de mercados /demanda.

- Definición del producto.

(2) Calidad de Conformidad se incluyen aquí el conjunto de acciones y programas que el destino turístico, su órgano gestor, debe llevar a cabo para poner a disposición de los consumidores turísticos el producto o productos turísticos idóneo/s para lograr la satisfacción óptima de las necesidades y expectativas de sus respectivos producto- mercado. Está formado por las variables:

- Calidad de conformidad previa al consumo turístico.

- Calidad de conformidad posterior al consumo turístico.

(3) Innovación viene representada por el conjunto de acciones y programas que el destino turístico lleva a cabo para estimular en el sector privado y para desarrollar en los productos de titularidad pública, la cultura de la innovación permanente como factor clave para el logro de una posición competitiva sostenible. Formado por:

- Innovación en el producto.

- Gestión de los factores para la innovación. 


\section{Dimensión 3.- Posicionamiento}

- El posicionamiento comprende el conjunto de acciones que tienen por objetivo lograr transmitir eficazmente al consumidor el conjunto de valores que integran el producto turístico ofrecido y que ha de responder a una estrategia previamente fijada en relación con su entorno y con los recursos y capacidades disponibles.

\section{Factores Clave:}

(1) Estrategias, el destino turístico, a través de su órgano gestor, debe haber llevado a cabo un análisis, tanto del entorno competitivo, como de los recursos y capacidades disponibles y, en función de ello haber formalizado una estrategia de posicionamiento. Variables a considerar:

\section{- Definición.}

- Ejecución.

- Comunicación.

- Distribución.

Por otra parte, el desarrollo de las subvariables que entrañan cada una de estas dimensiones, factores y variables son las que se enuncian a continuación: 


\section{D1.- FC 1.1- Variable 1.1.1: Organización y estructura}

\section{Subvariables:}

1- El destino turístico dispone de un órgano específico de gestión de la política turística local (Gestor del Desarrollo Turístico, GDT), independiente de la corporación pública competente en el territorio.

2- El GDT tiene presupuesto propio e independiente para su funcionamiento interno.

3- La estructura organizativa del GDT está dimensionada en función de su capacidad para generar

4- En el GDT están proporcionalmente representados los distintos colectivos empresariales, sociales, culturales, medio ambientales y políticos que tengan incidencia directa en el producto turístico local.

5- El GDT dispone de unos estatutos o normas de funcionamiento interno formalizadas y conocidas por todos los integrantes.

6- El GDT tiene una misión definida que se revisa, al menos, cada cinco años.

7- La dirección del GDT debe recaer en personas debidamente especializadas en gestión turística.

8- El proceso de selección y nombramiento de la dirección del GDT debe haber respondido a criterios de objetividad y transparencia. 


\section{D1.- FC 1.1.- Variable 1.1.2: Programas de actuación}

\section{Subvariables:}

1- Las actuaciones del GDT responden a una planificación estratégica concertada entre los distintos agentes del destino turístico.

2- El GDT tiene definido un presupuesto anual para las actuaciones en materia de desarrollo turístico.

3- Este presupuesto es independiente del que corresponde a los distintos colectivos o entidades que lo forman.

4- Todos los colectivos integrantes del GDT realizan una aportación económica al presupuesto adecuada a su representatividad.

5- El programa de actuaciones del GDT comprende actuaciones tanto de producto como de comercialización.

6- El proceso de toma de decisiones en el GDT se rige por criterios de eficiencia.

7- El proceso de toma de decisiones en el GDT se rige por criterios de eficacia política.

8- El GDT dispone de mecanismos adecuados para evaluar los resultados de las acciones realizadas. 


\section{D1.- FC 1.2- Variable 1.2.1: Vertebración de la industria turística local \\ Subvariables:}

1- El destino turístico tiene claramente identificados a los distintos colectivos profesionales e industriales que participan directamente en el proceso productivo turístico.

2- El DT tiene claramente identificados a los distintos colectivos profesionales e industriales proveedores del proceso productivo turístico.

3- Al menos la mitad de estos colectivos disponen de su correspondiente representación profesional (sindicatos, colegios y asociaciones profesionales, etc.)

4- Las asociaciones profesionales representan a más de la mitad de la oferta censada de cada uno de los colectivos.

5- Las asociaciones profesionales han sido creadas conforme a la legislación vigente.

6- Los criterios de asociación, pertenencia y exclusión se rigen por criterios democráticos.

7- La representatividad de las asociaciones y colectivos profesionales son reconocidos por la Administración Pública. 


\section{D1.- FC 1.2- Variable 1.2.2: Desarrollo de la industria turística local}

\section{Subvariables:}

1- El GDT dispone de un censo, permanentemente actualizado, de las empresas y entidades que participan en el proceso productivo.

2- El GDT gestiona y/o coordina un programa de ayuda/orientación para la creación y puesta en marcha de nuevos negocios turísticos.

3- El GDT gestiona y/o coordina un programa de formación permanente para el desarrollo de los recursos humanos turísticos.

4- El GDT realiza acciones de estimulación/incentivos para la implantación de empresas de importancia estratégica para el desarrollo turístico.

5- El DT fomenta la existencia de un marco legal adecuado para la generación de seguridad jurídica en la industria turística.

6- $\quad$ El GDT conoce el nivel de producción anual de la industria turística radicada en el territorio.

7- El GDT conoce los índices anuales de inversión pública y privada en el territorio, directamente relacionados con la industria turística. 


\section{D1.- FC 1.3.- Variable 1.3.1: Nivel de desarrollo económico.}

\section{Subvariables:}

1- El GDT conoce y tiene anualmente documentados los principales parámetros económicos de ámbito nacional y regional.

2- El GDT conoce y tiene formalmente documentados los principales parámetros económicos de los países o regiones de origen de los consumidores turísticos.

3- El GDT conoce y tiene anualmente documentado el número y la evolución de empleos turísticos directos y no directos del destino turístico y el porcentaje que representan en relación al resto de empleos.

4- El GDT conoce y tiene documentado el nivel de gasto turístico en el destino turístico.

5- El GDT tiene definidos, implantados y documentados un conjunto de indicadores de relevancia económica que incluirán, como mínimo, los anteriores.

6- El GDT tiene definidos, documentados e implantado un sistema continuo de recopilación de datos y análisis de la información económica.

7- El GDT tiene definida y asignada la responsabilidad de la gestión de la información económica.

8- Los distintos indicadores económicos obtenidos se recogen en un informe anual y se distribuye/ difunde entre los interesados/ actores relevantes del destino turístico. 


\section{D1.- FC 1.3- Variable 1.3.2: Desarrollo sociocultural}

\section{Subvariables:}

1- El GDT conoce y tiene documentados los principales parámetros sociales de su territorio (población, edad, porcentaje de emigración/inmigración, escolaridad).

2- El GDT conoce el sistema de valores, creencias y actitudes de cada segmento social de la población.

3- El GDT conoce las pautas de consumo de la población local y dispone de indicadores sobre calidad de vida.

4- El GDT dispone de un archivo histórico-documental que refleja la evolución del destino y sus habitantes.

5- El GDT realiza acciones específicas encaminadas a compatibilizar el uso turístico de los recursos con el disfrute de la población local.

6- El GDT recopila, publica y/o difunde periódicamente información relativa a las actividades culturales que se desarrollan en el destino turístico.

7- El GDT fomenta la participación de la población local directamente o a través de los sectores económicos y culturales más representativos, en el diseño de programas específicos y en la implantación de acciones de relevancia turística. 


\section{D1.- FC 1.3- Variable 1.3.3: Desarrollo medioambiental}

\section{Subvariables:}

1- El GDT tiene establecidos unos objetivos generales de gestión medio ambiental integral del espacio considerado turístico.

2- Existen protocolos de actuación en materia de protección de los recursos naturales sometidos al uso intensivo turístico.

3- Existen programas de actuación documentados en materia de protección y control de los recursos naturales de alto valor ecológico.

4- El GDT tiene definidos, implantados y documentados un conjunto de indicadores específicos de sostenibilidad medioambiental.

5- El GDT estimula e incentiva la implantación de programas internacionales de gestión medioambiental entre los distintos segmentos económicos con incidencia directa en el producto turístico.

6- El GDT estimula y favorece las prácticas correctas de gestión medioambiental entre la población local.

7- El GDT fomenta la divulgación de prácticas correctas de respeto medioambiental entre los turistas y visitantes. 


\section{D2.- FC 2.1- Variable 2.1: Investigación de mercados}

\section{Subvariables:}

1- El DT/ GDT dispone de una persona o grupo de personas responsables de la gestión y seguimiento de las tareas de investigación de mercados.

2- El DT/ GDT dispone de la asignación permanente de una partida presupuestaria para realizar la investigación de mercados.

3- Las actividades de investigación se realizan, como mínimo, cada cinco años.

4- Se realizan informes con el análisis de los resultados de la investigación

5- Se lleva a cabo la difusión de los resultados entre los diversos organismos públicos y privados con interés en la industria turística.

6- Se dispone de un sistema regular para la obtención de la información en el destino turístico.

7- Se dispone de convenios de colaboración con entidades e instituciones especializadas que faciliten la mejor ejecución de las actividades de investigación.

8- Existe un centro de documentación/archivos tanto para uso propio como para apoyo de la industria turística local y de los centros de investigación. 


\section{D2.- FC 2.1- Variable 2.2: Definición del producto}

\section{Subvariables:}

1- El GDT tiene bien definidos y evaluados los atributos/valores del producto principal que reconoce el mercado.

2- El GDT tiene bien definidos y evaluados los atributos/valores estratégicos que permitan un posicionamiento en el mercado.

3- El GDT tiene bien identificados los distintos productos que se ofrecen en el destino turístico.

4- El GDT tiene bien identificados los valores y atributos que ofrece cada producto relevante del destino turístico, en relación a los segmentos de mercado a los que se dirige.

5- El GDT tiene definidos e identificados los principales procesos que conforman cada uno de los productos- segmentos de mercado ofrecidos en su D.T.

6- El GDT lleva a cabo periódicamente acciones de concertación e intercambio de información entre los responsables públicos y privados de creación de productos turísticos en el destino turístico.

7- El GDT estimula la realización de programas público-privados para gestionar, conjuntamente, las expectativas de la demanda en relación al producto/s ofertado/s.

8- El GDT favorece la realización sistemática de cursos de formación que ayuden a un mejor conocimiento de las necesidades de los distintos segmentos de demanda identificados. 


\section{D2.- FC 2.2- Variable 2.2.1- Calidad de conformidad previa al consumo turístico}

\section{Subvariables:}

1- El GDT tiene definidos unos objetivos generales de calidad para el destino turístico.

2- El GDT tiene definidos unos objetivos específicos de calidad para los diferentes productos que integran el destino turístico.

3- El GDT tiene definidos unos estándares de calidad a lograr en los diferentes procesos que integran cada uno de los productos turísticos identificados en el destino turístico.

4- El GDT tiene definidos, implantados y documentados, indicadores de gestión de calidad que permitan la evaluación sistemática del cumplimiento de los objetivos de calidad definidos en los estándares.

5- El GDT lleve a cabo acciones regulares de control de los niveles de calidad ofrecidos en los servicios turísticos de titularidad pública.

6- El GDT conoce, actualiza y difunde toda la información relativa a los distintos programas de aseguramiento de la calidad disponibles en el mercado.

7- El GDT estimula la implantación de programas de gestión de calidad entre los distintos proveedores externos de la industria y los servicios turísticos.

8- El GDT favorece la realización de programas periódicos de formación en gestión de calidad para las personas que intervienen en los distintos procesos del producto turístico. 


\section{D2.- FC 2.2- Variable 2.2.2- Calidad de conformidad posterior al consumo turístico}

\section{Subvariables:}

1- El objetivo es evaluar si el DT/ GDT lleva a cabo las acciones y programas necesarias para conocer el nivel de satisfacción de los consumidores del producto turístico.

2- El GDT dispone de un sistema continuo de obtención de información sobre el nivel de satisfacción de los consumidores turísticos, respecto de los distintos productos/mercados identificados.

3- El GDT dispone de un sistema continuo de obtención de información sobre el nivel de satisfacción general de los consumidores turísticos con el destino turístico en su conjunto.

4- El GDT dispone de una partida presupuestaria específica y permanente para obtener dicha información.

5- El GDT dispone de un sistema continuo de obtención de información sobre el nivel de satisfacción general de la población local con el turismo.

6- El GDT da a conocer públicamente los resultados de satisfacción obtenidos.

7- El GDT lleva a cabo acciones regulares de coordinación público- privada con objeto de analizar y proponer medidas de mejora de los resultados de satisfacción obtenidos.

8- El GDT documenta formalmente los indicadores de satisfacción obtenidos.

9- El GDT planifica un programa de medidas correctoras/ de mejora para los diversos procesos de titularidad pública integrantes del destino turístico. 


\section{D2.- FC 2.3- Variable 2.3.1- Innovación en el producto}

\section{Subvariables:}

1- El GDT dispone de un inventario actualizado sobre recursos y factores de atracción que forman la base de su producto/s.

2- El GDT dispone de un inventario de recursos y factores con potencial de atracción.

3- En el D.T existe una efectiva colaboración público - privada para la gestión, mantenimiento y puesta en valor turístico de estos recursos.

4- El GDT dispone de un programa abierto de incentivos a la innovación turística.

5- El DT/ GDT dispone de presupuestos destinados a la investigación y el desarrollo de nuevos productos/ procesos.

6- El GDT está integrado en una red de gestión de conocimiento aplicado.

7- El GDT conoce y recoge en informes periódicos las tendencias generales en la creación de nuevos productos turísticos.

8- El GDT dispone de información sobre posibles productos sustitutivos. 


\section{D2.- FC 2.3- Variable 2.3.2- Gestión de la innovación}

\section{Subvariables:}

1- El DT dispone de un órgano permanente de gestión y fomento de la mejora continua/innovación.

2- Los integrantes de dicho órgano/comité representan a todos los sectores económicos que participan en la producción turística del destino.

3- El sistema de acceso, permanencia y exclusión en dicho órgano/comité está formalmente documentado.

4- Las acciones llevadas a cabo por dicho órgano/comité son reconocidas por el GDT/ DT.

5- El GDT realiza acciones de coordinación con otras Administraciones públicas, tanto en sentido vertical como horizontal, para el fomento conjunto de la innovación.

6- El GDT realiza acciones específicas con objeto de atraer y mantener recursos humanos cualificados en el destino turístico.

7- El GDT estimula la implantación de empresas y/o Entidades especializadas en I+D+ I compatibles con el turismo. 


\section{D3- FC 3.1- Variable 3.1.1: Definición de las estrategias}

\section{Subvariables:}

1- El ente gestor realiza un análisis del macro entorno del sector, como máximo, cada cinco años.

2- El GDT realiza un análisis del micro entorno, como máximo, cada cinco años.

3- El GDT tiene identificados cuáles son los destinos directamente competidores.

4- El GDT conoce las estrategias de posicionamiento que siguen los destinos directamente competidores.

5- El GDT conoce las estrategias de posicionamiento que siguen los posibles destinos turísticos complementarios.

6- El GDT dispone de un Plan Estratégico/Plan Director/Plan de Desarrollo que define la estrategia de desarrollo.

7- El GDT dispone e un Plan Estratégico/Plan Director/Plan de Desarrollo que defina las estrategias competitivas.

8- En la definición de la estrategia participan los diversos colectivos sociales y profesionales implicados en el desarrollo turístico del destino. 


\section{D3.- FC 3.2- Variable 3.2.1: Comercialización}

\section{Subvariables:}

1- El destino turístico dispone de una única identidad corporativa.

2- El destino turístico dispone de una identidad corporativa que responde a la estrategia de posicionamiento previamente definida.

3- La identidad corporativa del destino turístico se respeta en todos los soportes de comunicación del destino por parte del sector público.

4- La identidad corporativa del destino turístico se respeta en todos los soportes de comunicación que utilice el sector privado.

5- Todas las acciones de comunicación realizadas por el GDT responden a un plan de actuación previamente diseñado.

6- Todos los colectivos implicados en el desarrollo turístico son partícipes de las acciones de comunicación desarrolladas por el GDT.

7- El GDT tiene identificados los canales de distribución por los que la demanda accede a la compra del destino.

8- El GDT realiza siempre acciones de evaluación post- acción para determinar el nivel de eficiencia de las mismas.

\subsubsection{Análisis de los resultados}

Con los resultados obtenidos de los cuestionarios válidos efectuamos un análisis factorial para reducir el número de subvariables, manteniendo un adecuado nivel de información sobre la muestra. La extracción de factores se realizó por el método de componentes principales. Se aplicó el método de rotación normalización Varimax con Kaiser, convergiendo en factores que finalmente han constituido el modelo definitivo descrito a continuación: 


\section{Dimensión 1: Eficiencia}

El objetivo estratégico de esta dimensión es conocer si el desarrollo turístico está siendo un eficaz instrumento para el logro del bienestar y la mejora de la calidad de vida de la comunidad local.

\section{Factor clave 1.1- Órgano de gestión (GDT)}

El objetivo final de este factor clave es analizar si existe un órgano especializado e independiente que gestione de forma coordinada el desarrollo competitivo del destino turístico.

\section{Variable 1.1.1- Organización y estructura}

El objetivo operativo de esta variable será evaluar si el GDT dispone de la estructura y organización idóneos para coadyuvar eficientemente en el logro de la competitividad del D.T.

\section{Subvariables:}

1- En el GDT están proporcionalmente representados los distintos colectivos empresariales, sociales, culturales, medio ambientales y políticos que tengan incidencia directa en el producto turístico local.

2- El GDT tiene una misión definida que se revisa, al menos, cada cinco años. 
3- El proceso de selección y nombramiento de la dirección del GDT debe haber respondido a criterios de objetividad y transparencia.

\section{Variable 1.1.2- Programas de actuación}

El objetivo operativo de esta variable es evaluar si el GDT dispone de un programa de trabajo que sea acorde con los objetivos propios de un desarrollo turístico competitivo y sostenible.

\section{Subvariables:}

1- Las actuaciones del GDT responden a una planificación estratégica concertada entre los distintos agentes del destino turístico.

2- El GDT tiene definido un presupuesto anual, propio e independiente de las entidades u organizaciones que lo forman, para las actuaciones en materia de desarrollo turístico.

3- El GDT dispone de mecanismos adecuados para evaluar la eficiencia y eficacia de los resultados de las acciones realizadas. 
Factor clave 1.2- Desarrollo de la industria turística local

El objetivo final de este factor clave será analizar si se está apoyando el desarrollo de la industria turística asentada en el espacio territorial y las industrias afines y conexas, que participan en la cadena de valor del proceso turístico en el DT.

Variable 1.2.1- Vertebración de la industria turística local

El objetivo operativo de este procedimiento será evaluar el nivel de estructuración y representatividad de la industria turística local.

Subvariables:

El DT tiene claramente identificados a los distintos

1- colectivos profesionales e industriales proveedores del proceso productivo turístico.

La representatividad de las asociaciones y colectivos

2- profesionales son reconocidos por la Administración Pública. 


\section{Variable 1.2.2- Desarrollo de la industria turística local}

El objetivo operativo de esta variable es evaluar si por parte del destino turístico y/o del GDT se llevan a cabo las acciones de apoyo y estímulo necesarias para el desarrollo de la industria turística local.

\section{Subvariables:}

1- El GDT gestiona y/o coordina un programa de formación permanente para el desarrollo de los recursos humanos turísticos.

2- El GDT realiza acciones de estimulación/incentivos para la implantación de empresas de importancia estratégica para el desarrollo turístico.

3- El GDT conoce los índices anuales de inversión pública y privada en el territorio, directamente relacionados con la industria turística.

\section{Factor clave 1.3- Nivel de bienestar de la comunidad local}

El objetivo final de este factor clave será analizar el nivel de satisfacción de la comunidad local respecto del desarrollo turístico, dado el carácter instrumental que este último ha de tener para el logro de la calidad de vida y nivel de bienestar óptimo de aquella. 


\section{Variable 1.3.1- Nivel de desarrollo económico.}

El objetivo operativo de esta variable será evaluar si el DT/ GDT dispone de la información adecuada que permita conocer y gestionar adecuadamente los impactos económicos positivos y negativos como consecuencia del desarrollo de la actividad turística.

\section{Subvariables:}

1- $\quad$ El GDT conoce y tiene anualmente documentado el número y la evolución de empleos turísticos directos y no directos del destino turístico y el porcentaje que representan en relación al resto de empleos.

2- $\quad$ El GDT conoce y tiene documentado el nivel de gasto turístico en el destino turístico.

3- El GDT tiene definidos, implantados y documentados un conjunto de indicadores de relevancia económica que incluirán, como mínimo, los anteriores.

\section{Variable 1.3.2- Desarrollo sociocultural}

El objetivo operativo de esta variable será evaluar si el DT/ GDT dispone de la información adecuada que permita conocer y gestionar adecuadamente los impactos socioculturales positivos y negativos como consecuencia del desarrollo de la actividad turística. 


\section{Subvariables:}

1- El GDT conoce y tiene documentados los principales parámetros sociales de su territorio (población, edad, porcentaje de emigración/inmigración, escolaridad,..).

2- El GDT fomenta la participación de la población local directamente o a través de los sectores económicos y culturales más representativos, en el diseño de programas específicos y en la implantación de acciones de relevancia turística.

\section{Variable 1.3.3- Desarrollo medioambiental}

El objetivo operativo de esta variable será evaluar si el DT/ GDT dispone de la información adecuada que permita conocer y gestionar adecuadamente los impactos medioambientales positivos y negativos como consecuencia de la actividad turística.

\section{Subvariables:}

1- Existen protocolos de actuación en materia de protección de los recursos naturales sometidos al uso intensivo turístico. 
2- El GDT estimula y favorece las prácticas correctas de gestión medioambiental entre la población local.

\section{Dimensión 2: Calidad}

El objetivo estratégico de esta dimensión es conocer si el producto ofrecido responde adecuadamente a las necesidades y expectativas del turista actual y a las previsibles de la demanda potencial.

\section{Factor clave 2.1- Calidad de diseño}

El objetivo final de este factor clave será analizar si el DT/ GDT lleva a cabo las acciones adecuadas para conocer de forma continuada y sistemática las necesidades y expectativas de su demanda real y poder efectuar así las especificaciones precisas para la creación del producto.

\section{Variable 2.1.1- Investigación de mercados}

El objetivo operativo de esta variable es evaluar si el DT/ GDT lleva a cabo las acciones necesarias para disponer de la información necesaria para conocer el nivel de expectativas y necesidades de su demanda real y potencial.

\section{Subvariables:}


1- El GDT dispone de una persona o grupo de personas responsables de la gestión y seguimiento de las tareas de investigación de mercados.

2- Las actividades de investigación se realizan, como mínimo, cada cinco años.

3- Se lleva a cabo la difusión de los resultados entre los diversos organismos públicos y privados con interés en la industria turística.

\section{Variable 2.1.2- Definición del producto.}

El objetivo operativo de esta variable es evaluar si el DT/ GDT lleva a cabo todas las acciones necesarias para garantizar que la definición del producto responde fielmente a las especificaciones del producto previamente definidas.

\section{Subvariables:}

1- El GDT tiene bien identificados los distintos productos que se ofrecen en el destino turístico así como los valores y atributos que los caracterizan.

2- El GDT tiene definidos e identificados los principales procesos que conforman cada uno de los productossegmentos de mercado ofrecidos en su D.T 
3- El GDT lleva a cabo periódicamente acciones de concertación e intercambio de información entre los responsables públicos y privados para la creación de productos en el destino turístico.

\section{Factor clave 2.2- Calidad de Conformidad.}

El objetivo final de este factor clave es analizar si el GDT lleva a cabo el conjunto de acciones adecuados para garantizar que el producto/s turístico/s ofrecido/s responde/n de forma óptima a las necesidades y expectativas de sus respectivos productos-mercados.

Variable 2.2.1- Calidad de conformidad previa al consumo turístico

El objetivo operativo de esta variable es evaluar si el DT/GDT tiene definido e implantado un sistema de calidad global e integral para todo el destino turístico como producto.

\section{Subvariables:}

1- El GDT tiene definidos unos objetivos generales de calidad para el destino turístico 
2- $\quad$ El GDT tiene definidos unos estándares de calidad a lograr en los diferentes procesos que integran cada uno de los productos turísticos identificados en el destino turístico

3- El GDT estimula la implantación de programas de gestión de calidad entre los distintos proveedores externos de la industria y los servicios turísticos

\section{Variable 2.2.2- Calidad de conformidad posterior al consumo turístico.}

El objetivo operativo de esta variable es evaluar si el DT/ GDT lleva a cabo las acciones y programas necesarias para conocer el nivel de satisfacción de los consumidores actuales del producto turístico.

\section{Subvariables:}

1- el GDT dispone de un sistema continuo de obtención de información sobre el nivel de satisfacción de los consumidores turísticos, respecto de los distintos productos/mercados identificados.

2- el GDT dispone de un sistema continuo de obtención de información sobre el nivel de satisfacción general 
de los consumidores turísticos con el destino turístico en su conjunto.

3- El GDT documenta formalmente los indicadores de satisfacción obtenidos.

\section{Factor clave 2.3- Innovación}

El objetivo final de este factor clave será evaluar si el DT/ GDT lleva a cabo el conjunto de acciones y programas necesarios para estimular la cultura de la innovación, y la gestión de los elementos relacionados en el DT, como factor clave para el logro de una posición competitiva sostenible.

\section{Variable 2.3.1- Innovación en el producto}

El objetivo operativo de esta variable es evaluar si el DT/ GDT lleva a cabo las acciones y programas oportunos para estimular la cultura de la innovación en el destino turístico y en sus organizaciones y empresas.

\section{Subvariables:}

1- $\quad$ En el D.T existe una efectiva colaboración público privada para la gestión, mantenimiento y puesta en valor turístico de estos recursos. 
2- El GDT dispone de un programa abierto de incentivos a la innovación turística.

3- El GDT está integrado en una red de gestión de conocimiento aplicado.

\section{Vari̊able 2.3.2- Gestión de la innovación}

El objetivo de este variable es evaluar que el DT/ GDT dispone de un sistema de gestión permanente de la innovación como parte integrante de la política de calidad y mejora del producto turístico ofrecido.

\section{Subvariables:}

1- El DT dispone de un órgano permanente de gestión y fomento de la mejora continua/innovación.

2- Los integrantes de dicho órgano/comité representan a todos los sectores económicos que participan en la producción turística del destino.

\section{Dimensión 3: Posicionamiento.}

El objetivo estratégico de esta dimensión es conocer si el DT/ GDT lleva a cabo el proceso estratégico adecuado que permita diseñar una imagen de 
organización, unos valores y unas ofertas, de manera tal que los consumidores comprendan, valoren y se sientan atraídos por lo que propone el DT.

\section{Factor clave 3.1- Estrategias}

El objetivo final de este factor clave es analizar si el DT/ DMO ha llevado a cabo un análisis previo adecuado, tanto del entorno como de los recursos y capacidades disponibles para, posteriormente, formalizar una estrategia de posicionamiento adecuada.

\section{Variable 3.1.1- Definición de las estrategias}

El objetivo de esta variable es evaluar si el DT/ GDT ha llevado

a cabo un proceso adecuado para elegir su estrategia de posicionamiento más idónea.

\section{Subvariables:}

1- El DT/ GDT lleva a cabo un análisis del macroentorno turístico con una frecuencia no superior a cinco años.

2- $\quad$ El DT/ GDT lleva a cabo un análisis del microentorno turístico con una frecuencia no superior a cinco años.

3- $\quad$ El DT/ GDT tiene identificados cuáles son los destinos turísticos directamente competidores. 


\section{Factor Clave 3.2- Marketing}

El objetivo final es analizar si el DT/ GDT lleva a cabo un programa/ plan de marketing que define y sistematiza todo el conjunto de acciones que deben desarrollarse para lograr un posicionamiento óptimo en sus mercados de referencia.

\section{Variable 3.2.1- Comercialización}

El objetivo operativo de esta variable es evaluar si el DT/ GDT está llevando a cabo las medidas oportunas para lograr la comercialización adecuada de su producto.

\section{Subvariables}

1- El DT/ GDT dispone de una identidad corporativa que responde adecuadamente a la estrategia de posicionamiento previamente diseñada.

2- La identidad corporativa se respeta en todos los soportes de comunicación que utiliza el sector privado.

3- El GDT/ DT tiene identificados los canales de distribución por los que la demanda accede a la compra del DT y sus respectivos productos. 
Tabla 20 Modelo de Auditoría de Gestión Turística Competitiva (AGTC)

\section{DIMENSIÓN 1: EFICIENCIA}

FACTOR CLAVE 1.1 Órgano de gestión

Variable 1.1.1- Organización y estructura

Variable 1.1.2- Programas de actuación

FACTOR CLAVE 1.2 Desarrollo de la industria turística local

Variable 1.2.1- Estructuración de la industria local

Variable 1.2.2- Desarrollo de la industria local

FACTOR CLAVE 1.3 Bienestar de la comunidad local

Variable 1.3.1- Desarrollo económico

Variable 1.3.2- Desarrollo sociocultural

Variable 1.3.3- Desarrollo medioambiental

\section{DIMENSIÓN 2: CALIDAD}

FACTOR CLAVE 2.1 Calidad de diseño

Variable 2.1.1- Investigación de mercados

Variable 2.1.2- Definición del producto

FACTOR CLAVE 2.2 Calidad de conformidad

Variable 2.2.1- Calidad de conformidad previa al consumo

Variable 2.2.2- Calidad conformidad posterior al consumo 


\section{FACTOR CLAVE 2.3 Innovación}

Variable 2.3.1- Innovación en el producto

Variable 2.3.2- Gestión de los factores para la innovación

DIMENSIÓN 3: POSICIONAMIENTO

FACTOR CLAVE 3.1 Estrategias

Variable 3.1.1- Elección de estrategias

FACTOR CLAVE 3.2 Marketing

Variable 3.2.1- Plan de Marketing

Los resultados de la valoración otorgada por los expertos a cada una de las subvariables finalmente consideradas, se muestran en la tabla 21. Las puntuaciones medias se sitúan, en su mayoría, en torno a la escala del valor cuatro por lo que el grado de variación de las respuestas es muy limitado. Esta cuestión, si bien es positiva en el sentido de expresar el grado de consenso existente entre los expertos en torno al valor que debe adoptar la variable, dificulta, en alguna medida, el establecimiento de una ponderación de las mismas ya que el grado de oscilación se sitúa en algo más de un punto entre el valor mínimo alcanzado $(3,60)$ y el máximo obtenido $(4,91)$, no pudiéndose deducir de los resultados una ponderación determinante ni siquiera en las dimensiones, en el sentido de valorar más, por ejemplo, la calidad que la eficiencia o ésta antes que el posicionamiento. La media del conjunto de subvariables de la dimensión (1), eficiencia, representa una 
4,41 sobre 5. La dimensión (2), calidad, de 4,27 y la dimensión (3) posicionamiento es, en conjunto, la mejor valorada con una ligera superioridad cifrada en el 4,49 .

Tabla 21

Valoración otorgada por los expertos a las subvariables

\begin{tabular}{|ll|}
\hline Variable 1.1.1: Organización y estructura & $(4,68)$ \\
\hline 1) representación & $(4,04)$ \\
\hline 2) misión & $(4,45)$ \\
\hline 3) dirección & \\
\hline & \\
\hline Variable 1.1.2: Programas de actuación & $(4,91)$ \\
\hline 1) planificación estratégica concertada & $(4,41)$ \\
\hline 2) presupuesto anual & $(4,61)$ \\
\hline 3) evaluación de la eficiencia y de la eficacia & $(4,69)$ \\
\hline & $(4,23)$ \\
\hline & $(3,97)$ \\
\hline Variable 1.2.1: Vertebración de la industria turística local & $(4,46)$ \\
\hline 1) identificación & \\
\hline 2) representatividad & \\
\hline
\end{tabular}


Variable 1.3.1: Nivel de desarrollo económico

1) indicadores de empleo

2) indicadores de gasto turístico

3) indicadores económicos

$(4,50)$

Variable 1.3.2: Desarrollo sociocultural

1) indicadores sociales

2) participación social $(4,56)$

Variable 1.3.3: Desarrollo medioambiental

1) protocolos protección

2) gestión medioambiental $(4,60)$

Variable 2.1.1: Investigación de mercados

1) responsables

2) planificación

3) difusión $(4,61)$

Variable 2.1.2: Definición del producto

1) valores y atributos

2) productos/segmentos $(4,22)$

3) concertación $(4,49)$ 


\begin{tabular}{|c|c|}
\hline \multicolumn{2}{|c|}{ Variable 2.2.1:Calidad de conformidad previa al consumo turístico } \\
\hline 1) objetivos generales & $(4,43)$ \\
\hline 2) estándares & $(4,54)$ \\
\hline 3) programas de gestión & $(3,94)$ \\
\hline \multicolumn{2}{|c|}{ Variable 2.2.2: Calidad de conformidad posterior al consumo turístico } \\
\hline 1) satisfacción productos/mercados & $(4,20)$ \\
\hline 2) satisfacción destino & $(4,56)$ \\
\hline 3) documentación indicadores & $(3,89)$ \\
\hline \multicolumn{2}{|l|}{ Variable 2.3.1: Innovación en el producto } \\
\hline 1) colaboración público-privada puesta en valor turístico & $(4,65)$ \\
\hline 2) programa de incentivos & $(4,46)$ \\
\hline 3) red de gestión del conocimiento & $(3,92)$ \\
\hline \multicolumn{2}{|l|}{ Variable 2.3.2: Gestión de la innovación } \\
\hline 1) órgano permanente & $(4,14)$ \\
\hline 2) representación & $(4,30)$ \\
\hline \multicolumn{2}{|l|}{ Variable 3.1.1: Definición de las estrategias } \\
\hline 1) análisis del macroentorno & $(4,65)$ \\
\hline 2) análisis del microentorno & $(4,24)$ \\
\hline 3) destinos competidores & $(4,33)$ \\
\hline
\end{tabular}


Variable 3.2.1: Comercialización

1) identidad corporativa

2) soportes de comunicación

3) canales de distribución

A partir de estas puntuaciones se calculó la escala de valoración final del modelo Para ello se partió de la determinación de cuál debía ser la puntuación máxima de cada dimensión, otorgándoseles un valor de cien puntos (100) a cada una estableciendo así la puntuación total de las tres dimensiones en trescientos puntos (300). Una vez establecido este montante, repartimos el valor proporcional de cada dimensión entre el número de factores clave que le corresponden a las medias de cada dimensión y éste, a su vez, entre las variables y subvariables obteniéndose las puntuaciones que se señalan en la tabla 22 .

Tabla 22. Criterios de puntuación del modelo

\begin{tabular}{|c|c|c|c|c|c|c|c|}
\hline \multirow[t]{2}{*}{ DIMENSIONES } & \multirow{2}{*}{$\begin{array}{l}\text { FACTORES } \\
\text { CLAVES }\end{array}$} & \multirow[t]{2}{*}{ VARIABLES } & \multirow[t]{2}{*}{ Subvariables } & \multicolumn{4}{|c|}{ valoración } \\
\hline & & & & SV & $\mathrm{V}$ & $\mathrm{FC}$ & $\mathrm{D}$ \\
\hline \multirow[t]{9}{*}{ D1 } & & & & & & & 100 \\
\hline & FC1.1 & & & & & 34 & \\
\hline & & V1.1.1 & & & 16 & & \\
\hline & & & SV1.1.1.1 & 6 & & & \\
\hline & & & SV1.1.1.2 & 5 & & & \\
\hline & & & SV1.1.1.3 & 5 & & & \\
\hline & & V1.1.2 & & & 18 & & \\
\hline & & & SV1.1.2.1 & 7 & & & \\
\hline & & & SV1.1.2.2 & 5 & & & \\
\hline
\end{tabular}




\begin{tabular}{|c|c|c|c|c|c|c|c|}
\hline & & & SV1.1.2.3 & 6 & & & \\
\hline & & & & & & & \\
\hline & & & & & 34 & & \\
\hline & $\mathrm{FC} 1.2$ & & & & & 32 & \\
\hline & & V1.2.1 & & & 16 & & \\
\hline & & & SV1.2.1.1 & 9 & & & \\
\hline & & & SV1.2.1.2 & 7 & & & \\
\hline & & & & & & & \\
\hline & & V1.2.2 & & & 16 & & \\
\hline & & & SV1.2.2.1 & 6 & & & \\
\hline & & & SV1.2.2.2 & 5 & & & \\
\hline & & & SV1.2.2.3 & 5 & & & \\
\hline & & & & & & & \\
\hline & & & & & 32 & & \\
\hline & $\mathrm{FC} 1.3$ & & & & & 34 & \\
\hline & & V1.3.1 & & & 11 & & \\
\hline & & & SV1.3.1.1 & 4 & & & \\
\hline & & & SV1.3.1.2 & 3 & & & \\
\hline & & & SV1.3.1.3 & 4 & & & \\
\hline & & & & & & & \\
\hline & & V.1.3.2 & & & 11 & & \\
\hline & & & SV1.3.2.1 & 5 & & & \\
\hline & & & SV1.3.2.2 & 6 & & & \\
\hline & & & & & & & \\
\hline & & V1.3.3 & & & 12 & & \\
\hline & & & SV1.3.3.1 & 6 & & & \\
\hline & & & SV1.3.3.2 & 6 & & & \\
\hline & & & & & & & \\
\hline & & & & & 34 & & \\
\hline & & & & & & 100 & \\
\hline D2 & & & & & & & 100 \\
\hline & $\mathrm{FC} 2.1$ & & & & & 34 & \\
\hline
\end{tabular}




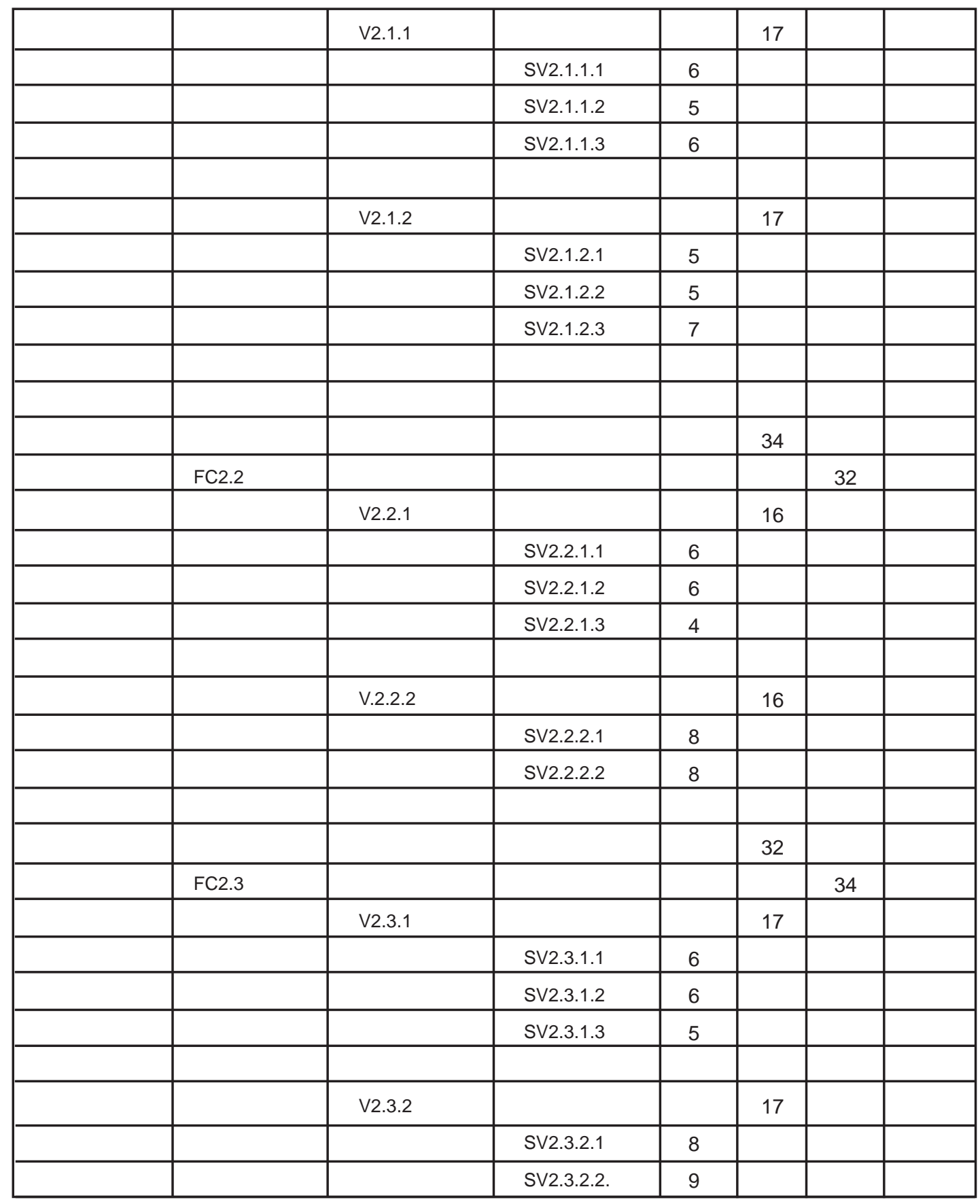




\begin{tabular}{|l|l|l|l|l|l|l|l|}
\hline & & & & & 34 & & \\
\hline & & & & & & 100 & \\
\hline D3 & & & & & & & 100 \\
\hline & FC3.1 & & & & & 49 & \\
\hline & & V3.1.1 & & & 49 & & \\
\hline & & & SV3.1.1.1 & 17 & & & \\
\hline & & & SV3.1.1.2 & 16 & & & \\
\hline & & & SV3.1.1.3 & 16 & & & \\
\hline & & & & & & & \\
\hline & & & & & 49 & & \\
\hline & FC3.2 & & & & & 51 & \\
\hline & & V3.2.1 & & & 51 & & \\
\hline & & & SV3.2.1.1 & 18 & & & \\
\hline & & & SV3.2.1.2 & 16 & & & \\
\hline & & & SV3.2.1.3 & 17 & & & \\
\hline & & & & & & & \\
\hline & & & & & 51 & & \\
\hline & & & & 300 & 300 & 100 & 300 \\
\hline
\end{tabular}

Calculados estos valores, queda por resolver el problema de la determinación de cuál ha de ser la puntuación mínima que debe obtener un destino para situarlo en unos niveles aceptables de competitividad. Se estimó que la simple obtención de la mitad de la puntuación máxima posible (150 puntos sobre 300) no era suficiente, por lo que centramos la atención en determinar qué subvariables debían ser consideradas estratégicas y otorgarles así un mayor peso específico para, de este modo, poder determinar ese nivel aceptable de competitividad.

En este punto consideramos que debían entenderse como estratégicas aquellas 
subvariables que hubieran obtenido, dentro de cada variable, la máxima puntuación por parte de los expertos (tabla 23). Por tanto, el nivel aceptable de puntuación o mínimo de competitividad de un destino turístico vendría determinado por la suma del $50 \%$ del valor de esas subvariables estratégicas, cantidad que representa un total de 60 puntos (sobre 120 posibles) más el $50 \%$ de la suma del resto de subvariables, que representa 120 puntos (sobre 240 posibles) por lo que la suma de ambas cantidades, la mitad de la puntuación total más la mitad de las subvariables estratégicas, arrojan un resultado de 180 puntos, siendo ésta la cantidad que consideramos adecuada para representar el umbral mínimo de competitividad.

Consideramos que debían entenderse como estratégicas aquellas subvariables que hubieran obtenido, dentro de cada variable, la máxima puntuación por parte de los expertos (tabla 23).

Así, entendemos que el nivel aceptable o mínimo de competitividad de un destino turístico - en términos de puntuación- vendría determinado por la suma del 50\% del valor de esas subvariables estratégicas que representa 60 puntos (sobre 120 posibles) más el 50\% de la suma del resto de subvariables que representa 120 puntos (sobre 240 posibles) por lo que la suma de ambas cantidades, la mitad de la puntuación total más la mitad de las subvariables estratégicas, arrojan un resultado de 180 puntos, siendo ésta la cantidad de puntos que consideramos adecuada para representar el umbral mínimo de competitividad. 


\section{Tabla 23 Subvariables estratégicas}

\begin{tabular}{|c|c|c|}
\hline $\begin{array}{l}\text { Subvariable } \\
\text { Estratégica }\end{array}$ & $\begin{array}{l}\text { Putuación } \\
\text { expertos }\end{array}$ & $\begin{array}{l}\text { Puntuación } \\
\text { mínima } \\
(50 \%)\end{array}$ \\
\hline 1.1 .1 .1 & 4,68 & 3 \\
\hline 1.1.2.1 & 4,91 & 3,5 \\
\hline 1.2.1.1 & 4,46 & 4,5 \\
\hline 1.2.2.1 & 4,69 & 3 \\
\hline 1.3.1.1 & 4,51 & 2 \\
\hline 1.3.2.2 & 4,56 & 3 \\
\hline 1.3.3.1 & 4,71 & 3 \\
\hline 2.1.1.1 & 4,64 & 3 \\
\hline 2.1.2.3 & 4,49 & 3,5 \\
\hline 2.2.1.2 & 4,54 & 3 \\
\hline 2.2.2.2 & 4,56 & 4 \\
\hline 2.3.1.1 & 4,65 & 3 \\
\hline 2.3.2.1 & 4,14 & 4 \\
\hline 3.1.1.1 & 4,65 & 8,5 \\
\hline 3.2.1.1 & 4,74 & 9 \\
\hline TOTAL & & 60 \\
\hline
\end{tabular}




\subsubsection{Validación del modelo}

La siguiente etapa de la investigación consistió en verificar la operatividad del modelo diseñado aplicándolo a un destino turístico que se encontrara en fase incipiente de desarrollo o cuyo producto no hubiera alcanzado aún el grado de madurez, tal y como se formuló al inicio de la investigación, puesto que es en éstos donde un instrumento de estas características despliega toda su efectividad.

Así, teniendo en cuenta tanto el trabajo previamente desarrollado sobre el papel de la comunidad local en el desarrollo turístico, como el objetivo para el cual fue diseñado el modelo, escogimos la localidad de Morella (Castellón) para llevar a cabo esta validación.

La metodología empleada consistió, en primer lugar, en la transformación del modelo teórico en un cuestionario práctico de autoevaluación (anexo.4) dirigido a los responsables de la gestión turística local que respondiera a criterios objetivos, fácilmente verificables en una auditoría posterior y cuya principal cualidad radicara tanto en la rapidez de su cumplimentación como en la sencillez de su valoración. En segundo lugar, en la elección del grupo nominal (Delbecq y Van de Ven, 1971) idóneo para contestar a las cuestiones planteadas. Este grupo se seleccionó tanto por sus conocimientos sobre la gestión turística, como por su situación profesional actual o por la posible experiencia acumulada en puestos representativos que hubieran ocupado en el pasado.

En este sentido, escogimos a cinco integrantes de los que, finalmente, colaboraron tres en todo el proceso hasta su finalización. Sus características 
personales combinaban los siguientes factores de interés: pertenencia a la industria privada o al sector público; implicación directa en la gestión/planificación turística y conocimiento profundo del sector, del destino y de la gestión local.

En un primer momento el cuestionario de autoevaluación se hizo llegar a cada participante y, una vez obtenidas las respuestas individuales, se les reunió con objeto tanto de evaluar la propia efectividad del método, como la de verificar los resultados finales del grupo.

En el aspecto formal, los miembros del grupo coincidieron en destacar la claridad y orden en la formulación de las preguntas, puesto que no tuvieron dificultades a la hora de su cumplimentación, lo que les permitió llevarla a efecto en un tiempo cercano a los 60 minutos. No obstante lo anterior, en este análisis detallado de los resultados comprobamos que ligeras modificaciones en el texto podría facilitar aún más su resolución. En este sentido, las subvariables inicialmente consideradas 2.2.2.2 y 2.2.2.3 no añadían valor por separado, en concreto esta última incluso no había obtenido en su momento una puntuación relevante por parte de los expertos $(3,89)$ por lo que se optó por reconducirlas en el modelo de auditoría a una sola subvariable (2.2.2.2) reconsiderando, consecuentemente, la formulación de la valoración.

En relación al contenido, existía unanimidad entre las contestaciones individuales en un $80 \%$ del total de preguntas. El $20 \%$ restante ponía de manifiesto, en general, la necesidad de mejorar la coordinación públicoprivada en algunos aspectos de la gestión, pero, fundamentalmente, en el grado en que la información circula en el destino. La principal divergencia 
se percibía en la distinta visión y conocimiento manifestada por los representantes del sector público, más amplia, con respecto a la manifestada por el sector privado (tabla 24), síntoma inequívoco de que, en muchos aspectos de la gestión de los destinos turísticos, la falta de una formulación documental de aquellos introduce esas carencias o brechas en la información de que disponen los distintos actores.

Tabla 24 Divergencias sector público/sector privado

\begin{tabular}{|c|c|c|c|}
\hline REFERENCIA & CUESTIÓN & PÚBLICO & PRIVADO \\
\hline 1.1.1.2.a) & El GDT tiene definida una misión corporativa & SI & NO \\
\hline 1.1.2.2..a) & $\begin{array}{l}\text { Existe una política presupuestaria específica } \\
\text { para el GDT independiente de los colectivos } \\
\text { que lo integran }\end{array}$ & SI & NO \\
\hline 1.1.2.2.b) & $\begin{array}{l}\text { Esta política se encuentra formalmente } \\
\text { establecida }\end{array}$ & SI & NO \\
\hline 1.1.2.2.c) & Esta política está documentada & SI & $\mathrm{NO}$ \\
\hline 1.2.1.1.a) & $\begin{array}{l}\text { El GDT dispone de un registro documental de } \\
\text { los distintos colectivos profesionales y } \\
\text { empresariales que intervienen directamente o } \\
\text { indirectamente en el proceso productivo turístico }\end{array}$ & SI & NO \\
\hline 1.2.1.1.b) & $\begin{array}{l}\text { El GDT dispone de un registro documental de } \\
\text { los distintos organismos públicos con } \\
\text { competencia directa en el proceso productivo } \\
\text { turístico }\end{array}$ & SI & $\mathrm{NO}$ \\
\hline 1.2.1.1.d) & $\begin{array}{l}\text { El destino turístico dispone de información } \\
\text { suficiente y relevante sobre la composición de } \\
\text { los miembros de los colectivos sociales }\end{array}$ & SI & NO \\
\hline
\end{tabular}




\begin{tabular}{|c|c|c|c|}
\hline 1.2.1.2.c) & $\begin{array}{l}\text { (...) Disponen de registro documental de los } \\
\text { miembros que lo integran }\end{array}$ & SI & $\mathrm{NO}$ \\
\hline $1.2 .1 .2 . \mathrm{d})$ & $\begin{array}{l}\text { (...) Disponen de un programa de actuación y } \\
\text { de presupuesto económico propio }\end{array}$ & SI & $\mathrm{NO}$ \\
\hline $1.2 .2 .1 . \mathrm{d})$ & $\begin{array}{l}\text { El GDT destina parte de su presupuesto a la } \\
\text { gestión y/o coordinación de programas de } \\
\text { formación para los recursos humanos turísticos }\end{array}$ & SI & $\mathrm{NO}$ \\
\hline 1.2.2.2.a) & $\begin{array}{l}\text { El GDT tiene definidas las necesidades } \\
\text { (empresas/productos) estratégicas para la mejora } \\
\text { de la competitividad del DT }\end{array}$ & SI & $\mathrm{NO}$ \\
\hline 1.3.1.2.a) & $\begin{array}{l}\text { Existen indicadores del número de turistas y } \\
\text { visitantes recibidos en el destino, su composición } \\
\text { y su evolución }\end{array}$ & SI & $\mathrm{NO}$ \\
\hline 1.3.1.2.c) & $\begin{array}{l}\text { El GDT dispone de información sobre el índice } \\
\text { de utilización de los servicios turísticos por los } \\
\text { turistas y visitantes }\end{array}$ & SI & $\mathrm{NO}$ \\
\hline 1.3.1.2.d) & $\begin{array}{l}\text { El GDT dispone de información sobre el nivel } \\
\text { medio de precios de los servicios turísticos en } \\
\text { el destino por categorías }\end{array}$ & SI & $\mathrm{NO}$ \\
\hline 1.3.2.2.a) & $\begin{array}{l}\text { El GDT dispone de información relevante sobre } \\
\text { el grado de sensibilización turística de la } \\
\text { población local }\end{array}$ & SI & $\mathrm{NO}$ \\
\hline 1.3.2.2.b) & $\begin{array}{l}\text { El GDT comunica regularmente a la población } \\
\text { local, a través de los medios de comunicación, } \\
\text { las actuaciones de relevancia turística que se } \\
\text { van a realizar }\end{array}$ & SI & $\mathrm{NO}$ \\
\hline
\end{tabular}




\begin{tabular}{|c|c|c|c|}
\hline $1.3 .2 .2 . \mathrm{d})$ & $\begin{array}{l}\text { El GDT fomenta la participación activa de los } \\
\text { sectores sociales más representativos en el diseño } \\
\text { de programas específicos en materia turística }\end{array}$ & SI & $\mathrm{NO}$ \\
\hline 1.3.2.2.E) & $\begin{array}{l}\text { El GDT fomenta la participación activa de los } \\
\text { sectores sociales más representativos en el diseño } \\
\text { e implantación de programas y acciones en } \\
\text { materia turística }\end{array}$ & SI & $\mathrm{NO}$ \\
\hline 1.3.3.1.a) & $\begin{array}{l}\text { El GDT tiene definidos y documentados cuáles } \\
\text { son y dónde se sitúan los principales recursos } \\
\text { naturales territoriales sometidos a uso turístico }\end{array}$ & SI & $\mathrm{NO}$ \\
\hline $1 \cdot 3 \cdot 3.2 . d)$ & $\begin{array}{l}\text { El GDT colabora en la difusión entre la } \\
\text { población local y los turistas de información } \\
\text { sobre prácticas de respeto medioambiental }\end{array}$ & SI & $\mathrm{NO}$ \\
\hline 1.3.3.2.e) & $\begin{array}{l}\text { El GDT incentiva la práctica de actuaciones } \\
\text { medioambientales correctas entre la población } \\
\text { residente y los turistas }\end{array}$ & SI & $\mathrm{NO}$ \\
\hline 2.1.2.1.b) & $\begin{array}{l}\text { El GDT tiene documentado y actualizado el } \\
\text { catálogo de productos turísticos privados } \\
\text { ofertados en el DT }\end{array}$ & SI & $\mathrm{NO}$ \\
\hline 2.1.2.1.c) & $\begin{array}{l}\text { El GDT tiene documentado y actualizado el } \\
\text { catálogo de productos y servicios turísticos } \\
\text { públicos ofertados en el DT }\end{array}$ & SI & $\mathrm{NO}$ \\
\hline $2.1 \cdot 2.3 . \mathrm{e})$ & $\begin{array}{l}\text { El GDT recoge documentalmente los principales } \\
\text { acuerdos adoptados en materia de coordinación } \\
\text { y cooperación para la creación de productos } \\
\text { turísticos en el DT }\end{array}$ & SI & $\mathrm{NO}$ \\
\hline
\end{tabular}




\begin{tabular}{|c|c|c|c|}
\hline 2.2.1.1.a) & $\begin{array}{l}\text { El GDT tiene definidos objetivos de calidad } \\
\text { para los productos y servicios de carácter público } \\
\text { integrados en el DT }\end{array}$ & SI & NO \\
\hline 2.2.1.1.b) & $\begin{array}{l}\text { EL GDT tiene documentados estos objetivos } \\
\text { de calidad para los productos y servicios de } \\
\text { carácter público integrados en el DT }\end{array}$ & SI & $\mathrm{NO}$ \\
\hline $2.2 .1 .3 . a)$ & $\begin{array}{l}\text { El GDT dispone de información sobre los niveles } \\
\text { de calidad alcanzados/grado de satisfacción de } \\
\text { los usuarios con respecto a los productos y } \\
\text { servicios más significativos del destino turístico }\end{array}$ & SI & $\mathrm{NO}$ \\
\hline 2.3.1.1.a) & $\begin{array}{l}\text { En el destino turístico se realizan acciones } \\
\text { formativas y de sensibilización tendentes al } \\
\text { fomento de la cooperación público-privada en } \\
\text { materia de innovación turística }\end{array}$ & SI & $\mathrm{NO}$ \\
\hline 2.3.1.1.c) & $\begin{array}{l}\text { Existen programas específicos para la puesta } \\
\text { en valor turístico de los recursos patrimoniales } \\
\text { y culturales }\end{array}$ & SI & $\mathrm{NO}$ \\
\hline 2.3.1.2.a) & $\begin{array}{l}\text { El GDT tiene integrado en su programación } \\
\text { anual una línea propia de estímulo a la } \\
\text { innovación }\end{array}$ & SI & NO \\
\hline 2.3.2.1.c) & $\begin{array}{l}\text { (...) El comité se reúne, como mínimo, } \\
\text { trimestralmente }\end{array}$ & $\mathrm{NO}$ & SI \\
\hline $3.2 .1 .3 . a)$ & $\begin{array}{l}\text { El GDT conoce los principales canales de } \\
\text { distribución por los que se comercializa el DT } \\
\text { en los principales destinos turísticos }\end{array}$ & SI & $\mathrm{NO}$ \\
\hline
\end{tabular}


Al inicio del documento de autoevaluación se define lo que consideramos es el ideal de ente gestor del destino turístico (GDT) en el siguiente sentido: "organismo, dotado de personalidad jurídica propia, integrado por representantes de los agentes principales de la comunidad local implicados en el desarrollo turístico, cuya única misión es la gestión de la planificación, la ejecución y el control de la política turística del destino".

Sin embargo, para entender también el porqué de la divergencia en las contestaciones en función de que sea el actor público o el privado quien responda, conviene señalar que en Morella, en la actualidad, es la Concejalía de Turismo y Cultura del Ayuntamiento quien lleva a cabo el desarrollo y la financiación mayoritaria de la política turística local. De esta Concejalía depende la oficina municipal de información turística integrada, a su vez, en la red tourist-info de la Comunidad Valenciana.

Junto a este organismo se sitúa el Patronato de Turismo de Morella. En él están integrados los empresarios turísticos, representados a través de la Asociación de Empresarios de Turismo de Morella y Comarca (ASETMYCO), y los representantes públicos provenientes del Ayuntamiento. El patronato participa activamente en las decisiones de política turística local mediante el diseño, asesoramiento y ejecución conjunta de la mayor parte de las acciones de política turística del destino, por lo que éste sería el órgano que, conceptualmente, estaría más próximo a la idea de ente gestor que propugnamos. Ahora bien, conviene hacer dos matizaciones:

La primera de ellas es que dicho órgano está dotado, en su práctica totalidad, por la aportación económica que lleva a cabo el Ayuntamiento por lo que el protagonismo, tal y como ocurre en la mayor parte de los municipios turísticos de España (fig. 14), es predominantemente público. La segunda 
matización es que dicho Patronato circunscribe sus actuaciones, casi exclusivamente, al diseño y realización de acciones de comunicación e imagen, siendo su participación en otros temas de política turística más limitada.

Figura 14 Organismos de gestión turística

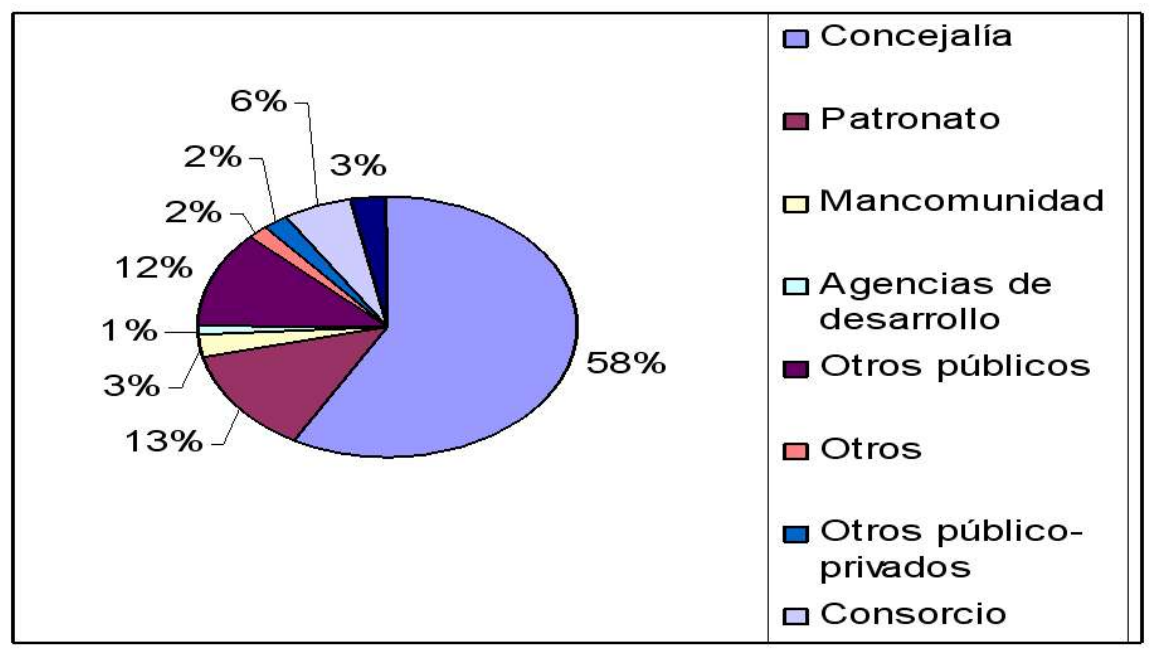

Fuente: Centro de Dirección Turística, ESADE (2005)

En todo caso, la dinámica habitual en la gestión de este ente es abierta y participativa entre los actores públicos y privados lo que sin duda redunda en un buen funcionamiento de los canales de información pero que, como se ha puesto de relieve en el análisis realizado, no alcanzaba a cubrir satisfactoriamente todas las facetas de la gestión del destino. Aunque existe vertebración empresarial, al no estar la gestión unificada profesionalmente la información no se encuentra centralizada y se aprecia una importante falta de liderazgo en el planteamiento de iniciativas turísticas. 
No obstante, dentro del Patronato se ha constituido recientemente un Comité de Innovación formado por jóvenes de la localidad que representan a todos los sectores con incidencia en el producto turístico local (hoteles, restaurantes, comercio, profesionales turísticos) con la misión de articular un conjunto de propuestas y actuaciones que, por un lado, aporten una mayor y mejor relación entre las generaciones futuras y el turismo local y, por otro, generen iniciativas e ideas que puedan nutrir el programa de actuaciones del Patronato Municipal de Turismo.

Tabla 25

Puntuación obtenida por el GDT de Morella

\begin{tabular}{|c|c|c|c|c|c|c|c|c|}
\hline \multirow{2}{*}{$\begin{array}{c}\text { D1MENSIONES } \\
\text { D1 }\end{array}$} & \multirow[t]{2}{*}{$\begin{array}{l}\text { FACTORES } \\
\text { CLAVE } \\
\end{array}$} & \multirow[t]{2}{*}{ VARIABLES } & \multirow[t]{2}{*}{ SUBVARIABLES } & \multicolumn{3}{|c|}{ VALOR } & \multicolumn{2}{|c|}{$\begin{array}{c}\text { PUNTUACIÓN } \\
\text { OBTENIDA }\end{array}$} \\
\hline & & & & & & 100 & 55,2 & \\
\hline \multirow[t]{11}{*}{ FC1.1 } & & & & & 34 & & & 25,4 \\
\hline & & V1.1.1 & & & & & & \\
\hline & & & & 16 & & & & \\
\hline & & & SV1.1.1.1 & 6 & & & 6 & \\
\hline & & & SV1.1.1.2 & 5 & & & 5 & \\
\hline & & & SV1.1.13 & 5 & & & 0 & \\
\hline & & V.1.1.2 & & & & & & \\
\hline & & & & 18 & & & & \\
\hline & & & SV1.1.2.1 & 7 & & & 7 & \\
\hline & & & SV1.1.2.2 & 5 & & & 5 & \\
\hline & & & SV1.1.2.3 & 6 & & & 2,4 & \\
\hline \multirow[t]{10}{*}{ FC1.2 } & & & & & 32 & & & $\overline{19,6}$ \\
\hline & & V1.2.1 & & & & & & \\
\hline & & & & 16 & & & & \\
\hline & & & SV1.2.1.1 & 9 & & & 5,4 & \\
\hline & & & SV1.2.1.2 & 7 & & & 7 & \\
\hline & & V1.2.2 & & & & & & \\
\hline & & & & 16 & & & & \\
\hline & & & SV1.2.2.1 & 6 & & & 1,2 & \\
\hline & & & SV1.2.2.2 & 5 & & & 3 & \\
\hline & & & SV1.2.2.3 & 5 & & & 3 & \\
\hline
\end{tabular}




\begin{tabular}{|c|c|c|c|c|c|c|c|}
\hline FC1.3 & & & & & & & \\
\hline & \begin{tabular}{|l|} 
V1.3.1 \\
\end{tabular} & & & 34 & & & 10,2 \\
\hline & & & 11 & & & & \\
\hline & & SV1.3.1.1 & 4 & & & 0 & \\
\hline & & SV1.3.1.2 & 3 & & & 1,8 & \\
\hline & & SV1.3.1.3 & 4 & & & 0 & \\
\hline & V1.3.2 & & & & & & \\
\hline & & & 11 & & & & \\
\hline & & SV1.3.2.1 & 5 & & & 0 & \\
\hline & & SV1.3.2.2 & 6 & & & 6 & \\
\hline & V1.3.3 & & & & & & \\
\hline & & & 12 & & & & \\
\hline & & SV1.3.3.1 & 6 & & & 1,2 & \\
\hline & & SV1.3.3.2 & 6 & & & 1,2 & \\
\hline D2 & & & & & 100 & 36,8 & \\
\hline \multirow[t]{11}{*}{ FC2.1 } & & & & 34 & & & 7,8 \\
\hline & V2.1.1 & & & & & & \\
\hline & & & 17 & & & & \\
\hline & & SV2.1.1.1 & 6 & & & 0 & \\
\hline & & SV2.1.1.2 & 5 & & & 0 & \\
\hline & & SV2.1.1.3 & 6 & & & 0 & \\
\hline & V2.1.2 & & & & & & \\
\hline & & & 17 & & & & \\
\hline & & SV2.1.2.1 & 5 & & & 3 & \\
\hline & & SV2.1.2.2 & 5 & & & 0 & \\
\hline & & SV2.1.2.3 & 7 & & & 4,8 & \\
\hline \multirow[t]{10}{*}{ FC2.2 } & & & & 32 & & & 4,8 \\
\hline & V2.2.1 & & & & & & \\
\hline & & & 16 & & & & \\
\hline & & SV2.2.1.1 & 6 & & & 2,4 & \\
\hline & & SV2.2.1.2 & 6 & & & 0 & \\
\hline & & SV2.2.1.3 & 4 & & & 0,8 & \\
\hline & V2.2.2 & & & & & & \\
\hline & & & 16 & & & & \\
\hline & & SV2.2.2.1 & 7 & & & 1,6 & \\
\hline & & SV2.2.2.2 & 9 & & & 0 & \\
\hline \multirow[t]{3}{*}{$\mathrm{FC} 2.3$} & & & & 34 & & & 24,2 \\
\hline & V2.3.1 & & & & & & \\
\hline & & & 17 & & & & \\
\hline
\end{tabular}




\begin{tabular}{|c|c|c|c|c|c|c|c|}
\hline & & SV2.3.1.1 & 6 & & & 3,6 & \\
\hline & & SV2.3.1.2 & 6 & & & 3,6 & \\
\hline & & SV2.3.1.3 & 5 & & & 0 & \\
\hline & V2.3.2 & & & & & & \\
\hline & & & 17 & & & & \\
\hline & & SV2.3.2.1 & 8 & & & 8 & \\
\hline & & SV2.3.2.2 & 9 & & & 9 & \\
\hline D3 & & & & & 100 & 10,2 & \\
\hline \multirow[t]{6}{*}{ FC3.1 } & & & & 49 & & & 0 \\
\hline & V3.1.1 & & & & & & \\
\hline & & & 49 & & & & \\
\hline & & SV3.1.1.1 & 17 & & & 0 & \\
\hline & & SV3.1.1.2 & 16 & & & 0 & \\
\hline & & SV3.1.1.3 & 16 & & & 0 & \\
\hline \multicolumn{8}{|l|}{ FC3.2 } \\
\hline & V3.2.1 & & & 51 & & & 10,2 \\
\hline & & & 51 & & & & \\
\hline & & SV3.2.1.1 & 18 & & & 0 & \\
\hline & & SV3.2.1.2 & 16 & & & 0 & \\
\hline & & SV3.2.1.3 & 17 & & & 10,2 & \\
\hline TOTALES & & & 300 & & 300 & & 102,2 \\
\hline
\end{tabular}

Finalmente, señalamos que del cruce de respuestas con la puntuación, Morella se sitúa en 102,2 puntos sobre el total posible de 300 (tabla 25) por lo que, en el estado actual, no alcanza el umbral mínimo de aceptación, situado en 180 puntos sobre el total.

La puntuación obtenida sitúa a Morella en términos absolutos a 77,8 puntos del mínimo establecido en la escala y a una distancia de prácticamente 198 puntos del máximo alcanzable por lo que, aparentemente, aún quedaría bastante recorrido hasta el umbral de aceptación o hasta la excelencia en la gestión. En concreto los factores clave que requieren una atención prioritaria son el FC1.3 (bienestar de la comunidad local), el FC 2.1 (calidad de diseño) 
y los factores FC3.1 (estrategias) y FC3.2 (marketing) correspondientes a la tercera de las dimensiones.

\section{Figura 15 Equilibrio de las Dimensiones Competitivas}

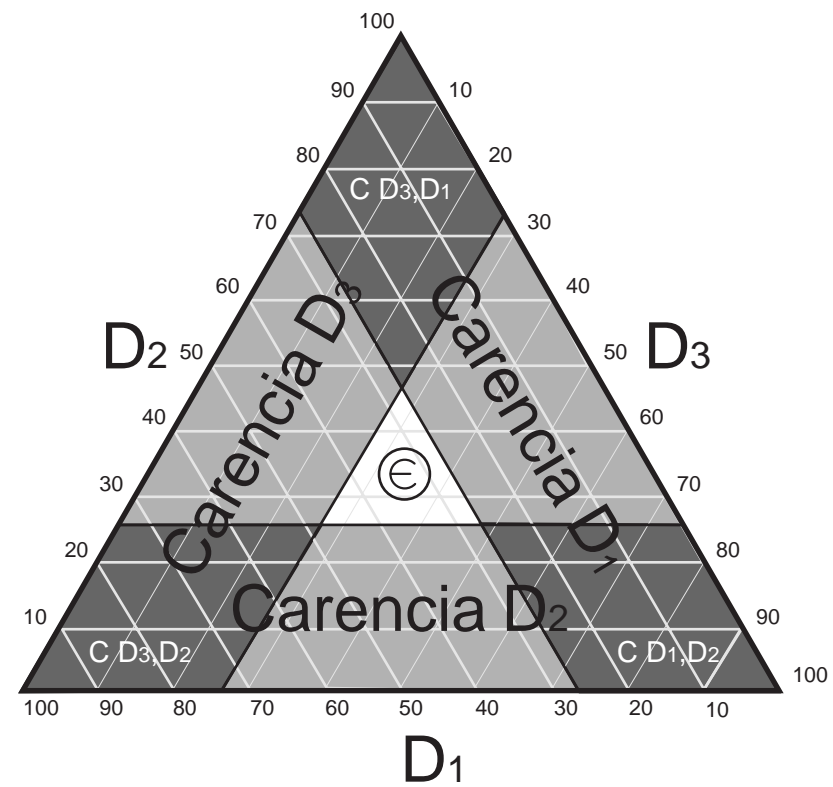

fuente: elaboracion propia

Un análisis pormenorizado revela un aspecto que ha de ser considerado en el proceso de evaluación por encima incluso del resultado que arroje la simple suma acumulada de cada una de las puntuaciones parciales obtenidas. Se trata de la integración de las dimensiones entre sí. En el transcurso de la investigación éstas se han valorado de una manera uniforme, otorgándosele relevancia a las tres sin que ninguna de ellas predomine de manera significativa sobre el resto. Por ello, la auditoría debe reflejar este aspecto de equilibrio, de tal manera que no fuera posible la paradoja de que un destino turístico 
alcance un nivel óptimo de puntuación exclusivamente mediante el juego de dos de las dimensiones. La figura 15 representa esta interacción en el que se sitúa un campo óptimo dentro del cual el destino que se considere estaría en situación de equilibrio. Como se observa en la figura 16, la gestión turística de Morella se sitúa en el exterior de este campo, al obtener los siguientes porcentajes:

PT 102,2 [ $\mathrm{D}_{1}$ 55,2; $\left.\mathrm{D}_{2} 36,8 ; \mathrm{D}_{3} 10,2\right]$

PT (100\%) [D $\left.(54,1 \%) ; \mathrm{D}_{2}(36 \%) ; \mathrm{D}_{3}(9,9 \%)\right]$

debiendose desplazar hacia la derecha en la medida que se perfeccione fundamentalmente la dimensión posicionamiento.

Figura 16 Situaciones de Equilibrio Competitivo del Destino Turístico Morella

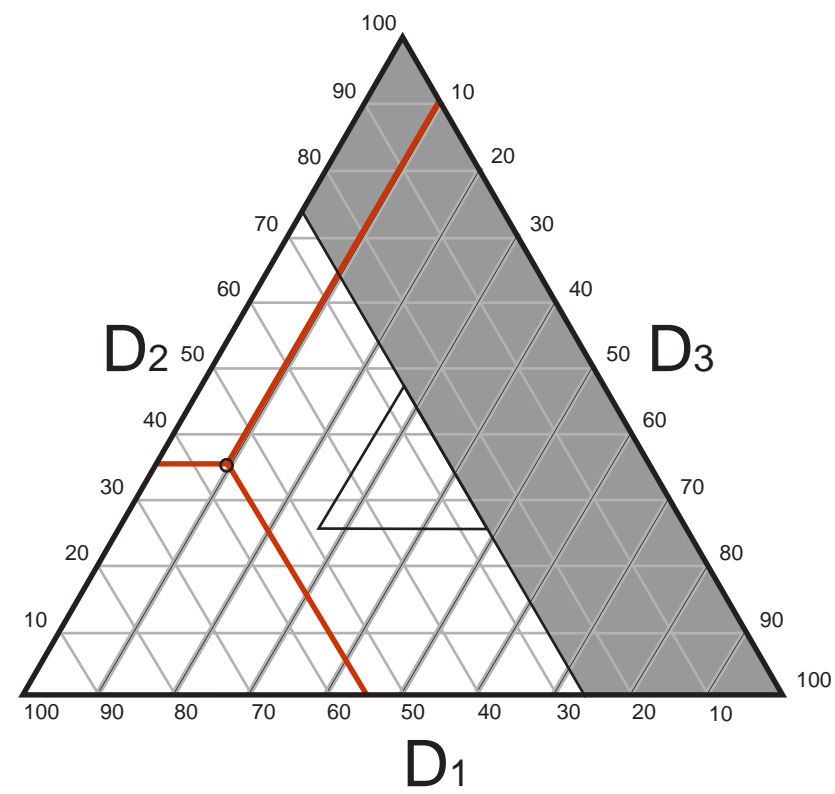

fuente: elaboracion propia 
CAPÍTULO 5

CONCLUSIONES Y RELEVANCIA DE LA INVESTIGACIÓN 

El modelo actual de destinos turísticos está caracterizado por el aumento constante de la oferta de productos y la globalización de la competencia, consecuencia, fundamentalmente, de las nuevas tecnologías aplicadas en el campo de la información y la distribución y, especialmente, en el ámbito de los transportes. En dicho modelo las ventajas competitivas, derivadas de la capacidad y habilidad de sus respectivos organismos gestores, superarán en importancia a las ventajas comparativas nacidas de las bondades y características propios del territorio y entorno que configuran el producto turístico territorial.

En este contexto, los destinos turísticos rurales o de interior deberán articular un modelo de desarrollo alejado de los modelos que tradicionalmente han sido utilizados por los destinos más consolidados tanto en la oferta turística de sol y playa como en la de ciudad. Ello es debido tanto a las características del producto ofertado, a la normalmente menor dimensión territorial, económica y social de los territorios en que se produce como al déficit general de infraestructuras con el que cuentan inicialmente, que implica que en esta situación de mayor fragilidad no se deban aplicar aquellos modelos.

Los organismos públicos en las sociedades modernas actuales deben cubrir con calidad y eficiencia un número creciente de necesidades, por lo que deben dotarse de estructuras de gestión altamente sensibilizadas con el entorno con el que interactúan, por un lado, y con una mayor flexibilidad en su operativa ordinaria interna, por otro. Ello es necesario para llevar a cabo su tarea de acuerdo a exigencias de efectividad, equidad, excelencia y sostenibilidad puesto que, no sólo es importante lo que hacen sino que se evalúa, y muy especialmente, cómo lo hacen, debiendo ser capaces de aportar valor añadido a los procesos de gestión en los que participan. 
Por tanto, la implantación en los destinos turísticos de sistemas de gestión que incorporen procesos de control basados en un conjunto de indicadores que permitan conocer el comportamiento de factores clave para el destino y su repercusión en los modelos de desarrollo previamente adoptados resulta fundamental. De esta manera se facilita la posterior toma de decisiones por sus correspondientes gestores, convirtiéndose en una necesidad incuestionable, tanto desde el punto de vista de la propia efectividad organizativa como desde el punto de vista de la legitimidad institucional y operativa.

No obstante la constatación de la dificultad de poder acotar, tanto en el ámbito teórico como práctico, el concepto de competitividad de los destinos turísticos, es indudable que es éste el planteamiento hacia el que se debe converger dada la situación e importancia actual del sector en nuestro país.

El proceso de gestión de los destinos turísticos debe tener como obligatoria referencia la búsqueda constante de la mejora del bienestar y de la calidad de vida de los habitantes de la comunidad local. El desarrollo turístico debe ser considerado no como un objetivo final en sí mismo, sino como un instrumento al servicio de la comunidad, de tal modo que sea ella la que determine, de forma endógena y no impuesta, cuál es el modelo de desarrollo turístico que desea y cuáles son los límites que la propia comunidad se desea autoimponer en el cumplimiento de este objetivo.

Asimismo, en la delimitación de quienes son los actores que deben estar representados en el proceso de desarrollo turístico, la comunidad local no puede quedar reducida a la industria turística local puesto que, por razones obvias, ésta se orientará a la búsqueda de la máxima productividad. Esta situación acabaría generando efectos de exclusión sobre el resto de residentes 
locales, que sí recibirán buena parte de los impactos negativos que el turismo genera pero, por el contrario, se beneficiarán muy poco de los impactos positivos, lo que acaba produciendo como inevitable consecuencia graves fracturas en la cohesión social de la comunidad local correspondiente.

Este efecto tiene consecuencias más perniciosas, si cabe, en el ámbito del desarrollo turístico rural dado que, por su menor dimensión, los impactos positivos y el logro de una posición de madurez en el ciclo de vida se alcanzan con mayor rapidez que en los destinos turísticos de mayor tamaño. Esta situación lleva aparejado, implícitamente, que el índice de irritabilidad entre los residentes locales haga su aparición más pronto, y, su impacto sobre la vida cotidiana sea más significativo, dada la mayor intensidad de convivencia que se produce en estos medios.

Para el caso concreto del municipio de Morella, se constata la importancia que ha alcanzado y las perspectivas que despierta el sector turístico en el ámbito económico y empresarial, siendo cada vez más las organizaciones que, provenientes de sectores económicos distintos, inician el desarrollo de actividades empresariales relacionadas con el turismo, situación que está provocando un aumento muy significativo de la competitividad dentro del sector, tanto por la vía de las organizaciones existentes como por la variedad y calidad de los productos ofertados.

En cuanto a la percepción que la población local tiene sobre los impactos del turismo en su territorio, se pueden extraer las siguientes conclusiones:

1) La percepción de los impactos económicos por la totalidad de la población de Morella, resultan evidentes, situación que confirma la hipótesis sostenida en la misma línea por investigaciones anteriores. 
2) Se constata la percepción del impacto positivo del turismo en el ámbito socio cultural como artífice del mantenimiento y restauración de los bienes públicos de carácter histórico-patrimonial.

3) El principal impacto social negativo es la percepción de generación de malestar y un incipiente conflicto interno en la población como consecuencia del desarrollo de la actividad turística.

4) Los impactos medioambientales, positivos y negativos, no son claramente percibidos por la población. No existen diferencias significativas entre las variables manifestadas por los distintos grupos de población. Su percepción generalizada es cuestionable.

5) Las dimensiones externas, especialmente la situación de la economía local, sirven para comparar las variaciones entre destinos, pero consideramos que no pueden ser determinantes de la percepción de los individuos de un destino entre sí. En todo caso explicaría el apoyo conjunto de la población residente hacia el turismo.

6) Las dimensiones intrínsecas, variables personales, únicamente el factor "relación profesional con el turismo" explica diferencias entre la población en el sentido de sobrevalorar los impactos positivos y atenuar los negativos.

Por otro lado, en nuestra investigación se ha puesto de manifiesto que el enfoque más adecuado para unir competitividad con destinos turísticos es aquél que exige el análisis y consideración de factores claves del éxito que tienen su origen en tres dimensiones fundamentales y que son la eficiencia, la calidad y el posicionamiento estratégico. Estas dimensiones deben ser 
abordadas desde un enfoque integrado y holístico, evitando aproximaciones parciales o sesgadas, como si de compartimentos estancos se tratara, puesto que sólo desde la obtención de niveles aceptables simultáneamente en ellas se puede lograr un nivel mínimo de competitividad.

Por lo que a la eficiencia se refiere, y teniendo en cuenta la dificultad actual de poder evaluarla de forma rigurosa en las actuaciones y programas que se llevan a cabo por los organismos gestores de los destinos turísticos, es imprescindible que se articulen los mecanismos necesarios para poder conocer cuál es el impacto que sus decisiones tienen en la mejora de la competitividad de los destinos. Esta situación comporta la necesidad de asumir un concepto de eficiencia más cercano a la valoración cualitativa "gestión óptima”, o al concepto de "buenas prácticas", que permitiría indicar y orientar sobre cómo se está llevando a cabo este proceso de gestión, más que a parametrizar modelos cuantitativos.

En la búsqueda de la eficiencia en los destinos turísticos, tal y como la hemos planteado en la investigación, se hace imprescindible la definición y puesta en marcha de entes gestores abiertos y participativos que, debidamente articulados en torno a una misión bien definida, diseñen y ejecuten un programa de actuación que responda a la elección estratégica que previamente se ha tomado. Dichos entes gestores habrán de afrontar, a su vez, adecuadamente los cambios continuos que el entorno turístico manifiesta, debiendo ser altamente eficientes en el manejo de los siempre escasos recursos públicos, situación mucho más evidente en los destinos turísticos de interior. En este apartado debemos concluir que la eficiencia debe plasmarse en la puesta en marcha de los mecanismos necesarios que garanticen, por un lado, la cooperación y coordinación constante entre las diferentes administraciones 
que siempre, debido a la multifuncionalidad del producto turístico, aparecerán tanto en sentido vertical - distintos ámbitos territoriales- como horizontal distintos departamentos dentro del mismo nivel territorial- y, por otro, con la iniciativa que integra el destino turístico, maximizando las sinergias que se derivan del diálogo y la coordinación constante.

La eficiencia en los destinos turísticos de interior y que se encuentran en una fase de desarrollo inicial, implica, igualmente, que los órganos de gestión de éstos lleven a cabo acciones de desarrollo y mejora del tejido productivo, estableciendo el marco idóneo para la generación y difusión del conocimiento que, a su vez, estimulará innovación como factor clave para la consecución y mantenimiento de la posición competitiva.

Por lo que a la calidad se refiere, es preciso poner de relieve que dado el actual nivel de desarrollo de los mercados turísticos, la presencia de ésta ya no puede ser un sólo elemento diferenciador positivo dentro de las estrategias competitivas de los destinos turísticos, sino que, al contrario, la calidad es una exigencia sine qua non, no sólo para poder alcanzar la posición competitiva deseada, sino también para mantenerla, de tal modo que los mercados actuales penalizan aquellos destinos que no incorporan los atributos de calidad como parte intrínseca del producto ofrecido.

Por lo tanto, la gestión de la calidad en los destinos turísticos deberá articularse desde una visión integral. La prestación del producto ha de contemplarse con orientación estratégica al cliente, de tal modo que todos los productos y servicios ofrecidos, con independencia de la titularidad pública o privada de sus gestores, deberán integrarse en la cadena de valor que el destino turístico ofrece al consumidor. Por otro lado, el proceso de gestión debe ser 
continuo, teniendo también al consumidor como punto inicial de partida, conociendo y evaluando sus expectativas y necesidades, continuando por la correcta definición y diseño de los productos y la producción de los mismos en los términos requeridos para, finalmente, evaluar el nivel de satisfacción que los mismos producen en el consumidor turístico.

Por otra parte, el logro de una posición competitiva sostenible sólo podrá conseguirse cuando la gestión de los destinos turísticos adopte el marco estratégico como instrumento imprescindible para definir la gestión de las organizaciones públicas con competencias en el diseño e implantación de las políticas y estrategias. Asimismo, es necesario establecer la línea de separación entre la política general que ha de regir el municipio o localidad en su conjunto, de la estrategia que debe marcar la pauta de la gestión del destino turístico como producto en el mercado y, por tanto, del ente gestor como organización responsable del mismo.

Los destinos turísticos de interior deberán buscar modelos de marketing propios y específicos, debiendo evitar la adopción mimética de aquellos que fueron utilizados por los destinos maduros de sol y playa en sus inicios puesto que, por un lado, el entorno en el que actúan es completamente distinto $\mathrm{y}$, por otro, porque dichos modelos son totalmente inoperantes en la actualidad, incluso para los propios destinos de sol y playa emergentes. No deberían olvidar que un buen plan de marketing siempre debe partir del diseño y creación de un buen producto, cuestión ésta que ninguna campaña de comunicación o política de promoción, puede soslayar.

A partir de la delimitación científica de las tres dimensiones que afectan a la competitividad de los destinos turísticos y de la definición del contenido de cada una de ellas, se ha desarrollado un modelo que, tras su validación, 
se ha revelado como instrumento apropiado para evaluar el desempeño de los entes de gestión turística de los destinos que se encuentren en su fase inicial de desarrollo. Ello es debido a que, aunque recoge aspectos complejos de planificación, organización y dirección estratégica, su planteamiento se revela como una guía metodológica altamente aplicable a los mismos.

Simultáneamente, la cuantificación de cada una de las variables que componen el modelo permite la comparación de los resultados de gestión entre distintos destinos, independientemente de la naturaleza de sus recursos, su dimensión o, en definitiva, su tipología de producto, por lo que permite situar a los destinos que utilicen esta metodología de evaluación/ auditoría en un ranking de competitividad.

Por tanto, el interés de este trabajo radica, por una parte, en la determinación empírica de cuáles son las dimensiones clave para alcanzar el éxito en la gestión competitiva de un destino y, por otra parte, en la aportación de un instrumento metodológico que permite auditar internamente el nivel de excelencia alcanzado en la co-gestión de un destino turístico en fase inicial de desarrollo. También se constituye en una herramienta que permite el análisis comparado entre destinos, por lo que, en futuras investigaciones, se podrán establecer índices básicos de actuación que permitan medir el grado de desempeño en el desarrollo de competencias y capacidades competitivas en la gestión de los destinos turísticos. 
CAPÍTULO 6

BIBLIOGRAFÍA 



\section{BIBLIOGRAFÍA}

AGUILÓ, E. (1998): "Política Turística", en Mella Márquez (coord.). Economía y Política Regional en España ante la Europa del siglo XXI. Edit. Akal Textos, Madrid. pp. 449-451.

AGUILÓ, E.; BARRÓS, V.; GARCÍA, M.A. y ROSELLÓ, J. (2003): Las Actitudes de los Residentes en Baleares frente al turismo. Universitat de les Illes Balears. Bancaja. Fundació Antoni Maura.

AIGNER, D. y CHU, S.F. (1968): “On Estimating the Industry Production Function", American Economic Review, 58, pp.826-839.

AIGNER, D., LOVELL, C. y SCHMIDT, P. (1977): "Formulation and Estimation of Stochastic Frontier Production Function Models", Journal of Econometrics, 6 pp. 21-37.

ALONSO, J. A. (1992): Ventajas Comerciales y Competitividad: Aspectos Conceptuales y Empíricos. Información Comercial Española, № 705, pp. 38-76.

ÁLVAREZ, A. y GONZALEZ, E. (1999): "Using Cross-Section Data to Adjust Technical Efficiency Indexes Estimated with Panel Data", American Journal of Agricultural Economics, 81 (4), pp. 891-894.

ALlEN, L. R., LONG, P. T., PERDUE, R.R. y KIESELBALCH, S. (1988): "The Impact of Tourism Development on Residents Perceptions of Community Life", Journal of Travel Research, 27 (1), pp. 16-21.

ALLEN, L.R., HAFER, H.R., LONG, R. y PERDUE, R.R. (1993): "Rural Residents' Attitudes toward Recreation and tourism Development", Journal of Travel Research, 31 (4), pp. 27- 33.

ANDERSON, J.E, (1994): "Public Policymaking. An Introduction". Citado por Olmeda Gómez, José en Ciencia de la Administración. Teoría de la Organización y Gestión Pública. Vol. I, pág. 496.

ANDREWS, R (1977): El Concepto de Estrategia de la Empresa, Ediciones Universidad de Navarra. Pamplona. 
ANSOFF, H.I. (1965): Corporate Strategy, New York: Mc Graw Hill.

ANTHONY, R., DEARDEN, J. y VANCIL, R. (1972): Management Control Systems: Text, Cases, and Readings, Richard D. Irwin. Inc.

ANTÓN, S. (1997): "Métodos y Técnicas para la Planificación Turística del Territorio". En J. Oliveras y S. Antón (Eds.) (1997): Turismo y Planificación del Territorio en la España de Fin de Siglo. Tarragona: GET, Univ. Rovira i Virgili pp. 5-44.

AP, J. (1990): "Residents' Perceptions Research on the Social Impacts of Tourism". Annals of Tourism Research, (17), pp. 610-616.

AP, J. (1992): "Residents' Perceptions on Tourism Impacts". Annals of Tourism Research, (19), pp. 665-690.

AP, J. y CROMPTON J. (1998): "Developing and Testing a Tourism Impact Scale". Journal of Travel Research, 37(2), pp.120-130.

APPELBAUM, S.; St-PIERRE, N. y GLAVAS, W. (1998): "Strategic Organizational Change: The Role of Leadership, Learning, Motivation and Productivity". Management Decision, 36 (5), pp. 289-301.

ARCHER B.H. y COOPER, C., (1994): "The Positive and the Negative Impacts of Tourism", en Theobald, W. (ed.), Global Tourism: The Next Decade, Butterworth-Heinemann, Oxford.

ARELlanO, D.(1992): "Teoría de la Organización y Análisis Organizacional: Hacia Nuevos Paradigmas". Documento de trabajo 6. Centro de Investigación y Docencia Económicas. México.

ARELLANO, D. (1997): "Análisis Organizacional: una perspectiva desde la estrategia". Documento de trabajo ${ }^{\circ} 26$. Centro de Investigación y Docencia Económicas. México.

ARGYRIS, C. (1985): Strategy Change and Defensive Routines, Pitman Publishing.

BAÑóN, R. y CARRILLO. E. (1997): La nueva Administración Pública. Alianza Universidad Textos, Madrid. 
BARNEY, J.B. (1991): "Firm Resources and Sustained Competitive Avantage". Journal of Management, (17), pp. 99-120.

BARNEY, J.B. (2001): "Is the Resource-Based View a Useful Perspective for Strategic Management Research? Yes". Academy of Management Review. 26 (1), pp. 41-58.

BASKERVILLE, R. y MYERS, M. (2002): "Information Systems as a Reference Discipline". MIS Quarterly, 26 (1).

BARZELAY, M. y O'KEAM, J., (1992): Gestión Pública Estratégica. Conceptos, Análisis y Experiencias: El Caso IPIA, ( $\left.2^{\mathrm{a}} \mathrm{Ed}\right)$. Ministerio de Economía y Hacienda. Instituto de Estudios Fiscales, Madrid.

BATTESE, G. y COELLI, T. (1995) : “A Model for Technical Ineffiency Effects in a Stochastic Frontier Production Function for Panel Data", Empirical Economics (20), pp.325-332.

BAUER, R. (1998): "Caos e Complexidade nas Organizacöes". Revista de Administraçao Publica. 32 (5), pp. 69 - 80, Río de Janeiro.

BAUZÁ, F. (1999): Aproximación a la Ciencia de la Administración. Gerencia aplicada a las Organizaciones Pública. Dykinson, Madrid.

BAZAGA, I. (1997): "El Planteamiento Estratégico en el Ámbito Público" en Bañón, R y Carrillo, E. (editores). La Nueva Administración Pública, Madrid.

BELTRÁN, J. (1996): "La construcción administrativa de la realidad social". Citado en Bazaga, I. (1997): "El planteamiento estratégico en el ámbito público" en Bañón, R y Carrillo E. La Nueva Administración Pública, Madrid.

BERGMAN, E. y FESER, E. (1999): Industrial and Regional Clusters: Concepts and Comparative Applications, Regional Research Institute, West Virginia University.

BOLES, J.N. (1966): "Efficiency Squared - Efficient Computation of Efficiency Indexes", Proceedings of the Thirty Ninth Annual Meeting of the Western Farm Economics Association, pp.137-142. 
BOULLON, R. (1990): Los Municipios Turísticos. Edit. Trillas, México.

BROUGHAM, J. y BUTLER, R. W. (1981) "A segmentation analysis of Resident Attitudes to the Social Impact of Tourism". Annals of Tourism Research (8), pp. 569-590.

BROWN, R. (2000): "Cluster Dynamics in Theory and Practice with Application to Scotland" en Regional and Industrial Policy Research, Paper, no 38, European Policies Research Centre, University of Strathclyde, U.K.

BRYSON, J. (1993): Strategic Planning for Public and Nonprofit Organizations. Pergamon Press. The Best of Long Range Planning, Oxford.

BUENO, E. (1995): "La Competitividad en la Empresa: un Enfoque de Organización y una Referencia a España”. Dirección y Organización, $\mathrm{n}^{\circ}$ 13, pp. 5-15.

BUESA, M. y MOLERO, J. (1998): "La Innovación Tecnológica en la Industria Española", en Economía Industrial de España: Organización, Tecnología e Internacionalización. Civitas, Madrid, pp. 203-243.

BULL, A. (1991): The economics of Travel and Tourism. Longman Sheshire PTY Limited, Londres.

BULL, A. (1994): La Economía en el Sector Turístico., Alianza Editorial, Madrid.

BURCH, J. y GRUDNITSKI, G. (1992): Diseño de Sistemas de Información. Grupo Noriega Editores, México.

BURTON, R. (1991): Travel Geographie. Pitman Publishing, Londres.

BUTLER, R (1980): "The Concept of a Tourist Area Cycle of Evolution: Implications for Management of Resources", en Canadian Geographer, 24, pp. 5-12.

BRITTON, S. (1991): "Tourism, Capital and Place: Towards a Critical Geography of Tourism", Environment and Planning, Society and Space, vol. 9, pp. 451-478. 
CABRERO, E. (1991): Retos y Perspectivas en la Administración Pública Mexicana. Entre la tradición y el cambio". Citado por Arellano, D. (1992), Centro de Investigación y Docencia Económicas, México.

CALS, J., MATAS, A. y RIERA, P. (1993): Evaluación de proyectos. Análisis de la Rentabilidad Social desde la perspectiva del Turismo y del Ocio. Secretaría General de Turismo de España, Madrid.

CAMISÓN, C. y MONFORT, V. (1993): "La Empresa Turística Valenciana: Diagnóstico Estratégico y Posicionamiento Competitivo", Papers de Turisme, $\mathrm{n}^{\circ} 12$, pp. 13-25.

CAMISÓN, C., PEDREÑO, A. y MONFORT, V. (1996): Introducción a la Economía del Turismo en España, Editorial Civitas, Madrid.

CANALS. J. (1991): Competitividad Internacional y Estrategia de la Empresa. Ariel, Barcelona.

CARROLL, A. (1989): Business and Society. Citado por Villoria, I. (1996), Instituto Nacional de Administración Pública (INAP), BOE, pág. 262.

CARPI, T. (1998): "Las Regiones Españolas y el Fomento de la Competitividad”. En Mella Márquez (coord.). Economía y Política Regional en España ante la Europa del siglo XXI. Edit. Akal Textos, Madrid.

CARUANA, A.; MONEY, A.H. y BERTHON, P.R. (2000): "Service Quality and Satisfaction. The Moderating Role of value". European Journal of Marketing, vol. 34, nº11/12, pp.1338-1353.

CAVES, R. y PORTER, M., (1977): "From Entry Barriers to Mobility Barriers: Conjectural Decisions and Contrived Deterrence to New Competition", Quaterly Journal of Economics, vol 91, pp. 241-261.

CHAFFEE, E., (1985): “Three Models of Strategy", Academy of Management Review, vol. 10, núm. 1, pp. 89-98.

CHANDLER, A., (1962): Strategy and Structure: Chapters in the History of American Industrial Enterprises, The MIT Press.

CHRISTENSEN, C. (2000): The Innovator's Dilemma. Harpers Collins. New York. 
CONGER, J. y CANUNGO, R. (1988): “The Empowerment Process: Integrating Theory and Practice". Academy of Management Review. Vol 13, $\mathrm{N}^{\mathrm{o}} 3$, pp.565-593.

COOL, K. y SCHENDEL, D. (1988): "Performance Differences Among Strategic Group Members", Strategic Management Journal, vol. 9, número 3, pp. 207-223.

COOPER,C., FLETCHER, E., GILBERT,D., y WANHILL, E. (1993): Tourism. Principles and Practice. Pitman, Londres.

CRIADO, A. y CARRIÓN, D. (2000): "Planificación y Dirección por objetivos", exposición en INSCAL, Madrid.

CRONIN, J. J. y TAYLOR, S.A. (1994): “SERVPERF versus SERVQUAI: reconcilling performance-based and perceptions-minus-expectations measurement of service quality". Journal of Marketing, vol. 60 (abril), pp. 31-46.

DALMAU, J.I., DE MIGUEL, E., PERIS, M. (1993): Análisis estratégico de los sectores industriales y de turismo en la Comunidad Valenciana, vol. II. Servicio de Publicaciones, Universidad Politécnica de Valencia.

DANIEL, R. (1961): "Management Information Crisis", Harvard Business Review, September-October, pp. 111-121.

DAVIS, D., ALLEN, J., y COSENZA, R.M. (1988): "Segmenting Local Residents by their Attitudes, Interests and Opinions toward Tourism". Journal of Travel Research (27) pp. 2-8.

DAY, E. y CRASK, M.R. (2000): "Value assessment: the antecedent of customer satisfaction". Journal of Consumer Satisfaction, Dissastifaction and Complaining Behavior, vol.13. pp. 52-61.

DEBREU, G. (1951): “The Coefficient of Resource Utilization”, Econometrica, 19(3) pp. 273-292.

DE BURGOS J., CÉSPEDES, J. y ÁLVAREZ, M.J. (2003). “Dirección de Operaciones de Servicios: Los Hoteles Españoles". Revista Europea de Dirección y Economía de la Empresa. Vol. 12, $\mathrm{N}^{\mathrm{o}}$ 1, pp. 83-98. 
DEIGHTON, J. (1992): "The Consumption of performance". Journal of Consumer Research, vol 19, (diciembre) pp. 362-372.

DELBECQ, A.L. y VAN DE VEN, A.H., (1971): “A group process model for problem identification and program planning". Journal of Applied Behavioral Science, vol.7, n³, pp. 466-492.

DE RUS, G. y LEÓN, C. (1997): "Economía del turismo. Un panorama”. Revista de Economía Aplicada, núm. 15, pp. 71-109.

DE RUS, G.,(2004): Análisis coste-beneficio. Evaluación económica de políticas y proyectos de inversión (2 $2^{\mathrm{a}} \mathrm{ed}$.) Ariel, Barcelona.

DIAMOND, P. y MIRRLEES, J. (1971): “Optimal Taxation and Public Production I. Production Efficiency" y "II. Tax Rules", American Economic Review, 61, 8-27 y 261-278.

DOGAN, H. Z. (1989): "Forms of Adjustment: Sociocultural Impacts of Tourism”. Annals of Tourism Research 16, pp. 223-239.

DONSIMI, M. y LEOZ-ARGÜELLES, V., (1981): "Strategic Groups: An Application to Foreing and Domestic Firms in Spain", Recherches Economiques de Louvain, septiembre, pp. 291-306.

DOSI, G., MALERBA, F. y ORSENIGO, L.(1994): "Evolutionary regimes and industrial dynamics", en Magnusson, L. (ed.): Evolutionary and NeoSchumpeterian Approaches to Economics. Kluwer Academic Publishers. Norwell, Mass, pp. 203-229.

DOXEY, G. (1975): “A Causation Theory of Visitor- Resident Irritants: Methodology and Research Inferences". Proceedings of the Travel and Tourism Research Association, 6th Sixth Annual Conference, Salt Lake City, San Diego, CA, pp. 195-198.

DRUCKER, P. (1979): La gerencia de empresas. Edhasa. Barcelona.

EISENHARDT, K.M., y MARTIN, J.A. (2000): "Dynamic capabilities: What are they". Strategic Management Journal, vol.21. pp. 1105-1121.

EL SAWY, O. (1985): "Implementation by Cultural Infusión: An Approach for Managing the Introduction of Information Technologies". MIS Quarterly. Junio. 
ENRIGHT, M. (2000): "The Globalization of Competition and the Localization of Competitive Advantage: Policies toward Regional Clustering" en Hood, N. Y Youngs. (eds) Globalization of Multinational Enterprise and Economic Development, Macmillan, London.

ENRIGHT, M., y NEWTON, J. (2004) "Tourism destination competitiveness: a quantitative approach". Tourism Management, Volume 25, Issue 6, December, pp. 777-788.

FAGERBERG, (1996): “Technology and competitiveness", Oxford Review of Economic Policy, vol. 12, núm. 3, pp. 39-51.

FAYOS, E. (1994): "Competitividad y Calidad en la Nueva Era del Turismo" Estudios Turísticos nº123, pp. 5-10.

FAYOS, E., GARCÍA P. Y MOREDA A. (2002): "A modest proposal: on the tourism policy and destination management research programme". Tedqual- OMT 1/2002, pp. 21-25.

FAYOS, E., FUENTES, L., y MUÑOZ, A.. (2003): "Estructura y funcionamiento de los destinos turísticos: el modelo FAS". Papeles OMT.DRH. Madrid.

FÄRE, R y LOVELL, C. (1978) : "Measuring the Technical Efficiency of Production", Journal of Economics Theory, 19, pp.150-162.

FARRELL, M. (1957): “ The measurement of Productive Efficiency”, Journal of Royal Statistics Society, Serie A, 120 (3), pp.81-253.

FEDERACIÓN ESPAÑOLA DE HOSTELERÍA (2003): "Situación del sector de hostelería; factores de cambio e innovación"; en La hostelería ante las competencias profesionales del nuevo milenio.

FELDSTEIN, M. (1976): "On the theory of Tax Reform", Journal of Public Economic 86.

FERNÁNDEZ, E., MONTES, J. y VÁZQUEZ, C. (1997): “La teoría de la ventaja competitiva basada en los recursos: Síntesis y estructura conceptual". Revista Europea de Dirección y Economía de la Empresa, vol. 6, n³3, pp. 11-32. 
FERNÁNDEZ, E. (1996): Innovación, tecnología y alianzas estratégicas: factores clave de la competencia. Editorial Civitas. Madrid.

FERNÁNDEZ, Z.(1992): “Algunas reflexiones sobre la competitividad empresarial y sus causas”. Información Comercial Española, nº705, pp. 139152.

FERNÁNDEZ, Z. (1993): "La organización interna como ventaja competitiva para la empresa". Papeles de economía española, nº56, pp. 178-193.

FÖRSUND, F., LOVELL, C. y SCHMIDT, P. (1980): “ A Survey of Frontier Production Functions and of Their Relationship to Efficiency Measurement", Journal of Econometrics, 13, pp.5-25.

FOSS, N. (1997): "Resources and strategy: problems, open issues, and ways ahead" in Nicolai Foss, ed (1997), Resources, Firms and Strategies, A reader in the resource-based perspectiva, Oxford Management Readers, Oxford University Press, pp. 345-367.

FREDLINE, E., y FAULKNER, B. (2000): "Host Community reactions. A cluster Analysis". Annals of Tourism Research, Vol. 27, n³ pp. 763-784.

FRIDOLÍN, X.(1995): Factores clave del éxito del sector industrial hotelero. Instituto de Estudios Turísticos, Secretaría General de Turismo de España, Madrid.

FULLANA, P. y AYUSO, S. (2001): Turisme sostenible. Generalitat de Catalunya, Rubes.Barcelona.

GARCÍA-FALCÓN, J.M. y OSORIO, J. (1998): SISTRAT: Un sistema de información de apoyo a la formulación de estrategias empresariales, Editorial Civitas, Madrid.

GARCÍA-FALCÓN, J. (1987): Formulación de estrategias de la empresa, Edit. CIES, Madrid).

GALLARZA G., GIL, I. y CALDERÓN, H. (2002) : "Imagen del destino. Hacia un marco conceptual". Annals of Tourism Research en Español, vol 4, nº 1 pp. 37-62. 
GALLEGO, J. (2004): Gestió pública del turisme. Fundació Universitat Oberta de Catalunya. Barcelona.

GALLEGO, J. y OSORIO, J. (2005) : Innovació en el turisme. Fundació Editorial UOC, Barcelona.

GALENDE, J. y DE LA FUENTE, J. (2003): "El Proceso de Innovación de la Empresa Española: Identificación de Patrones de Innovación”. Cuadernos de Economía y Dirección de la Empresa. Vol. 16, pp 145-171.

GARRIDO, S. (2003): Dirección Estratégica, Mc Graw Hill- Interamericana. Madrid.

GARVIN, D.A. (1983): “Quality on the line". Harvard Business Review, vol. 61, (Septiembre/Octubre), pp. 65-73.

GATTIKER, E. y KELLEY, H. (1999): "Morality and Computers: Attitudes and Differences in Judgements". Information Systems Research. Vol 10, $\mathrm{N}^{\mathrm{o}} 3$.

GEE C., MACKENS, J. y CHOY, D. (1989): The Travel Industry.Van Nostrand Reinhold, New York.

GENERALITAT VALENCIANA (2004): Consellería de Turismo. Noticies Turismo, Época II, $n^{\circ} 9$.

GIANINNI R. (1988): "Diritto amministrativo", citado por Villoria, M (1996).

GÖNENÇ, E.(1994): "Polítique industrielle: une nouvelle approche". L'Observateur de l'OCDE, núm. 187, pp 16-19. 
GLUECK, W. (1976): Business Policy, Strategy, Formation, and Management Action, Mc Graw-Hill.

GRANDE, E. y ABASCAL, E. (2001): Fundamentos y Técnicas de Investigación Comercial, $5^{\mathrm{a}}$ edición, Esic. Editorial, Madrid.

GRANT, R. (1991): "The resource-based theory of competitive advantage: implications for strategy formulation". California Management Review, Spring, 33, pp. 114-135.

GRANT, R. (1996): "Prospering in Dynamically-Competitive Environments: Organizational Capability as Knowledge Integration”. Organization Science. Vol 7, nº.

GRAY, J. (1982): “The Contributions of Economics to Tourism". Annals of Tourism Research, Vol. 9, pp. 105-125.

GREENE, W. (1980b): "Maximum Likelihood Estimation of Econometric Frontier Functions", Journal of Econometrics, 13 (1) pp. 27-56.

GUNN, C. (1972): Vacationscape: Designing Tourist Regions. Austin. University of Texas.

GUNN, C. (1994): Tourism Planning. Taylor \& Francis, ( $3^{\text {a }}$ edition), Washington.

GUNN, C. (1997) Vacationscape. Taylor \& Francis (3ª ed.) Washington.

GUNTER, P. y RUCKS, A. (1984): “Can Business Learn from Wargames?" Long Range Planning, vol 17, num.3, pp.123-128. 
GURSOY, D., JUROWSKY, C. y UYSAL, M. (2002) “Actitud de los residentes. Un enfoque de modelización estructural”. Annals of Tourism Research en español Vol. 4 n 1, pp. 63-92.

HALL, C.M. y PAGE, S. (1999): The Geographie of Tourism and Recreation, Routledge, Londres.

HALL, D. (1991): Organizations: Structures, Processes and Outcomes, Prentice -Hall.

HAMEL, G. y PRAHALAD G. (1995): Compitiendo por el Futuro. Ariel. Barcelona.

HARBERGER, A. (1974): Taxation and Welfare. Little Brown and Co., Boston.

HATTEN, K. y HATTEN, M. (1987): "Strategic Groups, Asymmetrical Mobility Barriers and Contestability", Strategic Management Journal , vol. 8, núm.4, pp 329-342.

HAX, A. y MAJLUF, N. (1984): Strategic Management: An Integrative Perspective, Prentice- Hall.

HAX, A. y MAJLUF, N. (1991): The Strategy Concept and Process: A pragmatic Approach, Prentice- Hall.

HENRY,H.(1980): “Appraising Company's Strengths and Weaknesses”, Managerial Planning, julio-agosto, pp. 31-36.

HERMIDA, J. SERRA, R. y KASTIKA, E. (1992): Administración \& Estrategia. Teoría y Práctica. (4 ${ }^{\mathrm{a}}$ Ed). Macchi. Buenos Aires.

HOFER, C. y SCHENDEL, D. (1978): Strategy Formulation: Analytical Concepts, West Publishing Company. 
HOMANS, G. (1961): Social Behavior: its elementary forms. Harcourt Brace Jovanovich. New York.

HINDS, P. y KIESLER, S. (1995): “Communications across Boundaries: Work, Structure and Use of Communication Technologies in a Large Organization". Organization Science. Vol. 6, Nº 4.

IGLESIAS, A y ARRIOLA J. (2004): El planteamiento estratégico de las organizaciones públicas. Una visión desde la teoría del caos. Universidad Rey Juan Carlos , Madrid

ITVA (1990): Libro Blanco del Turismo de la Comunidad Valenciana.

IVARS, J.A. (2003): Planificación turística de los espacios regionales en España, Ed. Síntesis. Madrid

JACOB, M. y BRAVO, A. (2001): Estudio exploratorio sobre la innovación en el sector turístico Balear. Colección estudios $\mathrm{N}^{\circ} 21$. Fundación Cotec. Madrid.

JAFARI, J. (1974): "The socio- Economic Effects of Tourism to Developing countries". Annals of Tourism Research, vol. 10 (3) , pp. 3-17.

JAFARI, J. (2002: "Tourism education and training models. Getting to the core of Destination Planning and Management". WT0- TEDQUAL N ${ }^{\circ} 5$, 1/2002 pp. 29-34.

JOHNSON, G. y SCHOLES K. (2001): Dirección Estratégica. (5 Ed), Prentice Hall, Madrid.

JONES, M. A. y SUH, J. (2000): “Transaction-specific satisfaction and overall satisfaction: an empirical analysis". Journal of Services Marketing, vol. 14, n12. pp. 141-153. 
JUROWSKI,C. (1994): "The Interplay of Elements Affecting Host Community Resident Attitudes toward Tourism: A Path Analytic Approach." PHD dissertation in Hospitality and Tourism, Virginia Polytechnic Institute and State University.

KANTER, R. (1989): “The New Managerial Work". Harvard Business Review. Noviembre-diciembre.

KING, M. (1983): "Welfare Analysis of Tax Reforms Using Household Data”, Journal of Public Economics 21, pp. 183-214.

KOTLER, P., BOWEN, J. ,MAKENS, J. (1997). Mercadotecnia para hotelería y turismo. Prentice-Hall Hispanoamericana, s.a. México.

KOTLER, N., y KOTLER, Ph., (2002): Estrategias y marketing de museos. Ariel. Barcelona.

KOTTER, P. (1994): Dirección de Marketing. Prentice Hall Internacional. Madrid.

KRIPPENDORF, J. (1987): The Holiday Makers: Understanding the impact of Leisure and Travel, Heinemann, London.

KRUGMAN, P. R. (1991): Geography and trade. Cambridge, Mass.: MIT Press.

KRUGMAN, P. R. (1994): Peddling Prosperity. W.W. Norton.

KOOPMANS, T. (1951): "An analysis of Production as an Efficient Combination of Activities", Koopmans, T (ed) Activity Analysis of Production and Allocation, Cowles Commission for Research in Economics, Monograph 13, Nueva York. 
LAGENDIJK, A. (1999 a): "The emergence of Knowledge-Oriented Forms of Regional Policy in Europe", Tijdschrift voor Economische en Sociale Geografie, Vol. 90, pp. 110-116.

LAGENDIJK, A. (1999 b): "Good Practices in Cluster Development Initiatives: A summary of an ADAPT Funded Analysis of Cluster Initiatives", CURDS, University of Newcastle Upon Tyne.

LAUDON, K. y LAUDON, J. (2004): Sistemas de Información Gerencial: Administración de la Empresa Digital. Pearson. México.

LEIBENSTEIN, H. (1966): “Allocative Efficiency vs. "X-efficiency”, American Economic Review, 56, pp. 392-415.

LEARNED, E., CHRISTINSEN, C., ANDREWS, K,. y GUTH, W, (1965): Business Policy: Text and Cases. Richard D. Irwing, Homewood, Ill.

LEE, H., LEE, Y. y YOO, D. (2000): “The determinants of perceived service quality and its relationship UIT satisfaction". Journal of Services Marketing, vol.14, n³, pp. 217-231.

LEW, A. y HALL, M. (1998): “The Geography of Sustainable Tourism. Lessons and Prospects", en Lew, A y Hall M: Sustainable Tourism. A geographical perspective, Longman Essex, pp. 199-203.

LIU, Z. (1994): “Tourism development. A systems analysis", en Seaton, A. (ed) Tourism. The state of the art, John Wiley and Sons, Chichester, pp 20-30. 
LORANGE, P, (1984): "Strategic Control: Some issues in Making it Operationally More Useful", en Lamb. R (ed), Competitive Strategic Management, Prentice Hall.

LOVELL, C.A.K. (1993): “Production Frontiers and Productive Efficiency”, en Fried, H.O; Lovell, C.A.K. y SCHMIDT, S.S (eds.): The Measurement of Productive Efficiency: Techniques and Applications. Oxford University Press.

LOVELL, C.A.K. (1995): “ Econometric Efficiency Analysis: A Policyoriented Review", European J. of Operational Research, 80, pp. 452-461.

McINTOSCH, R.W. y GOELDNER, C.R. (1990): Tourism Principles, Practices, Philosophies. Wiley, New York.

MALHOLTRA, A., MAJCHRZAK, A., CARMAN, R. y LOTT, V. (2001): "Radical Innovation without Collocation: A Case Study at Boeing Rocketdyne”. MIS Quarterly. Vol. 25, N².

MARSHACK, J. y ANDREES, W. ( 1944): "Random Simultaneous Equations and the Theory of Production”, Econometrica, 12, pp.143-205.

MATHIESON, A. y WALL, G. (1982): Tourism. Economic, Physical and Social Impacts, Longman Scientific \& Technical, U.K. En Español (1988) edit. Trillas, (México).

MEEUSEN, W. y VAN DEN BROECK, J. (1977): "Efficiency Estimation from Cobb-Douglas Production Functions with Componed Error", Internacional Economic Review, 18, pp. 435-444.

MELIÁN, A. y GARCÍA, J. (2003): "Potencial Competitivo del Turismo 
en un Destino". Annals of Tourism Research en español. Vol. 5 n², España: Universitat de les Illes Balears, pp. 344-365.

MILL, R. y MORRISON, A. (1992): The Tourism System. An introductory test, Prentice Hall, International.

MINISTERIO DE ECONOMÍA Y HACIENDA, SECRETARÍA DE ESTADO DE COMERCIO, TURISMO Y DE LA PYME (2000): Plan Integral de Calidad del Turismo Español.

MINISTERIO DE INDUSTRIA, COMERCIO Y TURISMO (1992): FUTURES. Plan Marco de Competitividad del Turismo Español.

MINISTERIO DE INDUSTRIA, COMERCIO Y TURISMO, TURESPAÑA, SECRETARÍA GENERAL DE TURISMO (1996):

FUTURES. Plan Marco de Competitividad del Turismo Español.

MINISTERIO DE MEDIO AMBIENTE (2003): Sistema Español de Indicadores Ambientales de Turismo.

MINTZBERG, H. y JORGENSEN, J. (1995): “Una Estrategia Emergente para la Política Pública”. Gestión y política Pública. No IV, 1. pp. 25 -46. México.

MINTZBERG, H. (1997): El proceso Estratégico. Prentice Hall Hispanoamericana. Madrid.

MONTFORT, V. (1999): Competitividad y factores críticos de éxito en los destinos turísticos mediterráneos: Benidorm y Peñíscola. Tesis Doctoral, Facultad de Ciencias Económicas y Empresariales, Universitat de València. 
MOORE, M. (1998): Gestión Estratégica y Creación de Valor en el Sector Público, Paidós, Barcelona.

MOSCOVICI, S. (1984): "The Phenomenom of Social Representations". In social Representation, R.M. Farr and S. Moscovici, eds., pp. 3-69. Cambridge: Cambridge University Press.

MOSCOVICI, S. (1988): "Notes toward a Description of Social Representations". European Journal of Social Psychology 18: pp. 211-250.

MURPHY, P.E. (1985): Tourism: A Community Approach. Routledge, New York.

MURPHY, P.E. PRITCHAR, M. P. y SMITH, B. (2000): “The destination product and its impacts on traveller perceptions". Tourism Management, vol. 21 pp. 43-52.

NAYAK, P. Y KETTERINGHAM, J. (1986): Breakthroughs. Rawson Associates.

NAVAS, J. y GUERRAS, L.(2002): La dirección estratégica de la empresa. ( $3^{\mathrm{a}}$ ed). Civitas, Madrid.

NELSON, R. y WINTER, S. (1982): An Evolutionary Theory of Economic Change. Harvard University Press. Cambridge, Mass.

NELSON, R. (1991): "Why do Firms Differ, and How does it Matter?". Strategic Management Journal, vol. 12, pp. 61-74.

O'HARE, M. (1988): Innovate!: how to gain and sustain competitive advantage. Blackwell. Oxford.

OLIVER, R. L. (1981): "Measurement and evaluation of satisfaction 
processes in retail settings". Journal of Retailing, vol. 57, n³ (otoño), pp. $25-48$.

OLIVER, R. L. (1989): "Processing of the satisfaction response in consumption: a suggested framework and research propositions". Journal of Consumer Satisfaction, Dissatisfaction and Complaining Behaviour, vol. 2, pp. 1-16.

OLIVER, R. L. (1993): “A conceptual model of service quality and service satisfaction: compatible goals, different concepts". Advances in Services Marketing Management. Swartz, A.T. ;Bowen, D.E. y Brown, S.W. (eds.), JAI Press Inc., Greenwich, CT, vol. 2, pp. 65-85.

OLIVER, R. L. (1997): Satisfaction: A behavioural Perspective on the Consumer. New York: the McGraw-Hill Companies, Inc.

OLMEDA, J., (1999): Ciencia de la Administración. Teoría de la Organización y Gestión Pública.. Vol. I, UNED, Madrid.

O'REILLY, A.M. (1986). "Tourism carrying capacity: concepts and issues". Tourism Management, 7 (4): 254-258.

ORGANIZACIÓN MUNDIAL DEL TURISMO (1992): Presentación de las tendencias del turismo hasta el año 2000 y después, Madrid.

ORGANIZACIÓN MUNDIAL DEL TURISMO (1993): Tendencias del turismo. Series mundiales: mundo, Madrid.

ORGANIZACIÓN MUNDIAL DEL TURISMO (1998): Introducción al Turismo, Madrid. 
ORGANIZACIÓN MUNDIAL DEL TURISMO (1999): Handbook for Developing and Using Indicators of Sustainable Tourism, Madrid.

ORGANIZACIÓN MUNDIAL DEL TURISMO (1999): Panorama 2020, Madrid.

ORGANIZACIÓN MUNDIAL DEL TURISMO (2002): "Building Competitiveness through Education, Training and Research". Think Tank on Destination Management, December, Madrid.

ORGANIZACIÓN MUNDIAL DEL TURISMO (2003). Co-operation and Partnerships in Tourism: A Global Perspective. Madrid, pp.1-3.

PAVITT, K. (1984): "Sectoral Patterns of Technical Change: Towards a Taxonomy and a Theory". Research Policy, Vol. 13, pp. 342-373.

PEARCE, W. D. (1981): Tourism development. Longman, ( $2^{\mathrm{a}}$ ed.), London.

PEARCE, W.D. (1993): Géographie du Tourisme. Nathan, Paris.

PEARCE, W.D. y WARFORD, J.J. (1993): World without end. Economics, Environment, and Sustainable Development, Oxford University Press.

PEDRAJA, F., SALINAS, J., SUÁREZ, J. (2001): “ La medición de la eficiencia en el sector público" en Álvarez Pinilla, A. (Coordinador), La medición de la eficiencia y la productividad, edit. Pirámide, Madrid.

PELIKAN,P. (1988) : “Can the imperfect innovation systems of capitalism be out performed", en G. Dosi et al (eds) Economic change and economic theory, London, Printer Publishers. 
PENROSE, E. (1951): "The theory of the Growth of the Firm". ResourcesFirms and Strategies, N. Foss ed., Oxford University Press, pp. 27-39.

PIGOU, A. (1928): A study in Public Finance, Macmillan, Londres (versión castellana de la tercera edición (1947) del Instituto de Estudios Fiscales, Madrid, 1962.

POON, A. (1989): “Competitive Strategies for a New Tourism”. Recreation and Hospitality Management, Vol. I, pp. 91-102.

POON, A. (1993): Tourism, Technology and Competitive Strategies, N.York, CAB International.

PORTER, M., (1979): “The Structure Within Industries and Companie's Performance", Review of Economics and Statistics, vol. 61, pp. 214-227.

PORTER, M. (1980): Competitive Strategy. Techniques for Analyzing Industries and Competitors, The Free Press, New York, USA. Traducido y reeditado por Compañía Editorial Continental, s.a., México D.F., 1982.

PORTER,M. (1985): Competitive Advantage. Creating and Sustaining Superior Performance, The Free Press, New York, USA. Traducido y reeditado por Compañía Editorial Continental, s.a., México D.F., 1987.

PORTER, M. (1990): “¿Dónde radicar la ventaja competitiva de las naciones?", Harvard Business Review.

PORTER, M. (1991): La ventaja competitiva de las naciones, Plaza \& Janés editores, Barcelona. 
PORTER, M. (1996): "What is Strategy? ”, Harvard Business Review, diciembre.

PORTER, M. (2003): Ser competitivo. Nuevas aportaciones y conclusiones. Ediciones Deusto.

PRIEM, R. y BUTLER, J. (2001): "Tautology in the resource-based view and the implications of externally determined resource value: further comments". Academy of Management Review, vol. 26, nº 1 pp. 57-66.

RAINES, P. (2001): “The Cluster Approach and the Dynamics of Regional Policy-Making" en Regional and Industrial Policy Research Paper, $\mathrm{n}^{\circ} 47$. European Policies Research Centre, University of Strathclyde, U.K.

RICHARDS, G. (2002): "Sistemas de atractivos turísticos. Un análisis del comportamiento cultural". Annals of Tourism Research en español. Vol. 4, $n^{\circ} 2$, España: Universitat de les Illes Balears, pp. 380-398.

RICHMOND, J (1974): "Estimating the Efficiency of Production", International Economic Review, 15(2), pp. 515-521.

RITCHIE, B. y CROUCH G., (1993): "Competitiveness in International Tourism: A Framework for Understanding and Analysis". Proceedings of the 43rd Congress of the Association Intrnationale d'Experts Scientifique du Tourisme (AIEST). October 17-23, San Carlos de Bariloche, Argentina pp. 23-71.

RITCHIE, B. y CROUCH G. (2000): "The Competitive Destination: A Sustainability Perspective”. Tourism Management, 21 (1), pp. 1-7

RITCHIE, B. y CROUCH G. (2003): The Competitive Destination: A 
Sustainable Tourism Perspective, Oxon, UK: CABI Publishing. ROBEY, D., ROSS, J. y BOUDREAU, M. (2002): "Learning to Implement Enterprise Systems: An Exploratory Study of the Dialectics of Change". Journal of Management Information Systems. Vol 19. $\mathrm{N}^{\mathrm{o}} 1$.

ROBINSON, E. (1932): The Structure of Competitive Industry, Nisbet, Londres.

ROCKART, J. (1979): "Chief Executives define their own data needs", Harvard Business Review, March- April.

RUBIO DE URQUÍA, J.L.(2002): “Gasto local y recursos tributarios". Tributos locales, $\mathrm{n}^{\circ} 19$, junio de 2002, pp. 7-13.

RUIZ, E. y GUÍA, J. (2004): "Financiación del municipio turístico y competitividad: estudio de los municipios turísticos de Cataluña”. Papers de Turisme, vol. 35, pp. 59-75.

RUSELL, R (1985) : "Measures of Technical Efficiency", Journal of Economics Theory, 35, pp.109-126.

RUST, R.T. y OLIVER, R.L. (1994): "Service quality insight and managerial implications from the frontier". Service Quality, New Directions in Theory and Practice. Rust, R.T. y Oliver, R.L. (eds.), Sage Publications. Cap. 1, pp. 5-20.

RYAN, C. y MONTGOMERY D. (1994): "The Attitudes of Bakewell Residents to Tourism and Issues in Community Responsive Tourism". Tourism Management (15) pp.358- 369.

SÁNCHEZ, J.(1991): "Participación, Neocorporativismo y Administración Económica", citado por Villoria, M. (1996) La Modernización de la 
Administración al servicio de la Democracia, pág. 324.

SANCHO, A.,GARCÍA, G., PEDRO, A., YAGய̈E, R.M. (2001): Auditoría de sostenibilidad en los destinos turísticos, ed. Instituto de Economía Internacional, Valencia.

SANDERS, I, (1998): Strategic Thinking and the New Science: Planning in the mistsd of chaos, complexity, and change. Free Press. New York.

SOLSONA, J. (1999). El turismo rural en la Comunidad Valenciana: análisis y planificación. Aplicación al Alto Mijares, sociedad castellonense de cultura, serie estudios económicos XII.

SCHALK, R., CAMPBELL, J. y FREESE, C. (1998): "Change and Employee Behaviour”. Leadership \& Organization Development Journal. Vol. 19, No 3, pp. 157-163.

SCHEIN, E. (1985): Organizational Culture and Leadership. Jossey-Bass. San Francisco.

SCHENDEL, D. y HATTEN, K, (1972): "Business Policy or Strategy Management: A view for an Emerging Discipline”, en Mitchell, V. Barth, R. y Mitchell, F. (eds) Academy of Management Proceedings.

SCHMIDT, P ( 1976): "On the Statistical Estimation of Parametric Frontier Production Functions", Review of Economics and Statistics, 58, pp.238-239.

SCHREDER, F.M. (1996): Industry Structure. Strategy and Public Policy. Harper Collins College Publishers. 
SCHUMPETER, J. (1934): The Theory of Economic Development. Harvard University Press. Cambridge, Mass.

SECALL, R. (2000): Economía, Historia e Instituciones del Turismo en España. Editorial Pirámide, Madrid.

SECRETARÍA GENERAL DE TURISMO (1992): Futures. Plan Marco de Competitividad del Turismo Español. Madrid.

SENGE, P., ROBERTS, C., ROSS, R., SMITH, B y KLEINER, A. (1999): La quinta disciplina en la práctica; cómo construir una organización inteligente. Granica, Barcelona.

SERRA, R. ( 2000): El nuevo juego de los negocios, Norma, Buenos Aires. SHEPPARD, R (1953): Cost and Production Functions, Princeton, NJ, Princeton Universit Press.

SIRILLI, G. y EVANGELISTA, R. (1998): “Technological innovation in services and manufacturing: results from Italian surveys". Research Policy, 27 (9), pp 881-899.

SOUSA DE VASCONCELLOS, J. y HAMBRICK, D. (1989): “Key Success Factors: Test of a General theory in the Mature Industrial-Product Secto", Strategic Management Journal, Vol. 10, pp. 367-382.

STACEY, R. (1994): Gestión del caos, Editorial S. Barcelona..

STEENKAMP, J.B.E.M. (1989): Product Quality. Assen/Maastricht, The Netherlands: Van Gorcum.

STEINER, G., MINER, J. y GRAY, E. ( 1977): Management Policy and 
Strategy: Text, Readings and Cases, MacMillán Publishing.

STEVENSON, H. (1985): "Resource Ssessment: Identifying Corporate Strenghths and Weaknesses", en Guth, W. (ed), Handbook of Business Strategy, Warren, Gorham \& Lamont.

SUMPSI, J.M. (1994): "La política agrarian y el futuro del mundo rural" en Revista de Estudios Agro-Sociales, no 169, (julio-septiembre),pp. 149173.

TEECE, D., PISANO, G., SHUEN, A. (1997): "Dinamic capabilities and strategic management". Strategic Management Journal, vol. 18, n17, pp. 509-533.

TUSHMAN, M. y ANDERSON, P. (1986): "Technological Discontinuities and Organizational Environments". Administrative Science Quarterly. Vol. 31. Septiembre.

TZU, S. (ed.1993): El arte de la guerra. Troquel, Madrid. VALLS, .F. (1996) : Las claves del mercado turístico, Deusto. VALLS, F., VILA, M.,BUSTAMANTE, X. y GUZMÁN,F. (2004): Gestión de destinos turísticos sostenibles. Edit. Gestión 2000, Madrid.

VELLAS, F. y BÉCHEREL, L. (1995): International Tourism, Macmillan Business, Londres.

VERA, J.F. y MARCHENA, J.L. (1995): "Efectos del turismo en las estructuras regionales periféricas. Una aproximación analítica”, XXI Reunión 
de Estudios Regionales. Factores de Desarrollo en Regiones Periféricas, Vigo.

VERA, J.F. (1996): "El papel de los Espacios Naturales Protegidos en áreas turísticas consolidadas: articulación y procesos de gestión”. Conferencia Internacional sobre Espacios Naturales y Turismo, NATATOUR, Las Palmas de G.C.

VERA, J.F. (coord.) (1997). Análisis territorial del Turismo, Barcelona, Ariel geografía.

VICERIAT, P. y TREBOUL, J. (2003): Innovation technologique dans les produits et services touristiques. Départament de Direction du Tourisme. France.

VILLORIA, M. (1996): La modernización de la Administración como instrumento al servicio de la democracia, Instituto Nacional de Administración Pública, INAP, Madrid.

VIÑALS, M.J. y BERNABÉ, A. (1999): Turismo en Espacios Naturales y Rurales. Servicio de Publicaciones de la Universidad Politécnica de Valencia.

WARD, J., GRIFFITHS, P. y WHITMORE, P. (1990): Strategic Planning for Information Systems. John Wiley \& Sons, Chichester.

WEAVER, D. y LAWTON, L. (2001): "Resident perceptions in the urbanrural fringe".Annals of tourism Research, vol. 28, n² pp. 439-458.

WERNERFELT, B. (1984): “A Resource-based view of the firm”, Strategic Management Journal, vol. 5, pp. 171-180. 
WISEMAN, J. (1990): "Principles of Political Economy. An Outline Proposal, Illustrated by Application to Fiscal Federalism", Constitutional Political Economy 1, 101-124.

WORLD TRAVEL AND TOURISM COUNCIL, AND WORLD TOURISM ORGANIZATION (1996): Agenda 21 for the Travel and Tourism Industry. Towards Environmentally Sustainable Development. Madrid.

WTO(2000): Public-Private Sector Cooperation. Enhancing Tourism Competitiveness, Madrid.

YEPES, V.(1999): “Las playas en la gestión sostenible del litoral”, Cuadernos de Turismo, $\mathrm{n}^{\circ} 4$.

ZEITHAML,V.A., PARASURAMAN, A. BERRY, L.L.Y. (1985): "Problems and strategies in service marketing". Journal of Marketing, vol. 49 (Primavera), pp. 33-46.

ZEITHAML,V.A. (1988): "Consumer perceptions of price, quality and value: a means-end model and synthesis of evidence". Journal of Marketing, vol. 52 (Julio), pp. 2-22.

ZEITHAML,V.A., PARASURAMAN, A. BERRY, L.L.Y. (1990): Delivering Quality Service: Balancing Customer Perceptions and Expectations. New York: Free Press.

ZEITHAML,V.A., PARASURAMAN, A. BERRY, L.L.Y. (1993): Calidad Total en la Gestión de Servicios. Cómo lograr el Equilibrio entre las Percepciones y las Expectativas de los Consumidores. Edit. Díaz de Santos, Madrid.

ZEITHAML,V.A., PARASURAMAN, A. BERRY, L.L.Y. (1993): "The nature and determinants of customer expectations of service". Journal of 
the Academy of Marketing Science, vol.21, (invierno), pp. 1-12.

ZEITHAML,V.A., BERRY, L.L.Y., PARASURAMAN, A. (1993). "The behavioural consequences of service quality". Journal of Marketing, vol. $60, \mathrm{n}^{\circ} 2, \mathrm{pp} .31-46$.

ZEITHAML,V.A., y BITNER, M.J. (2002). Marketing de Servicios. Un enfoque de integración del cliente a la empresa. Edit. McGraw-Hill/ Interamericana editores S.A. de C.V.

ZELLNER, A, KMENTA, J, y DREZE, J.( 1966) : "Specification and Estimation of Cobb-Douglas Production Functions", Econometrita, 34, pp. 784-795.

ZIESCHANG, K. (1984): “ An Extended Farrell Technical Efficiency Measure", Journal of Economic Theory, 33, pp.387-396. 

ANEXO 1 


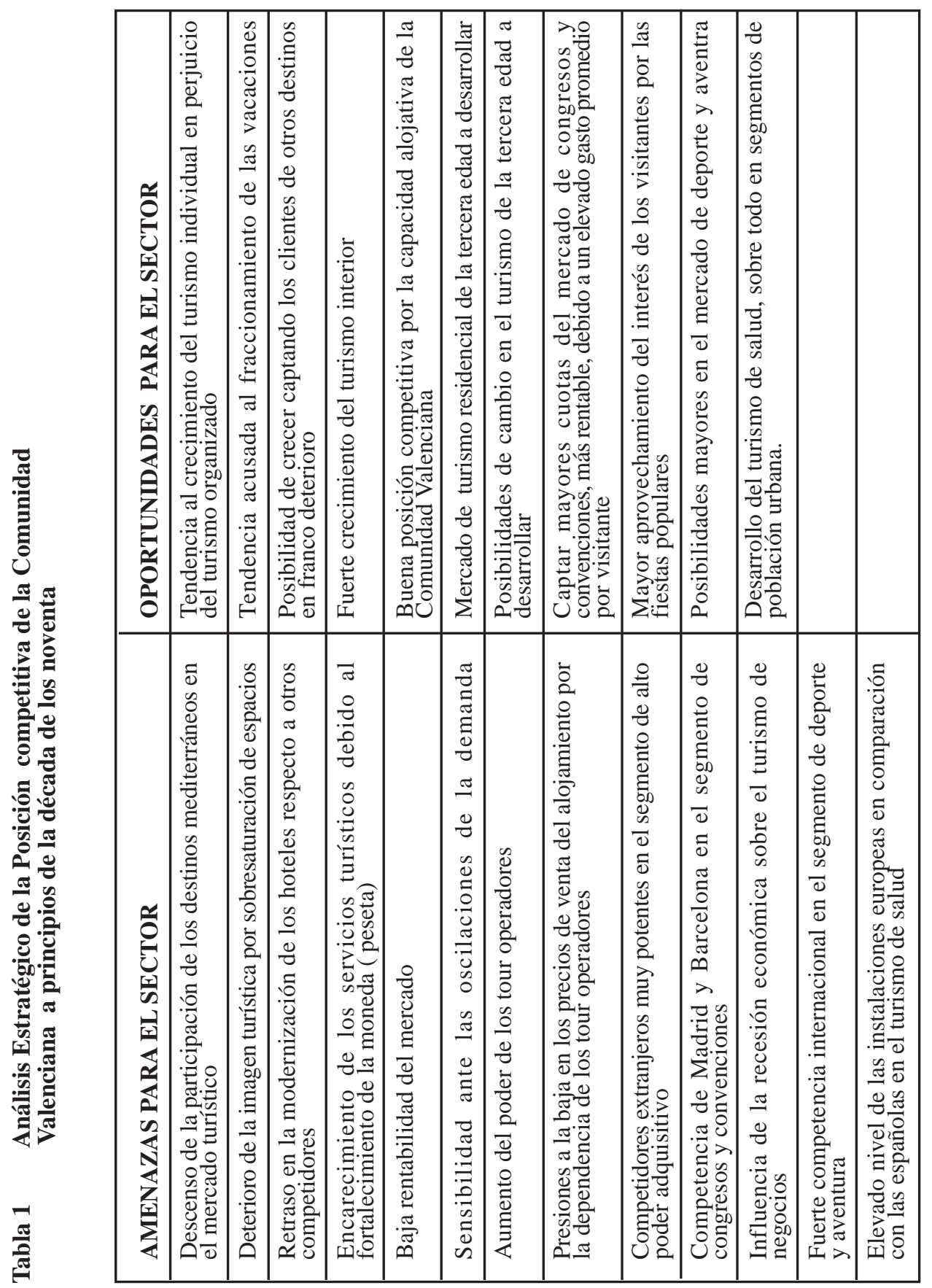




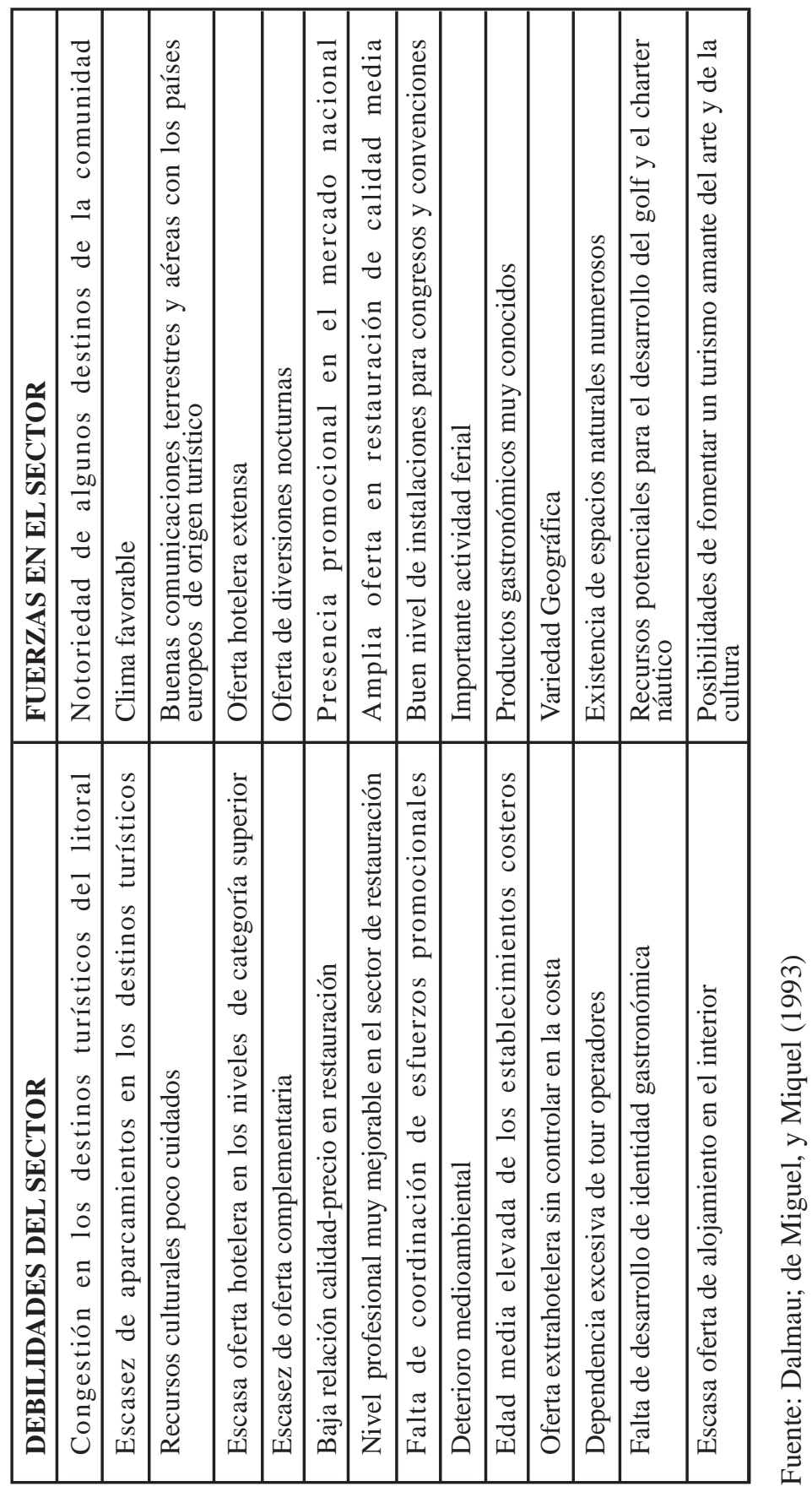




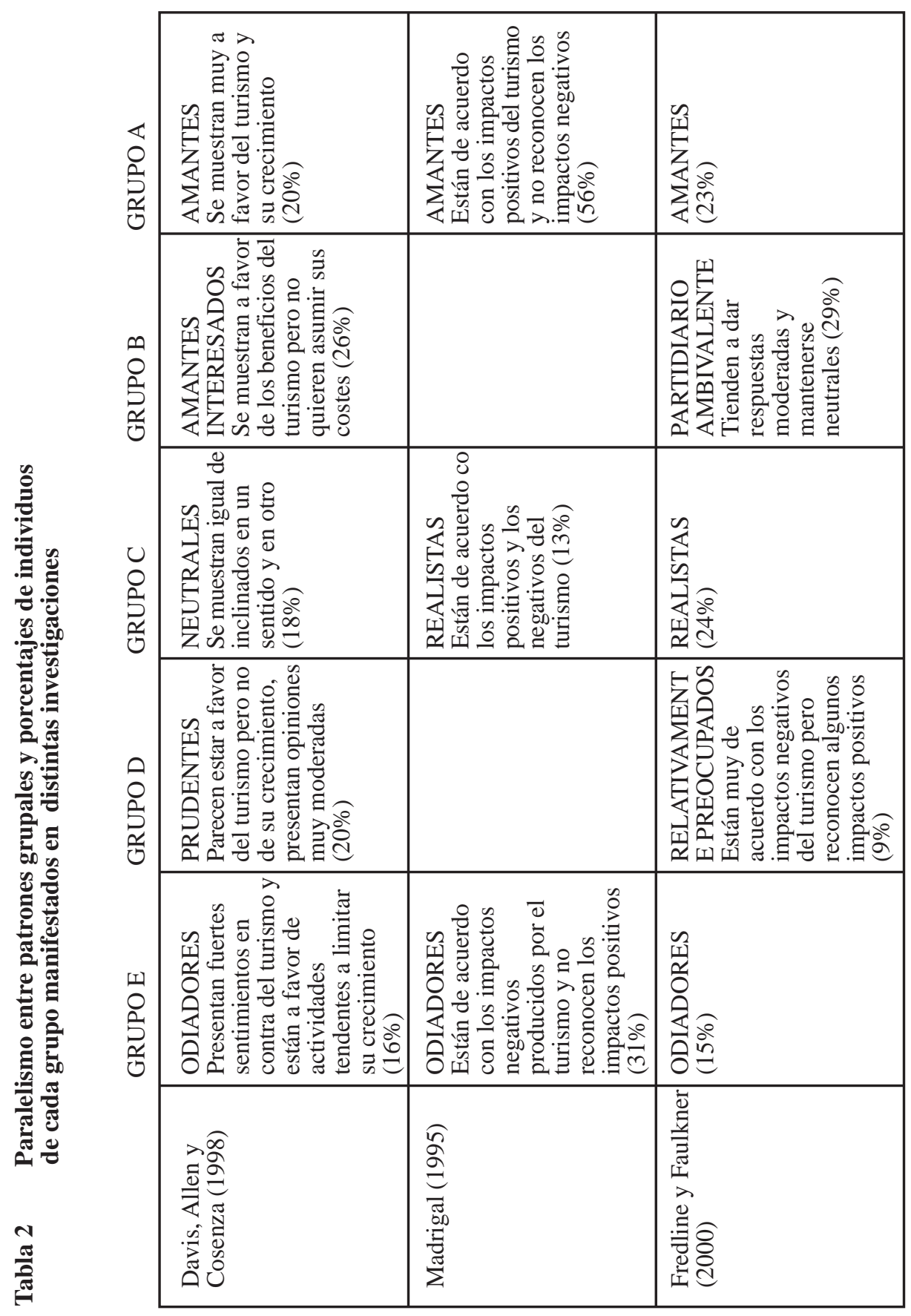




\begin{tabular}{|c|c|c|}
\hline 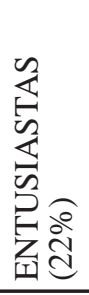 & 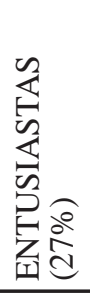 & 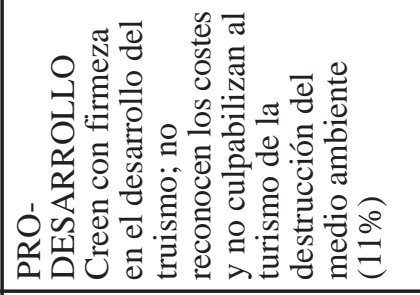 \\
\hline & & 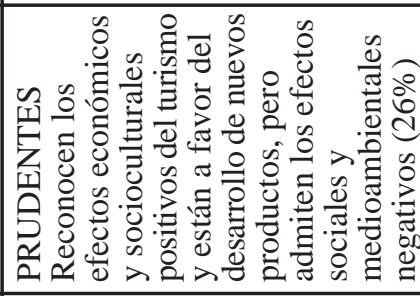 \\
\hline \multirow[t]{2}{*}{ 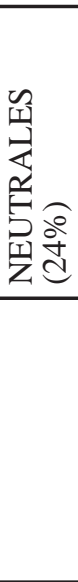 } & 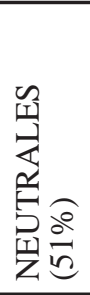 & 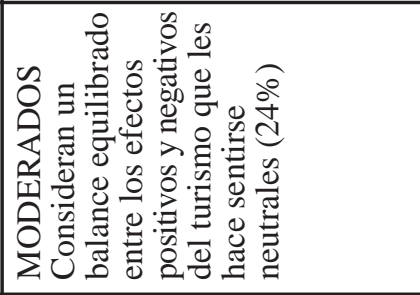 \\
\hline & & 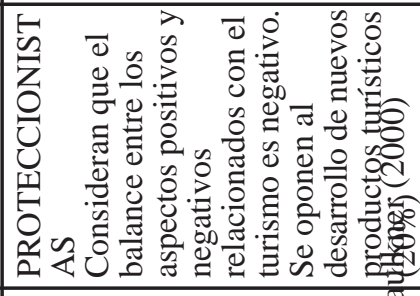 \\
\hline 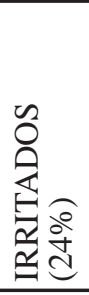 & 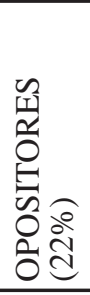 & 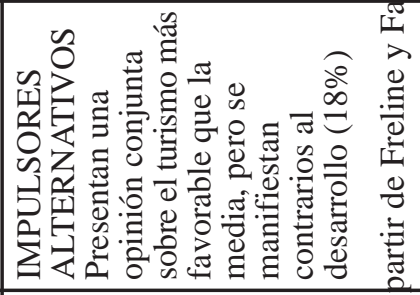 \\
\hline 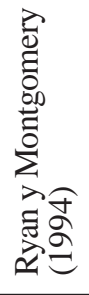 & 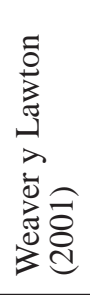 & 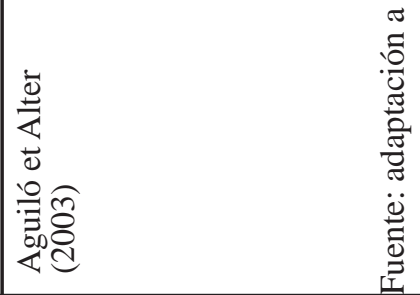 \\
\hline
\end{tabular}




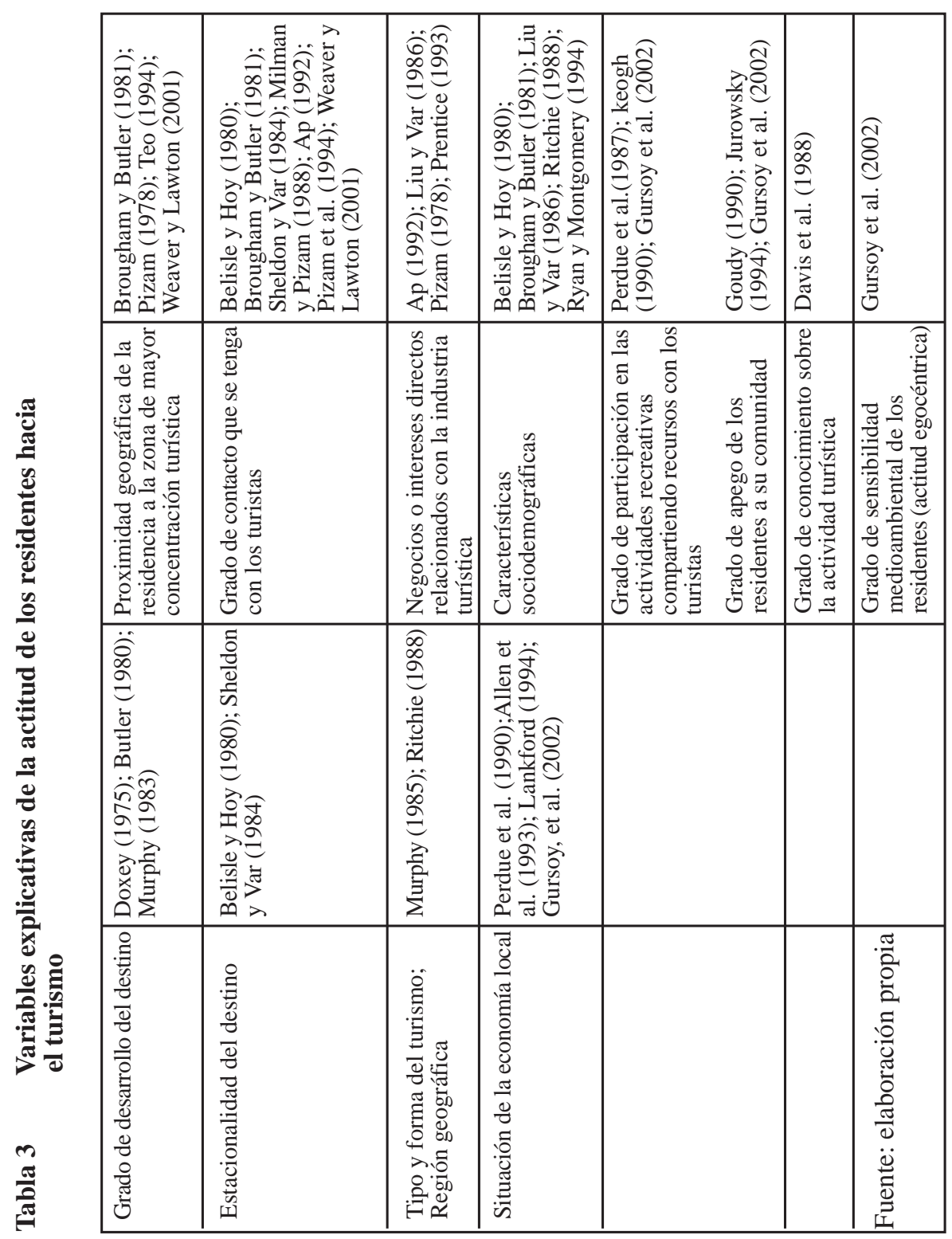




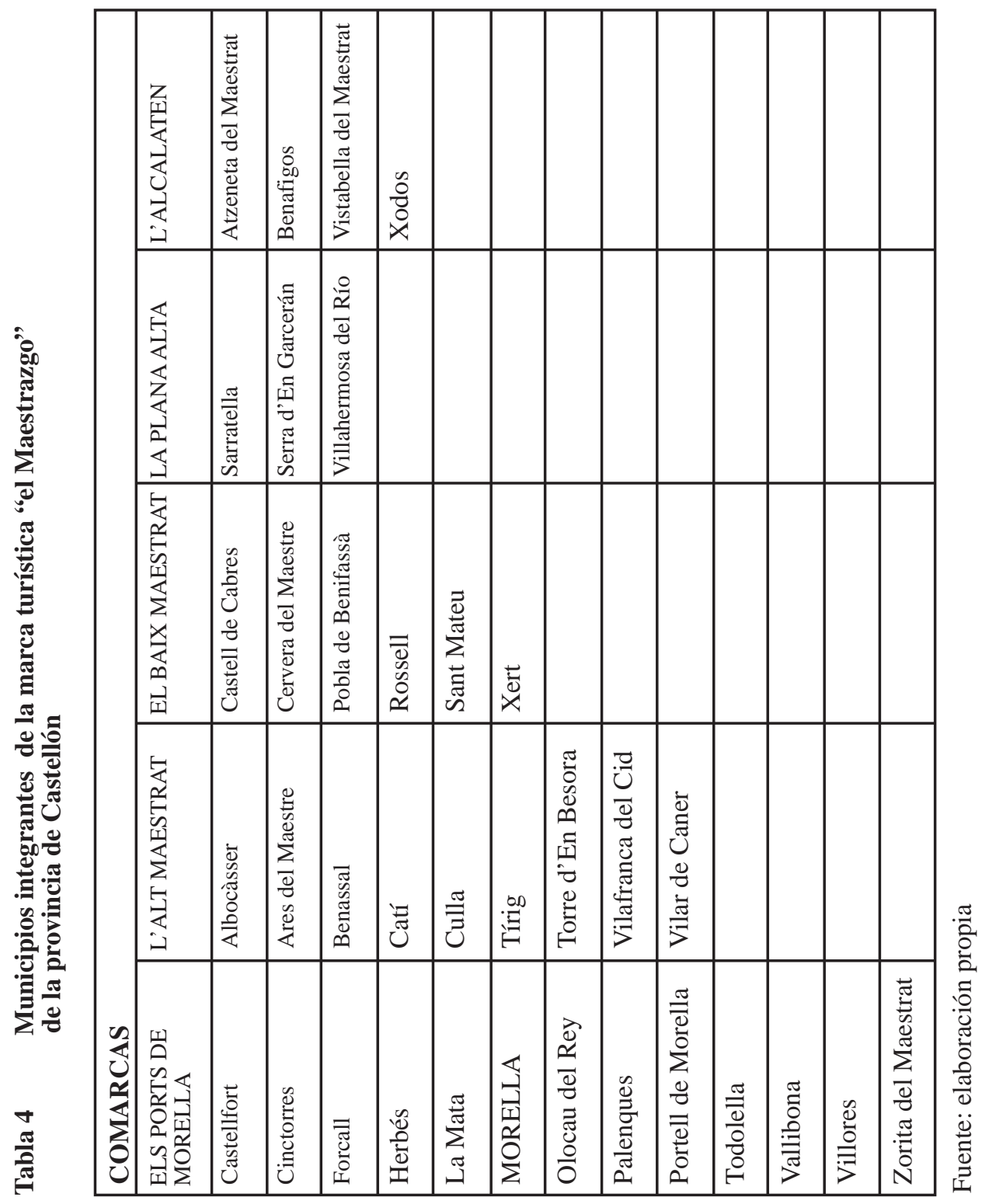




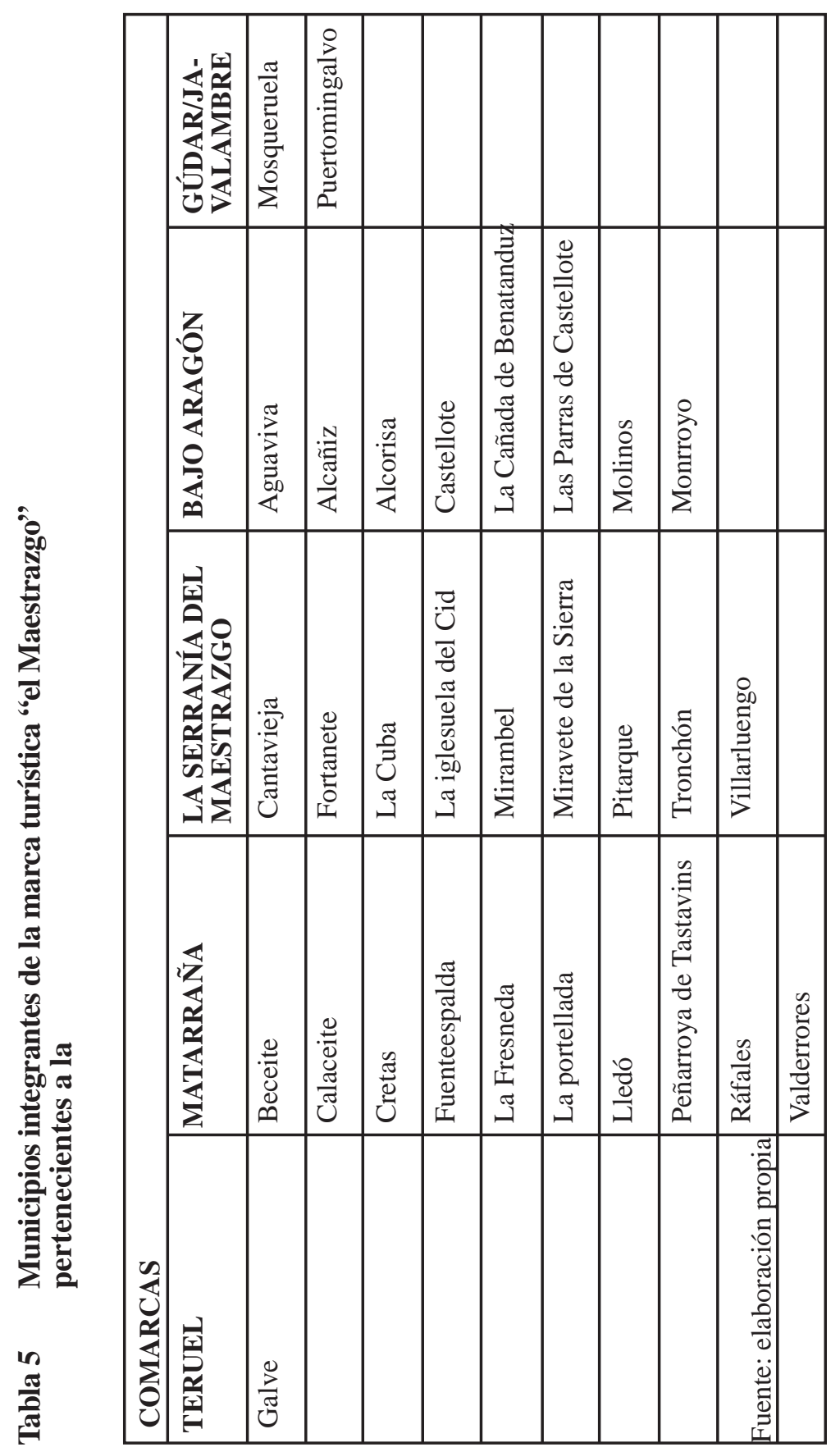




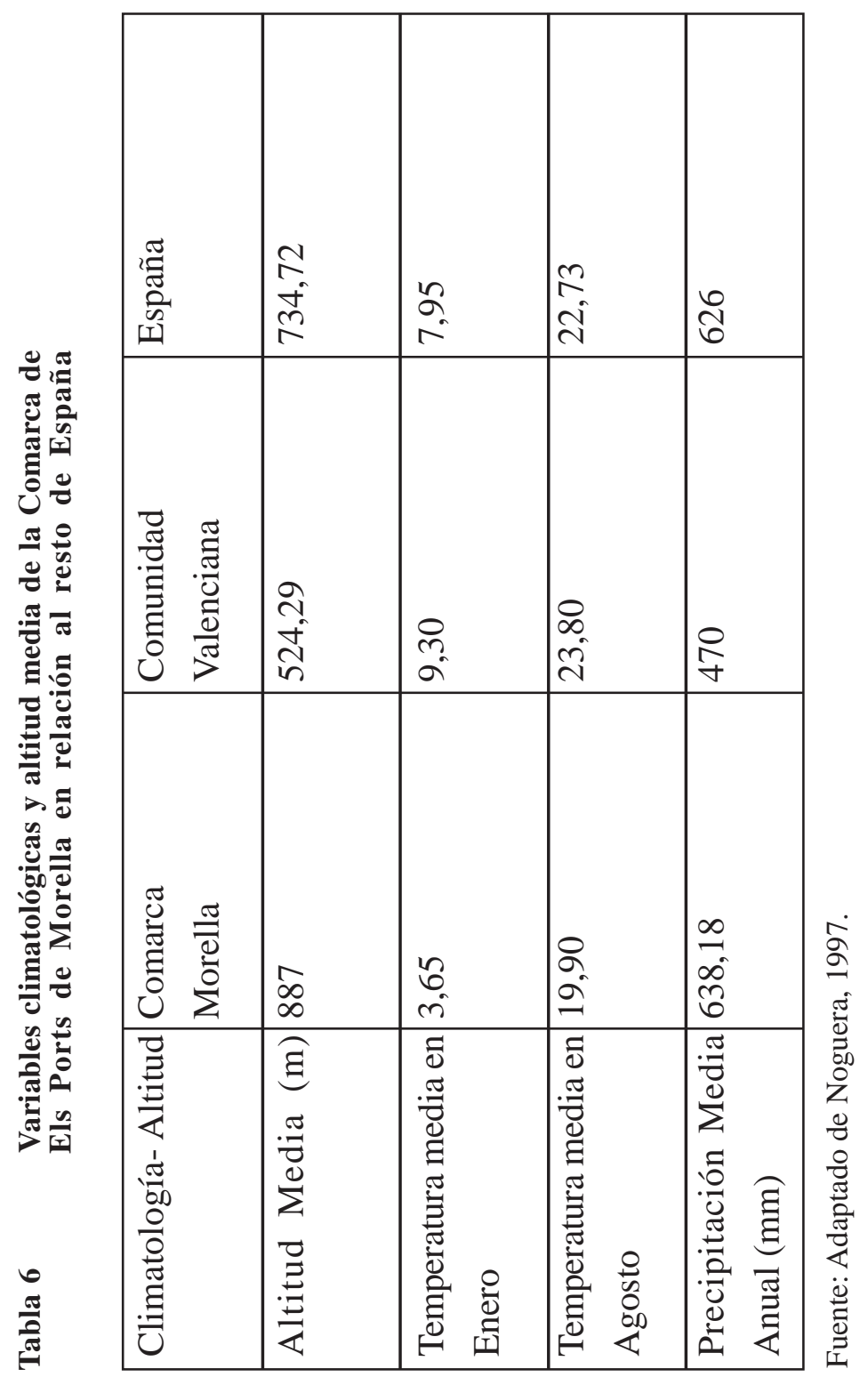




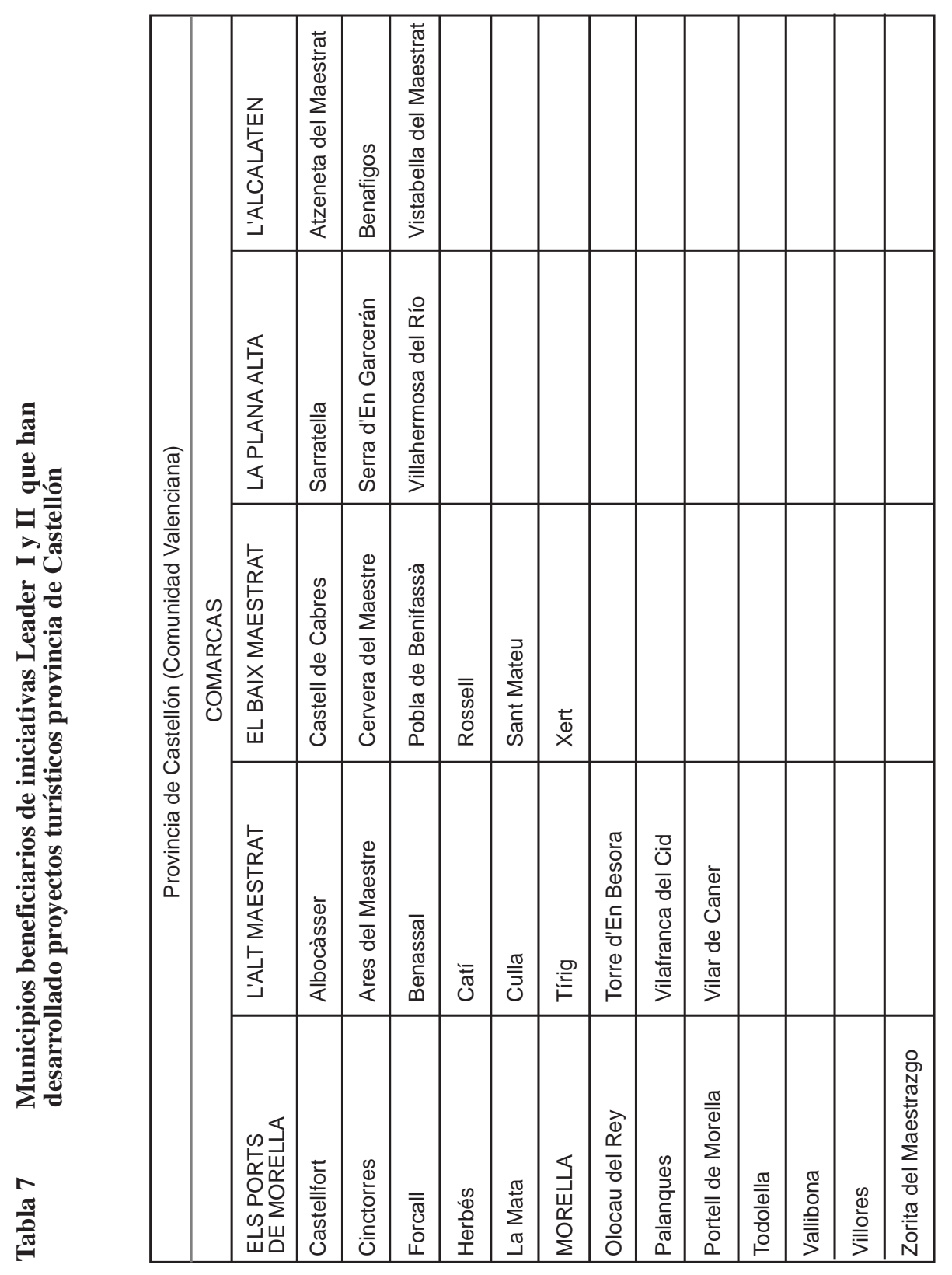

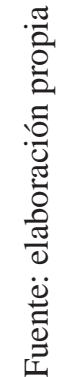




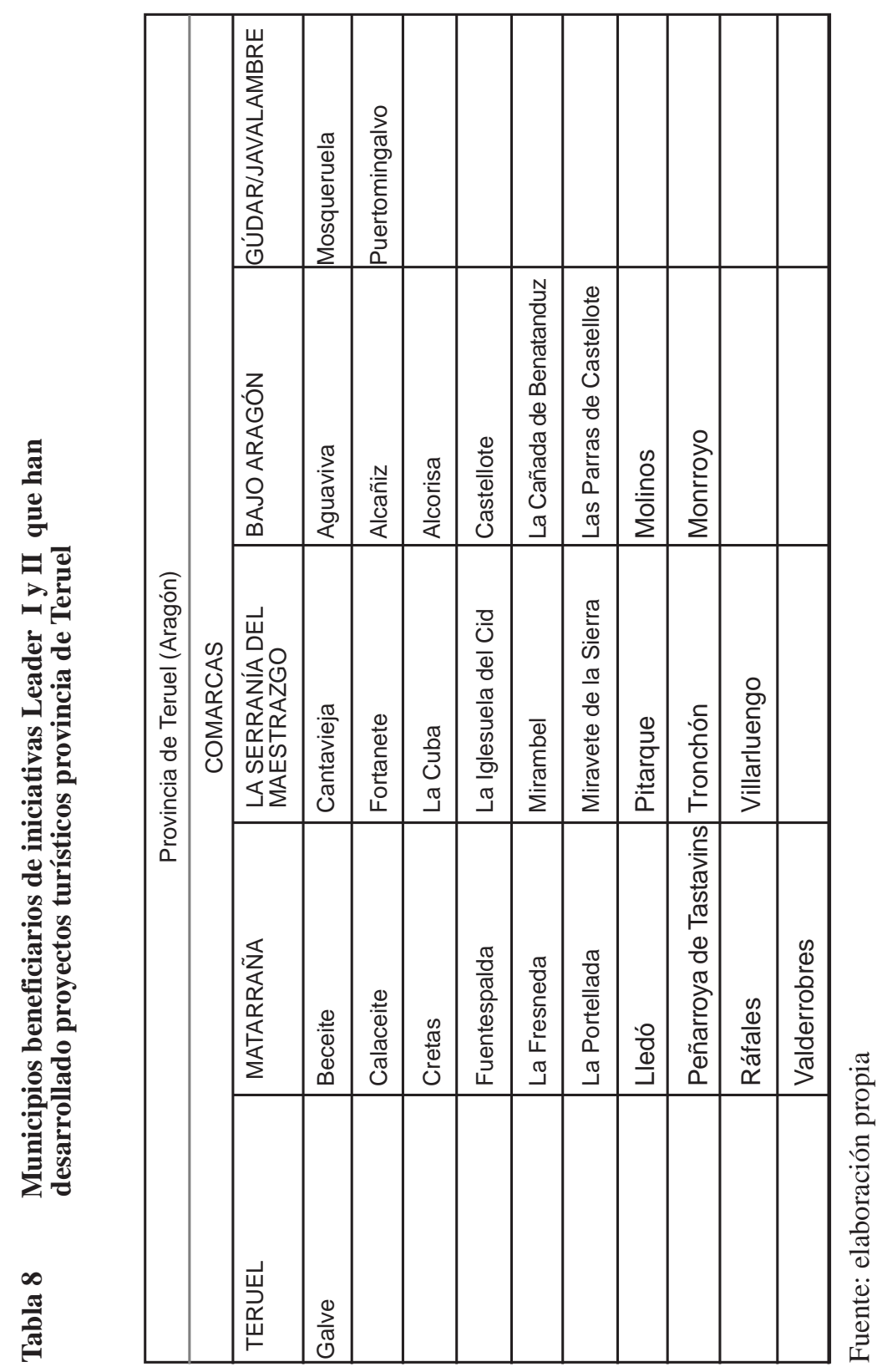




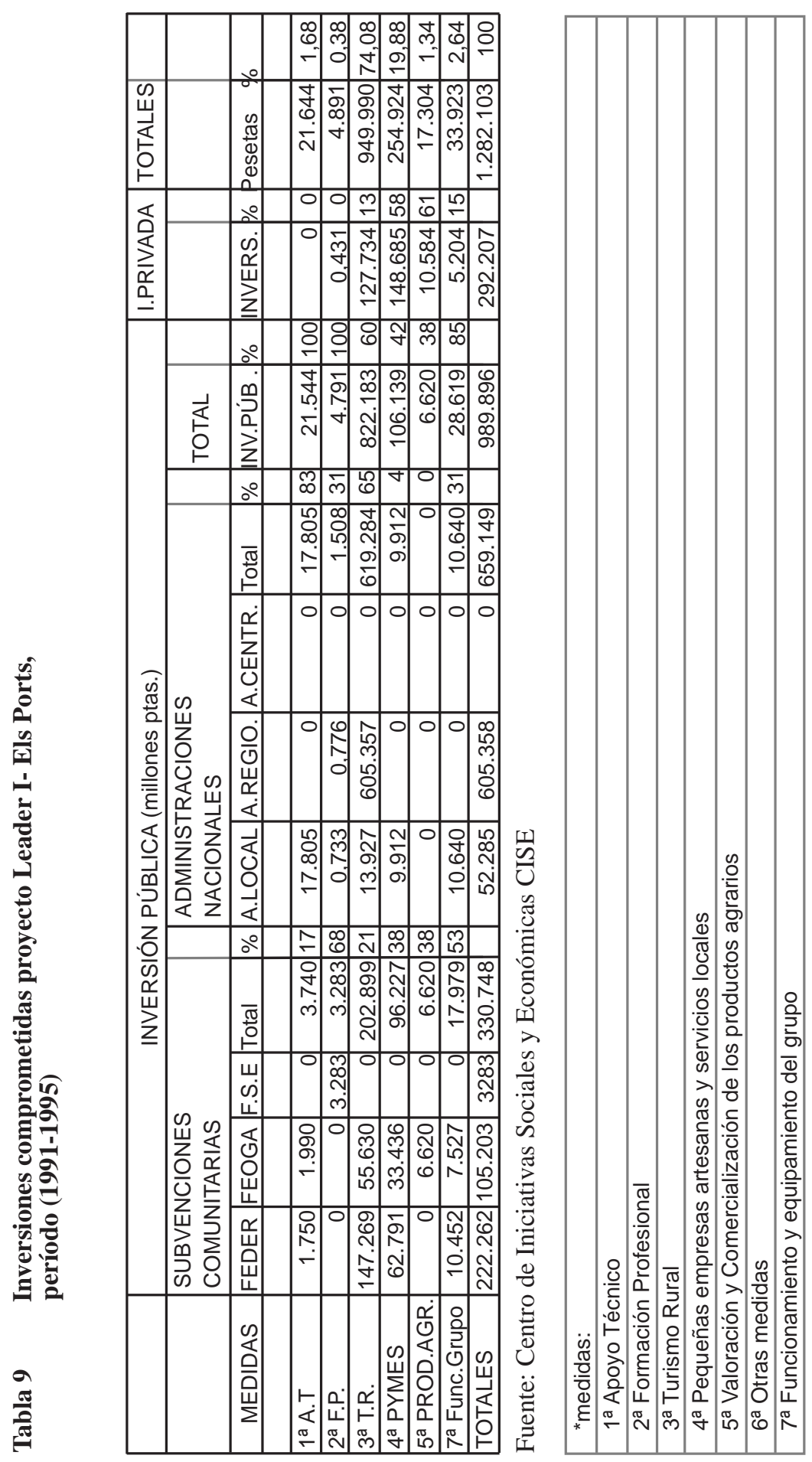




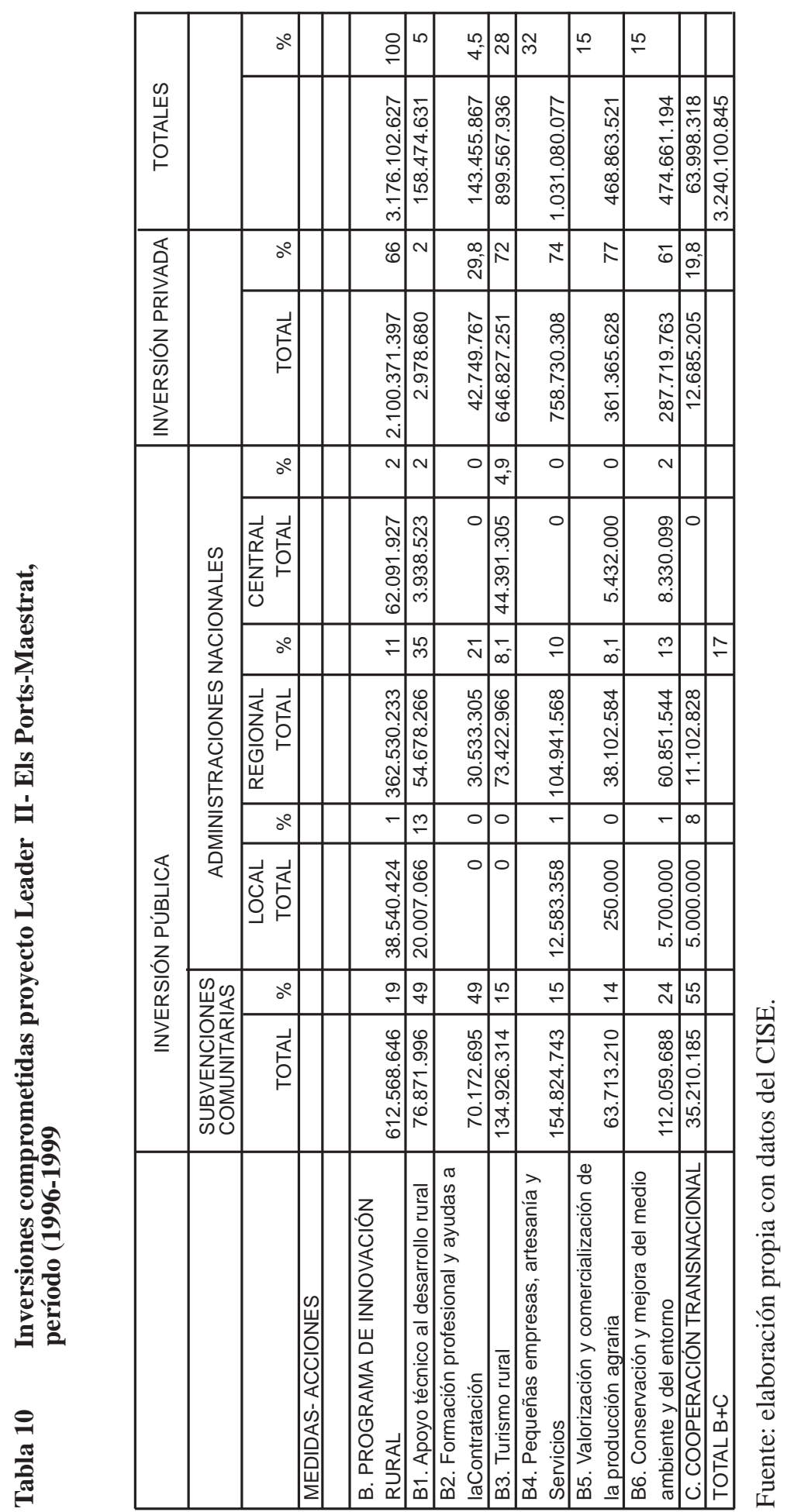


Tabla 11 Proyectos turísticos financiados con fondos del programa Leader I (Medida 3 ${ }^{\text {a }}$

\begin{tabular}{|c|c|c|c|}
\hline $\begin{array}{l}\text { IMPORTE } \\
\text { mill.ptas. }\end{array}$ & BENEFICIARIO & CONCEPTO & MUNICIPIO \\
\hline 6.128 & Patronato de Turismo & $\begin{array}{l}\text { Señalización de Rutas y } \\
\text { Caminos de "Els Ports" }\end{array}$ & $\begin{array}{l}\text { Zona de Actuación } \\
\text { Leader I }\end{array}$ \\
\hline 2.913 & Patronato de Turismo & $\begin{array}{l}\text { Catalogación espacios } \\
\text { naturales }\end{array}$ & $\begin{array}{l}\text { Zona de Actuación } \\
\text { Leader I }\end{array}$ \\
\hline 40.000 & Ayuntamiento de Vallibona & Rehabilitación casa cuartel & Vallibona \\
\hline 7.410 & $\begin{array}{l}\text { Ayuntamiento Castell } \\
\text { Cabres }\end{array}$ & $\begin{array}{l}\text { Restauración casa para } \\
\text { albergue municipal }\end{array}$ & Castell de Cabres \\
\hline 59.473 & $\begin{array}{l}\text { Asociación Cultural de } \\
\text { San Cristófol }\end{array}$ & $\begin{array}{l}\text { Rehabilitación Ermita } \\
\text { San Cristófol }\end{array}$ & $\begin{array}{l}\text { Todolella- } \\
\text { Cinctorres }\end{array}$ \\
\hline 53.409 & Ayuntamiento de Ares & Construcción de un hotel & Ares del Maestre \\
\hline 20.000 & Ayuntamiento P.Benifassar & Rehabilitación local social & P. de Benifassar \\
\hline 7.270 & Ayuntamiento Villores & $\begin{array}{l}\text { Rehabilitación local para } \\
\text { centro social }\end{array}$ & Villores \\
\hline 0,601 & Ayuntamiento de Cinctorres & $\begin{array}{l}\text { Rehabilitación ermita de } \\
\text { S. Marcos }\end{array}$ & Cinctorres \\
\hline 32.379 & Ayuntamiento de Vilafranca & $\begin{array}{l}\text { Creación infraestructura } \\
\text { turística }\end{array}$ & Vilafranca \\
\hline 66.615 & Ayuntamiento de Vilafranca & $\begin{array}{l}\text { Adecuación de una parcela } \\
\text { para camping }\end{array}$ & Vilafranca \\
\hline 8.000 & Ayuntamiento La Mata & $\begin{array}{l}\text { Acondicionamiento bajos } \\
\text { Ayuntamiento para mesón }\end{array}$ & La Mata \\
\hline 2.981 & Particular & Empresa guía turístico & Herbés \\
\hline 417.281 & $\begin{array}{l}\text { Ayuntamiento de Morella } \\
\text { Fábrica Giner }\end{array}$ & $\begin{array}{l}\text { Escuela permanente } \\
\text { deportes de la naturaleza }\end{array}$ & Morella \\
\hline 0,543 & Particular & Empresa guía turístico & Morella \\
\hline 212.293 & Ayuntamiento de Morella & $\begin{array}{l}\text { Museo Etnológico } \\
\text { Recuperación archivo }\end{array}$ & Morella \\
\hline 10.154 & Ayuntamiento de Morella & Pascual & Morella \\
\hline 2.469 & $\begin{array}{l}\text { Centre de Promoció E. I } \\
\text { Cultural de Morella }\end{array}$ & Seminario & Morella \\
\hline
\end{tabular}

Fuente: Centro de Iniciativas Sociales y Económicas CISE (Morella) 


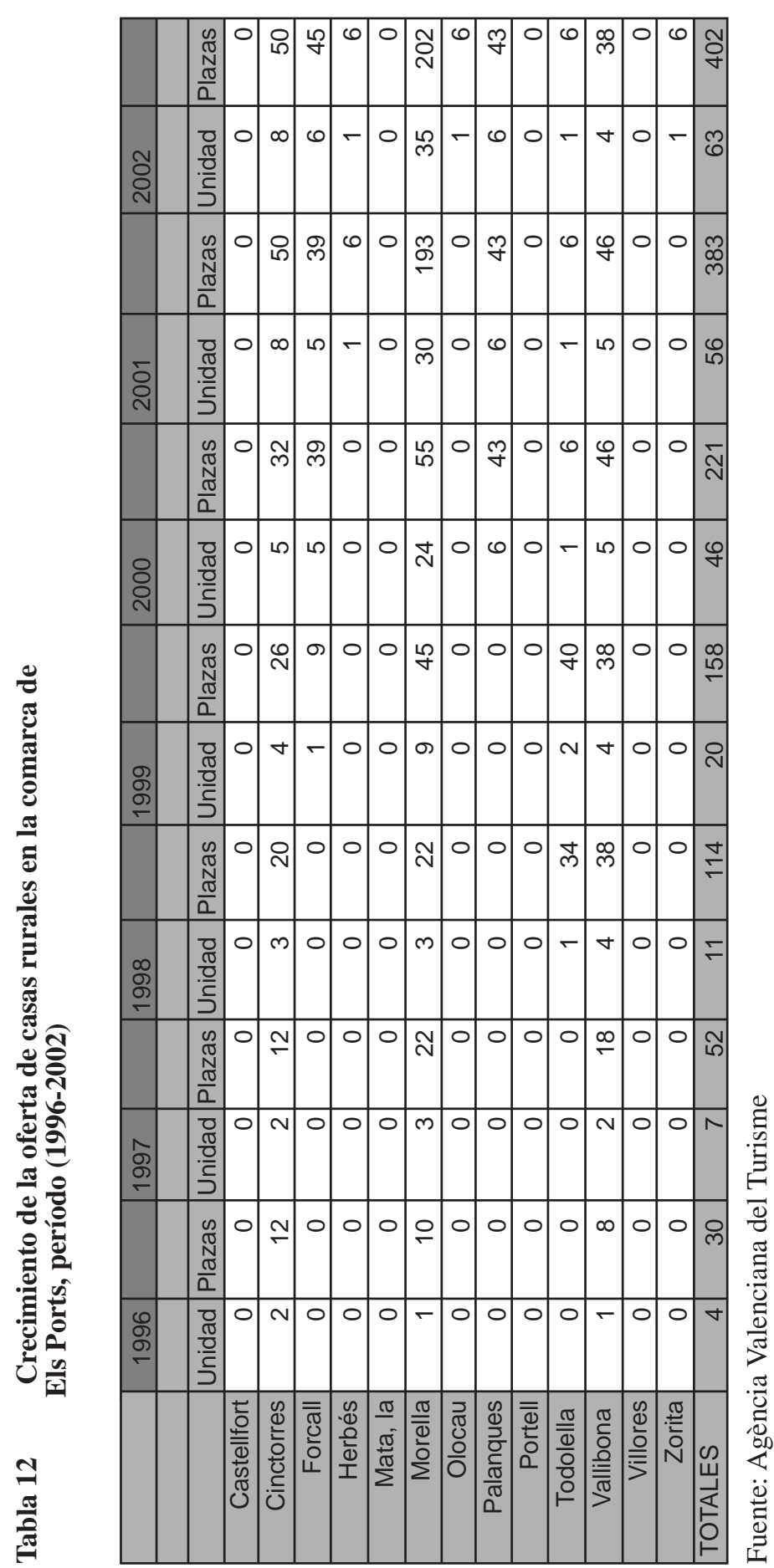


Tabla 13 Número de establecimientos hoteleros de la comarca de Els Ports

\begin{tabular}{|r|r|r|r|r|r|r|r|r|r|}
\hline & \multicolumn{1}{|c|}{1996} & \multicolumn{1}{l|}{1998} \\
\hline MUNICIPIOS & HOTE \\
& LES & $\begin{array}{r}\text { HOS } \\
\text { TALES }\end{array}$ & TOTAL & $\begin{array}{r}\text { HOTE } \\
\text { LES }\end{array}$ & $\begin{array}{r}\text { HOS } \\
\text { TALES }\end{array}$ & TOTAL & $\begin{array}{r}\text { HOTE } \\
\text { LES }\end{array}$ & $\begin{array}{r}\text { HOS } \\
\text { TALES }\end{array}$ & TOTAL \\
\hline Castellfort & 0 & 0 & 0 & 0 & 0 & 0 & 0 & 0 & 0 \\
\hline Cinctorres & 0 & 0 & 0 & 0 & 0 & 0 & 0 & 0 & 0 \\
\hline Forcall & 1 & 1 & 2 & 1 & 1 & 2 & 1 & 1 & 2 \\
\hline Herbés & 0 & 0 & 0 & 0 & 0 & 0 & 0 & 0 & 0 \\
\hline Mata, la & 0 & 0 & 0 & 0 & 0 & 0 & 0 & 0 & 0 \\
\hline Morella & 4 & 3 & 7 & 4 & 2 & 6 & 4 & 2 & 6 \\
\hline Olocau del Rey & 0 & 0 & 0 & 0 & 0 & 0 & 0 & 0 & 0 \\
\hline Palanques & 0 & 0 & 0 & 0 & 0 & 0 & 0 & 0 & 0 \\
\hline Portell de Morella & 0 & 0 & 0 & 0 & 0 & 0 & 0 & 0 & 0 \\
\hline Todolella & 0 & 0 & 0 & 0 & 0 & 0 & 0 & 0 & 0 \\
\hline Vallibona & 0 & 1 & 1 & 0 & 1 & 1 & 0 & 1 & 1 \\
\hline Villores & 0 & 0 & 0 & 0 & 0 & 0 & 0 & 0 & 0 \\
\hline Torita del Maestrazgo & 0 & 0 & 0 & 0 & 0 & 0 & 0 & 0 & 0 \\
\hline TOTAS & 5 & 5 & 10 & 5 & 4 & 9 & 5 & 4 & 9 \\
\hline
\end{tabular}




\begin{tabular}{|c|c|c|c|c|c|c|c|c|c|c|c|}
\hline \multicolumn{3}{|l|}{1999} & \multicolumn{3}{|l|}{2000} & \multicolumn{3}{|l|}{2001} & \multicolumn{3}{|l|}{2002} \\
\hline HOTE & $\mathrm{HOS}$ & & HOTE & HOST & & HOTE & HOST & & HOTE & HOST & \\
\hline LES & TALES & TOTAL & LES & ALES & TOTAL & LES & ALES & TOTAL & LES & ALES & TOTAL \\
\hline 0 & 0 & 0 & 0 & 0 & 0 & 0 & 0 & 0 & 0 & 0 & 0 \\
\hline 0 & 0 & 0 & 0 & 0 & 0 & 0 & 0 & 0 & 0 & 0 & 0 \\
\hline 1 & 1 & 2 & 1 & 1 & 2 & 1 & 1 & 2 & 1 & 1 & 2 \\
\hline 0 & 0 & 0 & 0 & 0 & 0 & 0 & 0 & 0 & 0 & 0 & 0 \\
\hline 0 & 0 & 0 & 0 & 0 & 0 & 0 & 0 & 0 & 0 & 0 & 0 \\
\hline 4 & 2 & 6 & 6 & 1 & 7 & 6 & 1 & 7 & 6 & 1 & 7 \\
\hline 0 & 0 & 0 & 0 & 0 & 0 & 0 & 0 & 0 & 0 & 0 & 0 \\
\hline 0 & 0 & 0 & 0 & 0 & 0 & 0 & 0 & 0 & 0 & 0 & 0 \\
\hline 0 & 0 & 0 & 0 & 0 & 0 & 0 & 0 & 0 & 0 & 0 & 0 \\
\hline 0 & 0 & 0 & 0 & 0 & 0 & 0 & 0 & 0 & 0 & 0 & 0 \\
\hline 0 & 1 & 1 & 0 & 1 & 1 & 0 & 1 & 1 & 0 & 1 & 1 \\
\hline 0 & 0 & 0 & 0 & 0 & 0 & 0 & 0 & 0 & 0 & 0 & 0 \\
\hline 0 & 0 & 0 & 0 & 0 & 0 & 0 & 0 & 0 & 0 & 0 & 0 \\
\hline 5 & 4 & 9 & 7 & 3 & 10 & 7 & 3 & 10 & 7 & 3 & 10 \\
\hline
\end{tabular}

Elaboración propia con estadísticas oficiales (Instituto Valenciano de Estadísitica- IVE) 
Tabla 14 Número de plazas en restaurantes de la zona Leader de desarrollo rural

\begin{tabular}{|c|c|c|c|c|c|c|c|}
\hline MUNICIPIOS & 1996 & 1997 & 1998 & 1999 & 2000 & 2001 & 2002 \\
\hline Castellfort & 0 & 0 & 0 & 0 & 0 & 0 & 0 \\
\hline Cinctorres & 75 & 75 & 75 & 1 & 75 & 75 & 75 \\
\hline Forcall & 130 & 130 & 195 & 0 & 285 & 285 & 285 \\
\hline Herbés & 44 & 44 & 44 & 0 & 44 & 40 & 40 \\
\hline Mata, la & 50 & 50 & 50 & 0 & 50 & 50 & 50 \\
\hline Morella & 638 & 614 & 759 & 0 & 1.021 & 1.021 & 856 \\
\hline Olocau del Rey & 30 & 30 & 30 & 1 & 30 & 30 & 30 \\
\hline Palanques & 0 & 0 & 0 & 0 & 32 & 32 & 32 \\
\hline Portell de Morella & 0 & 0 & 0 & 0 & 0 & 0 & 0 \\
\hline Todolella & 0 & 0 & 0 & 0 & 0 & 47 & 47 \\
\hline Vallibona & 25 & 25 & 25 & 0 & 25 & 25 & 25 \\
\hline Villores & 0 & 0 & 0 & 0 & 0 & 0 & 0 \\
\hline Zorita del Maestrazgo & 66 & 66 & 66 & 0 & 66 & 66 & 66 \\
\hline Albocàsser & 100 & 100 & 100 & 100 & 200 & 200 & 254 \\
\hline Ares del Maestre & 40 & 40 & 60 & 60 & 60 & 60 & 60 \\
\hline Benasal & 284 & 284 & 284 & 434 & 434 & 534 & 534 \\
\hline Catí & 168 & 168 & 168 & 168 & 168 & 168 & 168 \\
\hline Culla & 76 & 76 & 76 & 76 & 76 & 76 & 132 \\
\hline Torre d'En Besora, la & 0 & 0 & 0 & 0 & 0 & 0 & 0 \\
\hline Tírig & 0 & 0 & 0 & 0 & 0 & 0 & 0 \\
\hline Vilar de Canes & 0 & 0 & 0 & 0 & 0 & 0 & 0 \\
\hline Villafranca del Cid & 306 & 346 & 314 & 314 & 314 & 314 & 411 \\
\hline Atzeneta del Maestrat & 164 & 164 & 164 & 164 & 264 & 264 & 314 \\
\hline Benafigos & 40 & 40 & 40 & 40 & 40 & 40 & 40 \\
\hline Costur & 40 & 40 & 40 & 40 & 40 & 40 & 40 \\
\hline Figueroles & 0 & 0 & 0 & 0 & 80 & 80 & 80 \\
\hline Lucena del Cid & 118 & 118 & 118 & 118 & 118 & 118 & 118 \\
\hline Useres, les / Useras & 129 & 153 & 153 & 153 & 153 & 173 & 173 \\
\hline Vistabella del Maestrazgo & 110 & 185 & 185 & 185 & 285 & 285 & 355 \\
\hline Xodos / Chodos & 70 & 70 & 70 & 70 & 70 & 70 & 70 \\
\hline Castell de Cabres & 40 & 40 & 40 & 40 & 40 & 40 & 40 \\
\hline Cervera del Maestre & 112 & 112 & 112 & 112 & 112 & 112 & 112 \\
\hline Pobla de Benifassà, la & 320 & 320 & 320 & 320 & 230 & 230 & 230 \\
\hline Rossell & 40 & 40 & 40 & 40 & 40 & 40 & 106 \\
\hline Sant Mateu & 506 & 506 & 506 & 506 & 506 & 592 & 592 \\
\hline Xert / Chert & 193 & 448 & 453 & 453 & 453 & 453 & 453 \\
\hline Sarratella & 0 & 0 & 0 & 0 & 0 & 0 & 0 \\
\hline Sierra Engarcerán & 522 & 522 & 522 & 692 & 692 & 692 & 692 \\
\hline TOTAL & 4436 & 4806 & 5009 & 4087 & 6003 & 6252 & 6480 \\
\hline
\end{tabular}

Fuente: elaboración propia con estadísticas oficiales (IVE) 
Tabla 17 Ejemplo de ofertas-demandas antes de la estancia

\begin{tabular}{|c|c|}
\hline Necesidades & Soluciones tecnológicas \\
\hline $\begin{array}{l}\text { Información general para elegir un destino } \\
\text { (encontrar ideas, disponer de información } \\
\text { sobre eventos) }\end{array}$ & $\begin{array}{l}\text { Herramientas y motores de búsqueda. Sitios } \\
\text { web de países o regiones, de revistas o guías } \\
\text { de viaje. Sitios web temáticos. Páginas web } \\
\text { de los operadores turísticos y agencias de } \\
\text { viajes. Catálogos multimedia distribuidos } \\
\text { sobre Internet, DVD o CD-ROM. }\end{array}$ \\
\hline $\begin{array}{l}\text { Disposición de consejos y opiniones de } \\
\text { terceros sobre destinos turísticos. }\end{array}$ & $\begin{array}{l}\text { Guías turísticas en línea, asociaciones y } \\
\text { clubes de turismo en línea, bibliotecas de } \\
\text { fotografías. Acceso a web-cams. } \\
\text { Visita cartográfica al territorio. Visita virtual } \\
\text { a la zona, a la residencia o a la habitación } \\
\text { o apartamento. Web-cam del lugar o video } \\
\text { en línea. }\end{array}$ \\
\hline $\begin{array}{l}\text { Visualización de la zona geográfica y de la } \\
\text { residencia. }\end{array}$ & $\begin{array}{l}\text { Páginas web de empresas de transporte o } \\
\text { de sitios web especializados en comparación } \\
\text { de precios. Motores de búsqueda. Portales } \\
\text { de información nacional, regional o local. }\end{array}$ \\
\hline $\begin{array}{l}\text { Horarios de transporte. Comparación de } \\
\text { precios. Información sobre requisitos } \\
\text { (pasaporte, visado, vacunas) Información } \\
\text { linguística, sobre condiciones políticas o } \\
\text { sanitarias, monedas, etc. }\end{array}$ & $\begin{array}{l}\text { Sitios web especializados en información } \\
\text { meteorológica. }\end{array}$ \\
\hline $\begin{array}{l}\text { Información sobre la situación meteorológica } \\
\text { actual y/o prevista. }\end{array}$ & $\begin{array}{l}\text { Portales de reservas de alojamiento, } \\
\text { independientes o de cadenas hoteleras. }\end{array}$ \\
\hline $\begin{array}{l}\text { Reserva de alojamiento o de forfait. Compra } \\
\text { de billetes de transporte. }\end{array}$ & $\begin{array}{l}\text { Páginas web de empresas de transporte. } \\
\text { Sistemas de pago en línea seguros. } \\
\text { Generación de documentos de reserva o } \\
\text { billetes en el propio domicilio. }\end{array}$ \\
\hline $\begin{array}{l}\text { Transporte de equipajes hasta el lugar de la } \\
\text { estancia }\end{array}$ & $\begin{array}{l}\text { Empresa de transporte sobre Internet para } \\
\text { equipajes. }\end{array}$ \\
\hline $\begin{array}{l}\text { Compra de materiales necesarios para la } \\
\text { estancia (material deportivo, de invierno, } \\
\text { de playa) }\end{array}$ & Venta electrónica en Internet. \\
\hline
\end{tabular}

Fuente: Viceriat y Treboul (2003). 
Tabla 18 Ejemplo de ofertas-demanda durante la estancia

\begin{tabular}{|l|l|}
\hline Necesidades & Soluciones tecnológicas \\
\hline Guía hasta el lugar de destino & $\begin{array}{l}\text { Sistemas de guía electrónica a bordo de } \\
\text { vehículos mediante posicionamiento por } \\
\text { satélite. Información de proximidad por } \\
\text { medio de teléfonos móviles. }\end{array}$ \\
\hline Acceso a la estancia & $\begin{array}{l}\text { Servicio de recepción y de información } \\
\text { mediante sistemas de recepción automáticos. }\end{array}$ \\
\hline $\begin{array}{l}\text { Información sobre posibles actividades y } \\
\text { visitas }\end{array}$ & $\begin{array}{l}\text { TV interactiva con disponibilidad de } \\
\text { información en la habitación del cliente. } \\
\text { Quiosco interactivo en el lugar de } \\
\text { alojamiento con información y servicios en } \\
\text { línea. }\end{array}$ \\
\hline Comunicación con lugar de trabajo & $\begin{array}{l}\text { Conexiones de alta velocidad a Internet en } \\
\text { las habitaciones, con o sin cable. Televisores } \\
\text { con conexiones a Internet. }\end{array}$ \\
\hline Compartir fotografías y emociones. & Envío de mensajes por móviles (SMS). \\
\hline $\begin{array}{l}\text { Comprender los menús o la información } \\
\text { turística o cultural. }\end{array}$ & $\begin{array}{l}\text { Envío de fotografías y video a través de } \\
\text { teléfonos móviles dotados de tecnología } \\
\text { GPRS y UMPS. }\end{array}$ \\
\hline $\begin{array}{l}\text { Pago de servicios desde la habitación o el } \\
\text { apartamento. Pago de pequeñas compras. }\end{array}$ & \begin{tabular}{l} 
Sistemas móviles de traducción automática. \\
\hline Servicio de monedero electrónico.
\end{tabular} \\
\hline
\end{tabular}

Fuente: Viceriat y Treboul (2003). 
Tabla 19 Ejemplo de ofertas-demandas después de la estancia

\begin{tabular}{|l|l|}
\hline Necesidades & Soluciones tecnológicas \\
\hline $\begin{array}{l}\text { Publicación de la experiencia del viaje y } \\
\text { de las fotografías más interesantes para } \\
\text { recomendaciones a terceros. }\end{array}$ & $\begin{array}{l}\text { Sitios web de grupos de viajes, forums y } \\
\text { chats sobre viajes. }\end{array}$ \\
\hline $\begin{array}{l}\text { Recuerdos de la estancia para compartir } \\
\text { con amigos o familia. }\end{array}$ & $\begin{array}{l}\text { Servicios de personalización de visitas } \\
\text { estándar en las que se incluye fotos y video } \\
\text { del cliente, distribuidos en soporte CD- } \\
\text { ROM o DVD. }\end{array}$ \\
\hline $\begin{array}{l}\text { Noticias y ofertas promocionales } \\
\text { personalizadas procedentes del lugar de } \\
\text { vacaciones. }\end{array}$ & Listas de correo electrónico. \\
\hline
\end{tabular}

Fuente: Viceriat y Treboul (2003). 
ANEXO 2 


\section{ENCUESTA RESIDENTES}

§ Esta encuesta forma parte de un trabajo de investigación desarrollado por la Universidad Politécnica de Valencia en colaboración con el Patronato Municipal de Turismo de Morella. El objetivo es conocer la opinión de las personas que residen en la actualidad en Els Ports de Morella sobre el desarrollo turístico de su localidad.

§ Su opinión es muy importante por lo que le agradecemos su sinceridad y colaboración respondiendo a esta encuesta. Muchas gracias.

§ Por favor, marque con una cruz la opción que elija en cada pregunta, según su grado de acuerdo con las siguientes afirmaciones.

\section{ENQUESTA RESIDENTS}

§ Aquesta enquesta forma part d'un treball d'investigació dut a terme per la Universitat Politècnica de València en col/laboració amb el Patronat Municipal de Turisme de Morella. L'objectiu és conéixer l'opinió de les persones que resideixen en l'actualitat a Els Ports de Morella sobre el desenvolupament turístic de la seua localitat.

§ La seua opinió és molt important, per això, li agraïm la seua sinceritat i col/laboració en contestar aquesta enquesta. Moltes gràcies.

Per favor, marqueu amb una creu l'opció que elegiu en cada pregunta, d'acord amb el grau amb el que us identifiqueu amb les següents afirmacions

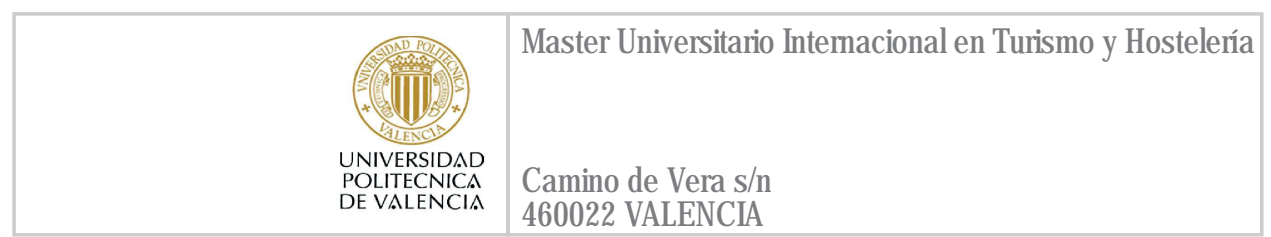




\section{ESCALA DE VALORACIÓN I ESCALA DE VALORACIÓ}

\begin{tabular}{|c|c|c|c|c|c|c|}
\hline 1 & 2 & 3 & 4 & 5 & 6 & 7 \\
\hline $\begin{array}{c}\text { Totalmente } \\
\text { en } \\
\text { Desacuerdo } \\
\text { Totalment } \\
\text { en desacord }\end{array}$ & $\begin{array}{c}\text { Bastante en } \\
\text { desacuerdo } \\
\text { Bastant en } \\
\text { desacord }\end{array}$ & $\begin{array}{c}\text { Algo en } \\
\text { desacuerdo } \\
\text { Un poc en } \\
\text { desacord }\end{array}$ & $\begin{array}{c}\text { Ni de } \\
\text { acuerdo ni } \\
\text { en } \\
\text { desacuerdo } \\
\text { Ni d'acord ni } \\
\text { en desacord }\end{array}$ & $\begin{array}{c}\text { Algo de } \\
\text { acuerdo } \\
\text { Un poc } \\
\text { d'acord }\end{array}$ & $\begin{array}{c}\text { Bastante de } \\
\text { acuerdo } \\
\text { Bastant } \\
\text { d'acord }\end{array}$ & $\begin{array}{c}\text { Totalmente } \\
\text { de Acuerdo } \\
\text { Totalment } \\
\text { d'acord }\end{array}$ \\
\hline
\end{tabular}




\section{Bloque 1 - IMPACTOS ECONÓMICOS DEL TURISMO Bloc 1 - IMPACTES ECONÒMICS DEL TURISME}

\begin{tabular}{|c|c|c|c|c|c|c|c|}
\hline & 1 & 2 & 3 & 4 & 5 & 6 & 7 \\
\hline $\begin{array}{l}\text { 1. El turismo aumenta las posibilidades } \\
\text { de empleo en la comarca } \\
\text { El turisme augmenta les possibilitats } \\
\text { de treball a la comarca }\end{array}$ & & & L & L & & & \\
\hline $\begin{array}{l}\text { 2. El turismo beneficia al comercio local } \\
\text { El turisme beneficia el comerç local }\end{array}$ & & & - & $\leftarrow$ & & & \\
\hline $\begin{array}{l}\text { 3. El turismo incrementa las posibilidades } \\
\text { de los residentes para hacer negocios } \\
\text { en la comarca } \\
\text { El turisme incrementa les possibilitats } \\
\text { dels residents per fer negocis la } \\
\text { comarca }\end{array}$ & & L & L & 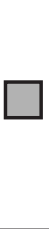 & & & \\
\hline $\begin{array}{l}\text { 4. El turismo ha mejorado la situación } \\
\text { económica de la comarca } \\
\text { El turisme ha millorat la situació } \\
\text { econòmica de la comarca }\end{array}$ & & & - & $L$ & & & \\
\hline $\begin{array}{l}\text { 5. Gracias al turismo hay más comercios } \\
\text { y más posibilidades de compras en } \\
\text { Morella para los residentes } \\
\text { Gràcies al turisme hi ha més comerços } \\
\text { i més possibilitats de compres en } \\
\text { Morella per als residents }\end{array}$ & & & - & L & & & \\
\hline $\begin{array}{l}\text { 6. El turismo es una buena alternativa } \\
\text { a las actividades agrícolas y ganaderas } \\
\text { El turisme és una bona alternativa a } \\
\text { les activitats agrícoles i ramaderes }\end{array}$ & & & L & $L$ & & & \\
\hline $\begin{array}{l}\text { 7. El turismo es una actividad } \\
\text { complementaria a otras rentas de la } \\
\text { población [ganancias] } \\
\text { EI turisme és una activitat } \\
\text { complementària a d'altres rendes de } \\
\text { la població [guanys] }\end{array}$ & & & - & $L$ & & & \\
\hline
\end{tabular}




\begin{tabular}{|c|c|c|c|c|c|c|c|}
\hline & 1 & 2 & 3 & 4 & 5 & 6 & 7 \\
\hline $\begin{array}{l}\text { 8. El turismo potencia el mantenimiento } \\
\text { de otras actividades económicas } \\
\text { [artesanía, industria agroalimentaria] } \\
\text { El turisme potencia el manteniment } \\
\text { d'altres activitats econòmiques } \\
\text { [artesania, indústria agroalimentària] }\end{array}$ & & & L & IL & L & & $\square$ \\
\hline $\begin{array}{l}\text { 9. Los negocios de hostelería } \\
\text { [alojamientos y restaurantes] } \\
\text { pertenecen mayoritariamente a } \\
\text { personas de Morella o de la Comarca. } \\
\text { Els negocis d'hostaleria [allotjaments } \\
\text { i restaurants] pertanyen } \\
\text { majoritàriament a persones de Morella } \\
\text { o de la Comarca. }\end{array}$ & 12 & 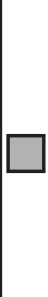 & $1-$ & $L$ & L & & $\square$ \\
\hline $\begin{array}{l}\text { 10. Los precios en los comercios han } \\
\text { aumentado debido al turismo } \\
\text { Els preus als comerços han augmentat } \\
\text { a causa del turisme }\end{array}$ & & \llcorner & 14 & L & ᄂ & & $\square$ \\
\hline $\begin{array}{l}\text { 11. Los impuestos locales han subido a } \\
\text { causa del turismo } \\
\text { Els impostos locals han pujat a causa } \\
\text { del turisme }\end{array}$ & L & & L & L & L & & $\square$ \\
\hline $\begin{array}{l}\text { 12. El precio de la vivienda se ha } \\
\text { incrementado en Morella debido al } \\
\text { turismo } \\
\text { El preu de l'habitatge s'ha incrementat } \\
\text { a Morella a causa del turisme }\end{array}$ & & & & 나 & 느 & & $\square$ \\
\hline $\begin{array}{l}\text { 13. El turismo perjudica la actividad } \\
\text { agraria y ganadera tradicional de la } \\
\text { zona } \\
\text { El turisme perjudica l'activitat agrària } \\
\text { i ramadera tradicional de la zona }\end{array}$ & & & & & & & $\square$ \\
\hline $\begin{array}{l}\text { 14. Actualmente, la economía de la } \\
\text { comarca no podría mantenerse sin el } \\
\text { turismo } \\
\text { Actualment, l'economia de la comarca } \\
\text { no podria mantenir-se sense el } \\
\text { turisme }\end{array}$ & L & & L & Lـ & L & & $\square$ \\
\hline $\begin{array}{l}\text { 15. El dinero público invertido en turismo } \\
\text { en la comarca debería haberse } \\
\text { dedicado a otros sectores económicos } \\
\text { El diner públic invertit en turisme a } \\
\text { la comarca hauria d'haver-se dedicat } \\
\text { a altres sectors econòmics }\end{array}$ & & & & L & |ㄴ. & & $\square$ \\
\hline $\begin{array}{l}\text { 16. Debido al turismo se han mejorado } \\
\text { las infraestructuras de acceso a } \\
\text { Morella } \\
\text { Gràcies al turisme s'han millorat les } \\
\text { infraestructures d'accés a Morella }\end{array}$ & & & & & 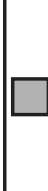 & & $\square$ \\
\hline
\end{tabular}


ESCALA DE VALORACIÓN | ESCALA DE VALORACIÓ

\begin{tabular}{|c|c|c|c|c|c|c|}
\hline 1 & 2 & 3 & 4 & 5 & 6 & 7 \\
\hline $\begin{array}{c}\text { Totalmente } \\
\text { en } \\
\text { Desacuerdo } \\
\\
\text { Totalment } \\
\text { en desacord }\end{array}$ & $\begin{array}{l}\text { Bastante en } \\
\text { desacuerdo } \\
\text { Bastant en } \\
\text { desacord }\end{array}$ & $\begin{array}{c}\text { Algo en } \\
\text { desacuerdo } \\
\text { Un poc en } \\
\text { desacord }\end{array}$ & $\begin{array}{c}\text { Ni de } \\
\text { acuerdo ni } \\
\text { en } \\
\text { desacuerdo } \\
\\
\text { Ni d'acord ni } \\
\text { en desacord }\end{array}$ & $\begin{array}{l}\text { Algo de } \\
\text { acuerdo } \\
\text { Un poc } \\
\text { d'acord }\end{array}$ & $\begin{array}{l}\text { Bastante de } \\
\text { acuerdo } \\
\text { Bastant } \\
\text { d'acord }\end{array}$ & $\begin{array}{c}\text { Totalmente } \\
\text { de Acuerdo } \\
\text { Totalment } \\
\text { d'acord }\end{array}$ \\
\hline
\end{tabular}




\section{BLOQUE 2 - IMPACTOS SOCIALES DEL TURISMO BLOC 2 - IMPACTES SOCIALS DEL TURISME}

[En los últimos diez años]

[Als últims deu anys]

\begin{tabular}{|c|c|c|c|c|c|c|c|}
\hline & 1 & 2 & 3 & 4 & 5 & 6 & 7 \\
\hline $\begin{array}{l}\text { 17. La población en la comarca ha } \\
\text { aumentado debido al efecto del }\end{array}$ & & & & & & & \\
\hline $\begin{array}{l}\text { La població en la comarca ha } \\
\text { augmentat gràcies a l'efecte del } \\
\text { turisme }\end{array}$ & & & L & ᄂ & & L & \\
\hline $\begin{array}{l}\text { 18. Se dispone de más actividades de } \\
\text { ocio y recreativas en la comarca para }\end{array}$ & & & & & & & \\
\hline $\begin{array}{l}\text { Es disposa de més activitats d'oci i } \\
\text { recreatives a la comarca per als jóvens }\end{array}$ & & & & & & & \\
\hline $\begin{array}{l}\text { 19. Los servicios públicos [sanidad, } \\
\text { educación] de Morella han mejorado }\end{array}$ & & & & & & & \\
\hline $\begin{array}{l}\text { Els serveis públics [sanitat, educació] } \\
\text { de Morella han millorat gràcies al } \\
\text { turisme }\end{array}$ & & & - & & & & \\
\hline 20. El turismo enriquece la vida cultural & & & & & & & \\
\hline $\begin{array}{l}\text { El turisme enriqueix la vida cultural } \\
\text { i social de Morella }\end{array}$ & & & L & L & & L & \\
\hline $\begin{array}{l}\text { 21. El turismo ha contribuido } \\
\text { positivamente a restaurar y mejorar }\end{array}$ & & & & & & & \\
\hline $\begin{array}{l}\text { El turisme ha contribuït positivament } \\
\text { a restaurar i millorar el patrimoni } \\
\text { cultural }\end{array}$ & & & L & & & L & \\
\hline 22. El turismo es una oportunidad para & & & & & & & \\
\hline $\begin{array}{l}\text { El turisme és una oportunitat per } \\
\text { conèixer altres persones }\end{array}$ & & & L & & & L & \\
\hline
\end{tabular}




\begin{tabular}{|c|c|c|c|c|c|c|}
\hline & $\mathbf{1}$ & & 3 & & 5 & \\
\hline $\begin{array}{l}\text { 23. El turismo permite que nuevos } \\
\text { residentes se establezcan en la } \\
\text { localidad } \\
\text { El turisme permet que nous residents } \\
\text { s'establisquen a la localitat }\end{array}$ & 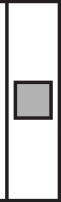 & & & & & \\
\hline $\begin{array}{l}\text { 24. Personalmente me agrada la presencia } \\
\text { de turistas en Morella } \\
\text { Personalment m'agrada la presència } \\
\text { de turistes a Morella }\end{array}$ & L & & & & & \\
\hline $\begin{array}{l}\text { 5l turismo favore } \\
\text { de las tradicione } \\
\text { El turisme afavol } \\
\text { de les tradicions }\end{array}$ & $\|$ & & & & & \\
\hline $\begin{array}{l}\text { 6. Por efecto del turismo se empobrece } \\
\text { la identidad cultural Morellana } \\
\text { Per efecte del turisme s'empobreix la } \\
\text { identitat cultural Morellana }\end{array}$ & L & & & & & \\
\hline $\begin{array}{l}\text { El desarrollo turístico ha generado } \\
\text { conflictos entre los residentes de } \\
\text { Morella } \\
\text { El desenvolupament turístic ha } \\
\text { generat conflictes entre els residents } \\
\text { de Morella }\end{array}$ & [ & & & & & \\
\hline $\begin{array}{l}\text { 28. La actividad } \\
\text { entre pobla } \\
\text { L'activitat } t \\
\text { entre la pol }\end{array}$ & L & & & & & \\
\hline $\begin{array}{l}\text { 9. La actividad turística ha generadd } \\
\text { mayor unión entre los miembro } \\
\text { la comunidad } \\
\text { L'activitat turística ha generat } \\
\text { major unió entre els membres } \\
\text { comunitat }\end{array}$ & [ & & & & & \\
\hline $\begin{array}{l}\text { 30. El desarrollo turístico actual requiere } \\
\text { de trabajadores extranjeros } \\
\text { El desenvolupament turístic actual } \\
\text { requereix treballadors estrangers }\end{array}$ & | & & & & & \\
\hline $\begin{array}{l}\text { 31. Los emigrantes extranjeros provocan } \\
\text { conflictos de convivencia } \\
\text { Els emigrants estrangers provoquen } \\
\text { conflictes de convivencia }\end{array}$ & $\|$ & & & & & \\
\hline $\begin{array}{l}\text { 32. La seguridad de Morella ha descendido } \\
\text { por efecto del turismo } \\
\text { La seguretat de Morella ha baixat por } \\
\text { efecte del turisme }\end{array}$ & L & & $L$ & & & \\
\hline
\end{tabular}




\section{ESCALA DE VALORACIÓN | ESCALA DE VALORACIÓ}

\begin{tabular}{|c|c|c|c|c|c|c|}
\hline 1 & 2 & 3 & 4 & 5 & 6 & 7 \\
\hline $\begin{array}{c}\text { Totalmente } \\
\text { en } \\
\text { Desacuerdo } \\
\text { Totalment } \\
\text { en desacord }\end{array}$ & $\begin{array}{c}\text { Bastante en } \\
\text { desacuerdo } \\
\text { Bastant en } \\
\text { desacord }\end{array}$ & $\begin{array}{c}\text { Algo en } \\
\text { desacuerdo } \\
\text { Un poc en } \\
\text { desacord }\end{array}$ & $\begin{array}{c}\text { Ni de } \\
\text { acuerdo ni } \\
\text { en } \\
\text { desacuerdo } \\
\text { Ni d'acord ni } \\
\text { en desacord }\end{array}$ & $\begin{array}{c}\text { Algo de } \\
\text { acuerdo } \\
\text { Un poc } \\
\text { d'acord }\end{array}$ & $\begin{array}{c}\text { Bastante de } \\
\text { acuerdo } \\
\text { Bastant } \\
\text { d'acord }\end{array}$ & $\begin{array}{c}\text { Totalmente } \\
\text { de Acuerdo } \\
\text { Totalment } \\
\text { d'acord }\end{array}$ \\
\hline
\end{tabular}


BLOQUE 3 - IMPACTOS MEDIOAMBIENTALES DEL TURISMO BLOC 3 - IMPACTES MEDIOAMBIENTALS DEL TURISME

\begin{tabular}{|c|c|c|c|c|c|c|c|}
\hline & 1 & 2 & 3 & 4 & 5 & 6 & 7 \\
\hline $\begin{array}{l}\text { 33. El turismo contribuye a preservar el } \\
\text { paisaje } \\
\text { El turisme contribueix a preservar } \\
\text { el paisatge }\end{array}$ & |L & L & L & |L & L & & L \\
\hline $\begin{array}{l}\text { 34. El turismo mejora las infraestructuras } \\
\text { locales de parques y jardines } \\
\text { El turisme millora les infraestructures } \\
\text { locals de parcs i jardins }\end{array}$ & L & - & L & $L$ & $L$ & & L \\
\hline $\begin{array}{l}\text { 35. Las infraestructuras que requiere el } \\
\text { sostenimiento de la actividad turística } \\
\text { estropean el paisaje de la comarca } \\
\text { Les infrastructures que requereixen } \\
\text { el sosteniment de l'activitat turística } \\
\text { fan malbé el paisatge de la comarca }\end{array}$ & $L$ & - & ᄂ & L & L & & L \\
\hline $\begin{array}{l}\text { 36. Durante la temporada alta hay } \\
\text { demasiada gente en Morella y no es } \\
\text { agradable vivir aquí } \\
\text { Durant la temporada alta hi ha massa } \\
\text { gent a Morella i no és agradable viure } \\
\text { ací }\end{array}$ & & ᄂ & L & L & & & L \\
\hline $\begin{array}{l}\text { 37. El turismo provoca congestión de } \\
\text { tráfico en Morella } \\
\text { El turisme provoca congestió de } \\
\text { trànsit a Morella }\end{array}$ & $\mathrm{L}$ & $\square$ & L & $L$ & L & & - \\
\hline $\begin{array}{l}\text { 38. La tranquilidad de los residentes se } \\
\text { ve negativamente afectada por el } \\
\text { ruido de coches y turistas } \\
\text { La tranquil·litat dels residents es veu } \\
\text { negativament afectada pel soroll dels } \\
\text { cotxes i dels turistes }\end{array}$ & |L & L & $\| \mathrm{L}$ & L & L & & \\
\hline
\end{tabular}




\section{BLOQUE 4 - SU PERCEPCIÓN DE MORELLA COMO DESTINO TURÍSTICO BLOC 4 - LA SEUA PERCEPCIÓ DE MORELLA COM A DESTINACIÓ TURÍSTICA}

39. Evalúe del $\mathbf{1}$ [menor importancia] al $\mathbf{7}$ [mayor importancia] cuál es, en su opinión, el atractivo principal de Morella para los turistas: Avalue del 1 [menor importància] al 7 [major importància] quin és, en la seua opinió, l'atractiu principal de Morella per als turistes:

\begin{tabular}{|c|c|}
\hline $\begin{array}{l}\text { § Compartir el patrimonio cultural [historia, tradiciones, fiestas] } \\
\text { Compartir el patrimoni cultural [historia, tradicions, festes] }\end{array}$ & \\
\hline $\begin{array}{l}\text { § Recorrer el patrimonio histórico-artístico [monumentos] } \\
\text { Recórrer el patrimoni historicoartístic [monuments] }\end{array}$ & \\
\hline $\begin{array}{l}\text { § Conocer el patrimonio paleontológico [fósiles] } \\
\text { Conèixer el patrimoni paleontològic [fòssils] }\end{array}$ & \\
\hline $\begin{array}{l}\text { §isfrutar de la naturaleza } \\
\text { Gaudir de la natura }\end{array}$ & \\
\hline $\begin{array}{l}\text { § Comprar productos agroalimentarios } \\
\text { Comprar productes agroalimentaris }\end{array}$ & \\
\hline $\begin{array}{l}\text { § Degustar la gastronomía de la zona } \\
\text { Degustar la gastronomia de la zona }\end{array}$ & \\
\hline $\begin{array}{l}\text { § Comprar artesanía } \\
\text { Comprar artesania }\end{array}$ & \\
\hline
\end{tabular}


ESCALA DE VALORACIÓN | ESCALA DE VALORACIÓ

\begin{tabular}{|c|c|c|c|c|c|c|}
\hline 1 & 2 & 3 & 4 & 5 & 6 & 7 \\
\hline $\begin{array}{c}\text { Totalmente } \\
\text { en } \\
\text { Desacuerdo } \\
\text { Totalment } \\
\text { en desacord }\end{array}$ & $\begin{array}{c}\text { Bastante en } \\
\text { desacuerdo } \\
\text { Bastant en } \\
\text { desacord }\end{array}$ & $\begin{array}{c}\text { Algo en } \\
\text { desacuerdo } \\
\text { Un poc en } \\
\text { desacord }\end{array}$ & $\begin{array}{c}\text { Ni de } \\
\text { acuerdo ni } \\
\text { en } \\
\text { desacuerdo } \\
\text { Ni d'acord ni } \\
\text { en desacord }\end{array}$ & $\begin{array}{c}\text { Algo de } \\
\text { acuerdo } \\
\text { Un poc } \\
\text { d'acord }\end{array}$ & $\begin{array}{c}\text { Bastante de } \\
\text { acuerdo } \\
\text { Bastant } \\
\text { d'acord }\end{array}$ & $\begin{array}{c}\text { Totalmente } \\
\text { de Acuerdo } \\
\text { Totalment } \\
\text { d'acord }\end{array}$ \\
\hline
\end{tabular}




\begin{tabular}{|c|c|c|c|c|c|c|c|}
\hline & 1 & 2 & 3 & 4 & 5 & 6 & 7 \\
\hline $\begin{array}{l}\text { 40. Considero que Morella es muy } \\
\text { conocida en toda España } \\
\text { Considere que Morella és molt } \\
\text { coneguda en tota Espanya }\end{array}$ & $\square$ & L & L & L & & L & - \\
\hline $\begin{array}{l}\text { 41. Considero que es necesario } \\
\text { promocionar Morella a nivel } \\
\text { internacional } \\
\text { Considere que és necessari } \\
\text { promocionar Morella en l'àmbit } \\
\text { internacional }\end{array}$ & $\|$ & & L & ᄂ & & L & \\
\hline $\begin{array}{l}\text { 42. La actividad turística en Morella está } \\
\text { correctamente gestionada } \\
\text { L'activitat turística a Morella està } \\
\text { correctament gestionada }\end{array}$ & L & & 나 & L & & & \\
\hline $\begin{array}{l}\text { 43. La actividad turística de Morella está } \\
\text { vinculada al desarrollo turístico de la } \\
\text { costa [Peñíscola] } \\
\text { L'activitat turística de Morella està } \\
\text { vinculada al desenvolupament turístic } \\
\text { de la costa [Peníscola] }\end{array}$ & $\mid L$ & & L & LL & L & $\|$ & \\
\hline $\begin{array}{l}\text { 44. Considero que el turismo en Morella } \\
\text { es alternativo al turismo de sol y } \\
\text { playa } \\
\text { Considere que el turisme a Morella } \\
\text { és alternatiu al turisme de sol i platja }\end{array}$ & $\square$ & & L & L & & & \\
\hline $\begin{array}{l}\text { 45. Personalmente estoy perfectamente } \\
\text { informado/a de los nuevos proyectos } \\
\text { e inversiones turísticas que se realizan } \\
\text { en la comarca } \\
\text { Personalment estic perfectament } \\
\text { informat/da dels nous projectes i } \\
\text { inversions turístiques que es realitzen } \\
\text { a la comarca }\end{array}$ & & & L & L & & & \\
\hline $\begin{array}{l}\text { 46. Personalmente apoyo el desarrollo } \\
\text { turístico de Morella y la Comarca } \\
\text { Personalment done suport al } \\
\text { desenvolupament turístic de Morella } \\
\text { i de la Comarca }\end{array}$ & $\|$ & & L & L & L & 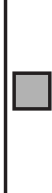 & \\
\hline
\end{tabular}




\section{DATOS SOCIO-DEMOGRÁFICOS Y RELACIÓN PERSONAL CON EL SECTOR TURÍSTICO \\ DADES SOCIODEMOGRÀFIQUES I RELACIÓ PERSONAL AMB EL SECTOR TURÍSTIC}

\section{CONFIDENCIALIDAD | CONFIDENCIALITAT}

\section{ESTE CUESTIONARIO ES COMPLETAMENTE ANÓNIMO}

La información que usted proporcione será tratada confidencialmente y siempre de forma agregada, de manera que las opiniones particulares que están protegidas por el secreto estadístico, no podrán ser identificadas. No se publicarán ni se facilitaran datos individualizados.

AQUEST QÜESTIONARI ÉS COMPLETAMENT ANÒNIM

La informació que vostè proporcione serà tractada confidencialment i sempre de forma agregada, de manera que les opinions particulars que estan protegides pel secret estadístic, no podran ser identificades. No es publicaran ni es facilitaran dades individualitzades. 


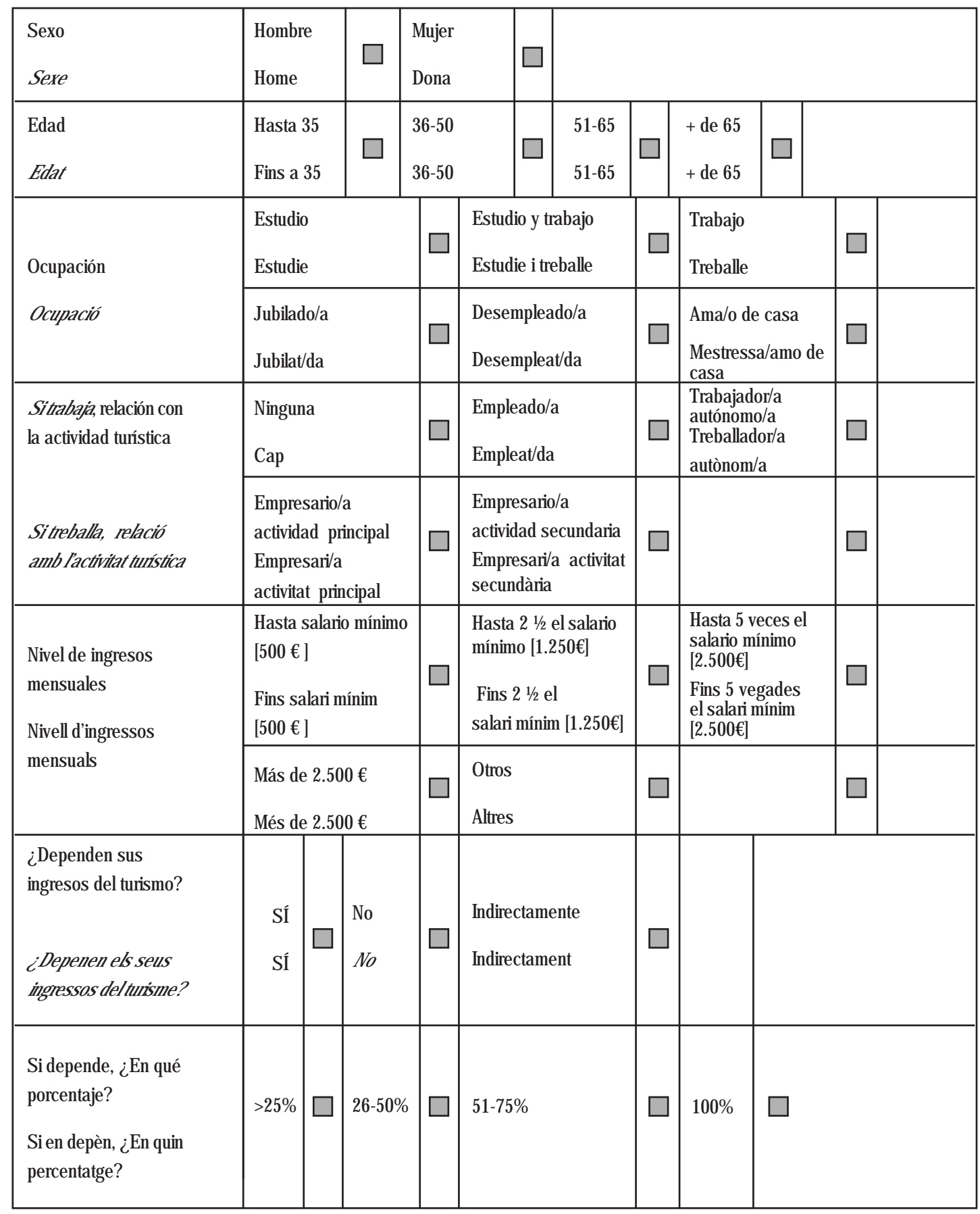




\section{RELACIÓN PERSONAL CON EL SECTOR TURÍSTICO RELACIÓ PERSONAL AMB EL SECTOR TURÍSTIC}

\begin{tabular}{|c|c|c|c|c|c|c|c|c|c|c|c|}
\hline \multicolumn{12}{|c|}{$\begin{array}{l}\text { Contacto personal con turistas } \\
\text { Contacte personal amb turistes }\end{array}$} \\
\hline \multicolumn{2}{|c|}{$\begin{array}{l}\text { Frecuentemente } \\
\text { Freqüentment }\end{array}$} & $\square$ & \multicolumn{3}{|c|}{$\begin{array}{l}\text { Algunas veces } \\
\text { Algunes vegades }\end{array}$} & $\square$ & \multicolumn{2}{|c|}{$\begin{array}{l}\text { Pocas veces } \\
\text { Poques vegades }\end{array}$} & $\square$ & $\begin{array}{l}\text { Ningún contacto } \\
\text { Cap contacte }\end{array}$ & $\square$ \\
\hline \multicolumn{12}{|c|}{$\begin{array}{l}\text { ¿Reside usted habitualmente más de } 6 \text { meses al año en Morella o Comarca? } \\
\text { ¿Resideix vosté habitualment més de } 6 \text { mesos a l'any a Morella o Comarca? }\end{array}$} \\
\hline $\begin{array}{l}\text { Sï } \\
\text { Sï }\end{array}$ & $\square$ & $\begin{array}{l}\text { No } \\
\text { No }\end{array}$ & ᄃ & & & & & & & & \\
\hline \multicolumn{12}{|c|}{$\begin{array}{l}\text { Tiempo de residencia en els Ports/Morella } \\
\text { Temps de residència als Ports/Morella }\end{array}$} \\
\hline $\begin{array}{l}\text { Fins } 1 \text { año } \\
\text { Fins a } 1 \text { any }\end{array}$ & $y$ & & & $\square$ & $\begin{array}{l}4-12 a \\
4-12 a\end{array}$ & $\begin{array}{l}\text { años } \\
\text { anys }\end{array}$ & $\square$ & $\begin{array}{l}13-20 \text { años } \\
13-20 \text { anys }\end{array}$ & $\square$ & $\begin{array}{l}\text { Más de } 20 \text { años } \\
\text { Més de } 20 \text { anys }\end{array}$ & $\square$ \\
\hline \multicolumn{12}{|c|}{$\begin{array}{l}\text { ¿Su vivienda es de propiedad personal o familiar? } \\
\text { ¿El seu habitatge és de propietat o familiar? }\end{array}$} \\
\hline $\begin{array}{l}\text { Sï } \\
\text { Sï }\end{array}$ & $\square$ & $\begin{array}{l}\text { No } \\
\text { No }\end{array}$ & $\square$ & & & & & & & & \\
\hline
\end{tabular}


MUCHAS GRACIAS POR SU COLABORACIÓN MOLTES GRÁCIES PER LA SEUA COL-LABORACIÓ

\section{OBSERVACIONES | OBSERVACIONS}




\section{ENTREVISTADOR | ENTREVISTADOR}

\section{CONTROL DE CAMPO | CONTROL DE CAMP}

\begin{tabular}{|l|l|}
\hline $\begin{array}{l}\text { Revisada } \\
\text { Revisada }\end{array}$ & \\
\hline $\begin{array}{l}\text { Codificada } \\
\text { Codificada }\end{array}$ & \\
\hline $\begin{array}{l}\text { Superv. Telefónica } \\
\text { Superv. Telefònica }\end{array}$ & \\
\hline Superv. Personal & \\
Superv. Personal & \\
\hline Grabada & \\
Enregistrada & \\
\hline Nula & \\
Nul·la & \\
\hline
\end{tabular}


ANEXO 3 



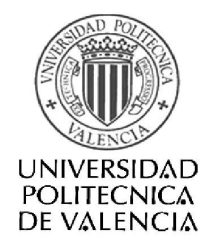

\section{GESTI ÓN COMPETI TI VA DE DESTI NOS TURÍ STI COS LOCALES}

\section{Encuesta a Expertos}

Esta encuesta tiene por objeto determinar cuál es, en su opinión, la importancia relativa que tiene cada uno de los ítems relacionados en las preguntas que a continuación se le formulan.

Es importante que su valoración sea lo más objetiva posible, con independencia de la complejidad que supondría llevar a cabo la acción en su ámbito de competencias.

Al final de cada planteamiento se ha dispuesto espacio en blanco por si desea sugerir, ampliar o realizar alguna observación a la cuestión planteada.

El tratamiento de la información se realizará de forma agregada y los datos reflejados en el cuestionario son absolutamente confidenciales

\section{Nombre}

\section{Cargo}

\section{País}

\section{Edad}

Hasta 25 26-35 36-55 Más de 55

\section{Titulación académica máxima}

Doctor/a Master/maestría

Licenciado/a, Ingeniero/a, Arquitecto Otros estudios 


\section{Cuestionario}

\begin{tabular}{|c|c|c|c|c|}
\hline $\begin{array}{c}\text { Sin } \\
\text { importancia }\end{array}$ & $\begin{array}{c}\text { Poca } \\
\text { importancia }\end{array}$ & Neutro & I mportante & $\begin{array}{c}\text { Muy } \\
\text { I mportante }\end{array}$ \\
1 & 2 & 3 & 4 & 5 \\
\hline
\end{tabular}

1. - El compromiso para el desarrollo turístico sostenible y, por tanto, competitivo requiere de la cooperación pública - privada en distintos ámbitos (planificación, inversión, promoción). Al respecto, en su opinión, ¿qué nivel de importancia debería tener cada uno de los siguientes items?

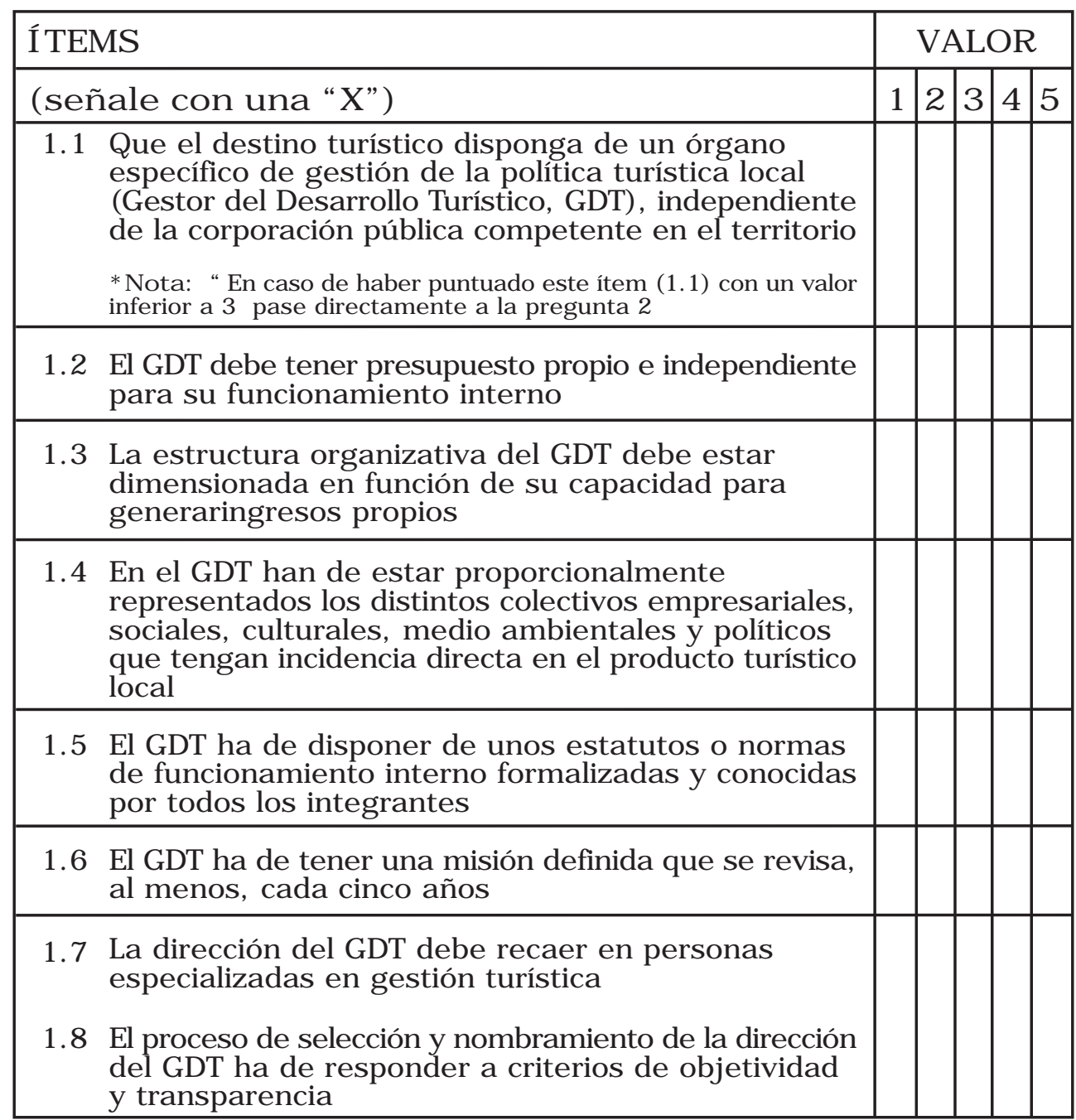


2.- Suponiendo la creación de un órgano especializado e independiente (GDT) con atribuciones para coordinar las acciones tendentes a un desarrollo sostenido del destino turístico, ¿en qué medida está ud. de acuerdo (valora) las siguientes afirmaciones?

\begin{tabular}{|c|c|c|c|c|c|c|}
\hline \multirow{2}{*}{\multicolumn{2}{|c|}{ ÍTEMS }} & \multicolumn{5}{|c|}{ VALOR } \\
\hline & & & \multirow[t]{2}{*}{2} & \multirow{2}{*}{\multicolumn{2}{|c|}{\begin{tabular}{l|l}
3 & 4 \\
\end{tabular}}} & \\
\hline 2.1 & $\begin{array}{l}\text { Las actuaciones del GDT deben responder a una } \\
\text { planificación estratégica concertada entre los distintos } \\
\text { agentes del destino turístico }\end{array}$ & & & & & \\
\hline 2.2 & $\begin{array}{l}\text { EI GDT debe tener definido un presupuesto anual } \\
\text { para las actuaciones en materia de desarrollo turístico }\end{array}$ & & & & & \\
\hline 2.3 & $\begin{array}{l}\text { Este presupuesto es independiente del que } \\
\text { corresponde a los distintos colectivos o entidades } \\
\text { que lo forman }\end{array}$ & & & & & \\
\hline 2.4 & $\begin{array}{l}\text { Todos los colectivos integrantes del GDT han de } \\
\text { realizar una aportación económica al presupuesto } \\
\text { adecuada a su representatividad }\end{array}$ & & & & & \\
\hline 2.5 & $\begin{array}{l}\text { El programa de actuaciones del GDT debería } \\
\text { comprender actuaciones tanto de producto como de } \\
\text { comercialización }\end{array}$ & & & & & \\
\hline 2.6 & $\begin{array}{l}\text { El proceso de toma de decisiones en el GDT se debe } \\
\text { regir por criterios de eficiencia }\end{array}$ & & & & & \\
\hline 2.7 & $\begin{array}{l}\text { El proceso de toma de decisiones en el GDT se debe } \\
\text { regir por criterios de eficacia política }\end{array}$ & & & & & \\
\hline & $\begin{array}{l}\text { Los integrantes del GDT deberán crear mecanismos } \\
\text { adecuados para evaluar los resultados de las acciones } \\
\text { realizadas }\end{array}$ & & & & & \\
\hline
\end{tabular}


3.- La investigación de mercados y el análisis sistemático de la demanda en el destino turístico requiere:

\begin{tabular}{|c|c|c|c|c|c|c|}
\hline ÍTE & MS & & VA & LC & & \\
\hline (se & lale con una "X") & 1 & 2 & 3 & 4 & 5 \\
\hline 3.1 & $\begin{array}{l}\text { La designación de una persona o grupo de personas } \\
\text { responsables de la gestión y seguimiento de las } \\
\text { tareas de investigación }\end{array}$ & & & & & \\
\hline 3.2 & $\begin{array}{l}\text { La asignación permanente de una partida } \\
\text { presupuestaria para realizar la investigación de } \\
\text { mercados }\end{array}$ & & & & & \\
\hline 3.3 & $\begin{array}{l}\text { Que las actividades de investigación se realicen, como } \\
\text { mínimo, cada cinco años }\end{array}$ & & & & & \\
\hline 3.4 & $\begin{array}{l}\text { La realización de informes con el análisis de los } \\
\text { resultados de la investigación }\end{array}$ & & & & & \\
\hline 3.5 & $\begin{array}{l}\text { La difusión de los resultados entre los diversos } \\
\text { organismos públicos y privados con interés en la } \\
\text { industria turística }\end{array}$ & & & & & \\
\hline 3.6 & $\begin{array}{l}\text { El diseño de un sistema regular de obtención de la } \\
\text { información en el destino turístico }\end{array}$ & & & & & \\
\hline 3.7 & $\begin{array}{l}\text { La celebración de convenios de colaboración con } \\
\text { entidades e instituciones que faciliten la mejor } \\
\text { ejecución de las actividades de investigación }\end{array}$ & & & & & \\
\hline 3.8 & $\begin{array}{l}\text { La existencia de un centro de documentación/archivos } \\
\text { tanto para uso propio como para apoyo de la } \\
\text { industriaturística local y de los centros de investigación }\end{array}$ & & & & & \\
\hline
\end{tabular}


4.- La concepción del producto global "destino turístico local" requiere:

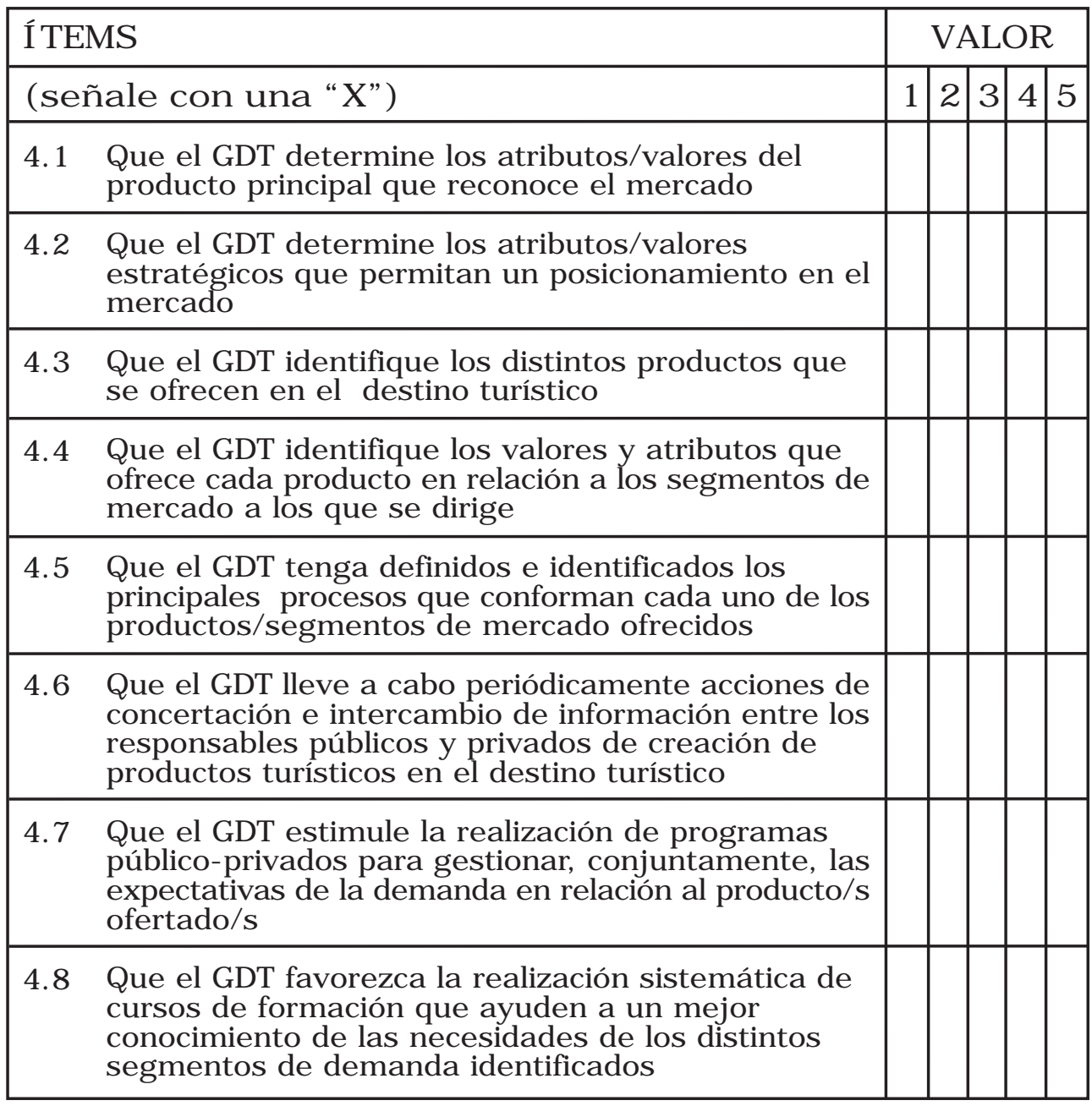


5. - Con objeto de que la percepción del destino turístico por parte de los consumidores turísticos se adecue a sus necesidades y supere sus expectativas, se requiere:

\begin{tabular}{|c|c|c|c|c|c|c|}
\hline ÍTE & MS & & VA & $\mathbf{L C}$ & & \\
\hline (se & ñale con una " $X$ ") & $\mathbf{1}$ & 2 & 3 & 4 & 5 \\
\hline 5.1 & $\begin{array}{l}\text { Que el GDT tenga definidos unos objetivos generales } \\
\text { de calidad para el destino turístico }\end{array}$ & & & & & \\
\hline 5.2 & $\begin{array}{l}\text { Que el GDT tenga definidos unos objetivos específicos } \\
\text { para los diferentes productos que integran el destino } \\
\text { turístico }\end{array}$ & & & & & \\
\hline 5.3 & $\begin{array}{l}\text { Que el GDT tenga definidos unos estándares de } \\
\text { calidad a lograr en los diferentes procesos que integran } \\
\text { cada uno de los productos turísticos identificados en } \\
\text { el destino turístico }\end{array}$ & & & & & \\
\hline 5.4 & $\begin{array}{l}\text { Que el GDT tenga definidos, implantados y } \\
\text { documentados indicadores de gestión de calidad que } \\
\text { permitan la evaluación sistemática del cumplimiento } \\
\text { de los objetivos de calidad definidos en los estándares }\end{array}$ & & & & & \\
\hline 5.5 & $\begin{array}{l}\text { Que el GDT lleve a cabo acciones regulares de control } \\
\text { de los niveles de calidad ofrecidos en los servicios } \\
\text { turísticos de titularidad pública }\end{array}$ & & & & & \\
\hline 5.6 & $\begin{array}{l}\text { Que el GDT conozca, actualice y difunda toda la } \\
\text { información relativa a los distintos programas de } \\
\text { aseguramiento de la calidad disponibles en el mercado }\end{array}$ & & & & & \\
\hline 5.7 & $\begin{array}{l}\text { Que el GDT estimule la implantación de programas } \\
\text { de gestión de calidad entre los distintos proveedores } \\
\text { externos de la industria y los servicios turísticos }\end{array}$ & & & & & \\
\hline 5.8 & $\begin{array}{l}\text { Que el GDT favorezca la realización de programas } \\
\text { periódicos de formación en gestión de calidad para } \\
\text { las personas que intervienen en los distintos procesos } \\
\text { del producto turístico }\end{array}$ & & & & & \\
\hline
\end{tabular}


6.- Con objeto de realizar un seguimiento del nivel de satisfacción tanto de los consumidores turísticos como de la población local que permita la progresiva implantación de medidas correctoras y/o de mejora se requiere:

\begin{tabular}{|c|c|}
\hline ÍTEMS & VALOR \\
\hline ( señale con una "X") & \begin{tabular}{l|l|l|l|l}
1 & 2 & 3 & 4 & 5
\end{tabular} \\
\hline
\end{tabular}

6.1 Que el GDT diseñe, implante y revise sistemáticamente un sistema continuo de obtención de información sobre el nivel de satisfacción de los consumidores turísticos, respecto de los distintos productos/mercados identificados

6.2 Que el GDT diseñe, implante y revise sistemáticamente un sistema continuo de obtención de información sobre el nivel de satisfacción general de los consumidores turísticos con el destino turístico en su conjunto

6.3 Que el GDT diseñe, implante y revise sistemáticamente un sistema continuo de obtención de información sobre el nivel de satisfacción general de la población local con el turismo

6.4 Que el GDT dé a conocer públicamente los resultados de satisfacción obtenidos

6.5 Que el GDT lleve a cabo acciones regulares de coordinación público- privada con objeto de analizar y proponer medidas de mejora de los resultados de satisfacción obtenidos

6.6 Que el GDT documente formalmente los indicadores de satisfacción obtenidos

6.7 Que el GDT planifique un programa de medidas correctoras/ de mejora para los diversos procesos de titularidad pública

6.8 Que exista una partida presupuestaria prevista para la obtención, análisis y difusión de la información 
7.- El fomento de la cultura de la innovación en el destino turístico va a depender de:

\begin{tabular}{|c|c|c|c|c|c|c|}
\hline \multirow{2}{*}{\multicolumn{2}{|c|}{ ÍTEMS }} & \multicolumn{5}{|c|}{ VALOR } \\
\hline & & 1 & 2 & 3 & 4 & 5 \\
\hline 7.1 & $\begin{array}{l}\text { Que el GDT disponga de un inventario actualizado } \\
\text { sobre recursos y factores de atracción que forman } \\
\text { la base de su producto/s }\end{array}$ & & & & & \\
\hline 7.2 & $\begin{array}{l}\text { Que el GDT disponga de un inventario de recursos } \\
\text { y factores con potencial de atracción }\end{array}$ & & & & & \\
\hline 7.3 & $\begin{array}{l}\text { Que exista una efectiva colaboración público - privada } \\
\text { para la gestión, mantenimiento y puesta en valor } \\
\text { turístico de estos recursos }\end{array}$ & & & & & \\
\hline 7.4 & $\begin{array}{l}\text { Que el GDT disponga de un programa abierto de } \\
\text { incentivos a la innovación turística }\end{array}$ & & & & & \\
\hline 7.5 & $\begin{array}{l}\text { Que existan presupuestos destinados a la investigación } \\
\text { y el desarrollo de nuevos productos/ procesos }\end{array}$ & & & & & \\
\hline 7.6 & $\begin{array}{l}\text { Que el GDT esté integrado en una red de gestión de } \\
\text { conocimiento aplicado }\end{array}$ & & & & & \\
\hline 7.7 & $\begin{array}{l}\text { Que el GDT conozca y recoja en informes periódicos } \\
\text { las tendencias generales en la creación de nuevos } \\
\text { productos turísticos }\end{array}$ & & & & & \\
\hline 7.8 & $\begin{array}{l}\text { Que el GDT disponga de información sobre posibles } \\
\text { productos sustitutivos }\end{array}$ & & & & & \\
\hline
\end{tabular}


8.- La gestión de la innovación como instrumento clave para el logro de una posición competitiva sostenida requiere:

\begin{tabular}{|c|c|c|c|c|c|}
\hline \multirow{2}{*}{\multicolumn{2}{|c|}{ ÍTEMS }} & \multicolumn{4}{|c|}{ VALOR } \\
\hline & & 1 & 23 & 4 & 5 \\
\hline \multirow[t]{2}{*}{8.1} & $\begin{array}{l}\text { Que el destino turístico disponga de un órgano } \\
\text { Permanente de gestión y fomento de la mejora } \\
\text { Continua/innovación }\end{array}$ & & & & \\
\hline & $\begin{array}{l}\text { * Nota: “En caso de haber puntuado este ítem ( } 8.1) \\
\text { con un valor inferior a } 3 \text { pase directamente al ítem }\end{array}$ & & & & \\
\hline 8.2 & $\begin{array}{l}\text { Que los integrantes de dicho órgano/comité } \\
\text { representen a todos los sectores económicos que } \\
\text { participan en la producción turística del destino }\end{array}$ & & & & \\
\hline 8.3 & $\begin{array}{l}\text { Que el sistema de acceso, permanencia y exclusión } \\
\text { en dicho órgano/comité esté formalmente } \\
\text { documentado }\end{array}$ & & & & \\
\hline 8.4 & $\begin{array}{l}\text { Que las acciones llevadas a cabo por dicho } \\
\text { órgano/comité sean reconocidas por el GDT }\end{array}$ & & & & \\
\hline 8.5 & $\begin{array}{l}\text { Que el GDT realice acciones de coordinación con otras } \\
\text { Administraciones públicas, tanto en sentido vertical } \\
\text { como horizontal, para el fomento conjunto de la } \\
\text { innovación }\end{array}$ & & & & \\
\hline 8.6 & $\begin{array}{l}\text { Que el GDT realice acciones específicas con objeto } \\
\text { de atraer y mantener recursos humanos cualificados } \\
\text { en el destino turístico }\end{array}$ & & & & \\
\hline 8.7 & $\begin{array}{l}\text { Que el GDT estimule la implantación de empresas } \\
\text { y/o Entidades especializadas en I+D compatibles con } \\
\text { el turismo }\end{array}$ & & & & \\
\hline
\end{tabular}


9.- El centro de la productividad y del crecimiento económico de un DT lo constituye la industria turística asentada en el espacio territorial y las industrias afines y conexas que, en tanto proveedores de productos y servicios, participan en la cadena de valor de las operaciones turísticas. La vertebración/ estructuración de estas industrias requieren en su opinión:

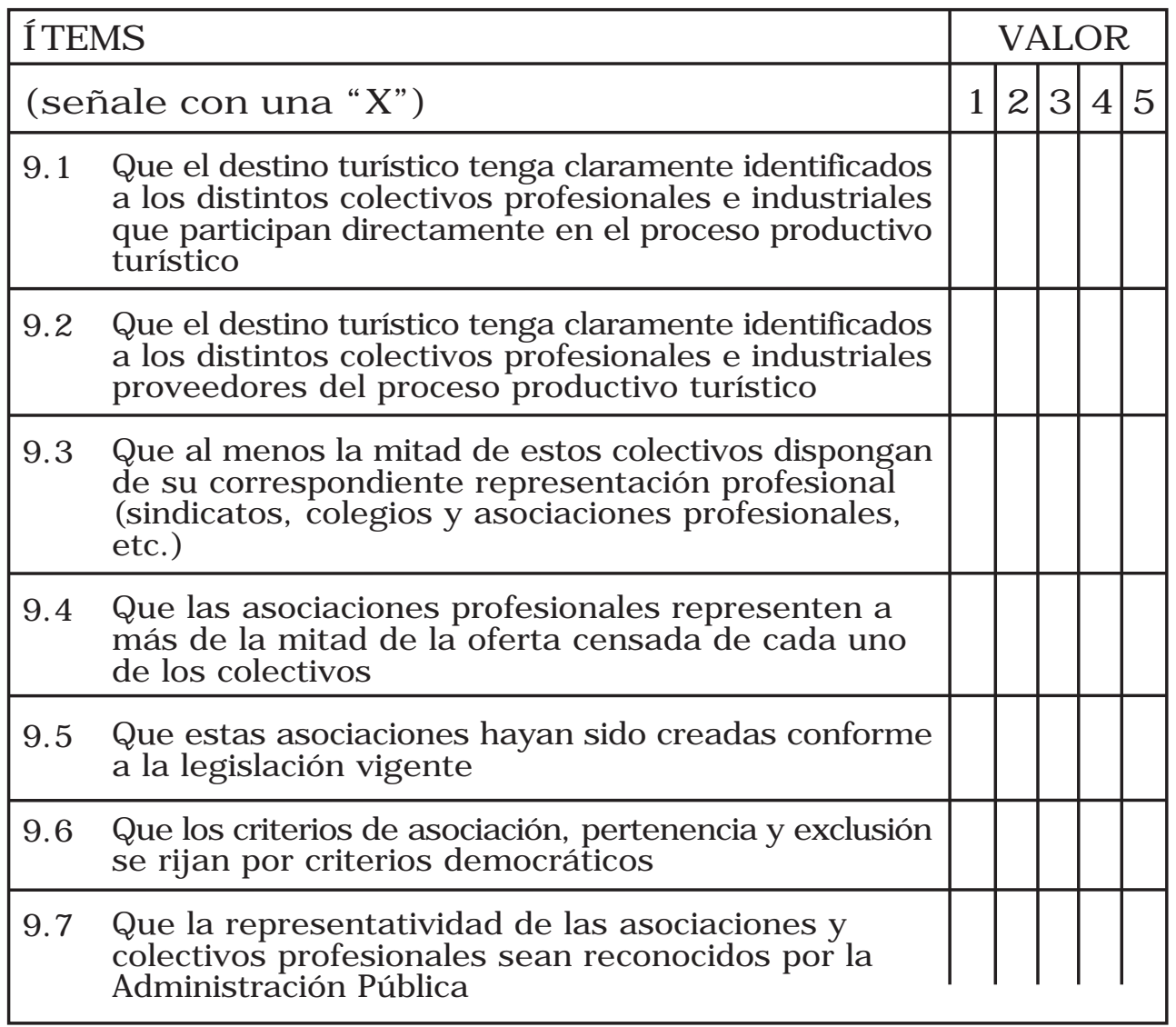


10.- La industria turística local debe intentar lograr unos niveles de desarrollo óptimo para, de este modo, contribuir a la mejora del bienestar de la comunidad local. En este sentido, valore los elementos que contribuirían, en su opinión, al desarrollo empresarial:

\begin{tabular}{|c|c|c|c|c|}
\hline ÍTEMS & & AL & OP & \\
\hline ( señale con una "X") & 12 & 3 & 4 & 5 \\
\hline $\begin{array}{l}\text { 10.1 Que el GDT disponga de un censo, permanentemente } \\
\text { actualizado, de las empresas y entidades que } \\
\text { participan en el proceso productivo }\end{array}$ & & & & \\
\hline $\begin{array}{l}\text { 10.2 Que el GDT gestione o coordine un programa de } \\
\text { ayuda/orientación para la creación y puesta en marcha } \\
\text { de nuevos negocios turísticos }\end{array}$ & & & & \\
\hline $\begin{array}{l}\text { 10.3 Que el GDT gestione o coordine un programa de } \\
\text { formación permanente para el desarrollo de los } \\
\text { recursos humanos turísticos }\end{array}$ & & & & \\
\hline $\begin{array}{l}\text { 10.4 Que el GDT realice acciones de estimulación/incentivos } \\
\text { para la implantación de empresas de importancia } \\
\text { estratégica para el desarrollo turístico }\end{array}$ & & & & \\
\hline $\begin{array}{l}\text { 10.5 La existencia de un marco legal adecuado para la } \\
\text { generación de seguridad jurídica }\end{array}$ & & & & \\
\hline $\begin{array}{l}\text { 10.6 Que el GDT conozca el nivel de producción anual de } \\
\text { la industria turística radicada en el territorio }\end{array}$ & & & & \\
\hline $\begin{array}{l}\text { 10.7 Que el GDT conozca los índices anuales de inversión } \\
\text { pública y privada en el territorio }\end{array}$ & & & & \\
\hline
\end{tabular}


11.- El desarrollo del turismo en un destino turístico debido a los impactos, positivos y negativos, que ejerce directa o indirectamente, ha de convertirse en un instrumento para lograr la mejora de bienestar y calidad de vida de la población residente, contribuyendo paralelamente al crecimiento económico y social del país. En relación al desarrollo económico, le pedimos que valore la importancia de los siguientes ítems:

\begin{tabular}{|c|c|c|c|c|c|c|}
\hline ÍTEI & MS & & VA & LC & & \\
\hline (seí & ñale con una “X") & 1 & 2 & 3 & 4 & 5 \\
\hline 11.1 & $\begin{array}{l}\text { Que el GDT conozca y tenga anualmente } \\
\text { documentados los principales parámetros económicos } \\
\text { de ámbito nacional y regional }\end{array}$ & & & & & \\
\hline 11.2 & $\begin{array}{l}\text { Que el GDT conozca y tenga formalmente } \\
\text { Documentados los principales parámetros económicos } \\
\text { de los países o regiones de origen de los consumidores } \\
\text { turísticos }\end{array}$ & & & & & \\
\hline 11.3 & $\begin{array}{l}\text { Que el GDT conozca y tenga anualmente } \\
\text { documentada el número y la evolución de empleos } \\
\text { turísticos directos y no directos del destino turístico } \\
\text { y el porcentaje que representan en relación al resto } \\
\text { de empleos }\end{array}$ & & & & & \\
\hline 11.4 & $\begin{array}{l}\text { El GDT conoce y tiene documentado el nivel de gasto } \\
\text { turístico en el destino turístico }\end{array}$ & & & & & \\
\hline 11.5 & $\begin{array}{l}\text { El GDT tiene definidos, implantados y documentados } \\
\text { un conjunto de indicadores de relevancia económica } \\
\text { que incluirán, como mínimo, los anteriores }\end{array}$ & & & & & \\
\hline 11.6 & $\begin{array}{l}\text { El GDT tiene definidos, documentados e implantado } \\
\text { un sistema continuo de recopilación de datos y análisis } \\
\text { de la información económica }\end{array}$ & & & & & \\
\hline 11.7 & $\begin{array}{l}\text { EI GDT tiene definida y asignada la responsabilidad } \\
\text { de la gestión de la información económica }\end{array}$ & & & & & \\
\hline 11.8 & $\begin{array}{l}\text { Los distintos indicadores económicos obtenidos se } \\
\text { recogen en un informe anual y se distribuye/ difunde } \\
\text { entre los interesados }\end{array}$ & & & & & \\
\hline
\end{tabular}


12.- El desarrollo sociocultural y la satisfacción de la población residente requeriría, en su opinión:

\begin{tabular}{|c|c|c|c|c|c|}
\hline Í TEMS & & VA & $\mathbf{L}$ & & \\
\hline ( señale con una "X") & 1 & 2 & 3 & 4 & 5 \\
\hline $\begin{array}{l}\text { 12.1 Que el GDT conozca y tenga documentados los } \\
\text { principales parámetros sociales de su territorio } \\
\text { (población, edad, porcentaje de } \\
\text { emigración/inmigración, escolaridad) }\end{array}$ & & & & & \\
\hline $\begin{array}{l}\text { 12.2 Que el GDT conozca el sistema de valores, creencias } \\
\text { y actitudes de cada segmento social de la población }\end{array}$ & & & & & \\
\hline $\begin{array}{l}\text { 12.3 Que el GDT conozca las pautas de consumo de la } \\
\text { población local y disponga de indicadores sobre } \\
\text { calidad de vida }\end{array}$ & & & & & \\
\hline $\begin{array}{l}\text { 12.4 Que el GDT disponga de un archivo histórico- } \\
\text { documental que refleje la evolución del destino y su } \\
\text { habitantes }\end{array}$ & & & & & \\
\hline $\begin{array}{l}\text { 12.5 Que el GDT realice acciones específicas encaminadas } \\
\text { a compatibilizar el uso turístico de los recursos con } \\
\text { el disfrute de la población local }\end{array}$ & & & & & \\
\hline $\begin{array}{l}\text { 12.6 Que el GDT recopile, publique y/o difunda } \\
\text { periódicamente información relativa a las actividades } \\
\text { culturales que se desarrollan en el destino turístico }\end{array}$ & & & & & \\
\hline $\begin{array}{l}\text { 12.7 Que el GDT fomente la participación de la población } \\
\text { local directamente o a través de los sectores } \\
\text { económicos y culturales más representativos, en el } \\
\text { diseño de programas específicos y en la implantación } \\
\text { de acciones de relevancia turística }\end{array}$ & & & & & \\
\hline
\end{tabular}


13. 1- ¿En qué medida considera ud. que la gestión local controlada de la actividad turística puede ayudar a preservar, mantener o reparar el medio ambiente? Señale su valoración:

\begin{tabular}{|c|c|c|c|c|}
\hline $\begin{array}{c}\text { Sin } \\
\text { importancia }\end{array}$ & $\begin{array}{c}\text { Poca } \\
\text { importancia }\end{array}$ & Neutro & I mportante & $\begin{array}{c}\text { Muy } \\
\text { I mportante }\end{array}$ \\
1 & 2 & 3 & 4 & 5 \\
\hline
\end{tabular}

En caso de conformidad, $(+3)$ ¿qué variables críticas han de ser consideradas por el GDT en este proceso?

\begin{tabular}{|c|c|c|c|c|}
\hline ÍTEMS & & $\mathbf{A L}$ & OI & \\
\hline ( señale con una " $X$ ") & 12 & 3 & & 5 \\
\hline $\begin{array}{l}\text { 13.2 Que el GDT tenga establecidos unos objetivos } \\
\text { generales de gestión medio ambiental integral del } \\
\text { espacio considerado turístico }\end{array}$ & & & & \\
\hline $\begin{array}{l}\text { 13.3 Que existan protocolos de actuación en materia de } \\
\text { protección de los recursos naturales sometidos al } \\
\text { uso intensivo turístico }\end{array}$ & & & & \\
\hline $\begin{array}{l}\text { 13.4 Que existan programas de actuación documentados } \\
\text { en materia de protección y control de los recursos } \\
\text { naturales de alto valor ecológico }\end{array}$ & & & & \\
\hline $\begin{array}{l}\text { 13.5 Que el GDT tenga definidos, implantados y } \\
\text { documentados un conjunto de indicadores específicos } \\
\text { de sostenibilidad medioambiental }\end{array}$ & & & & \\
\hline $\begin{array}{l}\text { 13.6 Que el GDT estimule e incentive la implantación de } \\
\text { programas internacionales de gestión medioambiental } \\
\text { entre los distintos segmentos económicos con } \\
\text { incidencia directa en el producto turístico }\end{array}$ & & & & \\
\hline $\begin{array}{l}\text { 13.7 Que el GDT estimule y favorezca las prácticas correctas } \\
\text { de gestión medioambiental entre la población local }\end{array}$ & & & & \\
\hline $\begin{array}{l}\text { 13.8 Que el GDT fomente la divulgación de prácticas } \\
\text { correctas de respeto medioambiental entre los turistas } \\
\text { y visitantes }\end{array}$ & & & & \\
\hline
\end{tabular}

Muchas gracias por sus aportaciones y por el tiempo tan amablemente dedicado a responder a este cuestionario de expertos 
ANEXO 3 bis 


\section{GÉSTI ÓN COMPETITI VA DE DESTI NOS TURÍ STI COS LOCALES}

\section{Encuesta a Expertos (2 a PARTE)}

Esta encuesta tiene por objeto determinar cuál es, en su opinión, la importancia relativa que tiene cada uno de los ítems relacionados en las preguntas que a continuación se le formulan.

Es importante que su valoración sea lo más objetiva posible, con independencia de la complejidad que supondría llevar a cabo la acción en su ámbito de competencias.

Al final de cada planteamiento se ha dispuesto espacio en blanco por si desea sugerir, ampliar o realizar alguna observación a la cuestión planteada.

El tratamiento de la información se realizará de forma agregada y los datos reflejados en el cuestionario son absolutamente confidenciales

\section{Nombre}

\section{País}




\section{Cuestionario}

ESCALA DE VALORACIÓN

\begin{tabular}{|c|c|c|c|c|}
\hline $\begin{array}{c}\text { Sin } \\
\text { importancia }\end{array}$ & $\begin{array}{c}\text { Poca } \\
\text { importancia }\end{array}$ & Neutro & I mportante & $\begin{array}{c}\text { Muy } \\
\text { I mportante }\end{array}$ \\
1 & 2 & 3 & 4 & 5 \\
\hline
\end{tabular}

14. - La transmisión eficaz al consumidor del conjunto de valores que integran el producto turístico requiere de una estrategia, previamente fijada, que relacione los recursos y capacidades disponibles con el entorno. En relación a la definición de la estrategia, ¿qué nivel de importancia debería tener, en su opinión, cada uno de los siguientes items?

\begin{tabular}{|c|c|c|c|c|c|}
\hline ÍTEMS & & VA & $\mathbf{L C}$ & & \\
\hline ( señale con una "X") & 1 & 2 & 3 & & 5 \\
\hline $\begin{array}{l}\text { 14.1 Que el ente Gestor del Desarrollo Turístico (GDT) } \\
\text { realice un análisis del macro entorno del sector como } \\
\text { máximo cada cinco años }\end{array}$ & & & & & \\
\hline $\begin{array}{l}\text { 14.2 Que el GDT realice un análisis del micro entorno } \\
\text { como máximo cada cinco años }\end{array}$ & & & & & \\
\hline $\begin{array}{l}\text { 14.3 Que el GDT tenga identificados cuáles son los destinos } \\
\text { directamente competidores }\end{array}$ & & & & & \\
\hline $\begin{array}{l}\text { 14.4 Que el GDT conozca las estrategias de posicionamiento } \\
\text { que siguen los destinos directamente competidores }\end{array}$ & & & & & \\
\hline $\begin{array}{l}\text { 14.5 Que el GDT conozca las estrategias de posicionamiento } \\
\text { que siguen los posibles destinos turísticos } \\
\text { complementarios }\end{array}$ & & & & & \\
\hline $\begin{array}{l}\text { 14.6 Que el GDT disponga de un Plan Estratégico/Plan } \\
\text { Director/Plan de Desarrollo que defina la estrategia } \\
\text { de desarrollo }\end{array}$ & & & & & \\
\hline $\begin{array}{l}\text { 14.7 Que el GDT disponga de un Plan Estratégico/Plan } \\
\text { Director/Plan de Desarrollo que defina las estrategias } \\
\text { competitivas }\end{array}$ & & & & & \\
\hline 14.8 Que en la definición de la & & & & & \\
\hline
\end{tabular}


15.- El destino turístico debe llevar a cabo un programa de actuaciones de marketing que concrete las actividades necesarias para lograr un posicionamiento óptimo en sus mercados de referencia, al respecto ¿qué valor alcanzan los siguientes aspectos de comercialización?

\begin{tabular}{|c|c|c|c|c|c|}
\hline Í TEM & & & VA & LC & \\
\hline (seña & iale con una "X") & 1 & 2 & 3 & 45 \\
\hline $15.1 \mathrm{c}$ & $\begin{array}{l}\text { Que el destino turístico disponga de una única } \\
\text { identidad corporativa }\end{array}$ & & & & \\
\hline $\begin{array}{rl}15.2 & c \\
c & p \\
p\end{array}$ & $\begin{array}{l}\text { Que el destino turístico disponga de una identidad } \\
\text { corporativa que responda a la estrategia de } \\
\text { posicionamiento previamente definida }\end{array}$ & & & & \\
\hline $\begin{aligned} 15.3 \mathrm{c} \\
\mathrm{r} \\
\mathrm{c}\end{aligned}$ & $\begin{array}{l}\text { Que la identidad corporativa del destino turístico se } \\
\text { respete en todos los soportes de comunicación del } \\
\text { destino por parte del sector público }\end{array}$ & & & & \\
\hline $\begin{array}{r}15.4 \mathrm{Q} \\
\mathrm{r} \\
\mathrm{u}\end{array}$ & $\begin{array}{l}\text { Que la identidad corporativa del destino turístico se } \\
\text { respete en todos los soportes de comunicación que } \\
\text { utilice el sector privado }\end{array}$ & & & & \\
\hline $\begin{array}{r}15.5 \mathrm{q} \\
\mathrm{p} \\
\mathrm{p}\end{array}$ & $\begin{array}{l}\text { Que todas las acciones de comunicación realizadas } \\
\text { por el GDT respondan a un plan de actuación } \\
\text { previamente diseñado }\end{array}$ & & & & \\
\hline $\begin{array}{r}15.6 \mathrm{C} \\
\mathrm{t} \\
\mathrm{C}\end{array}$ & $\begin{array}{l}\text { Que todos los colectivos implicados en el desarrollo } \\
\text { turístico sean partícipes de las acciones de } \\
\text { comunicación desarrolladas por el GDT }\end{array}$ & & & & \\
\hline $\begin{array}{rr}15.7 & Q \\
& d \\
c & c\end{array}$ & $\begin{array}{l}\text { Que el GDT tenga identificados los canales de } \\
\text { distribución por los que la demanda accede a la } \\
\text { compra del destino }\end{array}$ & & & & \\
\hline $\begin{array}{r}15.8 \underset{\mathrm{P}}{\mathrm{Q}} \\
\mathrm{P}\end{array}$ & $\begin{array}{l}\text { Que el GDT realice siempre acciones de evaluación } \\
\text { post- acción para determinar el nivel de eficiencia de } \\
\text { las mismas }\end{array}$ & & & & \\
\hline
\end{tabular}

Muchas gracias por sus aportaciones

$\square \quad$ Deseo recibir los resultados del estudio

Correo electrónico: 
ANEXO 4 



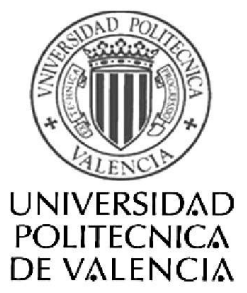

\section{MODELO DE AUDITORÍA PARA LA GESTIÓN COMPETITIVA DE UN DESTINO TURÍSTICO DE INTERIOR}

Este modelo de auditoría es el resultado final de un estudio de investigación que tiene como principal objetivo llegar a definir instrumentos de gestión para la mejora de la competitividad en los destinos turísticos de interior en su fase inicial de madurez del producto.

Una vez cumplimentada la autoevaluación de auditoría se podría llegar a determinar cuáles son las principales fortalezas y debilidades de gestión que presenta el destino turístico analizado, permitiendo a sus gestores la definición de políticas correctoras más adecuadas.

\section{DEFINICIONES PREVIAS:}

1 DESTINO TURÍSTICO (DT) :

"Espacio físico donde el turista pernocta al menos una noche. Se compone de diferentes productos turísticos que requieren de la existencia de una estructura de soporte, de atractivos y de recursos. Los destinos se delimitan a través de límites administrativos los cuales ayudan a la gestión del mismo, siendo su imagen y posicionamiento factores clave para alcanzar la competitividad" (OMT, 2002).

2 ENTE GESTOR DEL DESTINO TURÍSTICO (GDT):

Organismo, dotado de personalidad jurídica propia, integrado por representantes de los actores principales de la comunidad local implicados en el desarrollo turístico, cuya única misión es la gestión de la planificación, la ejecución y el control de la política turística del Destino.

NOTA: En la actualidad la mayoría de DT locales canalizan esta actividad a través de los Patronatos de Turismo, Consejos de Turismo o similares. 
Dimensión 1: eficiencia

El objetivo estratégico de esta dimensión es conocer si el desarrollo turístico está siendo un instrumento eficiente para el logro del bienestar y la mejora de la calidad de vida de la comunidad local.

Factor clave 1.1- Órgano de gestión (GDT)

El objetivo final de este factor clave es analizar la existencia y funcionamiento de un órgano especializado e independiente que gestione de forma coordinada el desarrollo competitivo del destino turístico.

Variable 1.1.1- Organización y estructura

El objetivo operativo de esta variable será evaluar si el destino turístico dispone de la estructura y organización idónea para gestionar eficientemente el logro de la competitividad.

Por favor, elija una de las siguientes opciones:

1- En el órgano actual de gestión del DT están proporcionalmente representados los distintos colectivos empresariales, sociales, culturales, medio ambientales y políticos que tienen incidencia directa en el producto turístico local

\begin{tabular}{|c|l|c|c|c|}
\hline a & $\begin{array}{l}\text { Existe un órgano de gestión del destino } \\
\text { turístico (GDT) }\end{array}$ & si & No & No sabe \\
\hline b & $\begin{array}{l}\text { La constitución de este órgano está } \\
\text { formalmente documentada }\end{array}$ & si & No & No sabe \\
\hline c & $\begin{array}{l}\text { En el GDT están representados todos los } \\
\text { colectivos del sector privado con incidencia } \\
\text { directa en el producto turístico local }\end{array}$ & si & No & No sabe \\
\hline d & $\begin{array}{l}\text { En el GDT están representados todos los } \\
\text { colectivos del sector público con incidencia } \\
\text { directa en el producto turístico local }\end{array}$ & si & No & No sabe \\
\hline
\end{tabular}



e Esta representación es proporcional/paritaria en relación a su importancia dentro del conjunto de producto turístico local

\begin{tabular}{|c|c|c|}
\hline Si & No & No sabe \\
& & \\
\hline
\end{tabular}

2-El GDT tiene una misión definida que se revisa, al menos, cada cinco años.

\begin{tabular}{|c|c|c|c|c|}
\hline a & El GDT tiene definida una misión corporativa & $\mathrm{Si}$ & No & No sabe \\
\hline $\mathrm{b}$ & $\begin{array}{l}\text { Esta misión corporativa es conocida por todos } \\
\text { los miembros del GDT }\end{array}$ & $\mathrm{Si}$ & No & No sabe \\
\hline C & $\begin{array}{l}\text { La misión se utiliza en todos los documentos } \\
\text { de comunicación interna del GDT }\end{array}$ & $\mathrm{Si}$ & No & No sabe \\
\hline $\mathrm{d}$ & $\begin{array}{l}\text { Aparece en los documentos de difusión } \\
\text { externa }\end{array}$ & $\mathrm{Si}$ & No & No sabe \\
\hline e & $\begin{array}{l}\text { Existe un sistema definido y documentado } \\
\text { de revisión sistemática de la misión }\end{array}$ & Si & No & No sabe \\
\hline \multicolumn{5}{|c|}{$\begin{array}{l}\text { 3-El proceso de selección y nombramiento de la dirección del } \\
\text { GDT debe haber respondido a criterios de objetividad y } \\
\text { transparencia }\end{array}$} \\
\hline a & $\begin{array}{l}\text { El GDT tiene definida formalmente la función } \\
\text { de dirección/gerencia }\end{array}$ & $\mathrm{Si}$ & No & No sabe \\
\hline $\mathrm{b}$ & $\begin{array}{l}\text { La dirección del GDT es desempeñada } \\
\text { profesionalmente por un gerente }\end{array}$ & Si & No & No sabe \\
\hline C & $\begin{array}{l}\text { El proceso de selección de candidatos se } \\
\text { realiza conforme a criterios de idoneidad, } \\
\text { objetividad y transparencia }\end{array}$ & $\mathrm{Si}$ & No & No sabe \\
\hline $\mathrm{d}$ & $\begin{array}{l}\text { La convocatoria de candidatos a la dirección } \\
\text { del GDT se realiza por procedimientos } \\
\text { públicos conocidos y documentados }\end{array}$ & $\mathrm{Si}$ & No & No sabe \\
\hline e & $\begin{array}{l}\text { En el proceso de selección del candidato } \\
\text { participan los representantes de los colectivos } \\
\text { del sector público y privado del Destino } \\
\text { Turístico (DT) /los colectivos representados } \\
\text { en el GDT }\end{array}$ & $\mathrm{Si}$ & No & No sabe \\
\hline
\end{tabular}


Variable 1.1.2- Programas de actuación

El objetivo operativo de esta variable es evaluar si el GDT dispone de un programa de trabajo que sea acorde con los objetivos propios de un desarrollo turístico competitivo y sostenible.

1-Las actuaciones del GDT responden a una planificación estratégica concertada entre los distintos agentes del destino turístico

\begin{tabular}{|c|c|c|c|c|}
\hline & $\begin{array}{l}\text { Existe un plan estratégico formalmente } \\
\text { documentado }\end{array}$ & Si & No & No sabe \\
\hline $\mathrm{b}$ & $\begin{array}{l}\text { La elaboración del plan estratégico responde } \\
\text { a un adecuado proceso metodológico }\end{array}$ & Si & No & No sabe \\
\hline c & $\begin{array}{l}\text { En la elaboración/revisión del plan estratégico } \\
\text { han participado los distintos agentes } \\
\text { empresariales y sociales del DT/ órganos } \\
\text { representados en el GDT }\end{array}$ & \begin{tabular}{|l} 
\\
\end{tabular} & $\square$ & No sabe \\
\hline $\mathrm{d}$ & $\begin{array}{l}\text { El DT/GDT tiene definido y documentado } \\
\text { un programa anual de actuaciones } \\
\text { coherente con el plan estratégico }\end{array}$ & $\mathrm{Si}$ & No & No sabe \\
\hline 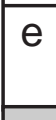 & $\begin{array}{l}\text { El programa de actuación recoge } \\
\text { documentalmente los objetivos instrumentales }\end{array}$ & $\mathrm{Si}$ & No & No sabe \\
\hline \multicolumn{5}{|c|}{$\begin{array}{l}\text { 2-EI GDT tiene definido un presupuesto anual, propio e } \\
\text { independiente de las entidades u organizaciones que lo forman, } \\
\text { para las actuaciones en materia de desarrollo turístico }\end{array}$} \\
\hline a & $\begin{array}{l}\text { Existe una política presupuestaria específica } \\
\text { para el GDT independiente de los colectivos } \\
\text { que lo integran }\end{array}$ & $\square$ & No & No sabe \\
\hline $\mathrm{b}$ & $\begin{array}{l}\text { Esta política se encuentra formalmente } \\
\text { establecida }\end{array}$ & Si & No & \\
\hline$C$ & Esta política está documentada & Si & No & No sabe \\
\hline d & $\begin{array}{l}\text { El presupuesto anual disponible es conocido } \\
\text { por todos los miembros del GDT }\end{array}$ & $\mathrm{Si}$ & No & No sabe \\
\hline e & $\begin{array}{l}\text { El presupuesto anual es exclusivo para las } \\
\text { actuaciones en materia de desarrollo turístico }\end{array}$ & $\mathrm{Si}$ & No & No sabe \\
\hline
\end{tabular}


3- El GDT dispone de mecanismos adecuados para evaluar la eficiencia y eficacia de los resultados de las acciones realizadas

\begin{tabular}{|l|l|c|c|c|}
\hline a & $\begin{array}{l}\text { El GDT tiene definidos los mecanismos de } \\
\text { control del cumplimiento de los objetivos } \\
\text { establecidos }\end{array}$ & Ni & No sabe & \\
\hline b & $\begin{array}{l}\text { El GDT tiene definidos los mecanismo de } \\
\text { evaluación de los resultados alcanzados }\end{array}$ & Si & No & No sabe \\
\hline c & $\begin{array}{l}\text { Los mecanismos de control y evaluación } \\
\text { está implantados en la organización del GDT }\end{array}$ & Si & No & No sabe \\
\hline d & $\begin{array}{l}\text { Los resultados de las acciones realizadas } \\
\text { son conocidos por los miembros del GDT }\end{array}$ & Si & No & No sabe \\
\hline e & $\begin{array}{l}\text { La comunidad local es conocedora de los } \\
\text { resultados de las acciones de relevancia } \\
\text { pública realizadas }\end{array}$ & No & No sabe \\
\hline
\end{tabular}

Factor clave 1.2- Desarrollo de la industria turística local

El objetivo final de este factor clave será analizar si se está apoyando el desarrollo de la industria turística asentada en el espacio territorial y las industrias afines y conexas, que participan en la cadena de valor del proceso turístico en el DT.

Variable 1.2.1- Vertebración de la industria turística local

El objetivo operativo de este procedimiento será evaluar el nivel de estructuración y representatividad de la industria turística local 
1-EI DT tiene claramente identificados a los distintos colectivos profesionales e industriales proveedores del proceso productivo turístico

\begin{tabular}{|c|c|c|c|c|}
\hline a & $\begin{array}{l}\text { EI GDT dispone de un registro documental } \\
\text { de los distintos colectivos profesionales y } \\
\text { empresariales que intervienen, directamente } \\
\text { o indirectamente en el proceso productivo } \\
\text { turístico }\end{array}$ & $\mathrm{Si}$ & 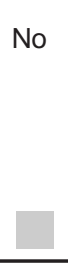 & No sabe \\
\hline$b$ & $\begin{array}{l}\text { El GDT dispone de un registro documental } \\
\text { de los distintos organismos públicos con } \\
\text { competencia directa en el proceso productivo } \\
\text { turístico }\end{array}$ & $\mathrm{Si}$ & No & No sabe \\
\hline$C$ & $\begin{array}{l}\text { Existe un registro documental de los distintos } \\
\text { colectivos sociales que intervienen en el DT }\end{array}$ & $\mathrm{Si}$ & No & No sabe \\
\hline$d$ & $\begin{array}{l}\text { El DT dispone de información suficiente y } \\
\text { relevante sobre la composición y miembros } \\
\text { de los colectivos profesionales y empresariales }\end{array}$ & $\mathrm{Si}$ & No & No sabe \\
\hline e & $\begin{array}{l}\text { El DT dispone de información suficiente, } \\
\text { relevante y pública sobre la composición y } \\
\text { miembros de los colectivos sociales }\end{array}$ & $\mathrm{Si}$ & No & No sabe \\
\hline \multicolumn{5}{|c|}{$\begin{array}{l}\text { 2-Las asociaciones y colectivos profesionales, integrados en } \\
\text { el GDT: }\end{array}$} \\
\hline a & $\begin{array}{l}\text { Tienen personalidad jurídica legalmente } \\
\text { reconocida }\end{array}$ & $\mathrm{Si}$ & No & No sabe \\
\hline$b$ & $\begin{array}{l}\text { Disponen de estatutos propios y órganos de } \\
\text { representación y funcionamiento legalmente } \\
\text { constituidos }\end{array}$ & $\mathrm{Si}$ & No & No sabe \\
\hline C & $\begin{array}{l}\text { Disponen de registro documental de los } \\
\text { miembros que lo integran }\end{array}$ & $\mathrm{Si}$ & No & No sabe \\
\hline d & $\begin{array}{l}\text { Disponen de un programa de actuación y de } \\
\text { presupuesto económico propio }\end{array}$ & $\mathrm{Si}$ & No & No sabe \\
\hline$e$ & $\begin{array}{l}\text { Los representantes de las organizaciones que } \\
\text { forman parte del GDT han sido elegidos } \\
\text { mediante criterios objetivos. }\end{array}$ & $\mathrm{Si}$ & No & No sabe \\
\hline
\end{tabular}


Variable 1.2.2- Desarrollo de la industria turística local

El objetivo operativo de esta variable es evaluar si por parte del destino turístico y/o del GDT se llevan a cabo las acciones de apoyo y estímulo necesarias para el desarrollo de la industria turística local.

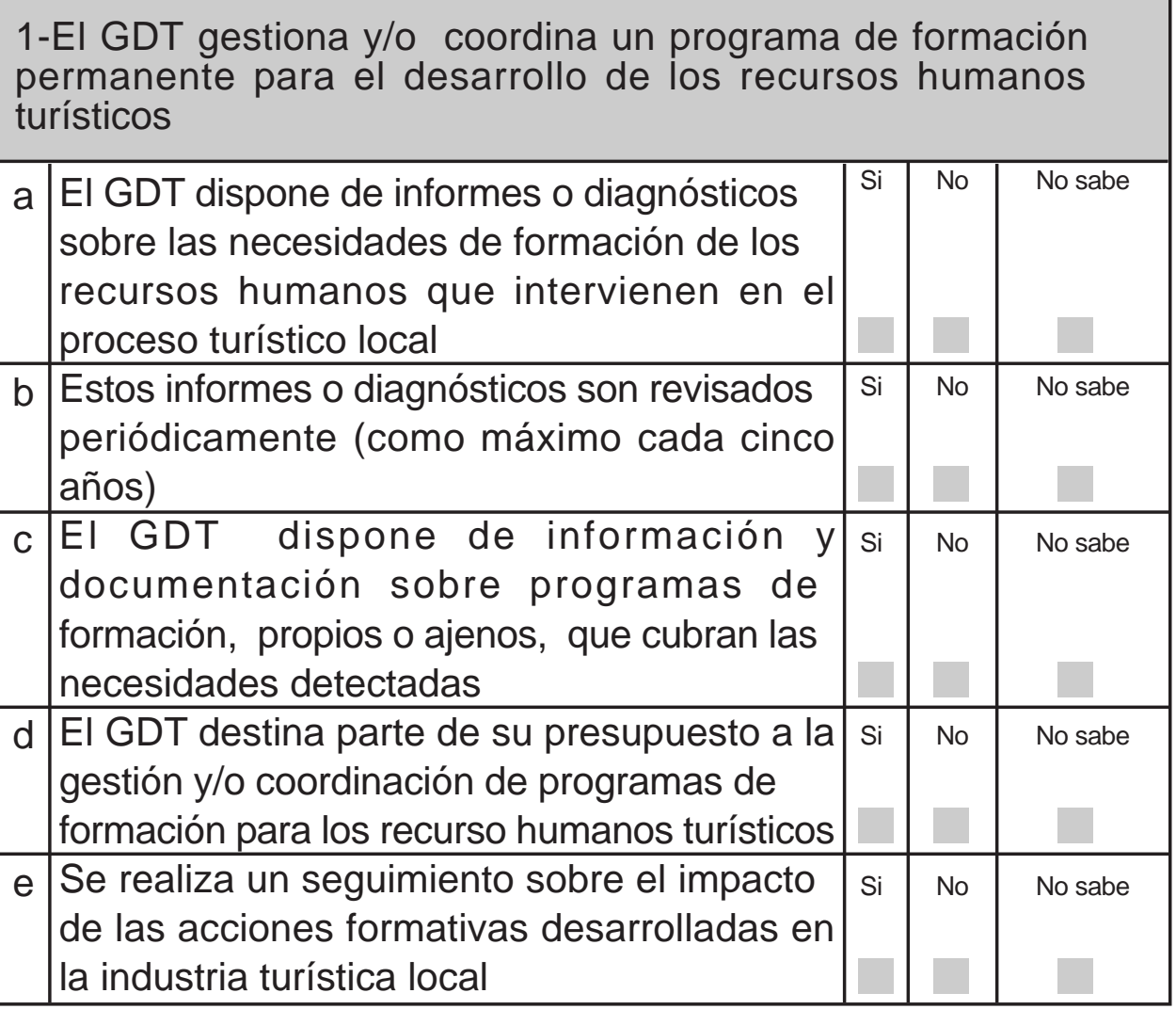


2- EI GDT realiza acciones de estimulación/incentivos para la implantación de empresas de importancia estratégica para el desarrollo turístico

\begin{tabular}{|l|l|l|l|l|}
\hline a & $\begin{array}{l}\text { El GDT tiene definidas las necesidades } \\
\text { (empresas/ productos) estratégicas para la } \\
\text { mejora de la competitividad del DT }\end{array}$ & & No & No sabe \\
\hline b & $\begin{array}{l}\text { El GDT desarrolla acciones de comunicación } \\
\text { con objeto de incentivar la incorporación de } \\
\text { empresas y/o profesionales al DT que } \\
\text { respondan a estas necesidades }\end{array}$ & No & No sabe \\
\hline c & $\begin{array}{l}\text { El GDT tiene establecido convenios de } \\
\text { colaboración con instituciones y } \\
\text { organizaciones de importancia estratégica } \\
\text { para el desarrollo turístico del DT }\end{array}$ & No & No sabe \\
\hline d & $\begin{array}{l}\text { El GDT dispone de recursos destinados a } \\
\text { facilitar la implantación de industrias turísticas } \\
\text { o conexas en el territorio }\end{array}$ & No & No sabe \\
\hline e & $\begin{array}{l}\text { El GDT participa activamente en programas } \\
\text { promovidos por otras instituciones y entidades } \\
\text { que puedan repercutir en la mejora de las } \\
\text { condiciones competitivas del DT }\end{array}$ & No & No sabe \\
\hline
\end{tabular}


3- El GDT conoce los índices anuales de inversión pública y privada en el territorio, directamente relacionados con la industria turística.

\begin{tabular}{|l|l|l|l|l|}
\hline a & $\begin{array}{l}\text { El GDT dispone de información sobre los } \\
\text { planes de inversión pública en el territorio } \\
\text { y su finalidad }\end{array}$ & No & No sabe \\
\hline b & $\begin{array}{l}\text { El GDT dispone de información anual sobre } \\
\text { los presupuestos públicos destinados al } \\
\text { desarrollo turístico local }\end{array}$ & Si & No & No sabe \\
\hline c & $\begin{array}{l}\text { El GDT dispone de información sobre los } \\
\text { índices de ejecución de presupuestos } \\
\text { públicos de años anteriores de las } \\
\text { actuaciones en materia turística }\end{array}$ & No & No sabe \\
\hline d & $\begin{array}{l}\text { El GDT tiene establecidos mecanismos para } \\
\text { conocer el índice de inversión privada anual } \\
\text { en el territorio en turismo }\end{array}$ & Si & No & No sabe \\
\hline e & $\begin{array}{l}\text { El GDT dispone de información sobre el } \\
\text { volumen de inversión anual que realizan } \\
\text { cada uno de los sectores implicados en el } \\
\text { proceso de desarrollo turístico local }\end{array}$ & No & No sabe & \\
\hline
\end{tabular}


Factor clave 1.3- Nivel de bienestar de la comunidad local

El objetivo final de este factor clave será analizar el nivel de satisfacción de la comunidad local respecto del desarrollo turístico, dado el carácter instrumental que este último ha de tener para el logro de la calidad de vida y nivel de bienestar óptimo de aquella.

Variable 1.3.1- Nivel de desarrollo económico.

El objetivo operativo de esta variable será evaluar si el DT/ GDT dispone de la información adecuada que permita conocer y gestionar adecuadamente los impactos económicos positivos y negativos como consecuencia del desarrollo de la actividad turística.

\begin{tabular}{|c|c|c|c|c|}
\hline & $\begin{array}{l}\text { EI GDT conoce y tiene anualmente document } \\
\text { la evolución de empleos turísticos directos y no } \\
\text { estino turístico y el porcentaje que representa } \\
\text { resto de empleos }\end{array}$ & & & \\
\hline $\mathrm{a}$ & \begin{tabular}{|l|} 
EI GDT dispone de información sobre el total \\
de empleo directo generado por la industria \\
en el destino turístico
\end{tabular} & $\mathrm{Si}$ & No & No sabe \\
\hline$b$ & $\begin{array}{l}\text { El GDT tiene documentado el número y la } \\
\text { evolución de los empleos turísticos directos } \\
\text { del destino turístico }\end{array}$ & $\mathrm{Si}$ & No & No sabe \\
\hline $\bar{c}$ & $\begin{array}{l}\text { EI GDT actualiza anualmente esta } \\
\text { información }\end{array}$ & $\overline{S i}$ & No & No sabe \\
\hline$d$ & \begin{tabular}{|l|} 
El GDT dispone de información sobre el total \\
de empleos (directos + indirectos) actuales \\
y los generados anualmente en el DT
\end{tabular} & $\overline{S i}$ & No & No sabe \\
\hline $\bar{e}$ & $\begin{array}{l}\text { EI GDT dispone de indicadores relevantes } \\
\text { sobre la cantidad y calidad del empleo turístico } \\
\text { en el territorio }\end{array}$ & $\mathrm{Si}$ & No & No sabe \\
\hline
\end{tabular}


2- El GDT conoce y tiene documentado el nivel de gasto turístico en el destino turístico

\begin{tabular}{|l|l|l|l|c|}
\hline a & $\begin{array}{l}\text { Existen indicadores del número de turistas } \\
\text { y visitantes recibidos en el destino, su } \\
\text { composición y su evolución }\end{array}$ & No & No sabe \\
\hline b & $\begin{array}{l}\text { El GDT dispone de información contrastada } \\
\text { sobre la estancia media de los turistas }\end{array}$ & Si & No & No sabe \\
\hline c & $\begin{array}{l}\text { El GDT dispone de información sobre el índice } \\
\text { de utilización de los servicios turísticos por los } \\
\text { turistas y visitantes }\end{array}$ & No & No sabe \\
\hline d & $\begin{array}{l}\text { El GDT dispone de información sobre el nivel } \\
\text { medio de precios de lo servicios turísticos en } \\
\text { el destino por categorías }\end{array}$ & No & No sabe \\
\hline e & $\begin{array}{l}\text { El GDT dispone de información documental } \\
\text { sobre el porcentaje mensual de ocupación } \\
\text { de la industria de hospedaje en el DT. }\end{array}$ & Ni & No & No sabe \\
\hline
\end{tabular}


3- EI GDT tiene definidos, implantados y documentados un conjunto de indicadores de relevancia económica que incluirán, como mínimo, los del apartado anterior

\begin{tabular}{|l|l|c|c|c|}
\hline a & $\begin{array}{l}\text { El GDT tiene seleccionados cuáles son los } \\
\text { indicadores económicos de mayor relevancia } \\
\text { para la actividad turística del DT }\end{array}$ & No & No sabe \\
\hline b & $\begin{array}{l}\text { El GDT tiene definido y documentado el } \\
\text { sistema de obtención de información para } \\
\text { el establecimiento de los indicadores } \\
\text { económicos }\end{array}$ & No & No sabe \\
\hline c & $\begin{array}{l}\text { El GDT tiene implantados y documentados } \\
\text { este conjunto de indicadores }\end{array}$ & Si & No & No sabe \\
\hline d & $\begin{array}{l}\text { El GDT tiene definido y documentado el } \\
\text { sistema de revisión de indicadores de } \\
\text { relevancia económica para el DT }\end{array}$ & Si & No & No sabe \\
\hline e & $\begin{array}{l}\text { El GDT elabora informes periódicos sobre los } \\
\text { datos más relevantes de la evolución de estos } \\
\text { indicadores }\end{array}$ & Si & No & No sabe \\
\hline
\end{tabular}


Variable 1.3.2- Desarrollo sociocultural

El objetivo operativo de esta variable será evaluar si el DT/ GDT dispone de la información necesaria que le permita conocer y gestionar adecuadamente los impactos socioculturales positivos y negativos como consecuencia del desarrollo de la actividad turística.

1- EI GDT conoce y tiene documentados los principales parámetros sociales de su territorio (población, edad, porcentaje de emigración/inmigración, escolaridad,...)

\begin{tabular}{|c|l|c|c|c|}
\hline a & $\begin{array}{l}\text { El GDT tiene seleccionados cuáles son los } \\
\text { principales parámetros sociales de su territorio }\end{array}$ & Si & No & No sabe \\
\hline b & $\begin{array}{l}\text { El GDT tiene documentados estos } \\
\text { parámetros }\end{array}$ & Si & No & No sabe \\
\hline c & $\begin{array}{l}\text { El GDT tiene definido e implantado un } \\
\text { sistema de captación de la información sobre } \\
\text { estos parámetros }\end{array}$ & si & No & No sabe \\
\hline d & $\begin{array}{l}\text { El GDT actualiza anualmente esta } \\
\text { información }\end{array}$ & Si & No & No sabe \\
\hline e & $\begin{array}{l}\text { El GDT actualiza temporalmente (indefinido) } \\
\text { esta información }\end{array}$ & si & No & No sabe \\
\hline
\end{tabular}


2- EI GDT fomenta la participación de la población local directamente o a través de los sectores económicos y culturales más representativos, en el diseño de programas específicos y en la implantación de acciones de relevancia turística.

\begin{tabular}{|l|l|l|l|l|}
\hline a & $\begin{array}{l}\text { El GDT dispone de información relevante sobre } \\
\text { el grado de sensibilización turística de la } \\
\text { población local }\end{array}$ & No & No sabe \\
\hline b & $\begin{array}{l}\text { El GDT comunica regularmente a la población } \\
\text { local, a través de los medios de comunicación, } \\
\text { las actuaciones de relevancia turística que se } \\
\text { van a realizar }\end{array}$ & No & No sabe \\
\hline c & $\begin{array}{l}\text { El GDT comunica a los sectores económicos } \\
\text { y sociales más representativos los planes y } \\
\text { actuaciones que se van a realizar en materia } \\
\text { turística }\end{array}$ & No & No sabe \\
\hline d & $\begin{array}{l}\text { El GDT fomenta la participación activa de los } \\
\text { sectores sociales más representativos en el } \\
\text { diseño de programas específicos en materia } \\
\text { turística }\end{array}$ & No & & No sabe \\
\hline e & $\begin{array}{l}\text { El GDT fomenta la participación activa de los } \\
\text { sectores sociales más representativos en el } \\
\text { diseño e implantación de programas y } \\
\text { acciones en materia turística }\end{array}$ & No & No sabe \\
\hline
\end{tabular}


Variable 1.3.3- Desarrollo medioambiental

El objetivo operativo de esta variable será evaluar si el DT/ GDT dispone de la información adecuada que permita conocer y gestionar adecuadamente los impactos medioambientales positivos y negativos como consecuencia de la actividad turística.

1- Existen protocolos de actuación en materia de protección de los recursos naturales sometidos al uso intensivo turístico

\begin{tabular}{|l|l|c|c|c|}
\hline a & $\begin{array}{l}\text { El GDT tiene definidos y documentados } \\
\text { cuáles son y dónde se sitúan los principales } \\
\text { recursos naturales territoriales sometidos a } \\
\text { uso turístico }\end{array}$ & Si & No & No sabe \\
\hline b & $\begin{array}{l}\text { El GDT tiene establecidos mecanismos de } \\
\text { control de información de relevancia } \\
\text { medioambiental de estos recursos naturales }\end{array}$ & Si & No & No sabe \\
\hline c & $\begin{array}{l}\text { El GDT dispone de indicadores de impacto de } \\
\text { la actividad turística en los recursos naturales } \\
\text { que forman parte del producto }\end{array}$ & No & No sabe \\
\hline d & $\begin{array}{l}\text { El GDT dispone de protocolos de actuación } \\
\text { en materia de protección de los recursos } \\
\text { naturales sometidos al uso turístico }\end{array}$ & Si & No & No sabe \\
\hline e & $\begin{array}{l}\text { El GDT dispone de protocolos de actuación } \\
\text { para supuestos de contingencias por el uso } \\
\text { turístico de dichos recursos }\end{array}$ & No & No sabe \\
\hline
\end{tabular}


2- El GDT estimula y favorece las prácticas correctas de gestión medioambiental entre la población local

\begin{tabular}{|l|l|l|l|l|}
\hline a & $\begin{array}{l}\text { El GDT colabora regularmente con los } \\
\text { organismos públicos con competencias en } \\
\text { materia de gestión medioambiental }\end{array}$ & Si & No & No sabe \\
\hline b & $\begin{array}{l}\text { EI GDT participa activamente en la } \\
\text { definición de prácticas correctas de gestión } \\
\text { medioambiental de aplicación en su territorio }\end{array}$ & Si & No & No sabe \\
\hline c & $\begin{array}{l}\text { El GDT participa activamente en el } \\
\text { seguimiento y control de la gestión } \\
\text { medioambiental de los recursos turísticos } \\
\text { naturales }\end{array}$ & No & No sabe \\
\hline d & $\begin{array}{l}\text { El GDT colabora en la difusión entre la } \\
\text { población local y los turistas de información } \\
\text { sobre prácticas de respeto medioambiental }\end{array}$ & Si & No & No sabe \\
\hline e & $\begin{array}{l}\text { El GDT incentiva la práctica de actuaciones } \\
\text { medioambientales correctas entre la población } \\
\text { residentes y los turistas }\end{array}$ & Si & No & No sabe \\
\hline
\end{tabular}




\section{Dimensión 2: calidad}

El objetivo estratégico de esta dimensión es conocer si el producto ofrecido responde adecuadamente a las necesidades y expectativas del turista actual y a las previsibles de la demanda potencial.

Factor clave 2.1- Calidad de diseño

El objetivo final de este factor clave será analizar si el DT/ GDT lleva a cabo las acciones adecuadas para conocer de forma continuada y sistemática las necesidades y expectativas de su demanda real y poder efectuar así las especificaciones precisas para la creación del producto.

Variable 2.1.1- Investigación de mercados

El objetivo operativo de esta variable es evaluar si el DT/ GDT lleva a cabo las acciones necesarias para disponer de la información necesaria para conocer el nivel de expectativas y necesidades de su demanda real y potencial. 
1- El DT/ GDT dispone de una persona o grupo de personas responsables de la gestión y seguimiento de las tareas de investigación de mercados

\begin{tabular}{|l|l|l|l|l|}
\hline a & $\begin{array}{l}\text { El GDT tiene definida, entre sus competencias, } \\
\text { la función de investigación de mercados }\end{array}$ & Si & No & No sabe \\
\hline b & $\begin{array}{l}\text { El GDT tiene a acceso a la información sobre } \\
\text { investigación de mercados de otras } \\
\text { instituciones y organismos públicos }\end{array}$ & si & No & No sabe \\
\hline c & $\begin{array}{l}\text { El GDT tiene formalmente asignada a una } \\
\text { persona/ institución la responsabilidad de la } \\
\text { gestión de la investigación, tanto la } \\
\text { desarrollada por medios propios como la } \\
\text { realizada externamente }\end{array}$ & No & No sabe \\
\hline d & $\begin{array}{l}\text { El GDT dispone de un presupuesto específico } \\
\text { para la realización/ gestión de las actividades } \\
\text { de investigación de mercados }\end{array}$ & Si & No & No sabe \\
\hline e & $\begin{array}{l}\text { Estas actuaciones se encuentran recogidas } \\
\text { dentro de el plan de actuaciones } \\
\text { correspondiente }\end{array}$ & Si & No & No sabe \\
\hline
\end{tabular}

2- Las actividades de investigación se realizan, como mínimo, cada cinco años

\begin{tabular}{|l|l|c|c|c|}
\hline a & $\begin{array}{l}\text { Existe un sistema documentado de obtención } \\
\text { de la información (proceso metodológico) }\end{array}$ & Si & No & No sabe \\
\hline b & $\begin{array}{l}\text { Este proceso sigue criterios científicos en su } \\
\text { aplicación (metodología correcta) }\end{array}$ & Si & No sabe \\
\hline c & $\begin{array}{l}\text { La actividad de investigación de mercados } \\
\text { se realiza con una periodicidad inferior a cinco } \\
\text { años }\end{array}$ & Si & No & No sabe \\
\hline d & $\begin{array}{l}\text { El proceso metodológico de investigación } \\
\text { se revisa y actualiza como mínimo cada cinco } \\
\text { años }\end{array}$ & Si & No & No sabe \\
\hline e & $\begin{array}{l}\text { Los resultados de los estudios de mercado } \\
\text { están vinculados a la elaboración/modificación } \\
\text { de los planes de desarrollo que elabora el } \\
\text { GDT }\end{array}$ & Si & No & No sabe \\
\hline
\end{tabular}


3- Se lleva a cabo la difusión de los resultados entre los diversos organismos públicos y privados con interés en la industria turística

\begin{tabular}{|l|l|l|l|l|}
\hline a & $\begin{array}{l}\text { El GDT dispone de información relevante } \\
\text { para la toma de decisiones estratégicas de } \\
\text { marketing turístico }\end{array}$ & No & No sabe \\
\hline b & $\begin{array}{l}\text { El GDT elabora informes periódicos sobre los } \\
\text { aspectos más relevantes de los mercados } \\
\text { turísticos }\end{array}$ & No & No sabe \\
\hline c & $\begin{array}{l}\text { El GDT facilita el acceso a la información } \\
\text { obtenida a aquellos organismos públicos } \\
\text { que puedan estar interesados en su } \\
\text { conocimiento }\end{array}$ & No & No sabe \\
\hline d & $\begin{array}{l}\text { El GDT facilita el acceso a la información } \\
\text { obtenida a aquellas organizaciones privadas } \\
\text { que puedan estar interesados en su } \\
\text { conocimiento }\end{array}$ & No & No sabe \\
\hline e & $\begin{array}{l}\text { El GDT difunde regularmente los resultados } \\
\text { de las investigaciones realizadas en materia } \\
\text { de investigación de mercados entre los } \\
\text { diversos colectivos económicos y sociales } \\
\text { de la localidad }\end{array}$ & No & No sabe \\
\hline
\end{tabular}


Variable 2.1.2- Definición del producto.

El objetivo operativo de esta variable es evaluar si el DT/ GDT lleva a cabo todas las acciones necesarias para garantizar que la definición del producto responde fielmente a las especificaciones del producto previamente definidas.

1- EI GDT tiene bien identificados los distintos productos que se ofrecen en el destino turístico así como los valores y atributos que los caracterizan

\begin{tabular}{|l|l|l|l|c|}
\hline a & $\begin{array}{l}\text { Todos los miembros de el GDT conocen los } \\
\text { productos y servicios integrantes del producto } \\
\text { turístico ofertado por el DT }\end{array}$ & No & No sabe \\
\hline b & $\begin{array}{l}\text { El GDT tiene documentado y actualizado el } \\
\text { catálogo de productos turísticos privados } \\
\text { ofertados en el DT }\end{array}$ & No & No sabe \\
\hline c & $\begin{array}{l}\text { El GDT tiene documentado y actualizado el } \\
\text { catálogo de productos y servicios turísticos } \\
\text { públicos ofertados en el DT }\end{array}$ & Si & No & No sabe \\
\hline d & $\begin{array}{l}\text { El GDT conoce y tiene identificados los valores } \\
\text { y atributos diferenciales de sus productos } \\
\text { turísticos }\end{array}$ & si & No & No sabe \\
\hline e & $\begin{array}{l}\text { El GDT conoce y tiene identificados los valores } \\
\text { y atributos diferenciales de sus productos con } \\
\text { respecto a otros destinos turísticos de su } \\
\text { mismo entorno competitivo }\end{array}$ & Si & No & No sabe \\
\hline
\end{tabular}


2- El GDT tiene definidos e identificados los principales procesos que conforman cada uno de los productos- segmentos de mercado ofrecidos en su D.T

\begin{tabular}{|l|l|c|c|c|}
\hline a & $\begin{array}{l}\text { El GDT tiene identificados los principales } \\
\text { procesos que integran el producto turístico } \\
\text { global }\end{array}$ & Si & No & No sabe \\
\hline b & $\begin{array}{l}\text { El GDT tiene documentados los procesos } \\
\text { que integran el producto turístico global }\end{array}$ & Si & No & No sabe \\
\hline c & $\begin{array}{l}\text { El GDT tiene definidas y documentadas las } \\
\text { variables críticas en la entrega de valor del } \\
\text { proceso turístico global del DT }\end{array}$ & Si & No & No sabe \\
\hline d & $\begin{array}{l}\text { El GDT tiene identificados los distintos } \\
\text { procesos que conforman cada uno de los } \\
\text { productos/segmentos de mercado ofrecidos } \\
\text { en el DT }\end{array}$ & Si & No & No sabe \\
\hline e & $\begin{array}{l}\text { El GDT tiene definidas y documentadas las } \\
\text { variables críticas en la entrega de valor de } \\
\text { cada uno de los procesos productivos }\end{array}$ & $\mathrm{Si}$ & No & No sabe \\
\hline
\end{tabular}


3- El GDT lleva a cabo periódicamente acciones de concertación e intercambio de información entre los responsables públicos y privados para la creación de productos en el destino turístico

\begin{tabular}{|l|l|l|l|l|}
\hline a & $\begin{array}{l}\text { Existe un órgano permanente de coordinación } \\
\text { pública de nivel local para la realización de } \\
\text { actividades en materia turística }\end{array}$ & No & No sabe \\
\hline b & $\begin{array}{l}\text { Existen protocolos o programas de } \\
\text { coordinación y cooperación con otros entes } \\
\text { públicos de diferente ámbito competencial } \\
\text { territorial }\end{array}$ & Si & No & No sabe \\
\hline c & $\begin{array}{l}\text { Existen convenios, programas o protocolos } \\
\text { para la coordinación y cooperación entre el } \\
\text { sector público y privado para la creación de } \\
\text { productos turísticos en el DT }\end{array}$ & No & No sabe \\
\hline d & $\begin{array}{l}\text { El GDT desarrolla, como mínimo una vez al } \\
\text { año, sesiones de trabajo específicas para } \\
\text { facilitar el proceso de creación de productos } \\
\text { turísticos en el DT }\end{array}$ & Si & No & No sabe \\
\hline e & $\begin{array}{l}\text { El GDT recoge documentalmente los } \\
\text { principales acuerdos adoptados en materia } \\
\text { de coordinación y cooperación para la creación } \\
\text { de productos turísticos en el DT }\end{array}$ & No & No sabe \\
\hline
\end{tabular}


Factor clave 2.2- Calidad de Conformidad.

El objetivo final de este factor clave es analizar si el GDT lleva a cabo el conjunto de acciones adecuados para garantizar que el producto/s turístico/s ofrecido/s responde/n de forma óptima a las necesidades y expectativas de sus respectivos productos-mercados.

Variable 2.2.1- Calidad de conformidad previa al consumo turístico

El objetivo operativo de esta variable es evaluar si el DT/GDT tiene definido e implantado un sistema de calidad global e integral para todo el destino turístico como producto.

1- El GDT tiene definidos unos objetivos generales de calidad para el destino turístico

\begin{tabular}{|l|l|l|l|c|}
\hline a & $\begin{array}{l}\text { El GDT tiene definidos objetivos de calidad } \\
\text { para los productos y servicios de carácter } \\
\text { público integrados el DT }\end{array}$ & si & No & No sabe \\
\hline b & $\begin{array}{l}\text { El GDT tiene documentados estos objetivos } \\
\text { de calidad para los productos y servicios de } \\
\text { carácter público integrados el DT }\end{array}$ & Si & No & No sabe \\
\hline c & $\begin{array}{l}\text { El GDT tiene asignado responsable/s del } \\
\text { seguimiento y cumplimiento de los objetivos } \\
\text { generales de calidad }\end{array}$ & Si & No & No sabe \\
\hline d & $\begin{array}{l}\text { El GDT evalúa anualmente el grado de } \\
\text { cumplimiento de los objetivos generales de } \\
\text { calidad }\end{array}$ & Si & No & No sabe \\
\hline e & $\begin{array}{l}\text { El GDT establece planes de mejora en función } \\
\text { de los objetivos evaluados }\end{array}$ & Si & No & No sabe \\
\hline
\end{tabular}


2- EI GDT tiene definidos unos estándares de calidad a lograr en los diferentes procesos que integran cada uno de los productos turísticos identificados en el destino turístico

\begin{tabular}{|c|c|c|c|c|}
\hline$b$ & $\begin{array}{l}\text { El GDT tiene definidos los estándares de } \\
\text { calidad a lograr en los diferentes procesos } \\
\text { que integran los productos y servicios turísticos } \\
\text { de titularidad pública }\end{array}$ & $\mathrm{Si}$ & No & No sabe \\
\hline C & $\begin{array}{l}\text { El GDT tiene documentados los estándares } \\
\text { de calidad a lograr en los diferentes procesos } \\
\text { que integran los productos y servicios turísticos } \\
\text { de titularidad pública }\end{array}$ & $\overline{\mathrm{Si}}$ & No & No sabe \\
\hline$d$ & $\begin{array}{l}\text { El GDT tiene asignadas responsabilidades } \\
\text { en el cumplimiento de los estándares de } \\
\text { calidad a lograr en los diferentes procesos } \\
\text { que integran los productos y servicios turísticos } \\
\text { de titularidad pública }\end{array}$ & $\overline{\mathrm{Si}}$ & No & No sabe \\
\hline $\mathrm{e}$ & $\begin{array}{l}\text { El GDT tiene definido, documentado e } \\
\text { implantado un sistema de control del } \\
\text { cumplimiento de los estándares }\end{array}$ & $\mathrm{Si}$ & No & No sabe \\
\hline & $\begin{array}{l}\text { El GDT dispone de al menos un indicador de } \\
\text { calidad para cada uno de los procesos }\end{array}$ & $\mathrm{Si}$ & No & No sabe \\
\hline
\end{tabular}


3- El GDT estimula la implantación de programas de gestión de calidad entre los distintos proveedores internos y externos del proceso productivo del destino turístico

\begin{tabular}{|l|l|l|l|c|}
\hline a & $\begin{array}{l}\text { El GDT dispone de información sobre los } \\
\text { niveles de calidad alcanzados/ grado de } \\
\text { satisfacción de los usuarios con respecto a } \\
\text { los productos y servicios más significativos } \\
\text { del destino turístico }\end{array}$ & No & No sabe \\
\hline b & $\begin{array}{l}\text { El GDT facilita el acceso a la información de } \\
\text { los datos anteriores }\end{array}$ & Si & No & No sabe \\
\hline c & $\begin{array}{l}\text { El GDT realiza acciones de comunicación } \\
\text { sobre sistemas de certificación de calidad } \\
\text { homologados aplicables a los productos y } \\
\text { servicios turísticos del DT }\end{array}$ & No & No sabe \\
\hline d & $\begin{array}{l}\text { El GDT realiza acciones de comunicación } \\
\text { sobre sistemas de certificación de calidad } \\
\text { homologados aplicables a los proveedores } \\
\text { de los productos y servicios turísticos del DT }\end{array}$ & $\mathrm{Si}$ & No & No sabe \\
\hline e & $\begin{array}{l}\text { El GDT promociona en sus acciones de } \\
\text { marketing a las empresas y organizaciones } \\
\text { que han obtenido certificaciones de calidad }\end{array}$ & Si & No & No sabe \\
\hline
\end{tabular}


Variable 2.2.2- Calidad de conformidad posterior al consumo turístico.

El objetivo operativo de esta variable es evaluar si el DT/ GDT lleva a cabo las acciones y programas necesarias para conocer el nivel de satisfacción de los consumidores actuales del producto turístico.

1- el GDT dispone de un sistema continuo de obtención de información sobre el nivel de satisfacción de los consumidores turísticos, respecto de los distintos productos/mercados identificados

\begin{tabular}{|l|l|l|l|c|}
\hline a & $\begin{array}{l}\text { El GDT tiene diseñado y documentado un } \\
\text { sistema de obtención de información sobre el } \\
\text { nivel de satisfacción de los consumidores } \\
\text { turístico respecto a los distintos } \\
\text { productos/mercados identificados }\end{array}$ & No & No sabe \\
\hline b & $\begin{array}{l}\text { El GDT tiene asignada/s persona/s } \\
\text { responsables de la gestión del sistema de } \\
\text { obtención de la información }\end{array}$ & No & No sabe \\
\hline c & $\begin{array}{l}\text { El GDT tiene implantado el sistema de de } \\
\text { obtención de la información }\end{array}$ & si & No & No sabe \\
\hline d & $\begin{array}{l}\text { El GDT evalúa periódicamente la idoneidad } \\
\text { del sistema }\end{array}$ & Si & No & No sabe \\
\hline e & $\begin{array}{l}\text { En los procesos de revisión y mejora del } \\
\text { sistema de obtención de información participan } \\
\text { expertos externos }\end{array}$ & Si & No & No sabe \\
\hline
\end{tabular}


2- El GDT documenta formalmente los indicadores de satisfacción obtenidos

\begin{tabular}{|l|l|l|c|c|}
\hline a & $\begin{array}{l}\text { El GDT dispone de información anual sobre } \\
\text { los índices de satisfacción de los } \\
\text { consumidores turístico respecto a los distintos } \\
\text { productos/mercados identificados }\end{array}$ & & No & No sabe \\
\hline b & El GDT tiene documentada esta información & $\mathrm{Si}$ & No & No sabe \\
\hline c & $\begin{array}{l}\text { El GDT tiene definido un procedimiento de } \\
\text { comunicación de los resultados obtenidos }\end{array}$ & $\mathrm{Si}$ & No & No sabe \\
\hline d & $\begin{array}{l}\text { Se realiza, al menos anualmente, una } \\
\text { presentación formal a los miembros de la } \\
\text { industria del conjunto de indicadores obtenidos }\end{array}$ & $\mathrm{Si}$ & No & No sabe \\
\hline e & $\begin{array}{l}\text { En función de los resultados obtenidos se } \\
\text { planifican los objetivos y acciones a desarrollar }\end{array}$ & $\mathrm{Si}$ & No & No sabe \\
\hline
\end{tabular}


Factor clave 2.3- Innovación

El objetivo final de este factor clave será evaluar si el DT/ GDT lleva a cabo el conjunto de acciones y programas necesarios para estimular la cultura de la innovación, y la gestión de los elementos relacionados en el DT, como factor clave para el logro de una posición competitiva sostenible.

Variable 2.3.1- Innovación en el producto y/o los procesos

El objetivo operativo de esta variable es evaluar si el DT/ GDT lleva a cabo las acciones y programas oportunos para estimular la cultura de la innovación en el destino turístico y en sus organizaciones y empresas.

1- En el D.T existe una efectiva colaboración público - privada para la gestión, mantenimiento y puesta en valor turístico de los recursos naturales, patrimoniales y culturales disponibles

\begin{tabular}{|l|l|c|c|c|}
\hline a & $\begin{array}{l}\text { En el destino turístico se realizan acciones } \\
\text { formativas y de sensibilización tendentes al } \\
\text { fomento de la cooperación público-privada en } \\
\text { materia de innovación turística }\end{array}$ & No & No sabe \\
\hline b & $\begin{array}{l}\text { Existen programas específicos para la puesta } \\
\text { en valor turístico de los recursos naturales }\end{array}$ & si & No & No sabe \\
\hline c & $\begin{array}{l}\text { Existen programas específicos para la puesta } \\
\text { en valor turístico de los recursos patrimoniales } \\
\text { y culturales }\end{array}$ & si & No & No sabe \\
\hline d & $\begin{array}{l}\text { En estos prog ramas se contempla } \\
\text { específicamente el papel a desempeñar tanto } \\
\text { por el sector público como por el privado }\end{array}$ & si & No & No sabe \\
\hline e & $\begin{array}{l}\text { Los resultados de la aplicación de los } \\
\text { programas se evalúan con una periodicidad } \\
\text { anual }\end{array}$ & si & No & No sabe \\
\hline
\end{tabular}


2- El GDT dispone de un programa abierto de incentivos a la innovación turística

\begin{tabular}{|l|l|l|l|l|}
\hline a & $\begin{array}{l}\text { El GDT tiene integrado en su programación } \\
\text { anual una línea propia de estímulo a la } \\
\text { innovación }\end{array}$ & No & No sabe \\
\hline b & $\begin{array}{l}\text { El GDT tiene asignado un responsable para } \\
\text { la búsqueda, coordinación y seguimiento de } \\
\text { planes y programas de incentivos a la } \\
\text { innovación turística }\end{array}$ & No & No sabe \\
\hline c & $\begin{array}{l}\text { El GDT tiene constantemente actualizada la } \\
\text { información relativa a las distintas } \\
\text { convocatorias de subvenciones e incentivos } \\
\text { públicos y privados disponibles en el mercado }\end{array}$ & Ni & No sabe & \\
\hline d & $\begin{array}{l}\text { El GDT facilita a los empresarios, profesionales } \\
\text { y particulares que los integran asesoramiento } \\
\text { sobre las distintas opciones de incentivos } \\
\text { disponibles }\end{array}$ & No & No sabe \\
\hline e & $\begin{array}{l}\text { El GDT facilita a los empresarios, profesionales } \\
\text { y particulares la tramitación de la } \\
\text { documentación necesaria para optar a } \\
\text { programas de incentivos públicos y privados }\end{array}$ & Si & No & No sabe \\
\hline
\end{tabular}


3- El GDT está integrado en una red de gestión de conocimiento aplicado

\begin{tabular}{|l|l|l|l|l|}
\hline a & $\begin{array}{l}\text { El GDT tiene suscritos convenios de } \\
\text { colaboración con organizaciones públicas que } \\
\text { desarrollen actividades de I+D+i }\end{array}$ & No & No sabe \\
\hline b & $\begin{array}{l}\text { El GDT tiene suscritos convenios de } \\
\text { colaboración con organizaciones privadas que } \\
\text { desarrollen actividades de I+D+i }\end{array}$ & No & No sabe \\
\hline c & $\begin{array}{l}\text { El GDT participa activamente en redes } \\
\text { institucionales de formación }\end{array}$ & Si & No & No sabe \\
\hline d & $\begin{array}{l}\text { El GDT participa activamente en redes } \\
\text { institucionales de investigación }\end{array}$ & Si & No & No sabe \\
\hline e & $\begin{array}{l}\text { El GDT facilita información a los miembros de } \\
\text { la industria turística local sobre los avances, } \\
\text { mejoras y tendencias que puedan ser de } \\
\text { utilidad en esta materia }\end{array}$ & No & No sabe \\
\hline
\end{tabular}


Variable 2.3.2- Gestión de la innovación

El objetivo de este variable es evaluar que el DT/ GDT dispone de un sistema de gestión permanente de la innovación como parte integrante de la política de calidad y mejora del producto turístico ofrecido.

1- EI DT dispone de un órgano permanente de gestión y fomento de la mejora continua/innovación

\begin{tabular}{|l|l|c|c|c|}
\hline a & $\begin{array}{l}\text { El DT dispone de un órgano/ comité } \\
\text { permanente para la mejora continua/ } \\
\text { innovación integrado dentro de la estructura } \\
\text { del GDT }\end{array}$ & No & No sabe \\
\hline b & $\begin{array}{l}\text { La estructura y organización de este comité } \\
\text { está formalmente documentada }\end{array}$ & Si & No & No sabe \\
\hline c & $\begin{array}{l}\text { El comité se reúne, como mínimo, } \\
\text { trimestralmente }\end{array}$ & Si & No & No sabe \\
\hline d & $\begin{array}{l}\text { Las actuaciones y acuerdos del comité están } \\
\text { formalmente documentados }\end{array}$ & Si & № & No sabe \\
\hline e & $\begin{array}{l}\text { Las conclusiones y propuestas del comité } \\
\text { son consideradas en el seno del GDT }\end{array}$ & Si & No & No sabe \\
\hline
\end{tabular}


2- Los integrantes de dicho órgano/comité representan a todos los sectores económicos que participan en la producción turística del destino

\begin{tabular}{|l|l|l|l|c|}
\hline a & $\begin{array}{l}\text { En el órgano/ comité de innovación está } \\
\text { representado el sector de hospedaje }\end{array}$ & No & No sabe \\
\hline b & $\begin{array}{l}\text { En el órgano/ comité de innovación está } \\
\text { representado el sector de restauración }\end{array}$ & Si & No & No sabe \\
\hline c & $\begin{array}{l}\text { En el órgano/ comité de innovación está } \\
\text { representado el sector de acogida en destino } \\
\text { (informadores turísticos, guías locales, } \\
\text { agencias receptoras...) }\end{array}$ & No & No sabe \\
\hline d & $\begin{array}{l}\text { En el órgano/ comité de innovación está } \\
\text { representado el sector de actividades conexas } \\
\text { y afines (comercios, ocio, actividades } \\
\text { complementarias....) }\end{array}$ & No & No sabe \\
\hline e & $\begin{array}{l}\text { El órgano/ comité está formado por } \\
\text { profesionales en activo en cada una de las } \\
\text { ramas productivas }\end{array}$ & Si & No & No sabe \\
\hline
\end{tabular}




\section{Dimensión 3: posicionamiento.}

El objetivo estratégico de esta dimensión es conocer si el DT/ GDT lleva a cabo el proceso estratégico adecuado que permita diseñar una imagen de organización, unos valores y unas ofertas, de manera tal que los consumidores comprendan, valoren y se sientan atraídos por lo que propone el DT.

Factor clave 3.1- Estrategias

El objetivo final de este factor clave es analizar si el DT/ DMO ha llevado a cabo un análisis previo adecuado, tanto del entorno como de los recursos y capacidades disponibles para, posteriormente, formalizar una estrategia de posicionamiento adecuada.

Variable 3.1.1- Definición de las estrategias

El objetivo de esta variable es evaluar si el DT/ GDT ha llevado a cabo un proceso adecuado para elegir su estrategia de posicionamiento más idónea.

1- EI DT/ GDT lleva a cabo un análisis del macro entorno turístico con una frecuencia no superior a cinco años

\begin{tabular}{|l|l|l|l|c|}
\hline a & $\begin{array}{l}\text { El DT/GDT dispone de información actualizada } \\
\text { y sistematizada relativa al macro entorno } \\
\text { turístico }\end{array}$ & No & No sabe \\
\hline b & $\begin{array}{l}\text { El DT/GDT tiene documentado un } \\
\text { procedimiento específico tendente a la } \\
\text { obtención de información, análisis y } \\
\text { sistematización de la misma }\end{array}$ & No & No sabe \\
\hline c & $\begin{array}{l}\text { El GDT tiene formalmente asignado un } \\
\text { responsable de este procedimiento }\end{array}$ & No & No sabe \\
\hline d & $\begin{array}{l}\text { El análisis del macro entorno se realiza con } \\
\text { una frecuencia no superior a cinco años }\end{array}$ & Si & No & No sabe \\
\hline e & $\begin{array}{l}\text { El análisis del macro entorno se realiza con } \\
\text { una frecuencia no superior a dos años }\end{array}$ & Si & No & No sabe \\
\hline
\end{tabular}


2- EI DT/ GDT lleva a cabo un análisis del micro entorno turístico con una frecuencia no superior a cinco años

\begin{tabular}{|l|l|c|c|c|}
\hline a & $\begin{array}{l}\text { El DT/GDT dispone de información actualizada } \\
\text { y sistematizada relativa al microentorno } \\
\text { turístico }\end{array}$ & No & No sabe \\
\hline b & $\begin{array}{l}\text { EI DT/GDT tiene documentado un } \\
\text { procedimiento específico tendente a la } \\
\text { obtención de información, análisis y } \\
\text { sistematización de la misma }\end{array}$ & No & No sabe \\
\hline c & $\begin{array}{l}\text { El GDT tiene formalmente asignado un } \\
\text { responsable de este procedimiento }\end{array}$ & Si & No & No sabe \\
\hline d & $\begin{array}{l}\text { El análisis del microentorno se realiza con una } \\
\text { frecuencia no superior a cinco años }\end{array}$ & Si & No & No sabe \\
\hline e & $\begin{array}{l}\text { El análisis del microentorno se realiza con una } \\
\text { frecuencia no superior a dos años }\end{array}$ & Si & No & No sabe \\
\hline
\end{tabular}

3- EI DT/ GDT tiene identificados cuáles son los destinos turísticos directamente competidores

\begin{tabular}{|l|l|c|c|c|}
\hline a & $\begin{array}{l}\text { a) El DT/GDT tiene identificados qué destinos } \\
\text { turísticos regionales y nacionales compiten } \\
\text { en el mismo producto/ mercado }\end{array}$ & No & No sabe \\
\hline b & $\begin{array}{l}\text { El DT/GDT tiene identificados qué destinos } \\
\text { turísticos internacionales compiten en el } \\
\text { mismo producto/mercado }\end{array}$ & si & No & No sabe \\
\hline c & $\begin{array}{l}\text { El DT/GDT tiene identificados los valores y } \\
\text { atributos principales de los destinos } \\
\text { competidores }\end{array}$ & si & No & No sabe \\
\hline d & $\begin{array}{l}\text { El DT/GDT se mantiene informado de las } \\
\text { innovaciones introducidas en los distintos } \\
\text { procesos en los destinos turísticos } \\
\text { directamente competidores }\end{array}$ & No & No sabe \\
\hline e & $\begin{array}{l}\text { El DT/GDT mantiene actualizada una base de } \\
\text { datos con información relevante sobre los } \\
\text { destinos turísticos competidores }\end{array}$ & si & No & No sabe \\
\hline
\end{tabular}


Factor clave 3.2- Marketing

El objetivo final es analizar si el DT/ GDT lleva a cabo un programa/ plan de marketing que define y sistematiza todo el conjunto de acciones que deben desarrollarse para lograr un posicionamiento óptimo en sus mercados de referencia.

Variable 3.2.1- Comercialización

El objetivo operativo de esta variable es evaluar si el DT/ GDT está llevando a cabo las medidas oportunas para lograr la comercialización adecuada de su producto.

1- EI DT/ GDT dispone de una identidad corporativa que responde adecuadamente a la estrategia de posicionamiento previamente diseñada

\begin{tabular}{|l|l|l|l|l|}
\hline a & $\begin{array}{l}\text { La identidad corporativa es el resultado de un } \\
\text { proceso metodológico de análisis de la } \\
\text { demanda turística y del producto ofrecido }\end{array}$ & No & No sabe \\
\hline b & $\begin{array}{l}\text { En el proceso de adopción de la identidad } \\
\text { corporativa han participado activamente los } \\
\text { diversos colectivos integrantes del GDT }\end{array}$ & si & No & No sabe \\
\hline c & $\begin{array}{l}\text { El diseño y ejecución de la identidad } \\
\text { corporativa ha sido realizado por especialista/s } \\
\text { en la materia }\end{array}$ & si & No & No sabe \\
\hline d & $\begin{array}{l}\text { La identidad corporativa adoptada responde } \\
\text { a los atributos y valores que se quieren } \\
\text { destacar del D.T }\end{array}$ & si & No & No sabe \\
\hline e & $\begin{array}{l}\text { La identidad corporativa es revisada con una } \\
\text { periodicidad no superior a los cinco años }\end{array}$ & Si & No & No sabe \\
\hline
\end{tabular}


2- La identidad corporativa se respeta en todos los soportes de comunicación que utiliza el sector privado

\begin{tabular}{|l|l|l|l|c|}
\hline a & $\begin{array}{l}\text { El GDT ha llevado/ lleva a cabo la adecuada } \\
\text { difusión de la identidad corporativa del DT } \\
\text { para que sea conocida y utilizada por el sector } \\
\text { privado turístico del D.T }\end{array}$ & No & No sabe \\
\hline b & $\begin{array}{l}\text { El GDT realiza un seguimiento de la utilización } \\
\text { que se efectúa de la identidad corporativa por } \\
\text { parte del sector privado del D.T }\end{array}$ & Si & No & No sabe \\
\hline c & $\begin{array}{l}\text { En los supuestos de utilización inadecuada o } \\
\text { incorrecta el GDT toma las medidas oportunas } \\
\text { para po der corregir esta situación }\end{array}$ & Si & No & No sabe \\
\hline d & $\begin{array}{l}\text { El GDT estimula e incentiva el uso de la } \\
\text { identidad corporativa entre la industria privada }\end{array}$ & Si & No & No sabe \\
\hline e & $\begin{array}{l}\text { El GDT recoge adecuadamente las } \\
\text { sugerencias y opiniones de la industria turística } \\
\text { respecto de la identidad corporativa }\end{array}$ & Si & No & No sabe \\
\hline
\end{tabular}


3- El GDT/ DT tiene identificados los canales de distribución por los que la demanda accede a la compra del D.T y sus respectivos productos.

\begin{tabular}{|l|l|l|l|l|}
\hline a & $\begin{array}{l}\text { El GDT conoce los principales canales de } \\
\text { distribución por los que comercializa el D.T } \\
\text { en los principales mercados turísticos }\end{array}$ & Ni & No & No sabe \\
\hline b & $\begin{array}{l}\text { Igualmente conoce el producto-mercado que } \\
\text { se comercializa por cada uno de los canales } \\
\text { de distribución identificados }\end{array}$ & Si & No & No sabe \\
\hline c & $\begin{array}{l}\text { El GDT y el sector privado Ilevan a cabo } \\
\text { acciones conjuntas de estímulo e incentivo en } \\
\text { estos canales }\end{array}$ & Si & No & No sabe \\
\hline d & $\begin{array}{l}\text { El GDT colabora activamente con el sector } \\
\text { privado realizando actuaciones de prospección } \\
\text { para identificar nuevos canales potenciales } \\
\text { de distribución turística }\end{array}$ & Ni & No & No sabe \\
\hline e & $\begin{array}{l}\text { El GDT y el sector privado Ilevan a cabo } \\
\text { acciones conjuntas de estímulo e incentivo } \\
\text { para lograr la consolidación de estos nuevos } \\
\text { canales emergentes. }\end{array}$ & Ni & No sabe \\
\hline FIN DEL CUESTIONARIO & No & \\
\hline
\end{tabular}

